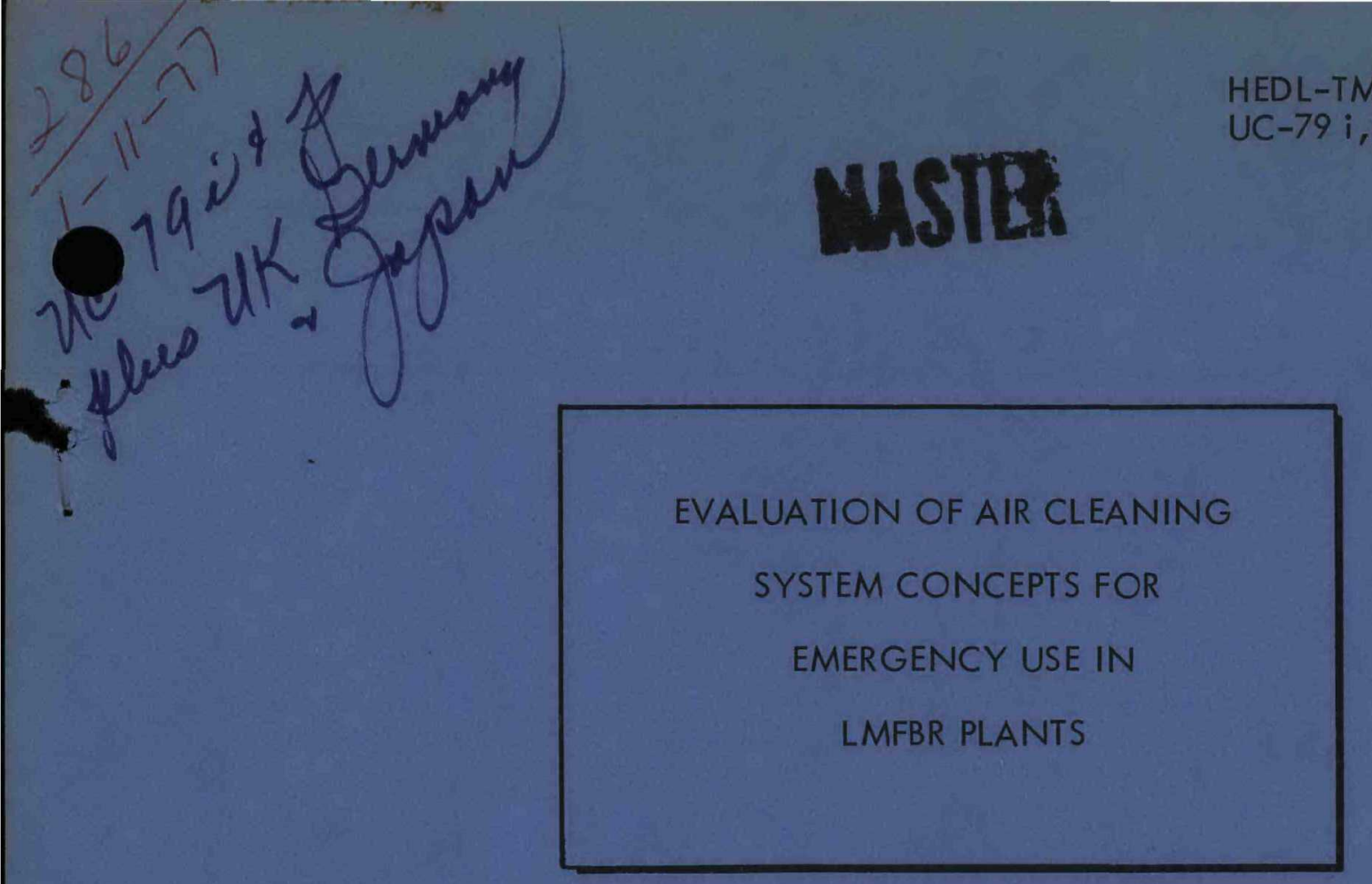

Prepared for the U.S. Energy Research and Development Administration under Contract No. E(45-1)-2170 


\section{DISCLAIMER}

Portions of this document may be illegible in electronic image products. Images are produced from the best available original document. 


\section{NOTICE}

This report was prepared as an account of work sponsored by the United States Government. Neither the United States nor the U.S. ERDA, nor any of their employees, nor any of their contractors, subcontractors, or their employees, makes any warranty, express or implied, or assumes any legal liability or responsibility for the accuracy, completeness or usefulness of any information, apparatus, product or process disclosed, or represents that its use would not infringe privately owned rights.

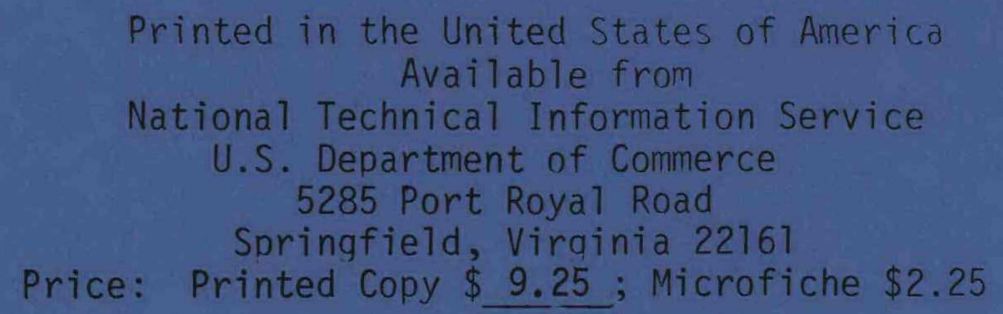


HEDL-TME 76-41

UC-79 $i, p$

\section{EVALUATION OF AIR CLEANING}

SYSTEM CONCEPTS FOR

EMER GENCY USE IN

LMFBR PLANTS

R. K. Hilliard

J. D McCormack

A. K. Postma

This report was prepared as an account of work The the United States nor the United States Energy Research and Development Admunstration, nor any of therr employees, nor any of therr contractors, subcontractors, or ther employees, chakes my warranty, express or lmplet, or asacy a mpletenes

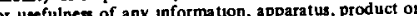
process declosed or represents that its use would not infrnige privately owned rights

December 1976

\section{Hanford Engineering Development Laboratory}

\begin{tabular}{|c|c|c|}
\hline $\begin{array}{l}\text { Operated by the } \\
\text { Westinghouse } \\
\text { Hanford Company }\end{array}$ & $\begin{array}{l}\text { A Subsidiary of } \\
\text { Westinghouse Electric } \\
\text { Corporation }\end{array}$ & $\begin{array}{l}\text { for the United States } \\
\text { Energy Resea rch and } \\
\text { Development Administration } \\
\text { Contract No E(45 } 112170\end{array}$ \\
\hline
\end{tabular}




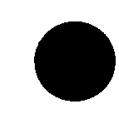

?

.

- 


\title{
EVALUATION OF AIR CLEANING SYSTEM \\ CONCEPTS FOR EMERGENCY USE IN LMFBR PLANTS
}

\author{
R. K. Hillard \\ J. D. McCormack
}

A. K. Postma

\begin{abstract}
Nineteen different air cleaning concepts are arranged into twenty-four systems and evaluated for use as accident mitigating systems in LMFBR plants. Both single, lowleakage containment plants and once-through operation applicable to containment/confinement plants are considered. Plant characteristics affecting air cleaning requirements are defined for 1000 MWe plants and a sodium and radiological release term is postulated. The accident conditions under which the emergency air cleaning system (EACS) must function is established by use of SOFIRE-II and HAA-3B computer codes. Criteria are developed for evaluating the various systems and for assigning comparative ratings. The numerical ratings are combined with information on cost and development potential to arrive at recommendations for the most promising systems. The conclusion is made that reliable and effective systems are feasible for use as engineered safety features for LMFBR plants, but that development effort is required for all the air cleaning concepts evaluated.
\end{abstract}




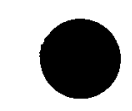

$?$

is 
1.0 INTRODUCTION ..........................

2.0 SUMMARY AND CONCLUSIONS .............. . .

3.0 DEFINITION OF REFERENCE CONTAINMENT DESIGNS . . . . . . . 3-

3.1 Discussion . . . . . . . . . . . . . . 3-1

3.2 Single Containment Design (Case I) ....... 3-1

3.3 Double Containment Design (Case II) . . . . . . 3-5

3.4 Containment/Confinement Design (Case III) . . . . . 3-8

4.0 EACS DESIGN BASIS SOURCE TERM . . . . . . . . . . 4-1

4.1 Basis for Selection of Design Basis Source Term . . . . 4-1

4.2 Accident Scenario for Three Cases . . . . . . . . 4-2

4.3 Aerosol Source Terms .............. 4-4

4.4 Thermal Conditions in Containment Building ..... 4-6

4.5 Aerosol Behavior ............... 4-9

4.6 Heat Generation in EACS by Fission Product Decay . . . 4-11

4.7 Comparison of Containment Concepts ....... . 4-14

4.8 EACS Design Basis Operating Conditions ...... . 4-14

5.0 CRITERIA AND PROCEDURE FOR EVALUATING EACS CONCEPTS . . . . 5-1

5.1 Criteria for Evaluating EACS Concepts . . . . . . . 5-1

5.2 Rating Technique ........... 5-2

5.3 Mandatory Criteria . . . . . . . . . . 5-3

5.4 Evaluation Procedure ........... 5-3

6.0 SELECTION OF AIR CLEANING SYSTEMS TO BE EVALUATED . . . . . 6-1

6.1 System Classification . . . . . . . . . . 6-1

6.2 Air Cleaning Systems to be Evaluated ....... 6-1

7.0 EVAlUATION RESULTS .................. . . .

7.1 EACS For Single Containment System Plants . . . . . 7-2

7.1.1 Recirculating - Prefilter, HEPA (SR-1) . . . 7-2

7.1.2 Recirculating - Deep Bed Graded Media

Filter (SR-2) ............ 7-19 
TABLE OF CONTENTS (Cont'd.)

Page

7.1.3 Direct Application - Acoustic Agglomerator (SD-17)............. 7-31

7.1.4 Recirculating - Bag Filter (SR-4) . . . . 7-50

7.1.5 Direct Application - Powder Discharge (SD-15) • 7-62

7.1.6 Recirculating - Electrostatic Precipitator (SR-12).......... 7-79

7.1 .7 0ther systems . . . . . . . . . . 7-94

7.2 EACS for Double Containment Plants . . . . . . 7-109

7.3 EACS For Containment/Confinement Plants . . . . . . 7-110

7.3.1 Scrubber - Demister, HEPA, Charcoal, HEPA (CF-22).............. 7-112

7.3.2 Confinement - Sand Bed Filter, HEPA, Charcoal, HEPA (CF-24) ........... 7-130

7.3.3 Other Systems for Use with Containment/ Confinement Plants ........ 7-150

7.4 Selection of Most Promising Systems ....... 7-160

7.4.1 Numerical Ratings for Single Containment Plant EACS ............ 7-160

7.4.2 Recommended Systems for Single Containment Plant................ 7-164

7.4.3 Numerical Ratings for Containment/ Confinement EACS .......... 7-169

7.4.4 Recommended Systems for Containment/ Confinement Plant . . . . . . . 7-169

7.4.5 Development Needs for Recommended Systems . . 7-172

8.0 ACKNOWLEDGEMENTS .................. 8-1

9.0 REFERENCES ....................... 9 . .

APPENDIX A AEROSOL BEHAVIOR ............... A-

APPENDIX B CRITERIA FOR EVALUATING EACS SYSTEMS . . . . . . B-2

APPENDIX C NUMERICAL RATINGS ............... $\mathrm{C}-1$ 


\section{LIST OF FIGURES}

Figure $\quad$ Page

1. Cross-Sectional View of Single Containment (Case I) . . . . 3-4

2. Cross-Sectional View of Double Containment (Case II) . . . 3-6

3. Cross-Sectional View of Containment/Confinement System (Case III) .............. 3-9

4. Temperature and Pressure in Containment Atmosphere for a Single Containment System ............ 4-8

5a. Schematic Flow Diagrams for Single Containment EACS Candidate Systems ............... 7-3

5b. Schematic Flow Diagrams for Single Containment EACS Candidate Systems .............. . 7-4

5c. Schematic Flow Diagrams for Single Containment EACS Candidate Systems . . . . . . . . . . . 7-5

6. Filter Building Orientation for Recirculating-Prefilter, HEPA, System SR-1.................. 7-8

7. Equipment Arrangement for Recirculating, Prefilter-HEPA System SR-1 .................... 7-9

8. Effect of Filter Loading on System SR-1 Air Flow Rate . . . 7-10

9. Equipment Arrangement for Recirculating - Graded Media Filter System SR-2 . . . . . . . . . . . . . 7-22

10. Graded Media Filter Details . . . . . . . . . . 7-23

11. Schematic Diagram of Acoustic Agglomerator for System SD-17. 7-36

12. Schematic Diagram of Nitrogen Delivery Pipe (SD-17) . . . 7-38

13. Aerosol Behavior Assumed for Dose Calculation (SD-17) . . 7-40

14. Dose Reduction Factor Calculated for Sonic Agglomeration in Single Containment (SD-17) .. . . . . . . . 7-42

15. Equipment Orientation for Bag Filter System SR-4 . . . . 7-52

16. Bag House Arrangement for System SR-4 . . . . . . . . . 7-53 
LIST OF FIGURES (Cont'd.)

Figure $\quad$ Page

17. Arrangement of Powder Storage Hoppers in the RCB

for System SD-15............ 7-65

18. Powder Storage Hopper and Rotating Spreader (SD-15) . . . 7-66

19. Effect of Delayed Powder Start on DRF (SD-15) . . . . 7-68

20. Effect of Powder Particle Size on DRF (SD-15) . . . . . 7-68

21. Effect of Powder Flow Rate on DRF (SD-15) . . . . . . 7-69

22. DRF as a Function of Mass of Powder Dispersed (SD-15) . . 7-70

23. Electrostatic Precipitator Arrangement Within the RCB

for System SR-12........... 7-84

24. Schematic Section of Electrostatic Precipitator and

Cel1 (SR-12).............. 7-85

25. Cyclone Particle Removal Efficiency as a Function of

Particle Size ............ . . 7-97

26. Schematic Diagrams for Containment/Confinement

Air Cleaning Systems Evaluated .......... 7-111

27. Schematic Diagram of Scrubber-Fi1ter EACS for System CF-22 . 7-116

28. Schematic Diagram of Scrubber Used in System CF-22 . . . 7-119

29. Schematic Diagram of Filter Pack for System CF-22 . . . . 7-120

30. Schematic Diagram of Sand Bed Filter System CF-24 for

Confinement Building Exhaust Air ........ . 7-137

31. Aggregate Used in Sand Bed Filter for System CF-24 . . . . 7-139

32. EACS Effectiveness Versus Credibility Ratings ...... 7-165

33. EACS Reliability Versus Credibility Ratings . . . . . 7-165

34. EACS Numerical Ratings Versus System Cost . . . . . 7-166 


\section{LIST OF FIGURES (Cont'd.)}

Figure

A-1. Aerosol Concentration in Single Containment . . . . . A A-4

A-2. Airborne Particle Size in Single Containment . . . . . A-5

A-3. Plutonium Leaked from Single Containment . . . . . . . A-7

A-4. Mass of Plutonium Calculated to Give Guidel ine Bone
Dose at Site Boundary ..... A-9

A-5. Total Mass Removed by EACS, Case I . . . . . . . A-10

A-6. Effect of Sodium Release on Mass of Plutonium Leaked . . . A-12 .

A-7. Temperature Rise in Concrete Floor of Containment Building, Case I ............... A-14

A-8. Water Released from Operating Floor Concrete, Case I . . . A-15

A-9. Aerosol Concentrations in Case II . . . . . . . . . A-17

A-10. Airborne Particle Size in Case II . . . . . . . . A-19

A-11. Aerosol Mass Collected by EACS in Case II . . . . . . A-20

A-12. Total Mass Leaked to Environment in Case II . . . . . A A-22

A-13. Airborne Particle Concentrations in Containment/ Confinement System Following DBA ......... . A-24

A-14. Airborne Particle Size in Containment/Confinement System Following DBA.............. A-25

A-15. Aerosol Mass Discharged to Stack from Containment/ Confinement System Following DBA ......... A-27

A-16. Calculated Plutonium Release to Yield 150-rem Dose at Site Boundary............. . A-28 


\section{LIST OF TABLES}

Table

Page

1.

Types of Containments Used in Current LMFBR Plants . . . 3-2

2. Summary of Reference Containment Design Parameters . . . 3-3

3. Assumed Release of Radioactive Materials from Reactor Head

4. Instantaneous Aerosol Source ............. 4-7

5. Summary of HAA-3B Aerosol Behavior Data........ 4-10

6. Decay Power Levels Projected for Case I . . . . . . . 4-12

7. Decay Power of Solids Collected in EACS for Case II . . 4-12

8. Decay Power of Solids Collected in EACS for Case III . - 4-13

9. Comparison of Containment Concepts . . . . . . . . 4-15

10. Summary of EACS Operating Conditions . . . . . . . . 4-16

11. Parameters Characterizing Accident Environment for

the Single Containment Case with EACS . . . . . . . 4-18

12. Parameters Characterizing Accident Environment for

the Confinement Building Case.......... 4-19

13. EACS Criteria Groups ................ 5-1

14. Rating Factors for EACS Evaluation . . . . . . . . 5-3

15. Criteria with Mandatory Acceptable Ratings . . . . . . 5-4

16. Types of Candidate Air Cleaning Components and Systems - 6-2

17. Candidate Air Cleaning Systems to be Evaluated . . . . 6-4

18. Index for Updating Plant Costs . . . . . . . . . 7-2

19. Design Parameters for System SR-1 . . . . . . . . . 7-7

20. Design Parameters for System SR-2 . . . . . . . . . 7-21

21. Design Parameters for Acoustic Agglomerator,

System SD-17................. 7-35 
LIST OF TABLES (Cont'd.)

Table $\quad \underline{\text { Page }}$

22. Design Parameters for Bag Filter System SR-4 . . . 7-51

23. Design Parameters for Powder Discharge - System SD-15 . 7-63

24. In-Containment Aerosol Particle Size During Delay

Period Before Powder Discharge ........ 7-67

25. Design Parameters for Recirculating-Electrostatic

Precipitator (System SR-12) ........ 7-81

26. Electrostatic Precipitator Particle Mobilities . . . . 7-82

27. Precipitator Size as a Function of $A_{E} / Q_{E}$ Ratio .... 7-83

28. Electrostatic Precipitator Parameters . . . . . . . 7-84

29. Design Parameters for Scrubber-Filter System (CF-22) . . 7-116

30. Loading Capacity of Hanford Sand Bed Filter . . . . . 7-131

31. Performance Data of Savannah River Sand Bed

Filter Tests .............. 7-132

32. Summary of Sodium Oxide Loading Tests of SNR-300 Sand

Bed Filter .............. . 7-133

33. Resistance Coefficients Calculated from Experimental

Measurement of Sand Filter Performance . . . . . . 7-135

34. Design Parameters for Sand Bed, HEPA, Charcoal, HEPA

System CF-24............ 7-136

35. Design Parameters for System CF-21A . . . . . . 7-152

36. Design Parameters for System CF-23 . . . . . . 7-159

37. Ranking of Twenty EACS Candidates by Total Score and by Criteria Groups - Single Containment Plant .... . 7-161

38. EACS Candidates Failing Mandatory Criteria Single Containment Plant ......... . . 7-162

39. Ranking of EACS After Elimination of Failed Systems Single Containment Plant .......... 7-163

40. Systems Rated Best by Several Selection Criteria Single Containment Plant .......... 7-167 
41. Ranking of Systems Favored for Single Containment Plants. 7-168

42. Air Cleaning Concepts Favored for Development for LMFBR Single Containment Plants ........ . 7-168

43. Ranking of EACS for Use in Containment/Confinement Plants with Either HCDA-DBA or Sodium Fire ... . . 7-170

44. Development Needs for Recommended EACS Concepts . . . . 7-173

A-1. HAA-3B Computer Code Cases for Single Containment . . . A-2

B-1. Criteria for Evaluating LMFBR Emergency Air Cleaning Systems in Single Containment Plants ........ B-2

B-2. Criteria for Evaluating LMFBR Emergency Air Cleaning Systems in a Containment/Confinement Plant ...... B-4

C-1. Numerical Rating of Systems SR-1 Through SR-7 . . . . C-2

C-2. Numerical Rating of Systems SR-8 Through SD-14 . . . C-3

C-3. Numerical Rating of Systems SD-15 Through SC-20 . . . C-4

C-4. Numerical Rating of Systems for Use with Containment/ Confinement.............. C-5 


\section{$1.0 \quad$ INTRODUCTION}

Air cleaning systems are used extensively in existing nuclear facilities for the purpose of controlling normal plant effluents and for mitigating the radiological consequences of postulated major accidents. The systems can be divided into three categories: containment atmosphere cleanup systems, ventilation exhaust systems, and process offgas systems. Systems with similar functions for use in Liquid Metal Fast Breeder Reactors (LMFBR) are in a developing stage and for application to major accidents will require significant modification and development before their practicability can be demonstrated.

The two features of an LMFBR which have the largest impact on air cleaning for accident mitigation purposes are the large inventory of plutonium in the fuel and the use of sodium as the coolant. Although each reactor must be evaluated on an individual basis, radiological analyses of site boundary doses for postulated severe accidents in LMFBRs show that inhalation of aerosol particles containing plutonium may be the major concern rather than thyroid dose from radioiodine, as is the case in light water reactors (LWR). (1) Thus, aerosol attenuation is the highest priority for LMFBR emergency air cleaning systems (EACS). The second feature of an LMFBR which strongly affects the design requirements for an EACS is the release of sodium during the postulated accident, with its attendant high aerosol mass concentration and chemical reactivity considerations.

The purpose of the work reported in this document was to evaluate al1 air cleaning concepts which appeared to have merit for use as accident consequence mitigating systems in LMFBR plants and to recommend the systems which have the greatest potential for development into practical engineered safety systems. Realization of this end goal would provide the designers of future commercial LMFBRs with a valuable option in designing containment systems to meet regulatory guidelines. The Nuclear Regulatory Commission (NRC) has expressed confidence in the reliability of air cleaning systems to perform their intended function in LWR plants. (2) Although the dose reduction factor (DRF) attainable by an EACS is smaller than some of the attenuation processes which can be postulated (1), the probability of attaining the design DRF is essentially unity. This provides added incentive to develop a suitable EACS for future LMFBR plants. 
The work reported here included the definition of reference plant $\left(1000 \mathrm{MW}_{\mathrm{e}}\right)$ features important to the EACS design, selection of an EACS design basis source term, definition of criteria for rating the various EACS candidates, making rudimentary conceptual designs of twenty-four candidate EACSs, evaluating the candidates against the criteria and ranking them against each other, and, finally, selection of the systems which appear most promising for development. 


\subsection{SUMMARY AND CONCLUSIONS}

The design requirements for an EACS are sensitive to the containment features of the plant. Since the type of containment which commercial LMFBRs will have is not known at this time, three reference plants using three significantly different containments were defined: single containment with one low-leakage outer barrier; double containment with a sealed head and cavity plus an outer, low-leakage barrier; and containment/confinement with a sealed head and cavity plus an outer conventional "confinement" building which is kept at a slightly negative pressure by ventilation exhaust fans. In the event of off-normal conditions, the latter plant diverts the confinement exhaust air flow through an EACS.

For each of the three reference plants, a containment release was postulated to establish the accident conditions under which the EACS must function. This containment release was specified to be sufficiently severe so that an EACS designed to handle this release could be expected to function reliably for releases associated with any accident likely to be postulated for future plants. The source term is based on an instantaneous release to the head compartment of 1 percent of the nonvolatile solids (including plutonium), 25 percent of the halogens and volatile fission products, 100 percent of the noble gases, $68 \mathrm{lb}(30 \mathrm{~kg})$ of sodium vapor and $5000 \mathrm{lb}(2300 \mathrm{~kg})$ liquid sodium. For the single containment plant, the 1ıquid sodium was assumed to burn as a pool fire. Releases associated with post-accident melt-through of the reactor vessel were assumed to be of a longer term and not to add to the initial short-term releases. For the containment/confinement plant, a secondary release was postulated (not simultaneous with the radiological source) of a $1000 \mathrm{ft}^{2} 93 \mathrm{~m}^{2}$ surface area sodium fire in the confinement building.

In order to define ambient conditions and aerosol properties resulting from the postulated accidents, the accident environment was studied with the aid of the SOFIRE-II code ${ }^{(3)}$, the HAA-3B code ${ }^{(4)}$, and by hand calculated estimates of water release from concrete. The output of these evaluations provided estimates of aerosol particle size, mass loadings, environmental temperature, pressure, and water partial pressure which served as design parameters for the air cleaning concepts. 
The engineering criteria developed to help evaluate the suitability of each air cleaning system included: system effectiveness, system reliability, containment compatibility, technological credibility, system flexibility, and fabrication effort.

Nineteen different air cleaning concepts were utilized by arranging them into twenty-four systems. A conceptual design was made for each system and an estimate was made of the initial installed cost for a commercial LMFBR. The cost estimate included engineering, contingency and an allowance for containment building modification to house the EACS equipment. The 24 EACS systems evaluated are as follows:

\begin{tabular}{|c|c|c|c|}
\hline $\begin{array}{l}\text { System } \\
\text { Number }\end{array}$ & Description & $\begin{array}{l}\text { Sys tem } \\
\text { Number }\end{array}$ & Description \\
\hline$S R-1$ & Prefilter - HEPA & SD-14 & Liquid Sprays \\
\hline SR-2 & Deep Bed Graded Media & SD-15 & Powder Discharge \\
\hline SR-3 & Sand Bed & SD-16 & Foam Encapsulation \\
\hline SR-4 & Bag Filter & SD-17 & Acoustic Agglomerator \\
\hline$S R-5$ & Cyclone & SD-18 & Direct Electro. Precip. \\
\hline SR-6 & Cyclone plus HEPA & SC-19 & Comb. Acoustic plus Cyclone \\
\hline SR-7 & Wet Scrubber & SC-20 & Comb. Powder plus Filter \\
\hline SR-8 & Fluidized Bed & & \\
\hline SR-9 & Acoustic plus Cyclone & CF-21A & Large HEPA, Charcoal, HEPA \\
\hline SR-10 & Mechanical Separator & $C F-21 B$ & Small HEPA, Charcoal, HEPA \\
\hline SR-11 & Settling Chamber & CF-22 & Wet Scrubber, HEPA, Char., HEPA \\
\hline SR-12 & Electrostatic Precipitator & CF-23 & Elec. Precip., HEPA, Char., HEPA \\
\hline$S R-13$ & Steam Conditioning & CF-24 & Sand Bed, HEPA, Char., HEPA \\
\hline
\end{tabular}

The systems designated "SR" represent those designed to recirculate and clean air in single containment systems. "SD" nomenclature refers to directacting systems in single containment systems; "SC" to combination systems in single containments; and "CF" is used to designate once-through systems applicable to containment/confinement plants. Systems suitable for single containment plants could be adapted for use in double containment plants, if desired.

In order to quantify the evaluation procedure, conceptual designs for each of the 24 candidate systems were developed. Two levels of scope design 
were made. The first involved rough estimates of size, cost, essential components, and effectiveness. From these first designs, several of the most promising systems were selected for a more detailed scope design. The conceptual designs were found to be necessary to identify and quantify technical problems associated with each system.

Each of the candidate system designs was evaluated by using the list of criteria developed for LMFBR application. For each criterion, numerical scores were assigned for all comparable systems, permitting a ranking of all systems. The systems applicable to single containment volumes were ranked as one group and those systems applicable to containment/confinement plants were ranked as a second group. The numerical ratings were combined with information on cost and development potential to arrive at recommendations for the most promising systems.

Development needs were identified during the process of making the scope designs. Assumed values for some of the design parameters were based on very limited information. The development efforts required to firm the designs of the most promising systems were listed in order of priority.

The work reported here substantiates the conclusion that reliable and effective EACSs are feasible for use as engineered safety systems for LMFBR plants, but that some development effort is needed for all the air cleaning concepts evaluated. The work supports the following specific conclusions:

1. Air cleaning is a promising engineered safety system for LMFBRs. It is virtually certain that a 2-hr DRF of 10 can be achieved with systems costing between $\$ 1$ million and $\$ 10$ million for single containment systems. For containment/confinement plants, decontamination factors of 100 to 1000 through the aircleaning system can be obtained by systems costing $\$ 1$ million to $\$ 5$ million.

2. The technological base for air cleaning for LMFBR plants is not sufficient to support an immediate application. For the most developed system currently available, development efforts appear to be modest. Lesser developed but potentially more attractive systems are available, and development applied to these would 
have a potentially high payoff in terms of reduced systems cost and possibly higher DRF's.

3. For single containment plants, the best system, judged from current technology, is a recirculating system with low efficiency prefilters followed by high efficiency particulate air (HEPA) filters. The cost of a 200,000 cubic feet per minute (CFM) $\left(95 \mathrm{~m}^{3} / \mathrm{s}\right.$ ) system which would give a $2-\mathrm{hr}$ DRF of 10 is $\$ 7.7$ million. Direct in-containment acoustic agglomeration of aerosols is a highly attractive candidate system because it is small in size and low in cost ( $\$ 2.8$ million). Considerably more development effort would be required to allow firm design of the acoustic agglomerator system than for the recirculating prefilter-HEPA system. A third system which appears promising is direct in-containment powder discharge, which is smal1 and intermediate in cost (\$3.9 million). Cyclone separators were found to have usefuliness individually and in combination with other components because of their high mass loading capacity and simplicity. Several other systems were judged to be feasible but less desirable because of higher cost, size, or lower reliability.

4. For a containment/confinement plant with a design basis source term encompassing both a radiological release and a sodium fire, the best system, judged from current technology, is a sand and gravel bed filter backed up by a HEPA-charcoal adsorber system. A significant reduction in the relatively high cost ( $\$ 4.5$ million) is believed possible by development of a sand bed with a high mass loading capacity. If the containment/confinement plant source term excludes a sodium fire, the best system is a conventional filter-adsorber system consisting of prefilters, HEPA filters and charcoal adsorbers and costing $\$ 870,000$.

5. All systems which use liquids were judged to be unfeasible for use in single containment plants because no suitable liquid could be identified. The vapor pressure and hydrogen formation potential 
of aqueous liquids prevented their use. Several of these systems would be very attractive if a suitable liquid could be identified.

6. An aerosol property which is poorly understood but which can have an impact on the performance of some types of EACSs is the stickiness and change of particle shape caused by adsorption of water vapor. Normal reactor containment building (RCB) atmospheres contain sufficient moisture and carbon dioxide to convert all of the released sodium oxide aerosol to sodium hydroxide and sodium carbonate. Additional water release from concrete surfaces exposed to the RCB atmosphere must be considered.

7. The 2-hr DRF provided by all the systems evaluated here was 10 because this was a design objective. Larger or smaller systems can be designed, yielding proportionate values of cost and DRF. 


\subsection{DEFINITION OF REFERENCE CONTAINMENT DESIGNS}

\subsection{Discussion}

The ambient conditions and operational requirements for an emergency air cleaning system depend strongly on the type of containment system provided for the reactor plant. Thus, the selection and description of the plant containment features is a prerequisite step before an evaluation of air cleaning systems can be made. A review of existing LMFBR plant containment designs revealed that no one type of containment system can be designated as being standard for future large LMFBR plants. ${ }^{(5-8)}$ For the purpose of this study, several reference designs were selected to provide a basis for establishing EACS design and operating conditions and requirements.

Containment systems for existing LMFBR plants or those currently being constructed can be classified into four categories, as shown in Table 1. Variations of these are possible, of course. In each system the reactor cavity and primary sodium equipment cells are sealed and provided with inerted atmospheres.

The first three containment types listed in Table 1 were selected for the present EACS study. Each of these three designs imposes significantly different requirements on an EACS, and each appears to offer an economically viable option to future reactor designers. The three reference designs are described in detail in the following sections of this report and are summarized in Table 2. The reactor is the same for each of the three reference plants: $1000 \mathrm{MW}_{\mathrm{e}}, 2430 \mathrm{MW}_{\mathrm{th}}, 15,300 \mathrm{~kg}$ heavy metal oxide $(13,500 \mathrm{~kg}$ as heavy metal), and fuel material is 25 percent $\mathrm{PuO}_{2}, 75$ percent $\mathrm{UO}_{2}$.

\subsection{Single Containment Design (Case I)}

The physical layout of the single containment reference plant is shown schematically in Figure 1. Only that portion of the containment vessel above the operating floor and head compartment is shown because only that part directly influences air cleaning operation. The physical dimensions chosen for the containment vessel are slightly larger than those provided in the Atomics International (AI) $1000 \mathrm{MW}$ conceptual design study. (9) Head compartment dimensions were taken from the preliminary scope design for the CRBR. 
TABLE 1

TYPES OF CONTAINMENTS USED IN CURRENT LMFBR PLANTS

Containment Type

Single

Double

Containment/

Confinement

Multiple, with Pumpback
Description

Open (or high-leakage) head compartment and low-leakage outer, compartment bujlding

Sealed, high pressure inner containment barrier, surrounded by a low-leakage, high pressure outer containment building

Sealed, low-leakage inner containment barrier, surrounded by a ventilated low pressure outer confinement building with discharge to a stack via an air cleaning system

Sealed, high pressure inner containment barrier surrounded by one or more outer barriers. A negative pressure zone is maintained in the outermost space by pumping back leakages to the inner containment space. Eventual venting to stack via air cleaning system is provided.
Reactor

FFTF EBR-II

FERMI

SEFOR $\operatorname{CRBR}(\mathrm{a})$

PFR

PHENIX

SNR -300

JOYO

MONJV

(a) If the sealed head compartment option is chosen, CRBR will be a double containment plant. 
TABLE 2

SUMMARY OF REFERENCE CONTAINMENT DESIGN PARAMETERS

\begin{tabular}{|c|c|c|c|}
\hline Parameter & Case I & Case II & Case III \\
\hline Type of Containment & Single Containment & Double Containment & Containment-Confinement \\
\hline Brief description & $\begin{array}{l}\text { Single, low-leakage } \\
\text { cylindrical steel } \\
\text { shell surrounding all } \\
\text { primary sodium systems. }\end{array}$ & $\begin{array}{l}\text { Sealed, inerted, high- } \\
\text { pressure inner con- } \\
\text { tainment surrounding } \\
\text { reactor vessel and head } \\
\text { compartments. An } \\
\text { outer low-leakage } \\
\text { cylindrical steel she } 11 \\
\text { surrounds the inner } \\
\text { containment. }\end{array}$ & $\begin{array}{l}\text { Sealed, inerted, high- } \\
\text { pressure inner con- } \\
\text { tainment surrounding } \\
\text { reactor vessel and head } \\
\text { compartments. A venti- } \\
\text { lated rectangular } \\
\text { building surrounds the } \\
\text { inner containment. }\end{array}$ \\
\hline \multicolumn{4}{|l|}{ Inner containment } \\
\hline Atmosphere & $N / A$ & $99 \% \quad \mathrm{~N}_{2} / 1 \% \mathrm{O}_{2}$ & $99 \% \mathrm{~N}_{2} / 1 \% \mathrm{O}_{2}$ \\
\hline $\begin{array}{l}\text { Volume, } \mathrm{ft}^{3}\left(\mathrm{~m}^{3}\right) \\
\text { Leak rate, } \% \text { day }\end{array}$ & $\begin{array}{l}N / A \\
N / A\end{array}$ & $\begin{array}{l}40 \mathrm{ft} D \times 50 \mathrm{ft} \mathrm{H} \\
(12.2 \mathrm{~m} \times 15.2 \mathrm{~m}) \text { hemi- } \\
\text { spherical top } \\
29,300(830) \\
100\end{array}$ & $\begin{array}{l}40 \mathrm{ft} D \times 50 \mathrm{ft} \mathrm{H} \\
(12.2 \mathrm{~m} \times 15.2 \mathrm{~m}) \text { hemi- } \\
\text { spherical top } \\
29,300(830) \\
100\end{array}$ \\
\hline \\
\hline $\begin{array}{l}\text { Size above oper- } \\
\text { ating floor }\end{array}$ & $\begin{array}{l}160 \mathrm{ft} D(48.8 \mathrm{~m}) \times \\
60 \mathrm{ft}(18.3 \mathrm{~m}) \text { straight } \\
\text { cylinder, with hemi- } \\
\text { spherical top }\end{array}$ & $\begin{array}{l}160 \mathrm{ft} D(48.8 \mathrm{~m}) \\
\times 60 \mathrm{ft}(18.3 \mathrm{~m}) \\
\text { straight cylinder, } \\
\text { with hemispherical top }\end{array}$ & $\begin{array}{l}105 \mathrm{ft} \times 204 \mathrm{ft} \times 105 \mathrm{ft} \\
(32.0 \mathrm{~m} \times 62.2 \mathrm{~m} \times 32.0 \mathrm{~m})\end{array}$ \\
\hline $\begin{array}{l}\text { Volume, } \mathrm{ft}^{3}\left(\mathrm{~m}^{3}\right) \\
\text { Leak rate, } \% \text { day }\end{array}$ & $\begin{array}{l}2.25 \times 10^{6}(63700) \\
0.1\end{array}$ & $\begin{array}{l}2.25 \times 10^{6}(63700) \\
0.1\end{array}$ & $\begin{array}{l}2.25 \times 10^{6}(63700) \\
15,0003 \text { CFM (ventilation) } \\
(7.1 \mathrm{~m} / \mathrm{s})\end{array}$ \\
\hline
\end{tabular}




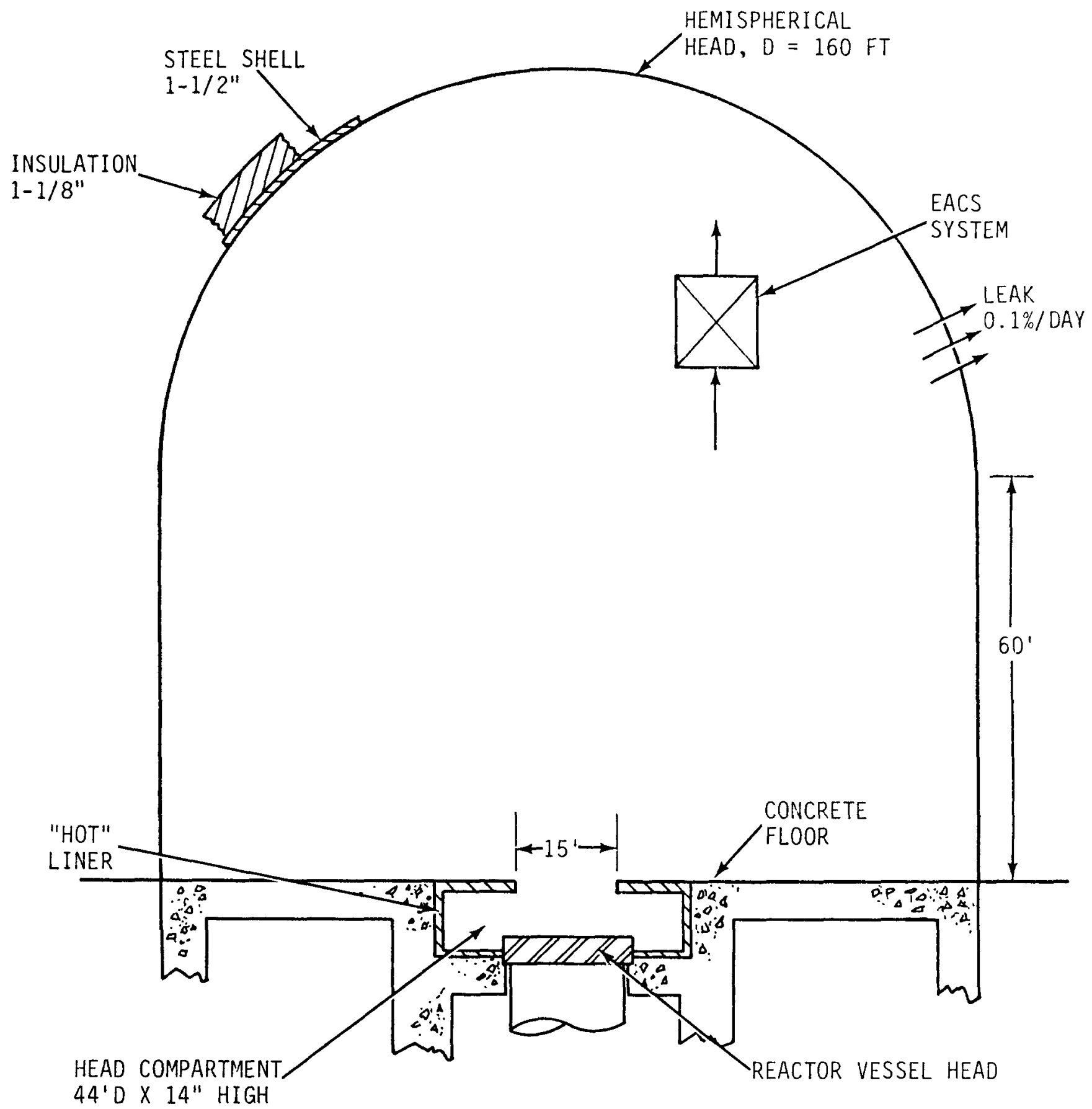

HEDL 7506-127-8

FIGURE 1. Cross-Sectional View of Single Containment (Case I). 
The single containment design shown is physically similar in design to the FFTF and CRBR systems built with the open head compartment option. It is also similar to the containment system provided for the British DFR. A major difference is the presence of an emergency air cleaning system. Such systems are not yet available, hence were not included in plants designed to date.

At the present time, the type and size of future EACS systems is unknown. For purposes of this study, an air cleaning system working on air in the containment vessel, with an effective removal rate of $5 \mathrm{hr}^{-1}$, was assumed. The system could be located either entirely internal to the containment vessel or in an external loop. This system could be either a recirculation type (e.g., filters) or a direct application system (e.g., sprays). The dose reduction factor for two hours resulting from operation of this system is ten. For longer periods of time, the dose reduction factor would be greater than ten.

Several features of the single containment design which importantly influence the accident consequences are the following. First, the reactor cavities are covered inside with "hot" liners (steel over firebrick) to eliminate potential sodium-concrete reactions and water release from concrete. Second, it was assumed that the grating covering the head compartment, and other head compartment equipment, would incorporate antisplash features which would prevent appreciable quantities of sodium spray from entering the outer containment building. Third, the operating floor of the outer containment building was specified to be concrete. An unlined concrete floor tends to maximize water release due to concrete heat-up.

\subsection{Double Containment Design (Case II)}

The principal physical difference between single and double containment schemes is the addition of a sealed dome over the reactor head compartment. The outer containment vessel was taken to be identical with that provided for the single containment case. The double containment scheme is shown schematically in vertical cross-section in Figure 2. 


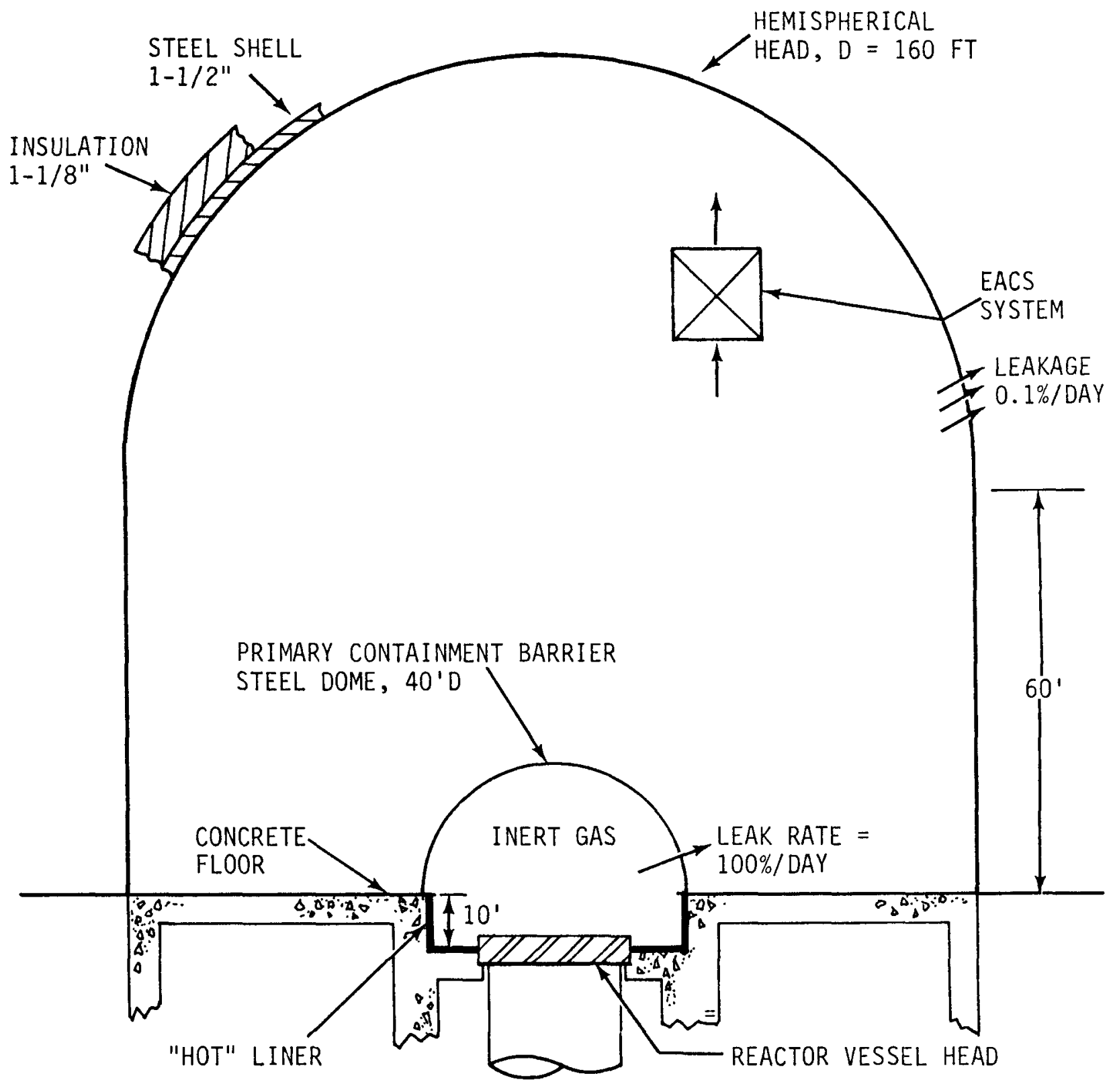

HEDL 7506-127-9

FIGURE 2. Cross-Sectional View of Double Containment (Case II). 
The physical size of the inner containment dome was selected as a hemisphere large enough to cover the reactor head compartment. This dome would be removed during refueling operations.

The double containment design shown in Figure 2 is similar in concept to the CRBR design, based on the inerted closed head option, and to FERMI. It is similar to SEFOR which used 10 psi inerted primary vaults as we11 as an outer steel containment vessel. This design is also conceptually similar to the design proposed for $1000 \mathrm{MW}_{\mathrm{e}}$ by $\mathrm{AI}$. (19) of these previous designs, only the AI conceptual design included an emergency air cleaning system.

As shown in Figure 2, the assumed air cleaning system is one which cleans the air in the outer containment atmosphere with an effective $\lambda$ of $2 \mathrm{hr}^{-1}$. This system gives a smaller dose reduction factor than the EACS used for the single containment case, and will treat much less concentrated aerosols because the primary volume allows appreciably more settling and plating than would occur in a single containment. An alternate air cleaning approach would be to clean the gas enclosed in the primary volume. For this, one could consider a liquid sodium spray because of the absence of oxygen and because the primary chamber is covered internally with a hot liner. This alternative point of application is noted here to point out one of the several different air cleaning configurations which are possible but which have not been evaluated in this report.

Design features which would have an appreciable effect on aerosol behavior in a double containment plant include the leak rate from primary, the size of the primary system, and the use of an inert gas in the primary volume. The leak rate of 100 percent per day is relatively large, and reflects the view that the primary system is smal1, that the cover must be removable, and that the primary volume is subjected to rapid increases in temperature and pressure. Lower design leak rates could be used, but would result in a more costly system. The aerosol source strength to the secondary volume is linearly dependent on the assumed leak rate. The small size of the primary volume was chosen to facilitate removal and storage of the dome during refueling. As a result of this small volume, relatively high pressures (approximately $30 \mathrm{psig)}$ are predicted to result from the DBA. An alternate 
lower pressure design would be one which incorporated a rupture diaphragm in the head compartment, which would vent the dome volume into the inerted vaults below the operating floor. Use of an inerted primary system allows design to a moderate pressure capability.

\subsection{Containment/Confinement Design (Case III)}

The containment/confinement design is in effect a double containment scheme in which the outer barrier is a ventilated building rather than a lowleakage containment shell. The outer building is maintained at a slightly negative pressure by an exhaust system which discharges air through suitable cleanup devices to a stack so that radioactive materials leaked from the primary containment are removed by filters or scrubbers. Compared to Case II, the containment/confinement concept trades a high leakage rate of processed air (filtered, elevated release) for a low leakage rate of unprocessed air. The containment/confinement scheme is shown schematically in vertical crosssection in Figure 3. Features of the containment system below the operating floor are not shown because they do not affect the behavior of the system under DBA conditions. It has, of course, been assumed that all leakage from the primary system is to the confinement building.

The physical size and features of the primary containment volume were assumed to be identical to those of Cases I and II. The outer confinement building size, and the capacity of the EACS, was taken from the General Electric $1000 \mathrm{MW}$ follow-on study. (10)

Case III design is similar in appearance to several existing designs. The British PFR reactor ${ }^{(11)}$ uses an inner containment scheme with an outer steel structural building. An important difference, compared to Case III, is that PFR uses a recirculating air cleaning system rather than a single pass system. The GE conceptual design ${ }^{(10)}$ used a confinement building and EACS system similar to Case III, but did not include a sealed primary containment capable of withstanding an HCDA.

Several features of Case III distinctly different from features in Cases I and II include the following: 


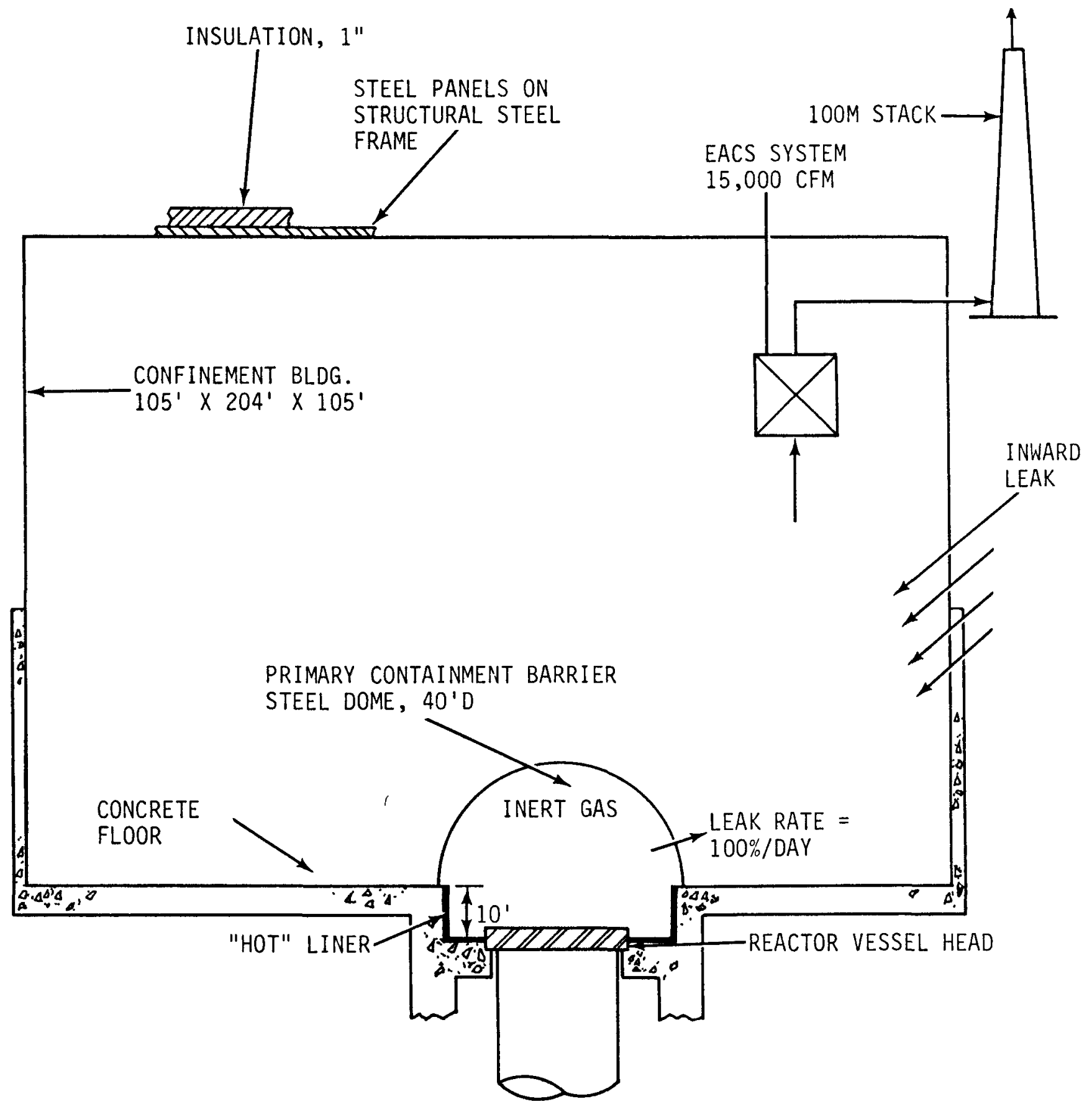

HEDL 7506-127.10

FIGURE 3. Cross-Sectional View of Containment/Confinement System (Case III). 
- All leakage is inward and is collected and treated before being released to the atmosphere.

- Atmospheric discharge is through an elevated release which reduces predicted doses at the site boundary by more than an order of magnitude compared to ground level release.

- Air cleaning is a vital part of the containment design, rather than being an engineered safety system to be added on.

- A higher efficiency for removal of radioactive materials in the EACS is needed in the Case III.

Although the specific kind of air cleaner (filter, scrubber, etc.) need not be specified, the total flow rate is specified as $15,000 \mathrm{CFM}(7.1 \mathrm{~m} / \mathrm{s})$. The efficiency required for this system is high compared to the systems chosen in Cases I and II. Based on preliminary analyses, it appears that the EACS system for Case III will have to achieve a decontamination factor of about 100 or more to give bone doses equivalent to that of a double containment plant.

Design features of the Case III system which importantly influence the accident consequences include the following. The primary system is the same as Case II, being inerted, possessing a hot liner, and having a leak rate of 100 percent per day. Another very important feature is the ventilation rate required to assure that no material leaks directly to the atmosphere from the confinement building. The specified ventilation flow rate of 15,000 CFM was chosen on the basis of the GE conceptual design. (9) 


\subsection{EACS DESIGN BASIS SOURCE TERM}

\subsection{Basis for Selection of Design Basis Source Term}

Definition of the design basis source term (DBST) for the air cleaning study provides a means for evaluating the conditions imposed upon, and performance of, containment systems incorporating an EACS. In selecting the DBST for this study, emphasis was placed on the quantities and type of radioactive materials and sodium which could become airborne, and therefore represent an air cleaning requirement. Relatively little attention was devoted to temperature or pressure histories, and none to structural implications of the DBST on the three cases considered.

As mentioned earlier in this report, postulation of the DBST as presented here is quite different than arriving at accident sequences and consequences through an in-depth accident analysis. Accident analysis is a continuing effort and it is probable that the accidents postulated here are more severe than those evaluated by analysts. Our choice is purposeful, in that air cleaning systems designed to handle the severe conditions imposed here will be well able to handle all accidents likely to be postulated on the basis of more sophisticated modeling.

A hypothetical core distruptive accident (HCDA) appears to be the most severe type of accident which can be postulated for evaluating containment system performance. Generally, the most severe consequence of an HCDA occurs when the initiating event is loss of flow without scram, and this was assumed in this study. ERDA is currently supporting a major analytical and experimental program to develop a source term model describing the release of fuel and fission products from the core to the cover gas and then from the reactor vessel to the head compartment. (12) At the present time, such a model is not completely available and releases postulated in this report are based on parametric studies, judgment, and precedent.

Additional interactions associated with postulated post-HCDA melt-through of the reactor vessel were not assumed to add to the initial short-term releases. This is based on studies which indicate that releases associated with 
the melt-through are delayed in time and are not likely to add to the initial short-term release.

\subsection{Accident Scenario for Three Cases}

Case I (Single Containment). The following events and physical phenomena characterize the design basis accident used to evaluate the conditions imposed on an EACS placed inside a single containment vessel.

- An hypothetical core disruptive accident (HCDA) initiated by loss of flow (LOF) without scram is postualted as the beginning event.

- U1timate core disassembly occurs as a result of a $\$ 100 / \mathrm{sec}$ recriticality reactivity ramp leading to partial core vaporization. (This mode of disassembly is assumed as an extreme upper bound. The probable mode of disassembly is by boil-out.)

- Sodium vapor is mixed with fuel vapor in the mass ratio of $\mathrm{Na} /$ fuel $=0.2$.

- The pressure pulse of the expanding fuel vapor bubble opens leak paths to the head compartment.

- Released fuel, fission products, and sodium vapors mix instantly with gas in the head compartment.

- Liquid sodium is splashed sufficiently that all head compartment oxygen reacts adiabatically with sodium, but no liquid sodium enters the main containment space.

- Hot gas in the head compartment expands adiabatically into the main containment air space above the operating floor.

- Liquid sodium burns to completion as a pool fire in the head compartment.

- Aerosol agglomeration, fallout and plateout occur in the containment vessel. 
- Aerosol removal is enhanced by operation of an EACS located in the reactor containment building (RCB).

- Aerosol leaks from containment to the outside atmosphere at the same fractional rate as gas leakage (no attenuation in the leak paths). Leakage is constant at the design specification at design pressure.

Case II (Double Containment). For Case II, the primary volume will retain released radioactive materials in the head compartment where fallout and plateout will be enhanced. The following events describe the accident scenario.

- Events up to and including release to the head compartment are identical to those described for Case I.

- Radioactive materials are instantly mixed with gas in the inerted primary chamber.

- Sodium reacts adiabatically with oxygen in primary gas $\left(1 \% 0_{2}\right)$.

- Aerosol agglomeration, fallout, and plateout occur in the primary volume.

- Gases and aerosols leak from the primary containment volume with no retention in the leak path.

- Aerosol settling, plating, agglomeration, and leakage occur in the outer containment volume.

- Aerosol removal in the secondary containment volume is enhanced by operation of an internal EACS.

Case III (Containment-Confinement). Case III events are identical to those for Case II up to and including leakage from the primary containment volume. In the secondary confinement building, the scenario is different. The following statements describe the events envisioned for Case III.

- Events up to and including leakage to the secondary containment volume are identical to those described for Case II. 
- The secondary confinement building normal ventilation intake and exhaust dampers close automatically on signal of off-normal conditions.

- The secondary confinement building is maintained at a slightly negative pressure by an emergency ventilation exhaust system which incorporates an EACS.

- Aerosol settling, plating, and agglomeration occur in the confinement building.

- Airborne aerosols and gases are cleaned by passing through the EACS, and the exhaust gas from the EACS enters the outside atmosphere through a stack.

- Outside air leaks into the confinement building at a rate equal to the EACS exhaust flow rate.

\subsection{Aerosol Source Terms}

The phrase "source term," as used in this document, refers to the release of materials from the primary reactor vessel to the next level of containment. For the single containment plant (Case I), the release is directly into the outer air-filled containment building via the open head compartment. For both the double containment (Case II) and containment/ confinement (Case III) plants, the release is into an inerted inner containment volume.

The fractional and mass releases of radioactive materials and sodium from the reactor vessel are summarized in Table 3 and discussed in the following paragraphs. 
TABLE 3

\section{ASSUMED RELEASE OF RADIOACTIVE MATERIALS}

FROM REACTOR HEAD

\begin{tabular}{|c|c|c|c|c|}
\hline Core Component & $\begin{array}{c}\text { Fraction of Core } \\
\text { Inventory Released } \\
\end{array}$ & $\begin{array}{c}\text { Mass } \\
\text { Released, } \mathrm{kg} \\
\end{array}$ & $\begin{array}{l}\text { Dominant } \\
\text { Elements } \\
\end{array}$ & Physical Form \\
\hline Noble gas & 1.0 & 11.4 & $\mathrm{Xe}, \mathrm{Kr}$ & Gas \\
\hline Volatile solids & 0.25 & 45 & $\begin{array}{l}\mathrm{Cs}, \mathrm{Rb}, \mathrm{Sb}, \\
\mathrm{Te}, \mathrm{Sr}, \mathrm{Ag}, \\
\mathrm{Se}, \mathrm{In}, \mathrm{Cd}, \mathrm{As}\end{array}$ & Aerosol \\
\hline $\begin{array}{l}\text { Non-volatile } \\
\text { solids }\end{array}$ & 0.01 & 153 & $\begin{array}{l}\text { Pu,U, } \\
\text { Other FP }\end{array}$ & Aerosol \\
\hline Halogens & 0.25 & 2.4 & $\mathrm{I}, \mathrm{Br}$ & $\begin{array}{l}98 \% \text { particulate } \\
1 \% \text { elemental } \\
1 \% \text { organic halide }\end{array}$ \\
\hline Liquid sodium & - & 2300 & $\mathrm{Na}$ & Liquid spray \\
\hline Vapor sodium & -- & 30 & $\mathrm{Na}$ & Vapor \\
\hline
\end{tabular}

Noble gas release of 100 percent was chosen because the core average temperature predicted for a $\$ 100 / \mathrm{sec}$ ramp is well above the fuel melting point, which would allow most of the noble gas to escape. The assumed release of 100 percent is also consistent with Regulatory Safety Guides for light water reactors $(L W R)^{(13,14)}$ and with the safety evaluation of FFTF performed by the Nuclear Regulatory Commission.

The fractional release for fuel and non-volatile fission products was chosen as 1 percent of the inventory because this fraction has been used by the Nuclear Regulatory Commission, and because 1 percent is intermediate between extreme values of fuel vaporization predicted in the bubble for a $\$ 100 / \mathrm{sec}$ ramp at the time of slug impact with the top head.

For volatile solids, the 25 percent release number was chosen to reflect the expectation that volatile solids would be released to a greater extent than non-volatile solids, and the desire to define an upper limit decay heat source for the EACS. In addition, the predicted core average temperature is above the normal boiling point of the most abundant volatile solids. Halogen release was taken as 25 percent to be consistent with NRC guides for LWR plants. $(13,14)$ 
Sodium vapor was assumed to be released in the concentration found to optimize work energy, i.e., 20 weight percent of the fuel vapor. Liquid sodium released to the head compartment was taken as 5000 pounds $(2300 \mathrm{~kg})$. This number was thought to be an upper limit, which would represent a severe loading for the EACS in Case I.

The instantaneous aerosol source composition and related characteristics are listed in Table 4.

\subsection{Thermal Conditions in Containment Building}

Thermal conditions in the containment atmosphere are important because the ambient temperature experienced by an EACS influences the requirements for materials of construction and because water released from concrete depends on the concrete temperature. The leak rate from containment would also be dependent on thermal conditions within the RCB, although in this study no credit was taken for reduced leakage at pressure lower than design pressure. Temperatures and pressures resulting from the Case I DBST were predicted using the SOFIRE-II code ${ }^{(3)}$ as modified for use at HEDL. Results of the SOFIRE analysis are shown in Figure 4, where temperature and pressure are shown as a function of time to 48 hours. Heat sources included both the sodium fire and the decay heat of the fission products released to containment.

Both temperature and pressure show an initial peak due to mixing of the hot head compartment gas with the gas in the containment vessel. The minimum which occurs between 1 and 2 hours reflects heat transfer to containment structures. The increase in temperature between 2 hours and 48 hours results from fission product decay heat for the material released from the core. It appears that a maximum temperature of about $300^{\circ} \mathrm{F}\left(150^{\circ} \mathrm{C}\right)$ would be reached at about 60 hours. At longer times, the temperature would decay, eventualiy falling to the ambient atmospheric temperature. The maximum pressure reached approximately 6 psig $\left(4.14 \times 10^{4} \mathrm{~Pa}\right)$ coincident with the time of maximum temperature.

The SOFIRE-II code assumes a dry atmosphere. Release of water from concrete is neglected, but may cause significant additional pressure, as discussed in Appendix A page A-11. 
TABLE 4

INSTANTANEOUS AEROSOL SOURCE

\section{Parameter}

Composition, $\mu \mathrm{g}$

Fuel (as oxide)

Volatile solids

Halogens

$\mathrm{Na}_{2} \mathrm{O}$

Total

Gas volume, $\mathrm{cm}^{3}$

Initial aerosol mass concentration, $\mu \mathrm{g} / \mathrm{cm}^{3}$

Initial concentration, particles $/ \mathrm{cm}^{3}$

Particle density, $\mathrm{g} / \mathrm{cm}^{3}$

Particle density modification

factor, $\alpha$

Initial particle mass median

diameter (MMD), $\mu \mathrm{m}$

Geometric standard

deviation, $\sigma_{\mathrm{g}}$

Mass fraction as $\mathrm{Pu}$
Case I

Single Containment Inner Containment

$1.53 \times 1011$

$4.50 \times 10^{10}$

$2.80 \times 10^{9}$

$6.38 \times 10^{11}$

$8.39 \times 10^{71}$

$6.4 \times 10^{10}$

13.1

$7.95 \times 10^{7}$

2.74

0.25

1.0

2.0

0.0402
0.25

1.0

2.0

$1.53 \times 1011$

$4.50 \times 10_{9}^{10}$

$2.80 \times 10_{10}^{9}$

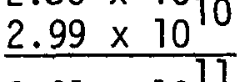

$2.31 \times 10^{11}$

$8.2 \times 10^{8}$

280

$7.70 \times 10^{8}$

6.0

0.146 


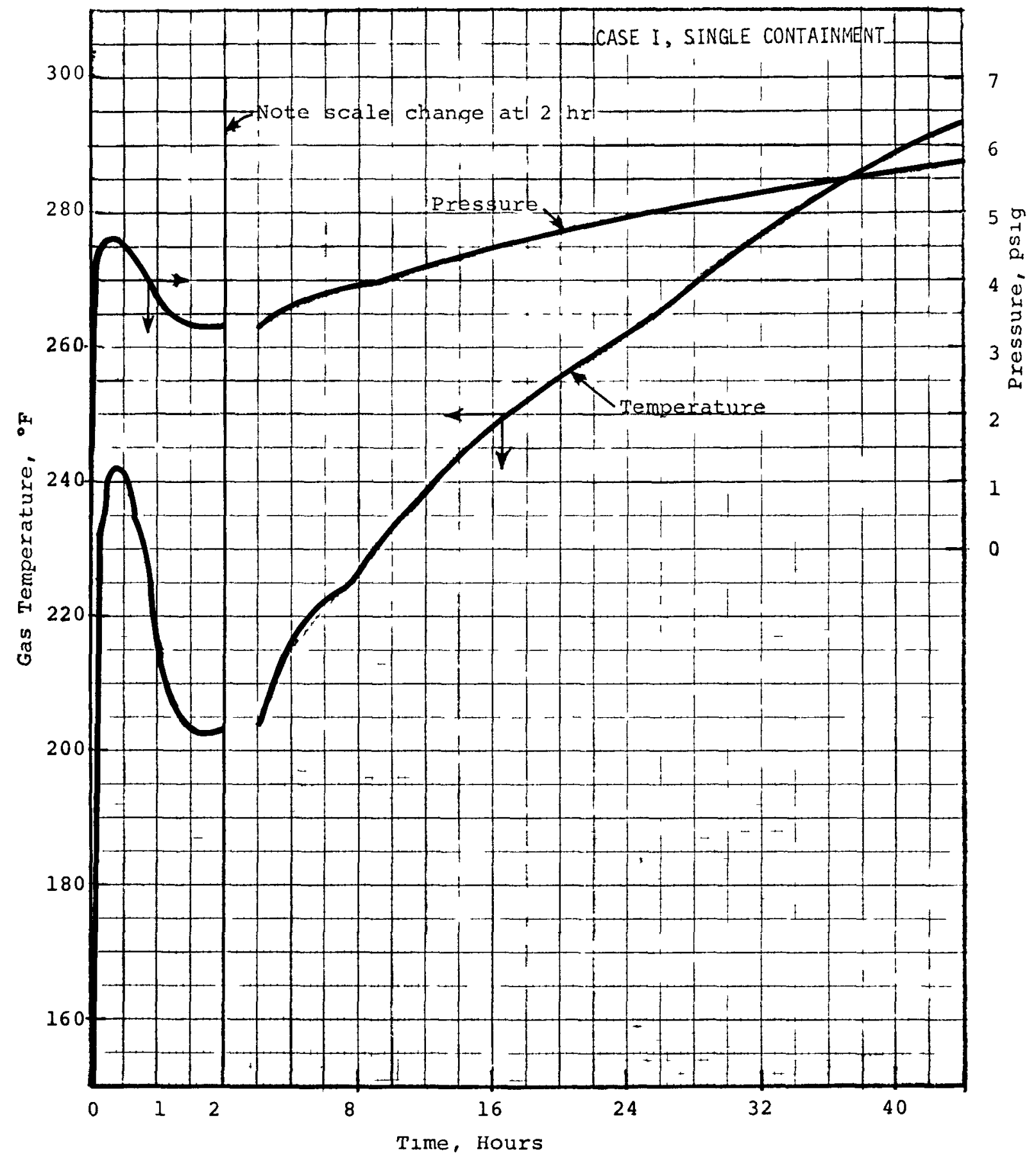

FIGURE 4. Temperature and Pressure in Containment Atmosphere for a Single Containment System. 
For the double containment plant (Case II), a detailed analys is of thermal conditions for the secondary containment vessel was not carried out because only very small energy sources appear to be present in the outer containment space for the assumed accident. However, cooling of the primary containment would have to be provided, or heat transfer from primary to secondary containment would occur. With adequate cooling of the primary barrier, the temperature in the secondary building would increase only a few tens of degrees at most, indicating that water release from concrete would be negligible, and that the EACS would be exposed to temperatures in the range of $80^{\circ} \mathrm{F}$ to $150^{\circ} \mathrm{F}\left(27-66^{\circ} \mathrm{C}\right)$. Pressure in the outer building would be close to atmospheric.

In the containment/confinement plant (Case III), ambient temperature, pressure, and humidity of air in the confinement building will be essentially the same as outside air, because all air entering the confinement does so through leak paths in the building walls. Therefore, the ambient conditions would vary with geographic location and season. If required, temperature and relative humidity could be altered by installation of eqiupment within the confinement building. However, the conditions likely to be encountered are not severe, and when this is coupled with the low aerosol loading, it is unlikely that the precise values of temperature, pressure, and humidity will be important. It is likely, however, that sufficient atmospheric moisture could be present to cause the aerosol particles to become sticky.

\subsection{Aerosol Behavior}

Aerosol behavior within the containment spaces and leakage from the outer containment building were analyzed using the HAA-3B computer code. The results are presented in detail for the three reference plant designs in Appendix A. From the data in Appendix A, information regarding the aerosol behavior and mass leaked to the environs was extracted and is summarized in Table 5 .

Other conclusions that can be drawn from the Appendix $A$ data are:

- The magnitude of the initial particle size assumed for input to the HAA-3B code (up to 1.0 MMD) has essentially no effect on aerosol behavior after the first few minutes. 
TABLE 5

SUMMARY OF HAA-3B AEROSOL BEHAVIOR DATA

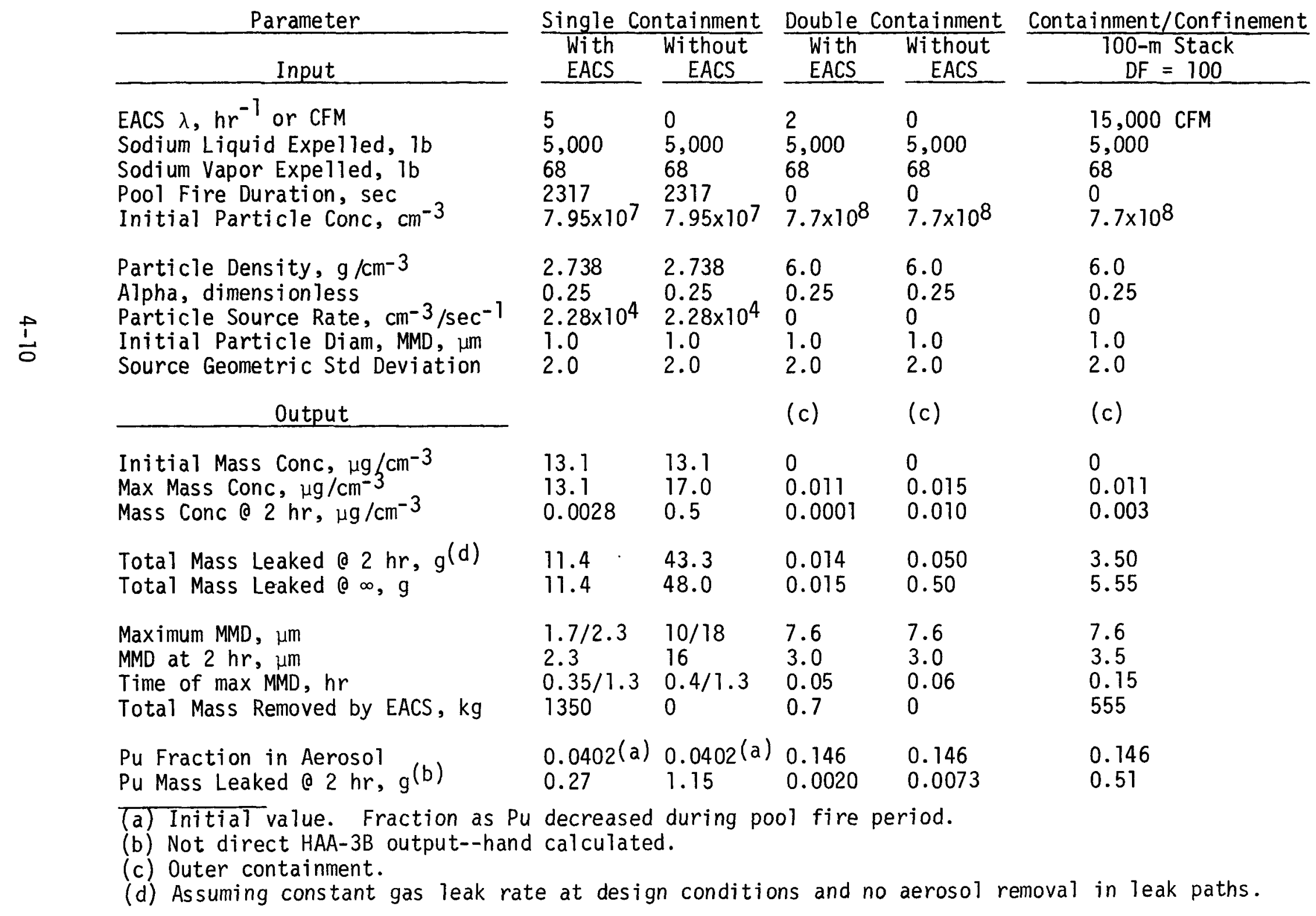


- The value assumed for ALPHA, the particle density modification factor, has a significant effect on the calculated aerosol behavior (in the absence of an EACS). A better basis for selecting the correct value is needed.

- When an EACS is used, the assumed values used for aerosol properties (ALPHA, initial particle size, particle density, agglomeration efficiency) are unimportant because the operation of the EACS completely overshadows the natural removal processes. However, the design of the EACS is affected by the aerosol properties.

- The quantity of sodium released from the reactor vessel has no effect on the mass of plutonium leaked to the environs when an EACS is provided. Without an EACS, the mass of plutonium leaked is unaffected for quantities of sodium above 1000 pounds $(450 \mathrm{~kg})$, but approximately triples for no sodium release.

- Significant quantities of water may be released from concrete surfaces, even for small temperature increases. Improved methods of predicting water release are needed.

4.6 Heat Generation in EACS by Fission Product Decay

Decay heat associated with the design basis source terms is appreciable. Values of decay heat for FFTF fuel were scaled up on the basis of core power level and exposure. Values of decay heat used in the SOFIRE-II calculation are listed in Table 6 for the several source term categories. Also shown is the heat associated with the fission products which would be removed by the EACS. The EACS heat source was calculated on the assumption that 100 percent of the airborne fission products (excluding noble gases) would be collected after one hour. The energy production rate from the EACS deposit is high during the first 24 hours, and disposal of this heat would require consideration in EACS design for a single containment plant.

The total mass collected in the EACS in Case II (double containment) is very small, and thus the heat generation rate of the collected material is low compared to the values listed in Table 6 for Case I. The decay heat for material collected on the EACS was computed and the results are shown in Table 7. 
TABLE 6

DECAY POWER LEVELS PROJECTED FOR CASE I (SINGLE CONTAINMENT)

(Decay power in units of $10^{6} \mathrm{Btu} / \mathrm{hr}$ ) $(\mathrm{a})$

\begin{tabular}{|c|c|c|c|c|c|c|}
\hline $\begin{array}{l}\text { Time After } \\
\text { Shutdown, hr }\end{array}$ & $\begin{array}{c}100 \% \text { of } \\
\text { Noble Gases } \\
\end{array}$ & $\begin{array}{l}25 \% \text { of } \\
\text { Halogens }\end{array}$ & $\begin{array}{l}25 \% \text { of Volatile } \\
\text { Solids } \\
\end{array}$ & $\begin{array}{r}1 \% \text { of Non- } \\
\text { Volatile Solids }\end{array}$ & Total & $\begin{array}{l}\text { In EACS } \\
\text { Deposit }\end{array}$ \\
\hline $\begin{array}{c}0 \\
1 \\
7.4 \\
24 \\
72 \\
120 \\
192\end{array}$ & $\begin{array}{l}22.4 \\
4.34 \\
2.12 \\
1.00 \\
0.376 \\
0.279 \\
0.188\end{array}$ & $\begin{array}{l}10.8 \\
3.87 \\
2.12 \\
1.35 \\
0.745 \\
0.491 \\
0.285\end{array}$ & $\begin{array}{l}13.5 \\
2.24 \\
0.507 \\
0.418 \\
0.232 \\
0.133 \\
0.0758\end{array}$ & $\begin{array}{l}3.68 \\
0.65 \\
0.386 \\
0.262 \\
0.177 \\
0.140 \\
0.1113\end{array}$ & $\begin{array}{l}50.4 \\
11.1 \\
5.13 \\
3.03 \\
1.53 \\
1.04 \\
0.66\end{array}$ & $\begin{array}{l}0.0 \\
6.6 \\
3.0 \\
2.0 \\
1.2 \\
1.0 \\
0.47\end{array}$ \\
\hline
\end{tabular}

\section{TABLE 7}

DECAY POWER OF SOLIDS COLLECTED IN EACS FOR CASE II (DOUBLE CONTAINMENT)

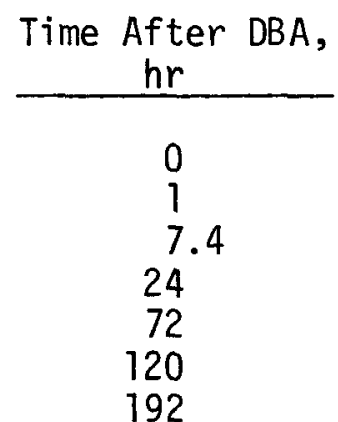

\begin{tabular}{c} 
FP Decay Heat, (a) \\
Btu/hr \\
\hline 0 \\
14,200 \\
7,260 \\
4,860 \\
2,780 \\
1,810 \\
995
\end{tabular}

(a) 1 BTU/hr $=0.293 \mathrm{~W}$ 
The energy production rates shown in Table 7 are modest, and would result in a negligible rise in temperature during EACS operation. However, they should be considered when analyzing loss of flow conditions for the EACS after operation for an hour or so.

For the confinement building (Case III), the total mass collected in the EACS is very small, and thus the heat generation rate of the collected material is low compared to the values listed in Table 6 for Case I. The HAA-3b code results for Case III indicate that 0.39 percent of the mass initially airborne in the primary leaks to the confinement building, and that of this, 63 percent reaches the EACS. Therefore, only 0.246 percent of mass released to the primary is collected by the EACS. Based on data presented in Table 7, the heat generation rate associated with this mass was computed. The results are summarized in Table 8 . The decay heating levels shown in Table 8 are modest and could be easily handled by the EACS design for Case III. Air flowing through the EACS at $15,000 \mathrm{CFM}\left(7.1 \mathrm{~m}^{3} / \mathrm{s}\right)$ would be heated only $0.3^{\circ} \mathrm{F}$ $\left(0.17^{\circ} \mathrm{C}\right)$ at most, showing the very small impact of decay heat in this case.

TABLE 8

DECAY POWER OF SOLIDS COLLECTED IN EACS FOR CASE III (CONTAINMENT/CONFINEMENT)

Time After Shutdown, $\mathrm{hr}$

0

7.4

24

72

120

192
FP Decay Power, $\mathrm{Btu} / \mathrm{hr}$ (a)

(a) $1 \mathrm{BTU} / \mathrm{hr}=0.293 \mathrm{~W}$ 


\subsection{Comparison of Containment Concepts}

An evaluation of various containment concepts is beyond the scope of the present study. However, the analyses performed here provide some bases for a general comparison. It must be strongly emphasized, however, that variations in each of the reference plant designs could greatly alter the conclusions.

Table 9 is a compilation of data selected from the previous sections of this report for total mass and plutonium leaked to the environment. Using standard meteorological data $(14)$, an arbitrary site exclusion radius of 1 mile $(1609 \mathrm{~m})$ and a population center distance of $6.2 \mathrm{miles}(10,000 \mathrm{~m})$, the bone doses are calculated for the three reference containment designs. The information is presented for plants with and without an EACS operating, and for two EACS efficiency levels for the containment/confinement plant. The ranking, in order of ascending dose, are the same at each distance and are as follows:

\begin{tabular}{|c|c|}
\hline Rank & System \\
\hline 1 & Double Containment with EACS \\
\hline 2 & Conta inment/Confinement, $D F=1000$ \\
\hline 3 & Double Containment without EACS \\
\hline 4 & Containment/Confinement, $D F=100$ \\
\hline 5 & Single Containment with EACS \\
\hline 6 & Single Containment without EACS \\
\hline
\end{tabular}

\subsection{EACS Design Basis Operating Conditions}

The HAA-3B and SOFIRE-II output data which are important to EACS design are summarized in Table 10. Since most of the parameters are time-dependent, values for several times are listed. It should be noted that the listed values are for plants with an EACS operating at design efficiency.

The comparison of containment systems made in Section 4.7 indicates that, if a double containment system is provided, an EACS may not be required. This conclusion cannot be substantiated until additional information becomes available on accidents not considered in this report, e.g., a reactor melt-through; and until federal regulations are established for accident guideline dose limits on plutonium inhalation. However, for the accident conditions described 
TABLE 9

COMPARISON OF CONTAINMENT CONCEPTS

(For Source Term and Reference Plant Designs Defined in this Report)

\begin{tabular}{l}
\multicolumn{3}{c}{ Single Containment } \\
\hline No Natural With EACS \\
Cleanup Fallout $\begin{array}{l}\text { Fat } \\
\alpha=0.25\end{array}$
\end{tabular}

Double Containment Natura 7 With EACS

Fallout
$\alpha=0.25 \quad \lambda=2 \mathrm{hr}^{-1}$

Containment/

Confinement

EACS EACS

$\underline{D F}=100 \quad D F=1000$

Total Mass Leaked, g

\begin{tabular}{|c|c|c|c|c|c|c|c|}
\hline $\begin{array}{l}2 \mathrm{hr} \\
\mathrm{t}=30 \mathrm{~d}\end{array}$ & $\begin{array}{c}110 \\
4.3 \times 10^{4}\end{array}$ & $\begin{array}{l}43 \\
48\end{array}$ & $\begin{array}{l}11 \\
11\end{array}$ & $\begin{array}{l}0.05 \\
0.50\end{array}$ & $\begin{array}{l}0.014 \\
0.015\end{array}$ & $\begin{array}{l}3.5 \\
5.6\end{array}$ & $\begin{array}{l}0.35 \\
0.56\end{array}$ \\
\hline & & & & & & & \\
\hline $\begin{array}{l}2 \mathrm{hr} \\
\mathrm{t}=30 \mathrm{~d}\end{array}$ & $\begin{array}{l}2.8 \\
1100\end{array}$ & $\begin{array}{l}1.2 \\
1.4\end{array}$ & $\begin{array}{l}0.27 \\
0.27\end{array}$ & $\begin{array}{l}0.0073 \\
0.073\end{array}$ & $\begin{array}{l}0.0020 \\
0.0022\end{array}$ & $\begin{array}{l}0.51 \\
0.81\end{array}$ & $\begin{array}{l}0.05] \\
0.018\end{array}$ \\
\hline
\end{tabular}

Bone Dose o 1 mile, rem

$\begin{array}{llllllll}2 \mathrm{hr} \text { exposure } & 650 & 270 & 62 & 1.8 & 0.50 & 6.3 & 0.63 \\ 30 \text { day exposure } & 2.4 \times 10^{5} & 320 & 62 & 18 & 0.54 & 10 & 1.0\end{array}$

Bone Dose 0.2 mile, rem

$1.8 \times 10^{4} \quad 23 \quad 4.5$

$1.3 \quad 0.04$

$4.5 \quad 0.45$ 
TABLE 10

SUMMARY OF EACS OPERATING CONDITIONS

\section{Parameter}

EACS cleanup rate

Gas Temperature, ${ }^{\circ} \mathrm{F}$

$0-0.5 \mathrm{hr}$ (avg)

$0.5-1.0 \mathrm{hr}$

1.0-2.0 hr

Maximum

Pressure, psig

$0-0.5 \mathrm{hr}$

$0.5-1.0 \mathrm{hr}$

1.0-2.0 hr

Maximum

Aerosol Conc, $\mu \mathrm{g} / \mathrm{cm}^{3}$

$0-0.5 \mathrm{hr}$ (avg.)

$0.5-1.0 \mathrm{hr}$

1.0-2.0 hr

Maximum

Aerosol Particle MMD, $\mu \mathrm{m}$

$0-0.5 \mathrm{hr}$

$0.5-1.0 \mathrm{hr}$

1.0-2.0 hr

Aerosol Particle Density

Material density, $\mathrm{g} / \mathrm{cm}^{3}$

Density modification factor, $\alpha$

Effective density, $\mathrm{g} / \mathrm{cm}^{3}$

FP Decay Heat Loading in

EACS, $10^{3} \mathrm{Btu} / \mathrm{hr}$

$t=7 \mathrm{hr}$

$\mathrm{t}=7 \mathrm{hr}$

$\mathrm{t}=24 \mathrm{hr}$

$t=120 \mathrm{hr}$

$\mathrm{t}=200 \mathrm{hr}$

Total Mass Loading

in EACS, $\mathrm{kg}$

$t=0.5 \mathrm{hr}$

$t=1.0 \mathrm{hr}$

$\mathrm{t}=2.0 \mathrm{hr}$

$t=\infty$

$\frac{\text { Case I }}{\text { Single }}$

$\frac{\text { Case II }}{\text { Double }}$

$\lambda=5 \mathrm{hr}^{-1}$

$\lambda=2 \mathrm{hr}^{-1}$

90

Case III

Containment/

Confinement

$15,000 \mathrm{CFM}$, $\mathrm{DF}=100$

240

230

205

300

4.5

4.2

3.3

6.0

5

1.5

0.1

13

1.7

2.0

2.3

2.74

0.25

0.68

6600

3000

2000

1000

450

1000

1300

1350

1350
120

140

150

$\begin{array}{ll}<1 & 0 \\ 1 & 0 \\ 1 & 0 \\ 1.5 & 0\end{array}$

0.01

0.01

0.008

0.003

0.011

50- 100

40-100

110

0

0

0.003

$<0.001$

0.011

5

4

3.5

3.0

6.0

6.0

0.25

0.25

1.5

1.5

14

7.2

6.3

7.1

4.9

5.0

1.8

1.9

1.0

1.0

$\begin{array}{ll}0.4 & 0.12 \\ 0.6 & 0.20 \\ 0.7 & 0.35 \\ 0.7 & 0.56\end{array}$


here and for the presently suggested guideline bone dose of $150 \mathrm{rem}$, it appears that for a double containment plant an EACS would not be required to meet most siting requirements, although it would certainly add to the margin of safety. Therefore, for the purpose of evaluating EACS for development, only the single containment and containment/confinement type systems will be considered at this time. Table 11 presents the most probable ranges of values for the important accident conditions which impact EACS design for the single containment case. The data in Table 11 are based on Table 10, but have been modified with engineering judgment to provide conservatism in the EACS design requirements. Similar data are presented for the containment/confinement plant in Table 12. Because a sodium fire in the confinement building would impose a severe loading on the EACS, Table 12 also includes a list of environmental conditions for the case of a postulated large sodium fire in the confinement building. For the purposes of this report, it is assumed that the DBST and the sodium fire would not occur simultaneous?ly. 


\section{Parameter}

1. Aerosol source

2. Maximum containment gas temperature

3. Maximum containment pressure

4. Containment pressure transient

5. Containment atmosphere humidity

6. Maximum aerosol mass conc.

7. Mass collected by EACS (max)

8. Water/sodium weight ratio for aerosol particle

9. Aerosol size distribution

10. Particle material density

11. Particle density modification factor

12. Effective density of particles

13. Aerodynamic equivalent diameter (b)

14. FP decay heat in EACS collected mass, $10^{6} \mathrm{Btu} / \mathrm{hr}$

$$
\begin{aligned}
& t=1 \mathrm{hr} \\
& t=2 \mathrm{hr} \\
& t=7 \mathrm{hr} \\
& t=24 \mathrm{hr} \\
& t=120 \mathrm{hr} \\
& t=200 \mathrm{hr}
\end{aligned}
$$

Probable Value

Puff release followed by sodium pool fire. Upper bound $1 \%$ of fue 1 , $25 \%$ halogens, $25 \%$ volatile solids, $100 \%$ noble gases, 5000 lbs sodium

$300^{\circ} \mathrm{F}$

$10 \mathrm{psig}$

$0.2 \mathrm{psi} / \mathrm{sec}$ for $15 \mathrm{sec}$

0 to saturated

$20 \mu \mathrm{g} / \mathrm{cm}^{3}$

$2000 \mathrm{~kg}$

$0-10$

$1.7 \mu \mathrm{mMMD}, \sigma_{\mathrm{g}}=2$

$2.7 \mathrm{~g} / \mathrm{cm}^{3}$

0.25

0.7

$1.4 \mu \mathrm{m} \mathrm{AED}$
10

10

5

3

1.5

0.7

(a) EACS $\lambda=5 \mathrm{hr}^{-1}$
(b) Equivalent particle with density of $1.0 \mathrm{~g} / \mathrm{cm}^{3}$ 
PARAMETERS CHARACTERIZING ACCIDENT ENVIRONMENT

FOR THE CONFINEMENT BUILDING CASE

\section{Parameter}

1. Aerosol source

2. Confinement building atmospheric temperature

3. Confinement building pressure

4. Confinement pressure transient

5. Confinement atmosphere humidity

6. Maximum aerosol mass concentration

7. Mass collected by EACS

8. Water/sodium weight ratio for aerosol particle

9. Aerosol size distribution

10. Particle material density

11. Particle density modification factor

12. Effective density of particles

13. Aerodynamic equivalent diameter

14. FP decay heat in collected mass, $10^{3} \mathrm{Btu} / \mathrm{hr}$

$$
\begin{aligned}
& t=1 \mathrm{hr} \\
& t=2 \mathrm{hr} \\
& t=7 \mathrm{hr} \\
& t=24 \mathrm{hr} \\
& t=120 \mathrm{hr} \\
& t=200 \mathrm{hr}
\end{aligned}
$$

Probable Values (a)

DBST ${ }^{(\mathrm{b})}$

Leakage from primary containment after HCDA

-10 to $110^{\circ} \mathrm{F}$

0 psig

0

$10-100 \% \mathrm{RH}$

$0.02 \mathrm{\mu g} / \mathrm{cm}^{3}$

$1 \mathrm{~kg}$

$1-100$

4.0 $\mu \mathrm{m} \mathrm{MMD,} \mathrm{sg}=2$

$6 \mathrm{~g} / \mathrm{cm}^{3}$

0.25

$1.5 \mathrm{~g} / \mathrm{cm}^{3}$

4.9 im AED

10

10

10

7

3

1.5
Sodium Fire

$40 \mathrm{lb} / \mathrm{min}$ sodium released into confinement bldg

-10 to $300^{\circ} \mathrm{F}$

0 psig

0

$0-100 \% \mathrm{RH}$

$25 \mathrm{\mu g} / \mathrm{cm}^{3}$

$1000 \mathrm{~kg}^{(\mathrm{c})}$

$1-10$

$2 \mu \mathrm{m} \mathrm{MMD,} \sigma \mathrm{g}=2$

$2.3 \mathrm{~g} / \mathrm{cm}^{3}$

0.25

$0.6 \mathrm{~g} / \mathrm{cm}^{3}$

$1.5 \mu \mathrm{m}$ AED

(a) For 15,000 CFM ventilation rate.

(b) Not considering a sodium fire in confinement building.

(c) As $\mathrm{NaOH}$. 


\subsection{CRITERIA AND PROCEDURE FOR EVALUATING EACS CONCEPTS}

\subsection{Criteria for Evaluating EACS Concepts}

The conservative EACS operating conditions have been summarized in Table 11 for single containment and in Table 12 for containment/confinement systems. Because of the obvious differences in EACS requirements for these two systems, separate criteria have been defined for both types of containment. For each case, however, the criteria are classed into six main groups, shown in Table 13. A more detailed listing of criteria is given in Appendix B.

TABLE 13

EACS CRITERIA GROUPS

Group No.

1

3

4

5

6
Criterion

System Effectiveness

The EACS shal1 be effective in reducing the release of radioactive substances to the environment under DBST conditions.

System Reliability

The EACS shall have a high degree of reliability in startup and continuance of operation during the entire accident period.

Containment Compatibility

The presence and operation of the EACS shall not degrade the normal effectiveness of the containment building.

Technological Credibility

The effectivness of the EACS sha11 be clearly demonstrable by experience, mathematical mode1s and testing.

System Characteristics and Flexibility

The EACS performance shall not be critically dependent on the accident environment conditions and shall accommodate possible future design changes.

Fabrication Effort

The system shall be readily designed, fabricated and installed at reasonable cost and in a time frame consistent with plant construction. 


\subsection{Rating Technique}

In order to provide a basis for quantifying the evaluation, each group listed in Appendix $B$ is divided into several individual criteria to which a weight factor has been assigned, with a value commensurate with its importance to the worth of the system. The total value of all weight factors is 100. The criteria for evaluating an EACS in single containment systems are given in Table B-1.

Somewhat different criteria have been developed for the containment/ confinement system. For this containment concept, the EACS is an integral part of the plant confinement design and, as a result, a minimum decontamination factor (DF) of 100 is specified and the weighting factors have been changed somewhat with additional weight being placed on the reliability and compatability section. The criteria for evaluating an EACS in containmentconfinement systems are given in Table B-2. The total of the weighting factors remains at 100 , as in the previous case.

Using the requirements established previously in Tables 11 or 12 for the EACS design base, a conceptual design of the candidate air cleaning system was completed. On the basis of this preliminary design, the system was rated with a score of 0 to 4 (to the nearest 0.1 ), based on the extent that it met each criterion. Definitions of the rating factors are given in Table 14 .

While the definition of the rating is measured by the amount of development work required, the same rating factors are also applied to the acceptability of any intrinsic characteristics of the system for the criterion being considered. For example, the efficiency of a settling chamber is, by the physical forces involved, very dependent on particle size and no amount of development will change that dependence.

A system score is determined by summing the individual criterion scores which are the product of the criterion weight and the rating factor. The maximum system score possible is 400 . Examination of this score will be made and items of low score examined for possible design changes which could lead to improved ratings. 
TABLE 14

RATING FACTORS FOR EACS EVALUATION

Rating

Factor

Rating Description

4

Clearly acceptable.

Completely satisfies criterion.

3 Probably acceptable.

Some development may be required. May not completely meet the criterion, but is adequate.

$2 \quad$ Possibly acceptable.

A large development effort may be required. Barely meets or falls short of the criterion.

Probably inadequate. Low probability of meeting criterion even with large development effort.

$0 \quad$ Clearly unacceptable.

Zero probability of meeting the criterion.

\subsection{Mandatory Criteria}

Certain criteria are thought to be of such importance to the system that they are considered mandatory requirements and a minimum rating score of 2.0, based on Table 14, is required. These mandatory criteria are listed in Table 15.

\subsection{Evaluation Procedure}

The following steps summarize the evaluation procedure:

1. Definition of the system, including a preliminary conceptual design, utilizing the aerosol and containment atmosphere parameters listed in Tables 11 and 12.

2. Evaluation of the system by the criteria listed in Appendix $B$. (Calculational methods will differ according to the type of system being evaluated.)

3. The degree to which the system meets the criteria is quantified by assigning a rating factor from 0 to 4 (to the nearest 0.1 ), as described in Table 14. 
TABLE 15

CRITERIA WITH MANDATORY ACCEPTABLE RATINGS $(a)$

Single Containment ${ }^{(b)}$

la DRF of 10

1b Decay heat removal

1c Dry or sticky particles

1d Radiation resistance

2a Reliable startup

2b Pressure pulse

2c Storage life

2d Reliable operation

$3 b$ No pressure buildup

3c Size

3d Subcritical
Containment/Confinement $(c)$

la Minimum DF $=100$
Ib Dry or sticky particles
lc Radiation resistance
2a Reliable startup
2b Storage life
2c Reliable operation
3b Size
4b In-place testing

1a Minimum $D F=100$

Ib Dry or sticky particles

2c Reliable operation

4b In-place testing

(a) Acceptable is defined as a minimum rating factor of 2.0 , as defined in Table 14.

(b) Refer to Table B- 1 in Appendix $B$ for more detailed description.

(c) Refer to Table B-2 in Appendix B for more detailed description.

4. The system score for each individual criterion is obtained by multiplying the criterion weight factor (from Appendix B) by the assigned rating factor.

5. The overall system rating is calculated by summing the scores of the individual criteria. The maximum possibie score is 400 .

6. Systems that have a low rating for any individual criterion are examined for possible design changes which will improve their rating.

7. The systems are ranked according to total score.

8. A check on the ranking is made by listing those systems which have an unacceptable rating (rating factor of 0 or 1) for any 
criterion. The seriousness of the unacceptable ratings is assessed, considering both the seriousness of the impact on plant and EACS performance and the possibility of upgrading the rating by design change. Systems with a final unacceptable rating for any criterion considered to be critical are disqualified from further consideration, even though they may rank high by total score.

9. The final ranking is made by considering both the numerical score and the probability of successful application. Because many of the criteria are only semi-quantifiable, the evaluation and rating necessarily entail considerable judgment. 


\subsection{SELECTION OF AIR CLEANING SYSTEMS TO BE EVALUATED}

\subsection{System Classification}

The chief radiological hazard resulting from the DBST defined in Section 4 is the plutonium and solid fission products released to the containment building as respirable-size aerosol particles. Radioactive materials released in other forms, e.g., halogen vapor and noble gases, are of concern and their hazard should be investigated. However, it is believed that most of the halogens would be associated with aerosol particles $(15,16)$ and that the chief air cleaning objective is the removal of the aerosol particles. Consequently, the systems selected for evaluation in this report are aimed at removal of particulates. Iodine removal may become the objective of future studies.

Many types of air cleaning equipment are available for controlling particulate air pollutants. $(17-20)$ They can be classified into three general groups according to their mode of operation in LMFBR service:

- Gas recirculation

- Direct in-vessel application

- Gas purge.

In the gas recirculation mode, the EACS nemoves the contaminants from a flowing gas stream in a recirculating loop which can be located either entirely internal or external to the containment building.

Direct in-vessel application systems operate directly on the containment building atmosphere without incorporating a duct air flow system. An example of this class is the containment building spray system used in many LWR plants.

In the gas purge mode (also known as single-pass mode), the EACS is located in a ventilation system which discharges directly to the environs, normally through a stack.

\subsection{Air Cleaning Systems to be Evaluated}

Particle removal from the containment atmosphere may be accomplished by air cleaning components used singly or several types may be arranged into 
systems. The types of components and systems considered in this study are listed in Table 16.

TABLE 16

TYPES OF CANDIDATE AIR CLEANING COMPONENTS AND SYSTEMS

\section{For Recirculating or Purge Modes}

\section{Filters}

Prefilters (various types including demisters)

Bag Filters (various types)

Deep Bed Graded Media Filters

Sand Filters

High Efficiency Particulate Air (HEPA) Filters

Cyclone Separators

Mechanical Separators

Electrostatic Precipitators

Dry

Wet

Wet Scrubbers

Spray Chamber

Centrifugal Scrubber

Venturi Scrubber

Packed Bed

Fluidized Bed

Acoustic Agglomerator

Settling Chamber

Charcoal Bed

For Direct In-Vessel Application Mode

Containment Building Liquid Spray

Containment Building Powder Discharge

Foam Dispersa]

Acoustic Agglomerator

Electrostatic Precipitator 
Some of the components listed in Table 16 are not suitable for use alone, but may be useful as a part of a system. For some accidents, for example, a cyclone separator would not have a sufficient particle removal efficiency by itself, but in combination with a sonic agglomerator, the required overall efficiency and loading may be achievable. In a similar manner, charcoal beds have very poor particle removal capabilities, but may have value in removal of iodine vapor or iodine compounds to enhance the overall system performance.

The list of candidate systems for the direct in-vessel application mode is much shorter. These systems, which in principle handle the entire containment atmosphere, are capable of rapidly reducing the airborne material concentration. The timing in the utilization of such systems as powder discharge, which can only operate for a short time span, is obviously important.

Mixing of systems between the three modes of operation is also possible is some cases. For example, an acoustic agglomerator acting in-vessel could precondition the aerosol for subsequent improved removal by a recirculation sys tem.

The number of possible combinations (and variations) of components listed in Table 16 is very large. The twenty-four systems selected for evaluation in this report are listed in Table 17. The first twenty of these are designs for use in single containment plants, while the remaining four are for the containment/confinement type of plant. Obviously, the types of systems suitable for single containment plants could be adapted for use in the outer containment building of double containment plants if the additional dose reduction afforded by an EACS is desired. 
TABLE 17

CANDIDATE AIR CLEANING SYSTEMS TO BE EVALUATED

Sys tem

Number

SR-1

$S R-2$

$\mathrm{SR}-3$

SR-4

SR-5

SR-6

$S R-7$

SR-8

SR-9

SR-10

SR-11

SR-12

SR-13

SD-14

SD- 15

SD- 16

SD-17

SD- 18

SC- 19

SC-20

CF-21

CF-22

$\mathrm{CF}-23$

$\mathrm{CF}-24$
Systems for Use with Single or Double Containments

Recirculating - Prefilter, HEPA

Recirculating - Deep Bed Graded Media Filter

Recirculating - Sand Bed Filter

Recirculating - Bag Filter

Recirculating - Cyclone Separator

Recirculating - Cyclone Separator, High-Efficiency Filter

Recirculating - Wet Scrubber, Demister

Recirculating - Fluidized Bed

Recirculating - Acoustic Agglomerator, Cyclone

Recirculating - Mechanical Separator, High-Efficiency Filter

Recirculating - Settling Chamber, High-Efficiency Filter

Recirculating - Electrostatic Precipitator

Recirculating - Steam Conditioner, Demister

Direct Application - Liquid Sprays

Direct Application - Powder, Discharge

Direct Application - Foam Dispersal

Direct Application - Acoustic Agglomeration

Direct Application - Electrostatic Precipitator

Combination - Containment Acoustic Agglomerator plus Recirculating Cyclone

Combination - Containment Powder Discharge plus Recirculating Filter

Systems for Use with Containment/Confinement Plants

Prefilter - HEPA, Charcoal, HEPA

Scrubber - Demister, HEPA, Charcoa 1, HEPA

Electrostatic Precipitator-HEPA, Charcoal, HEPA

Sand Filter, HEPA, Charcoal, HEPA 


\subsection{EVALUATION RESULTS}

The results of the evaluations of the twenty-four systems listed in Table 17 are discussed in this section. A rudimental conceptual design was made for each system, with the design objective of achieving a 2-hour dose reduction factor (DFR) of ten. This is equivalent to an exponential removal coefficient, $\lambda$, of $5 \mathrm{hr}^{-1}$ maintained over the initial 2-hour period of time after accident initiation. Operation for longer periods of time is advantageous, but was not design objective.

The key assumptions and design parameters used were established after considering the aerosol properties and containment atmosphere conditions listed in Tables 11 and 12. Standard, commercially-available equipment sizes were specified where possible. Redundancy is provided, in accordance with regulatory guides for light water plants. (21)

Information on equipment performance with sodium or sodium oxide aerosols was used when such was available. In the absence of operating performance data specific to LMFBR accident conditions, published information for standard air pollution control equipment was used, with modifications for LMFBR conditions made according to the authors' judgement.

In general, an attempt was made to install the equipment inside the containment building if reasonable space envelopes could be achieved. However, the decision of whether to locate the equipment internally or externally is not germane to the objective of this evaluation, although it may affect the cost significantly.

Capital costs were estimated by referring to published cost information for similar equipment, where available. Cost data were adjusted to 1975 dollars by using the Chemical Engineering Plant Cost Index ${ }^{(22)}$ shown in Table 18. The cost estimates inlcude engineering, equipment, installation labor, and instrumentation for installation in an LMFBR plant of a size defined in Section 3.0. The cost of the building required to house the EACS equipment is included in the construction figure. Consideration is given to the high quality and standards required for nuclear safety systems. The allowance for contingency varies, depending on the confidence in the completeness of the system design. 
TABLE 18

INDEX FOR UPDATING PLANT COSTS

\begin{tabular}{|c|c|c|c|c|c|}
\hline Year & Index $(\mathrm{a})$ & $\begin{array}{c}1975 \\
\text { Update Factor }\end{array}$ & Year & Index $(a)$ & $\begin{array}{c}1975 \\
\text { Update Factor }\end{array}$ \\
\hline 1947 & 64.8 & 2.81 & 1962 & 102.1 & 1.78 \\
\hline 1948 & 70.2 & 2.59 & 1963 & 102.4 & 1.78 \\
\hline 1949 & 71.4 & 2.55 & 1964 & 103.3 & 1.76 \\
\hline 1950 & 73.9 & 2.46 & 1965 & 104.2 & 1.75 \\
\hline 1951 & 80.4 & 2.26 & 1966 & 107.2 & 1.70 \\
\hline 1952 & 87.3 & 2.24 & 1967 & 109.7 & 1.66 \\
\hline 1953 & 84.7 & 2.15 & 1968 & 113.7 & 1.60 \\
\hline 1954 & 86.1 & 2.11 & 1969 & 119.0 & 1.53 \\
\hline 1955 & 88.3 & 2.06 & 1970 & 125.7 & 1.45 \\
\hline 1956 & 93.9 & 1.94 & 1971 & 132.2 & 1.38 \\
\hline 1957 & 98.5 & 1.85 & 1972 & 137.2 & 1.33 \\
\hline 1958 & 99.7 & 1.83 & 1973 & 144.1 & 1.26 \\
\hline 1959 & 101.8 & 1.79 & 1974 & 165.4 & 1.10 \\
\hline 1960 & 102.0 & 1.78 & 1975 & $(182.0)$ & 1.00 \\
\hline 1961 & 101.5 & 1.79 & & & \\
\hline
\end{tabular}

(a) Chemical Engineering Plant Cost Index, Reference 22, and Chemical Engineering, recent issues, last page.

\subsection{EACS For Single Containment System Plants}

Schematic flow diagrams for the twenty systems proposed for use with single containment plants are shown in Figure 5. Eleven of these were judged to be feasible and are discussed in detail in the following sections. The remaining nine systems were deemed undesirable or not feasible, as discussed in Section 7.7.7.

\subsubsection{System SR-1, Recirculating - Prefilter, HEPA}

7.1.1.1 Background (SR-1). Air cleaning systems employing prefilters and high-efficiency particulate air (HEPA) filters have been used in nuclear installations since the early 1950s. Usually the system is operated in a once-through mode with exhaust to a stack, but some are used in the recirculation mode. For the once-through mode, a very high particle removal efficiency is normaliy required. Standard HEPA filters are rated at a minimum efficiency 


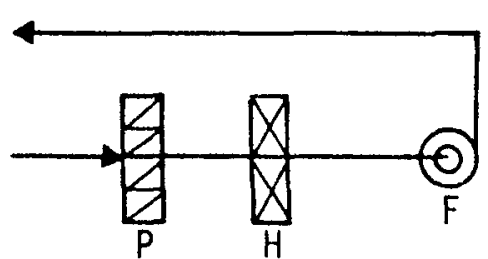

SR-1 RECIRCULATING-

PREFILTER, HEPA

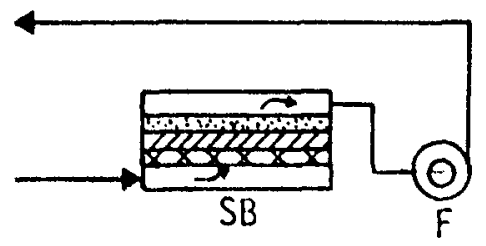

SR-3 RECIRCULATING-

SAND BED FILTER

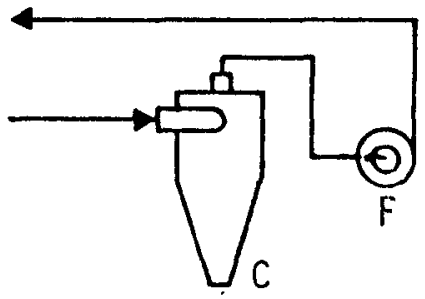

SR-5 RECIRCULATING-

CYCLONE SEPARATOR

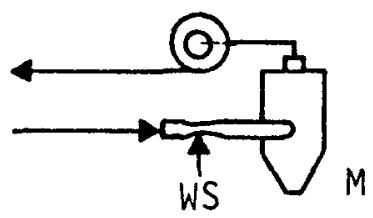

SR-7 RECIRCULATINGWET SCRUBBER, DEMISTER

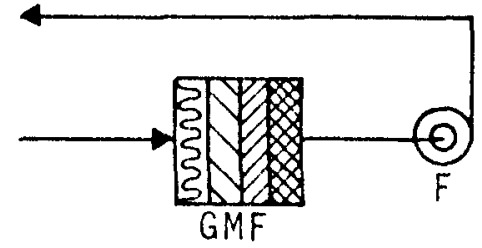

SR-2 RECIRCULATINGGRADED MEDIA FILTER

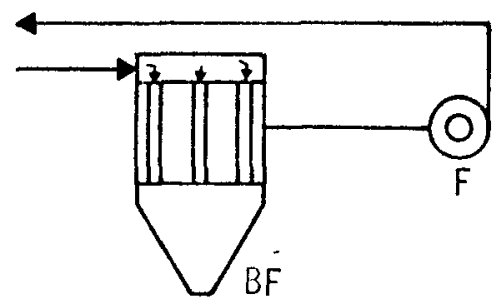

SR-4 RECIRCULATINC'-

BAG FILTER

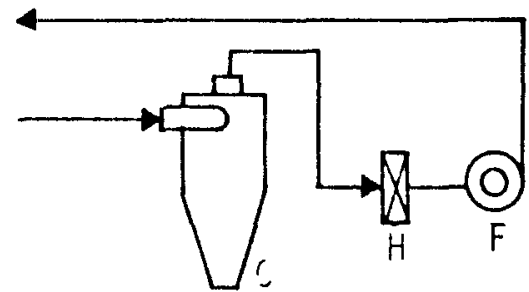

SR-6 RECIRCULATINGCYCIIONE, HEPA

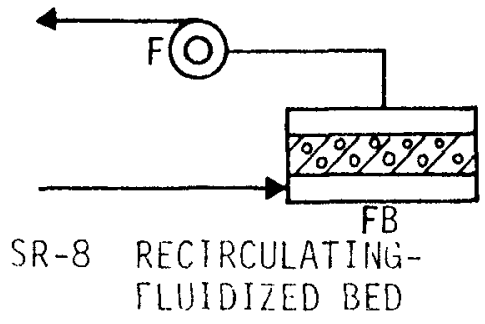

HEDL 7511-31.2

FIGURE 5a. Schematic Flow Diagrams for Single Containment EACS Candidate Systems. 


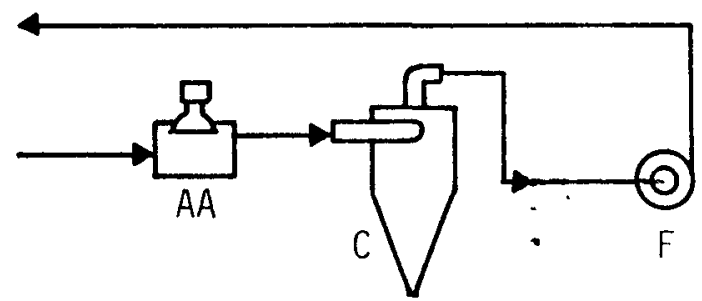

SR-9 RECIRCULATING - ACOUSTIC AGGLOMERATOR, CYCLONE

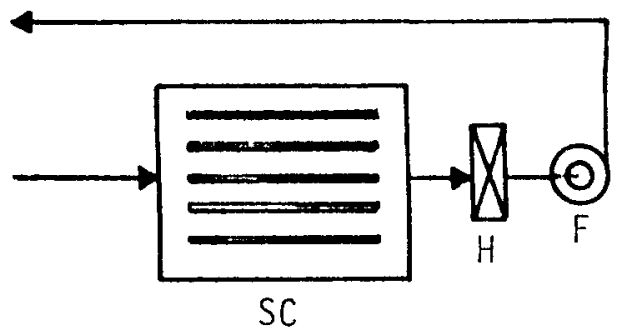

SR-11 RECIRCULATING - SETTLING CHAMBER, FILTER

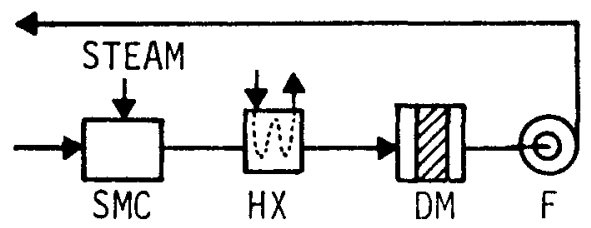

SR-13 RECIRCULATING - STEAM CONDITIONER, DEMISTER

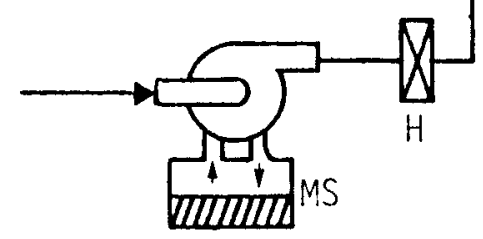

SR-10 RECIRCULATING - MECHANICAL SEPARATOR, FILTER

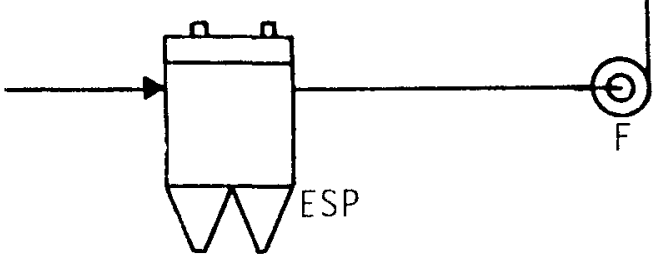

SR-12 RECIRCULATING - ELECTROSTATIC PRECIPITATOR

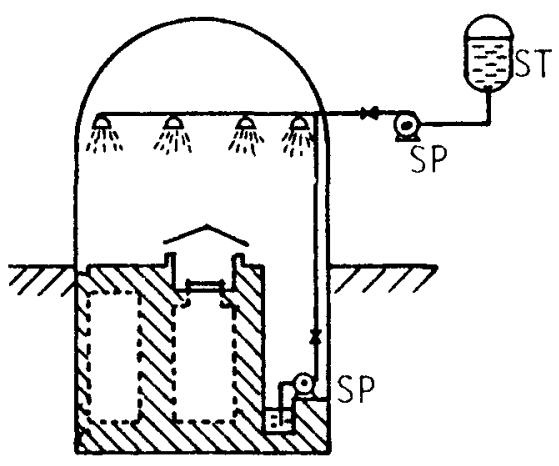

SD-14 DIRECT LIOUUID SPRAY

HEDL 7511-31.4

FIGURE 5b. Schematic Flow Diagrams for Single Containment EACS Candidate Systems. 


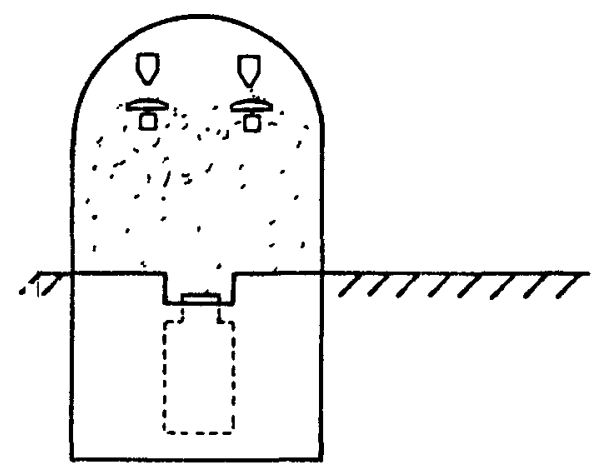

SD-15 DIRECT POWDER DISCHARGE

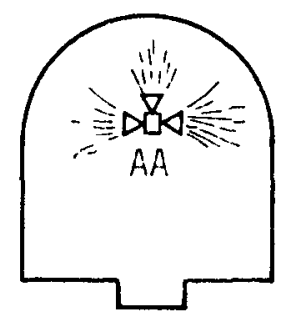

SD-17 DIRECT ACOLSTIC AGGLOMERATOR
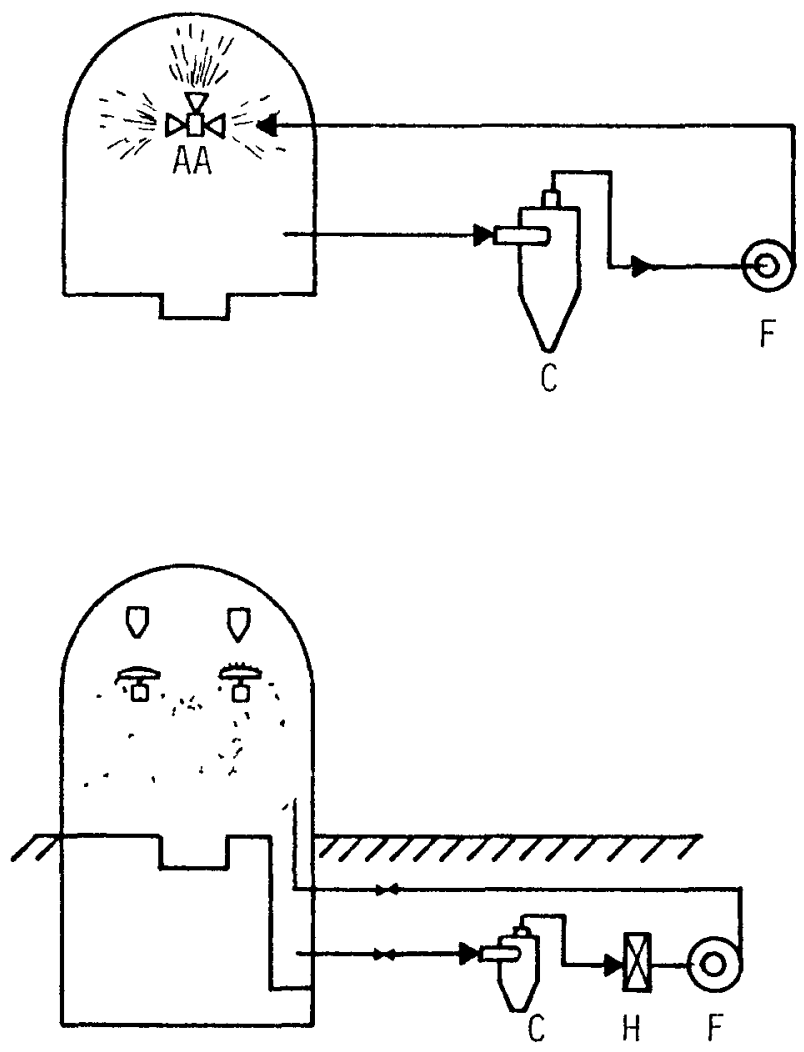

FIGURE 5C. Schematic Flow Diagrams for Single Containment EACS Candidate Systems.

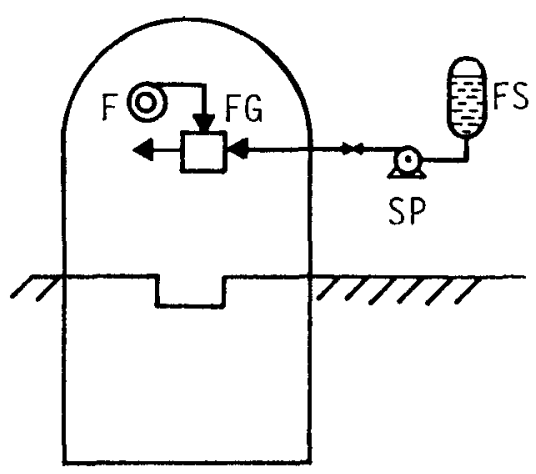

SD-16 DIRECT FOAM DISPERSAL

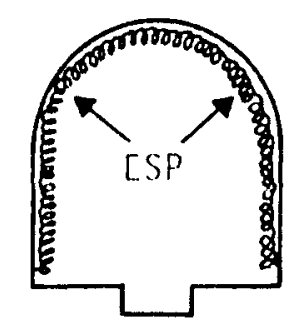

SD-18 ILLCTROSTATIC PRECIPITATOR

\section{SC, IG COMBINAIION - ACOUSTIC}

AGGLOMERATOR PLUS RECIRCULATING CYCLONE

HEDL 7511-31.1 
of 99.97 percent for $0.3 \mu \mathrm{m}$ diameter particles. (23) For the recirculating mode proposed for System SR-1, a high particle collection efficiency is not nearly as important as is the dust loading capacity. A recirculating system with particle penetration through the filters 100 times greater than that of a HEPA would increase the DRF by only 3 percent compared to a filter system with 100 percent collection efficiency. However, it is essential that the loading characteristics of the filters be adequate to retain the maximum load without causing excessive resistance to flow.

The dust loading capacity of a standard 1000 CFM HEPA filter is generally considered to be 4 ibs $(1.8 \mathrm{~kg})$ at normal flow velocity. (24) However, the loading capacity is dependent on the physical properties of the aerosol material, and may be considerably less than this. Prefilters generally are rated at higher loadings, but again this depends on the aerosol properties. Information concerning the loading capacities for the DBST aerosol described in this report is not available. Some data are available for Nak, sodium and sodium oxide fume. Dennis, et al., (25) reported a loading of NaK hydroxide fumes of only $0.07 \mathrm{lb}(0.032 \mathrm{~kg})$ per nominal $1000 \mathrm{CFM}$ HEPA at 5 in. $\mathrm{H}_{2} \mathrm{O}$ $\left(1.2 \times 10^{3} \mathrm{~Pa}\right)$ pressure drop, and approximately the same for a high-efficiency prefilter. Viles, et al., ${ }^{(26)}$ measured $\mathrm{Na}$ and $\mathrm{Na}_{x}$ retention on HEPA filters located downstream of graded media beds and reported approximately $0.081 \mathrm{~b}$ $(0.036 \mathrm{~kg})$ at 5 in. $\mathrm{H}_{2} 0$ for a nominal $1000 \mathrm{CFM}$ unit. The particle size was probably quite small in each of these tests, since little aging time was provided to permit agglomeration. Bohm $(27)$ burned sodium in normal air (humidity not stated) and reported a loading equivalent to $51 \mathrm{bs}(2.3 \mathrm{~kg})$ at 13 in. $\mathrm{H}_{2} \mathrm{O}\left(3.2 \times 10^{3} \mathrm{~Pa}\right)$ for a standard $1000 \mathrm{CFM}$ HEPA. Some unpublished data from other laboratories showed approximately 4 lb loading, though conditions were not well defined. It is concluded that, for the EACS-DBST conditions, both HEPA and prefilters would have a loading capacity of $4 \mathrm{lb}$ as $\mathrm{NaO}_{x}$ per nominal 1000 CFM ( $2 \mathrm{ft} \times 2 \mathrm{ft} \times 1 \mathrm{ft}$ ) unit when operated at 20 percent of normal flow rate. The flow resistance would be 4 in. $\mathrm{H}_{2} \mathrm{O}\left(1.0 \times 10^{3} \mathrm{~Pa}\right)$ across the prefilter; 6 in. $\mathrm{H}_{2} \mathrm{O}\left(1.5 \times 10^{3} \mathrm{~Pa}\right)$ across the HEPA. The correctness of this conclusion must be verified by development tests before a reliable system can be designed. 
7.1.1.2 Design Parameters (SR-1). The key assumptions and design parameters for System SR-1 are listed in Table 19.

TABLE 19

DESIGN PARAMETERS FOR SYSTEM SR-1

(Recirculating - Prefilters, HEPA)

Total Flow (all loops operating)(minimum) 200,000 CFM $\left(94.4 \mathrm{~m}^{3} / \mathrm{s}\right.$ )

Number of Loops

Flow Rate per Loop

5

Prefilters

Collection Efficiency

Number Units per Loop

Nominal Unit Size

Nominal Flow Rate per Unit

Nominal Velocity Through Unit

Limiting Pressure Drop

Loop Bank Arrangement

Loading Capacity per Unit

HEPA Filters

Collection Efficiency

Number units per Loop

Nominal Unit Size

Nominal Flow Rate per Unit

Nominal Velocity Through Filter Medium

Limiting Pressure Drop

Loop Bank Arrangement

Loading Capacity per Unit

$40,000 \mathrm{CFM}\left(18.9 \mathrm{~m}^{3} / \mathrm{s}\right)$

Fans

Number per Loop

Power Required, each

Motor Size, each

Flow Rate, new filters

Flow Rate, DBA-loaded filters

Ducts

Diameter

Average Length, intake

Average Length, exhaust

0.5
216
$2 f$

$2 \mathrm{ft} \times 2 \mathrm{ft} \times 1 \mathrm{ft}(0.61 \times 0.61 \times$

185 CFM $\left(0.087 \mathrm{~m}^{3} / \mathrm{s}\right)$

$46 \mathrm{ft} / \mathrm{min}(0.23 \mathrm{~m} / \mathrm{s})$

4 in. $\mathrm{H}_{2} \mathrm{O}(1000 \mathrm{~Pa})$

12 high $^{2}$ by 18 wide

$41 \mathrm{~b}(1.8 \mathrm{~kg})$

0.99

216

$2 \mathrm{ft} \times 2 \mathrm{ft} \times 1 \mathrm{ft}(0.61 \times 0.61 \times$

$185 \mathrm{CFM}\left(0.087 \mathrm{~m}^{3} / \mathrm{s}\right)$

$0.30 \mathrm{~m})$

$0.93 \mathrm{ft} / \mathrm{min}(0.0047 \mathrm{~m} / \mathrm{s})$

6 in. $\mathrm{H}_{2} \mathrm{O}(1500 \mathrm{~Pa})$

12 high $^{2}$ by 18 wide

$4 \mathrm{lb}(1.8 \mathrm{~kg})$

1

$135 \mathrm{HP}(100 \mathrm{kw})$

$150 \mathrm{HP}(112 \mathrm{kw})$

65,000 CFM 07.2 in. $\mathrm{H}_{2} \mathrm{O}$

$\left(30.7 \mathrm{~m}^{3} / \mathrm{s}\right.$ @ $\left.1800 \mathrm{~Pa}\right)$

$40,000 \mathrm{CFM}$ a 12 in. $\mathrm{H}_{2} \mathrm{O}$

$\left(18.9 \mathrm{~m}^{3} / \mathrm{s}\right.$ \& $3000 \mathrm{~Pa}$ )

36 in. $(0.91 \mathrm{~m})$

$100 \mathrm{ft}(30 \mathrm{~m})$

$200 \mathrm{ft}(60 \mathrm{~m})$ 
7.1.1.3 Conceptual Design (SR-1). The orientation of the filter building is shown in Figure 6 . It is a low-leakage cylindrical shaped building welded to the main reactor containment shell and thus constitutes an extension of the containment system. It is divided into five cells by vertical steel partitions. Each cell contains a bank of prefilters, a bank of HEPA filters and a fan, as shown in Figure 7. Individual intake and exhaust ducts and an equipment access port are provided for each cell. Isolation valves are not required, since there is no need to protect the filters from rapid pressurization.

Each loop recirculates gas at a minimum rate of 40,000 CFM $\left(18.9 \mathrm{~m}^{3} / \mathrm{s}\right)$ through two filter banks in series. The first bank contains 216 prefilter units, each with nominal $2 \mathrm{ft}$ by $2 \mathrm{ft}$ by $1 \mathrm{ft}(0.61 \times 0.61 \times 0.30 \mathrm{~m})$ dimensions, in an array of 12 units high by 18 wide. The second bank has an equal number and arrangement of similar sized HEPA filters. With this arrangement, aprroximately half of the aerosol mass is expected to be collected on the prefilters and the balance on the HEPA filters, and each type of filter would be loaded to 50 percent of $i$ ts loading capacity.

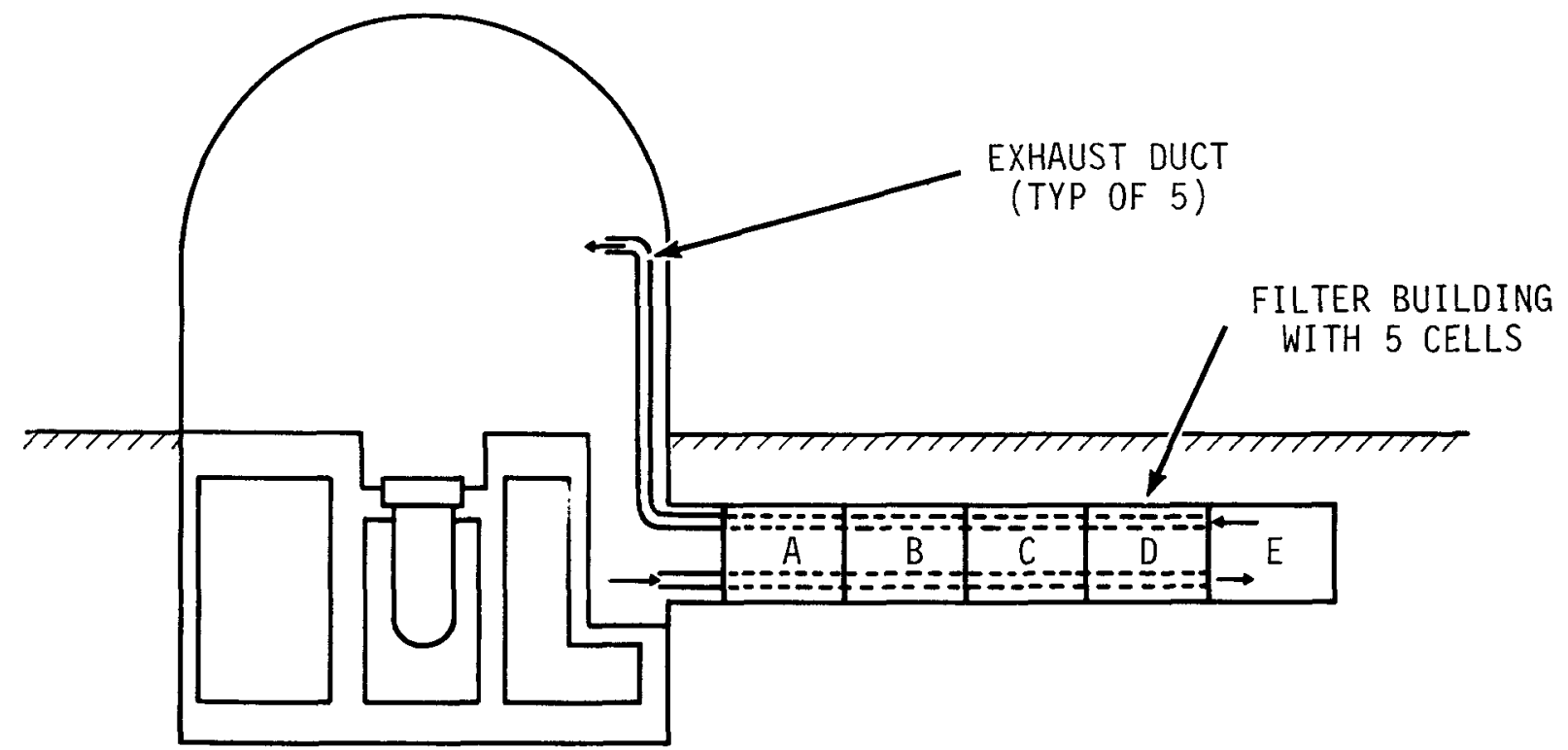

HEDL $7511-31.3$

FIGURE 6. Filter Building Orientation for Recirculating-Prefilter, HEPA, System SR-1. 


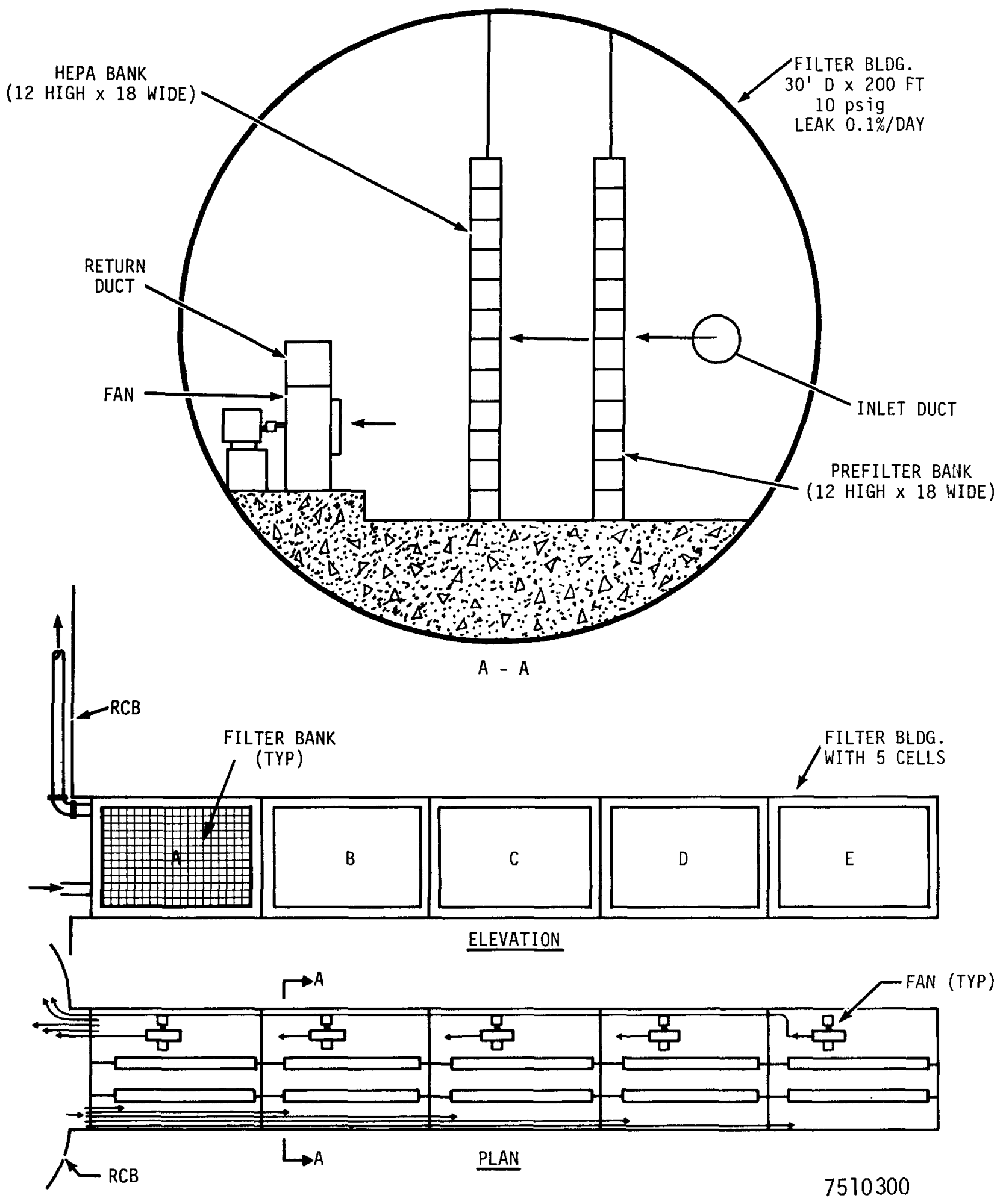

FIGURE 7. Equipment Arrangement for Recirculating, Prefilter-HEPA System SR-1. 
The prefilter efficiency can vary from 2 percent to 98 percent without overloading the HEPA filters. Because of the uncertainty in the loading capacity of both types of filters for the LMFBR accident conditions, this ability to handle a wide range of efficiency (and thus loading) is highly desirable. Each filter unit has a nominal flow of $185 \mathrm{CFM}\left(0.087 \mathrm{~m}^{3} / \mathrm{s}\right)$, approximately 20 percent of the manufacturer's nominal rating. This is a desirable feature because it reduces the pressure drop and increases the loading capacity. $(24,26)$

The fans are of the constant speed, direct drive, backward-curved bladed centrifugal type. Typical fan characteristics are shown in Curve A of Figure 8. It is sized to handle $40,000 \mathrm{CFM}\left(18.9 \mathrm{~m}^{3} / \mathrm{s}\right)$ at the maximum foreseable pressure drop of $12 \mathrm{in}$. $\mathrm{H}_{2} \mathrm{O}(3000 \mathrm{~Pa})$. This would be the loop flow resistance if the prefilter efficiency were only 5 percent and the balance of the aerosol was collected on the HEPA filters. At the start of the accident, when the filters are fresh, the loop flow rate would be $65,000 \mathrm{CFM}\left(30.7 \mathrm{~m}^{3} / \mathrm{s}\right)$ at 7.2 in. $\mathrm{H}_{2} \mathrm{O}(1800 \mathrm{~Pa})$.

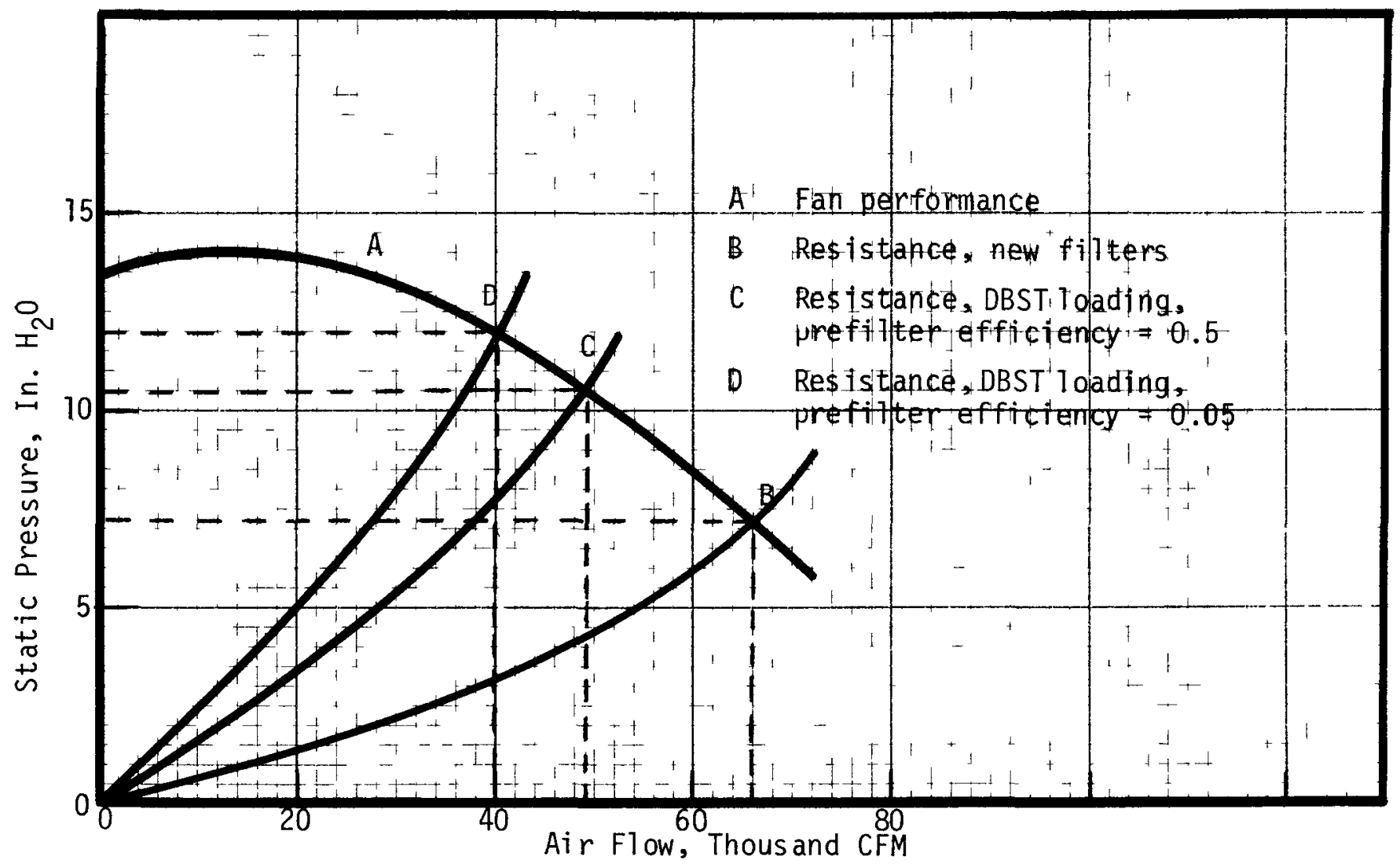

FIGURE 8. Effect of Filter Loading on System SR-1 Air Flow Rate. 
The fan horsepower rating was calculated from the following equation:

$$
H P=\frac{Q(\Delta P)}{6356 E_{f}}
$$

where: $H P=$ fan horsepower

$$
\begin{aligned}
Q & =\text { gas flow rate, CFM } \\
\Delta P & =\text { pressure drop across loop, in } \mathrm{H}_{2} \mathrm{O} \\
E_{f} & =\text { fractional fan efficiency. }
\end{aligned}
$$

Assuming a fan efficiency of 0.6 and a motor efficiency of 0.9 , each fan requires a $135 \mathrm{HP}(100 \mathrm{~kW})$ motor for a loop flowrate of $65,000 \mathrm{CFM}\left(30.7 \mathrm{~m}^{3} / \mathrm{s}\right)$; $150 \mathrm{HP}(112 \mathrm{~kW})$ motors, rated for continuous operation at $300^{\circ} \mathrm{F}$, are provided.

\subsubsection{Cost Estimate (SR-1).}

$\begin{array}{lc}\text { Construction, Equipment, and Building } & \frac{\$ 000}{4,300} \\ \text { Engineering (20\%) } & \frac{860}{5,160} \\ \text { Subtotal } & 5,760 \\ \text { Contingency (50\%) } & \underline{2,580} \\ \text { TOTAL COST } & 7,740\end{array}$

(a) 1975 dollars

\subsubsection{Conformity with Criteria (SR-1).}

- Criterion la. "A dose reduction factor ( $2 \mathrm{hr}$ ) of ten can be achieved for aerosol particles."

The DRF can be calculated from Equation (2), which assumes that the radioactive aerosol particles are released instantaneously (no continuing source) and the EACS operates at a constant flow rate and removal efficiency.

$$
D R F=\frac{\lambda t}{1-e^{-\lambda t}}
$$

where: $\quad D R F=$ dose reduction factor for the time period, $t$

$$
\begin{aligned}
& \lambda=\text { exponential removal rate coefficient, } \mathrm{hr}^{-1} \\
& \mathrm{t}=\text { time after release, } \mathrm{hr} \text {. }
\end{aligned}
$$


For a gas recirculation type system, the removal rate coefficient, $\lambda$, is defined by Equation (3).

$$
\lambda=\frac{Q_{R} E_{R}}{V}
$$

where: $Q_{R}=$ gas recirculation rate, $\mathrm{ft}^{3} / \mathrm{hr}$ at containment conditions $E_{R}=$ single pass removal efficiency $V=$ enclosed gas volume, $\mathrm{ft}^{3}$.

For the $\mathrm{Sr}-1$ system design at the minimum loop flow rate of 40,000 $\operatorname{CFM}\left(18.9 \mathrm{~m}^{3} / \mathrm{s}\right), \lambda$ equals $5.3 \mathrm{hr}^{-1}$ and the $(\mathrm{DRF})_{2} \mathrm{hr}$ equals 10.6 . The criterion is met completely. Rating $=3.5$.

- Criterion 1b. "Decay heat can be dissipated adequately."

The heat source from the radioactive materials collected on the filters is approximately at its maximum value of $1 \times 10^{7} \mathrm{Btu} / \mathrm{hr}$ $(3000 \mathrm{~kW})$ for the first three hours. During this period, the temperature of the air rises $45^{\circ} \mathrm{F}\left(25^{\circ} \mathrm{C}\right)$ as it passes through the filters during normal flow. The temperature of the deposited material would be only slightly higher. If total power is lost to the fans, the vertical ducts would induce natural draft to approximately 6 percent of normal flow. At this flow the deposited material would have a temperature of approximately $1000^{\circ} \mathrm{F}\left(540^{\circ} \mathrm{C}\right)$. It is concluded that decay heat removal is adequate, though more precise heat transfer calculations should be performed for an actual plant system. Rating $=3.2$.

- Criterion 1c. "Either dry or sticky particles can be treated effectively."

The design loading capacity used for this system (4 $1 \mathrm{~b}$ per $2 \mathrm{ft} x$ $2 \mathrm{ft} \times 1 \mathrm{ft}$ unit) is based on published information for sodium oxide in air with normal or low humidity ${ }^{(27)}$ and on some unpublished work, but the effect of moisture is inadequately understood. The system SR-1 design took this into account by providing additional filter area and lower flow velocity. Performance of this system with wet or dry particles is expected to be satisfactory, but 
confirmation of loading should be obtained by testing with full size filter units at design flow conditions. Rating $=2.0$.

- Criterion 1d. "System effectiveness is not degraded by the radiation dose caused by the accident over the required operating period." Recirculating filter systems using standard HEPA and prefilters are currently acceptable to NRC if they meet the Regulatory Guide 1.52 (?1) requirement of withstanding an integrated 30-day exposure of $10^{9}$ rads from deposited fission products. Since standard filter units are specified in the SR-1 design, it is concluded that their radiation resistance is adequate. Rating $=3.7$.

- Criterion 2a. "The EACS shall have a high probability of startup after initiation of the DBST."

The reliability of the system is good. The electric motor driven fans will have an emergency power source. Since the pressure pulse associated with the DBST is minor, there is very little chance of damaging the ducts, fan or filters. There are no isolation valves to be concerned with. The NRC has recently concluded: $(2 \cdot)$

"...the lack of a history of large-scale failures of air cleaning systems, the fact that there is recognition of unresolved issues and steps are being taken toward their solutions, and the examples giver of exceptional operating characteristics, should leave us with a high level of confidence in the reliability of the air cleaning systems employed today in nuclear facilities."

Rating $=3.8$.

- Criterion 2b. "The system shall be capable of withstanding the pressure pulse associated with the DBST."

With no isolation valves, the ducts leading to each side of the filter banks are always open to the containment building atmosphere. The fan in the downstream side of the filter banks would be the chief resistance to flow in that duct. The pressure pulse is rather $\mathrm{mild}(0.2 \mathrm{psi} / \mathrm{sec}$ or $1500 \mathrm{~Pa} / \mathrm{s}$ for $15 \mathrm{sec})$ and is probably of the same order as that caused normal fan startup. Rating $=3.0$. 
- Criterion 2c. "The system does not degrade during periods of unuse." Electric motors, switchgear, and fans are highly reliable equipment if maintained properly. The filter units slowly degrade with time, due both to natural aging and as a result of the periodic in-place testing which will be performed. However, the degradation is slow and predictable, and the units can be changed out during normal plant outages. Rating $=3.7$.

- Criterion 2d. "The system shall be capable of dependable operation over the required period of time under the DBST conditions of temperature, pressure, humidity, and aerosol loading."

Continuous operation over the initial 2-hour period is reasonably assured, with excessive flow resistance caused by aerosol loading being the greatest potential problem. Operation for 30 days appears nearly as dependable, but again the effect of loading must be ascertained by large-scale testing. Chemical attack by sodium oxide will lower the collection efficiency, but this would not occur until after the crucial first 2 hours and even then would not fail completely. Rating $=3.3$.

- Criterion 2e. "The system requires simple components and conservative design stress."

Filter systems, though frequently used in demanding circumstances, are inherently weak. High standards of design, fabrication, installation and maintenance are required, including seismic considerations. Rating $=3.6$.

- Criterion 3a. "Inadvertent operation of the EACS shall not harm plant equipment or constitute a hazard to personnel."

No harm to equipment or personnel would occur due to inadvertent operation of the SR-1 system. Rating $=4.0$.

- Criterion 3b. "Operation of the EACS shall not significantly increase the pressure within the containment building by gas injection, energy release or other means." 
The five fan motors require $675 \mathrm{HP}(500 \mathrm{kw})$ total power when operating at capacity. This is equivalent to approximately 17 percent of the fission product decay heat load during the first few hours. Thus, it will add a significant heat source for long periods of time. However, the filter building adds extra volume and heat sink area. Rating $=3.5$.

- Criterion 3c. "The size of the EACS shall be compatible with installation within or adjacent to the containment building." The 30-ft $(9.1 \mathrm{~m})$ diameter by $200-\mathrm{ft}(61 \mathrm{~m})$ long filter building occupies $140,000 \mathrm{ft}^{3}\left(4000 \mathrm{~m}^{3}\right)$ of space and is compatible with installation as an extension of the main reactor containment building. Rating $=2.7$.

- Criterion 3d. "The EACS shall maintain the collected aerosol mass in a subcritical configuration."

System SR-1 completely satisfies this criterion by spreading the aerosol over $2 \times 10^{5} \mathrm{ft}^{2}\left(1.9 \times 10^{4} \mathrm{~m}^{2}\right)$ of filter surface area. Rating $=4.0$.

- Criterion 4a. "The air cleaning concept is based on highly developed technology."

Aerosol filtration is a well-developed technology. 24,29$)$ Thirteen AEC-sponsored air cleaning conferences have been held on a biennial basis and the NRC has issued a regulatory guide for design, testing and maintenance of air filtration systems for LWR plants. Rating $=4.0$.

- Criterion 4b. "The EACS can be tested in-place for operability and efficiency."

In-place testing of filter banks for flow distribution and DOP particle collection efficiency is well established. $(21,30)$ Rating $=4.0$.

- Criterion 4c. "The EACS performance can be predicted by verified mathematical models."

The theory of particle filtration is well advanced, both for removal processes in the filters themselves ${ }^{(31)}$ and for the overall system. 
Large-scale verification tests have been performed for systems used in LWRs. (32) The chief limitation is imperfect knowledge of the aerosol properties, not a deficiency of the model. Rating $=4.0$.

- Criterion 4d. "The EACS equipment scaleup from currently available sizes to LMFBR plant application is smal1."

System SR-1 uses standard, commercially available filter units and fans. The number of filter units per loop is larger than existing systems, but this should not cause a serious scaleup problem. Rating $=3.8$.

- Criterion 5a. "The EACS is effective for the entire particle size spectrum expected during the accident."

The efficiencies of the prefilters and HEPA filters are not critically dependent on particle size. The loading capacity may be affected, but system SR-1 uses twice the minimum number of filter units to allow for some decrease in loading capacity. It is concluded that the criterion is adequately satisfied. Rating $=4.0$.

- Criterion 5b. "The system performance is not highly sensitive to the atmosphere temperature, pressure and relative humidity."

The system easily tolerates the environmental conditions associated with the DBST. However, chemical attack of glass fiber filter media by the deposited $\mathrm{Na} 2 \mathrm{O} / \mathrm{NaOH} / \mathrm{Na}_{2} \mathrm{CO}_{3}$ will occur, and this attack is accelerated at higher temperature and humidity. The chemical reactions probably are slow at the relatively low temperature involved $\left(\sim 200^{\circ} \mathrm{F}\right.$ for the initial 8-hour period). Even if gross failure should occur at longer times, it seems highly improbable that the collected mass of aerosol particles would be re-entrained in the respirable size range. Confirmatory testing is needed to determine the seriousness of this potential problem. Rating $=2.7$.

- Criterion 5c. "The system energy consumption is low."

The five fan motors require a total of $675 \mathrm{HP}(500 \mathrm{~kW})$. This is a significant power requirement, but is not considered impractical. Rating $=3.3$. 
- Criterion 5d. "The system can be modified to add halogen removal components, hydrogen recombiners and containment coolers."

System SR-1 is readily adaptable for incorporation of other flowthrough devices. The size of the filter building and arrangement of the components would probably differ from the conceptual design of SR-1. Backfitting would be expensive but not impossible. Rating $=4.0$.

- Criterion 5e. "The post-accident recovery is facilitated by the EACS."

System SR-1 would collect approximately 97 percent of the released aerosol mass on the filters. The filters are designed for remote removal, though this would be a difficult task for the DBST used in this analysis. Cleanup of the main reactor containment building would be facilitated because only 3 percent of the radioactive material would be on the surfaces. Rating $=3.0$.

- Criterion 6a. "The system cost is low. Capital cost is less than $\$ 10$ million; operating costs are low."

The installed cost of System SR-1 is estimated to be $\$ 7,700,000$. Approximately $40 \%$ of this cost is for the Filter Building. Rating $=2.5$.

- Criterion 6b. "Materials and techniques used in construction are readily available and easily fabricated."

All materials and techniques are standard. Rating $=4.0$.

- Criterion 6c. "Components and equipment are readily available." The fans will probably be special order, but are of a standard type. The filters are standard commercial units. All other equipment and controls are readily available. Rating $=3.0$.

\subsubsection{Mandatory Criteria (SR-1). All of the mandatory criteria} listed in Table 15 are satisfied with acceptable ratings for System SR-1. However, compliance with mandatory criterion lc (ability to handle dry or sticky particles) depends on inadequate design information concerning the 
effect of moisture on filter loading capacities, and this must be verified by development tests.

7.1.1.7 Rating (SR-1). The numerical rating of System $S R-1$ is as follows (refer to Table $C-1$ in Appendix $C$ for detailed ratings, and section 7.4 for comparison with other EACS systems).

\begin{tabular}{lr} 
System Effectiveness & 82.7 \\
System Reliability & 79.6 \\
Containment Compatability & 64.3 \\
Technological Credibility & 55.6 \\
System Characteristics and Flexibility & 37.1 \\
Fabrication Effort & 19.5 \\
\multicolumn{1}{c}{ TOTAL } & 338.5
\end{tabular}

7.1.1.8 Development Requirements (SR-1). Four areas where development testing is needed to provide increased confidence in the ability of a recirculating-prefilter, HEPA system to perform as a reliable EACS in an LMFBR are as follows:

- Loading capacity of prefilters and HEPA filters as a function of aerosol composition (fraction $\mathrm{NaO}_{x}$ ), humidity, gas velocity and aerosol particle size. The tests should be performed on full-scale prototype filter units at DBST conditions.

- Long-term performance (30 days) at DBST conditions. Effect of continued recirculation on flow characteristics of loaded filters. Chemical attack of filters by the sodium compounds. Resuspension of deposited materials.

- Decay heat removal. Measurement, using electrical simulation of decay heat, of the equilibrium temperature attained in the deposited aerosol cake and resulting damage to the filter for the loss of flow condition.

- Large-scale demonstration in a large containment vessel under DBST conditions to prove filter system performance and effective aerosol removal from containment atmosphere. 


\subsubsection{Recirculating - Deep Bed Graded Media Filter (SR-2)}

7.1.2.1 Background (SR-2). LeMar (33) attempted to develop a deep bed fibrous filter for collecting fumes from burning NaK as early as 1957 . He fabricated and tested a $2 \mathrm{ft}$ by $2 \mathrm{ft}$ by 18 inch deep $(0.61 \times 0.61 \times 0.45 \mathrm{~m})$ bed of bounded homogeneous Dynel fibers and reported filter plugging at a loading of 0.6 pounds of mixed hydroxides per $\mathrm{ft}^{2}$ of filter at 25 in. $\mathrm{H}_{2} \mathrm{O}$ pressure drop $\left(2.9 \mathrm{~kg} / \mathrm{m}^{2}\right.$ at $\left.6200 \mathrm{~Pa}\right)$.

Dennis (25) investigated several types of filters for use with Nak fumes, with a goal of achieving 90 percent collection efficiency and a fume loading capacity of $0.51 \mathrm{~b}$ per $\mathrm{ft}^{2}$ at a final resistance of $15 \mathrm{in}$. $\mathrm{H}_{2} \mathrm{O}\left(2.4 \mathrm{~kg} / \mathrm{m}^{2}\right.$ at $3700 \mathrm{~Pa}$ ). He concluded that small diameter fibers (mixture of $30 \mu \mathrm{m}$ and $10 \mu \mathrm{m}$ diameter) should give improved performance.

Viles, et al. (26), reasoned that the rapid resistance increases were caused by cake formation as a continuous layer and that this could be avoided or at least delayed by providing multiple layers of fibers having graded diameter and packing density, with increased collection efficiency in the direction of airflow. With such a filter configuration, collected particles would be more uniformly distributed throughout the layers of the bed. Initially, the deepest layer (smallest diameter fibers, highest packing density) would have the highest efficiency and would cnllect the major fraction of the incoming particles. As particles deposit on the intermediate layers, their efficiency increases until they become in turn the most efficient collectors and very little additional material reaches the deepest layer. Viles had an objective of attaining high efficiency for a once-through operating mode, so he added a HEPA filter in series. Most of Viles' work was performed with $0.78 \mathrm{ft}^{2}\left(0.072 \mathrm{~m}^{2}\right)$ beds. He expressed his results in terms of a "resistance coefficient" as defined in Equation (4).

$$
C_{R}=\frac{\Delta P}{H v}
$$

Where: $C_{R}=$ resistance coefficient, in. $\mathrm{H}_{2} \mathrm{O} /\left(\mathrm{lb} / \mathrm{ft}^{2}\right)(\mathrm{ft} / \mathrm{min})$

$\Delta \mathrm{P}=$ increased resistance to flow, in. $\mathrm{H}_{2} \mathrm{O}$

$H=$ fume loading capacity, $1 \mathrm{~b} / \mathrm{ft}^{2}$ of filter face area

$v=$ face velocity, ft/min. 
Viles' final design gave results with a value for $C_{R}$ averaging 3.36 . For the system SR-2 design conditions of $15 \mathrm{in} . \mathrm{H}_{2} \mathrm{O}(3700 \mathrm{~Pa})$ maximum flow resistance and velocities of 12 to $24 \mathrm{ft} / \mathrm{min}(0.061$ to $0.12 \mathrm{~m} / \mathrm{s})$, the loading would be 0.22 to $0.45 \mathrm{lb} / \mathrm{ft}^{2}\left(1.1\right.$ to $\left.2.2 \mathrm{~kg} / \mathrm{m}^{2}\right)$.

A $4 \mathrm{ft}$ by $6 \mathrm{ft}$ by 14.5 inch deep $(1.2 \times 1.8 \times 0.37 \mathrm{~m})$ graded media filter was fabricated at the EBR-II site for emergency use in a sampling cel1. (34) This filter was tested by passing sodium oxide fumes through it at a velocity of $22 \mathrm{ft} / \mathrm{min}(0.11 \mathrm{~m} / \mathrm{s})$. A value of 0.215 for $C_{R}$ can be calculated for the graded media filter from the EBR-II test data. This corresponds to a loading of 3.5 to $7.01 \mathrm{~b} / \mathrm{ft}^{2}\left(16.8\right.$ to $\left.33.6 \mathrm{~kg} / \mathrm{m}^{2}\right)$ for the $S R-2$ design conditions. This is approximately 20 times greater than could be inferred from Viles' data. (26) The more favorable result may be caused by the much higher concentration of particles and the drier air at the EBR-II test site.

For the SR-2 design, the conservative value of $0.331 \mathrm{~b} / \mathrm{ft}^{2}\left(16 \mathrm{~kg} / \mathrm{m}^{2}\right)$ is used, based on Viles' test data. Development testing under the EACS-DBST conditions defined in this report may warrant higher loading allowances.

\subsubsection{Design Parameters (SR-2). The key assumptions and design} parameters for system SR-2 are listed in Table 19.

7.1.2.3 Conceptual Design (SR-2). The orientation of the filter building is similar to that of system SR-1, shown in Figure 6 . It is a low-leakage cylindrical-shaped building located undergound and weided to the main reactor containment she11. It is divided into five cells by vertical steel partitions. Each cell contains two double banks of graded media filters, as shown in Figure 9. The fan exhausts the cell and discharges through a return duct to the reactor containment building (RCB). Contaminated air from the RCB enters the center plenum between each filter bank in each of the double filters and flows outward through the media to the cell atmosphere. There are no isolation valves in the ducts.

Each loop recirculates gas at a minimum rate of $43,000 \mathrm{CFM}\left(20.3 \mathrm{~m}^{3} / \mathrm{s}\right)$ when the filters are loaded. With fresh filters, the recirculation rate would be approximately $70,000 \mathrm{CFM}\left(33.0 \mathrm{~m}^{3} / \mathrm{s}\right)$. Each fan requires $200 \mathrm{HP}$ $(150 \mathrm{~kW})$ maximum; $250 \mathrm{HP}(186 \mathrm{~kW})$ motors are provided. The fans are of the same type specified for system SR-1. 
TABLE 20

DESIGN PARAMETERS FOR SYSTEM SR-2

(Recirculating - Deep Bed Graded Media Filter)

\section{Parameter}

Loops

Number of loops

Flow rate per loop, minimum

Total flow (a11 loops), minimum

Filter

Number of media grades

Filter module size

Total filter thickness

Air flow direction

Number filter banks per loop

Filter bank size

Collection efficiency, minimum

Total filter surface area per loop

Nominal velocity through media

Loading capacity

Filter pressure drop, maximum

\section{Fans}

Number per loop

Power required at max. flow, each

Motor size, each

Flow rate, new filters

Flow rate, DBA load

Ducts

Diameter

Average length, intake

Average length, exhaust
Value

5

43,000 CFM $\left(20 \mathrm{~m}^{3} / \mathrm{s}\right)$

215,000 CFM $\left(100 \mathrm{~m}^{3} / \mathrm{s}\right)$

6

$4 \mathrm{ft} \times 6 \mathrm{ft} \times 2 \mathrm{ft}(1.2 \times 1.8 \times 0.61 \mathrm{~m})$

$2 \mathrm{ft}(0.61 \mathrm{~m})$

In at center, out through

two vertical banks

4

Two $24 \mathrm{ft}$ by $30 \mathrm{ft}(7.3 \times 9.1 \mathrm{~m})$

Two $28 \mathrm{ft}$ by $30 \mathrm{ft}(8.5 \times 9.1 \mathrm{~m})$

0.9

$3120 \mathrm{ft}^{2}\left(290 \mathrm{~m}^{2}\right)$

$13.8 \mathrm{ft} / \mathrm{min}(0.070 \mathrm{~m} / \mathrm{s})$

$0.331 \mathrm{~b} / \mathrm{ft}^{2}\left(1.6 \mathrm{~kg} / \mathrm{m}^{2}\right)$

15 in. $\mathrm{H}_{2} \mathrm{O}(3700 \mathrm{~Pa})$

1

$200 \mathrm{HP}(150 \mathrm{~kW})$

$250 \mathrm{HP}(186 \mathrm{~kW})$

70,000 CFM o 7 in. $\mathrm{H}_{2} \mathrm{O}$

$\left(33 \mathrm{~m}^{3} / \mathrm{s} \text { at } 1700 \mathrm{~Pa}\right)^{2}$

43,000 CFM o 12 in. $\mathrm{H}_{2} \mathrm{O}$

$\left(20 \mathrm{~m}^{3} / \mathrm{s} \text { at } 3000 \mathrm{~Pa}\right)^{2}$

36 in. $(0.91 \mathrm{~m})$

$100 \mathrm{ft}(30 \mathrm{~m})$

$200 \mathrm{ft}(60 \mathrm{~m})$ 

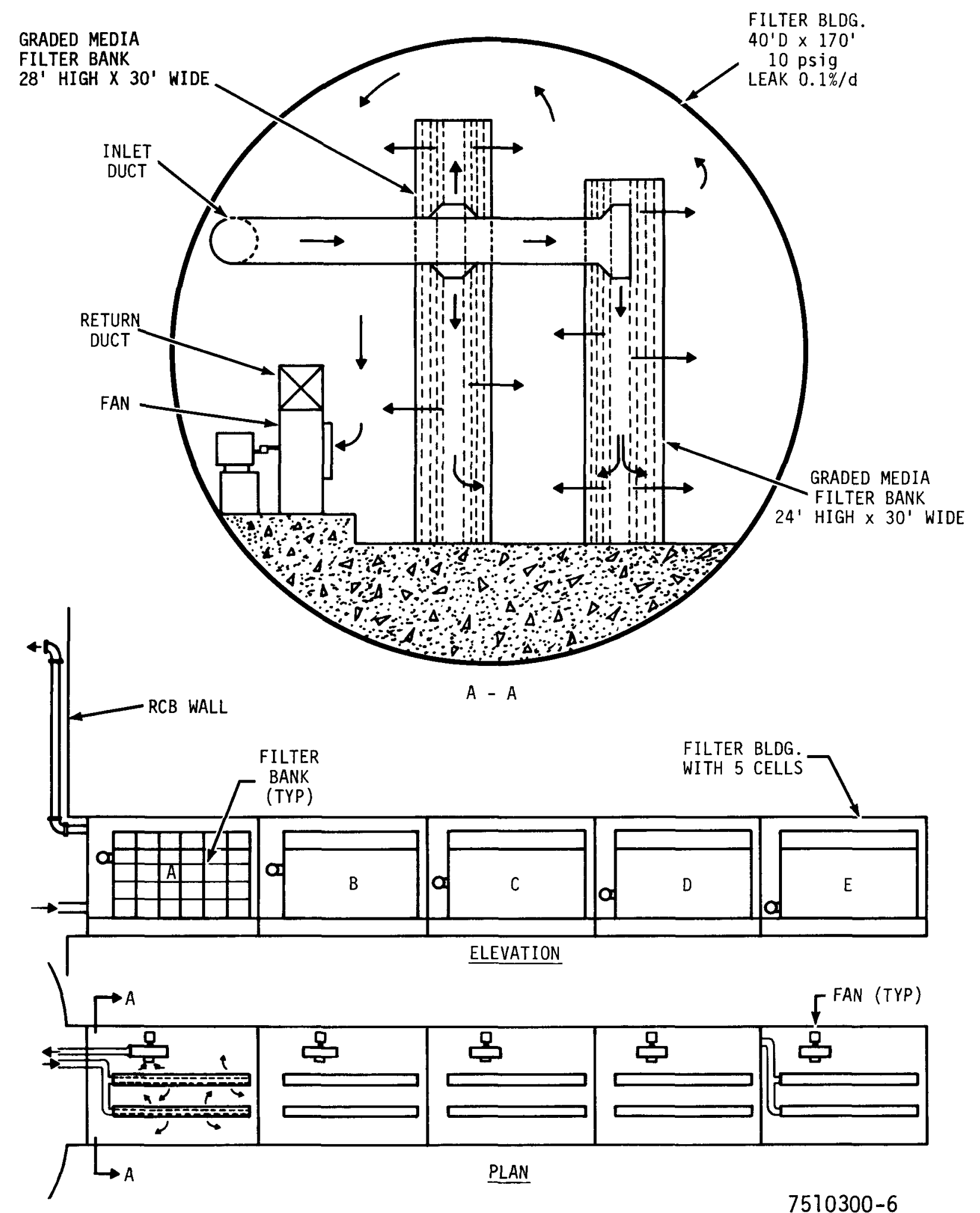

FIGURE 9. Equipment Arrangement for Recirculating - Graded Media Filter System SR-2. 
Figure 10 shows a sectional view of the double filter bank. In this design, six layers of media are used, with increasing packing density and smaller fiber diameter layers with increasing distance from the center. Air enters the center plenum and flows outward through the various layers at velocities ranging from $22 \mathrm{ft} / \mathrm{min}(0.11 \mathrm{~m} / \mathrm{s})$ with new filters to $13.8 \mathrm{ft} / \mathrm{min}$ $(0.070 \mathrm{~m} / \mathrm{s})$ at rated loading. Using the average values for the viles $(26)$ "advanced filter pack" tests, a loading of $0.33 \mathrm{lb} / \mathrm{ft}^{2}\left(1.6 \mathrm{~kg} / \mathrm{m}^{2}\right)$ is assumed.

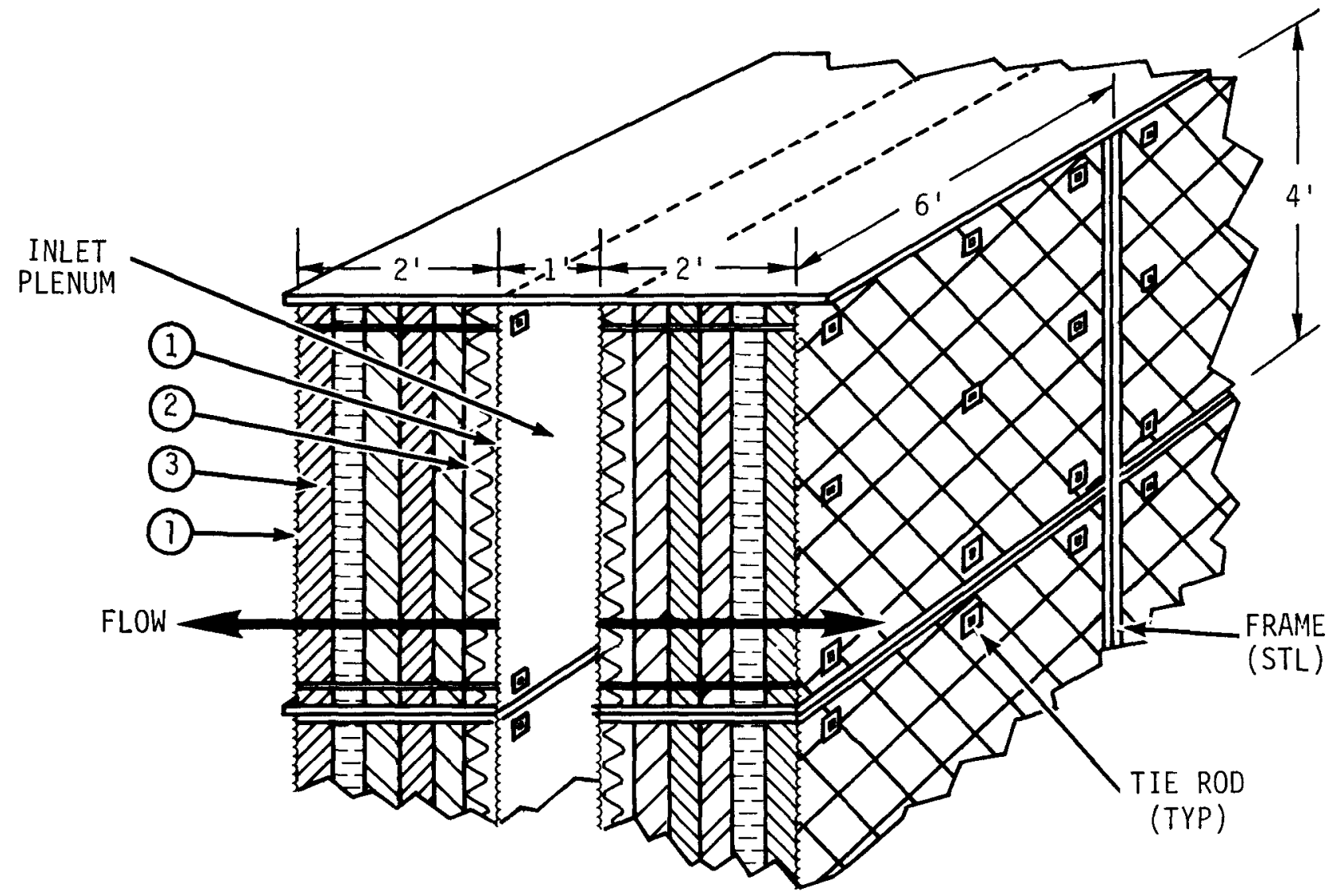

(1) METAL SCREEN

(2) COARSEST MEDIA

(3) FINEST MEDIA

HEDL 7511-31.6

FIGURE 10. Graded Media Filter Details. 
The early collection efficiency of the SR-2 design is specified to be 0.90 minimum. Viles' tests ${ }^{(26)}$ showed less than 10 percent penetration of the graded media bed when the bed was 10 percent loaded. Efficiencies approached 100 percent as the bed became loaded.

7.1.2.4 Cost Estimate (SR-2).

$\begin{array}{lr} & \$ 000(a) \\ \begin{array}{l}\text { Construction, Equipment, } \\ \text { and Building }\end{array} & 4,780 \\ \text { Engineering (20\%) } & \frac{950}{5,730} \\ \quad \text { Subtotal } & \underline{5,150} \\ \text { Contingency (55\%) } & \underline{3,880} \\ \text { TOTAL COST } & \end{array}$

(a) 1975 dollars

\subsubsection{Conformity with Criteria (SR-2).}

- Criterion 1a. "A dose reduction factor $(2 \mathrm{hr})$ of ten can be achieved for aerosol particles."

At the system minimum flow and efficiency conditions, the $2 \mathrm{hr}$ DRF is 10.3. The DRF would exceed this because of the higher recirculation rate at earlier times before the filter becomes loaded. Rating $=3.3$.

- Criterion 1b. "Decay heat can be dissipated adequately."

At the minimum design flow rate, the deposited material in the filter bed would be only slightly higher than the air temperature, which increases a maximum of $40^{\circ} \mathrm{F}\left(22^{\circ} \mathrm{C}\right)$ as it passes through the bed at early times. If power is lost to the fan, natural draft would sustain approximately 6 percent of normal flow and the temperature of the deposited material would rise to a maximum of approximately $1000^{\circ} \mathrm{F}\left(540^{\circ} \mathrm{C}\right)$. This should not damage the steel mesh or mineral fibers in the bed, but may cause the filter bank efficiency to decrease significantly. However, in order for this to happen, most of the heatgenerating aerosols have already been captured by the bed, so there would be little effect on the DRF. It is concluded that decay heat removal is adequate. Rating $=3.2$. 
- Criterion 1c. "Either dry or sticky particles can be treated effectively."

The design loading was based on tests performed with both liquid sodium fume and dry sodium oxide particles. ${ }^{(26)}$ No difference in loading was observed, but additional tests should be performed to determine this important parameter under high humidity conditions. Rating $=2.8$.

- Criterion 1d. "System effectiveness is not degraded by the radiation dose caused by the accident over the required operating period."

The average 30-day absorbed radiation dose to the filter media is approximately $1 \times 10^{9}$ rad. The filter media and filter frames can be constructed of materials capable of withstanding this dose, which is the same as calculated for LWR plants air cleaning systems. (21) Rating $=3.7$.

- Criterion 2a. "The EACS shall have a high probability of startup after initiation of the "DBST."

The reliability of system SR-2 components is high. An emergency power source will be provided for the fan motors. The pressure pulse associated with the accident is not severe. There are no isolation valves in the air ducts which require opening. Rating $=3.8$.

- Criterion 2b. "The system shall be capable of withstanding the pressure pulse associated with the DBST."

With no isolation valves, the ducts leading to each side of the filter banks are always open to the RCB atmosphere. The fan in the downstream side of the filters provides the chief resistance to flow during the pressure pulse. The pressure pulse is mild $(0.2 \mathrm{psi} / \mathrm{sec}$ for $15 \mathrm{sec}$ ) and the system should easily withstand it. Rating $=3.6$.

- Criterion 2c. "The system does not degrade during periods of unuse." The system SR-2 components are not subject to rapid deterioration. The electric motors, switchgear and fans are highly reliable if properly maintained. The filter units will degrade slowly, due both 
to in-place testing which will be performed periodically and natural aging. Some slight natural convection induced recirculation may occur, which would slowly load the filter with normal atmospheric dust. However, this would be very slow and predictable. Frangible duct barriers could be provided to prevent natural circulation during normal operations, if deemed necessary. Rating $=3.7$.

- Criterion 2d. "The system shal1 be capable of dependable operation over the required period of time under the DBST conditions of temperature, pressure, humidity and aerosol loading."

The fans and fan motors are designed to operate continuously in the accident environment. Some aerosol materiai iiy build up on the far blades, since the filters are only 90 percent efficient for the very early times. However, the fans are of a type designed for dirty industrial application and this should not present a problem. Proof testing of a prototype fan is advisable. Filter loading and flow resistance are the major uncertainties. The SR-2 design is based on rather meager test data which should be confirmed at large scale by testing under DBST conditions. Chemical attack by sodium oxide will occur, but this is not expected to be serious during the critical first two hours. Chemical attack will be 1 imited by the quantity of sodium oxide/hydroxide present, since the mass of filter media exceeds the sodium aerosol mass by a factor of 50. Again, the seriousness of chemical reaction must be determined by prototype testing. Rating $=3.5$.

- Criterion 2e. "The system requires simple components and conservative design stress."

The recirculating graded media filter system is inherently simple and can be designed with conservative design stresses. The system is exposed only to the differential pressures caused by the recirculating gas; the filter building withstands the full containment pressure. Rating $=3.4$. 
- Criterion 3a. "Inadvertent operation of the EACS shall not harm plant equipment or constitute a hazard to personnel."

System SR-2 completely meets this criterion. Rating $=4.0$.

- Criterion 3b. "Operation of the EACS shall not significantly increase the pressure within the containment building by gas injection, energy release or other means."

The five fan motors require $1000 \mathrm{HP}(750 \mathrm{~kW})$, which is equivalent to approximately 25 percent of the fission product decay heat release during the first few hours. This represents a significant addition of heat for a long period of time. However, the filter building adds 10 percent additional volume and 20 percent additional surface area for heat sink, which will nearly compensate for the added energy input. Rating $=3.4$.

- Criterion 3c. "The size of the EACS shall be compatible with installation within or adjacent to the containment building."

The 40-ft diameter by $170-\mathrm{ft}$ long (12-m diameter by $52-\mathrm{m}$ long) filter building occupies $220,000 \mathrm{ft}^{3}\left(6200 \mathrm{~m}^{3}\right)$ of space and is compatible with installation as an extension of the main containment building. Rating $=2.0$.

- Criterion 3d. "The EACS shall maintain the collected aerosol mass in a subcritical configuration."

System SR-2 completely satisfies this criterion by spreading the aerosol throughout $30,000 \mathrm{ft}^{3}\left(850 \mathrm{~m}^{3}\right)$ of filter media volume. Even if all the aerosol were retained on the initial 2-inch filter layer, the fissionable material density would be less than $0.11 \mathrm{~b} / \mathrm{ft}^{3}\left(1.6 \mathrm{~kg} / \mathrm{m}^{3}\right)$. Rating $=4.0$.

- Criterion 4a. "The air cleaning concept is based on highly developed technology."

Aerosol filtration is a well developed technology, $(24,29)$ but industrial use of graded media is limited. Rating $=2.5$.

- Criterion 4b. "The EACS can be tested in-place for operability and efficiency. 
Methods for in-place testing of filter banks for flow distribution and DOP particle collection efficiency are well known. $(21,30)$ The low efficiency of graded media may require added effort. Rating $=2.5$.

- Criterion 4c. "The EACS performance can be predicted by verified mathematical models."

The theory of particle filtration is well advanced, both for removal processes in the filters themselves ${ }^{(3 l)}$ and for the overall system. However, fibrous filter performance is highly dependent on aerosol particle properties and gas flow rate, which are variable for the design basis considered here. Since prediction of the absolute efficiency is not of paramount importance when the system is operated in the recirculating mode, present models are considered adequate. Rating $=3.5$.

- Criterion 4d. "The EACS equipment scaleup from currently available sizes to LMFBR plant application is small."

The original development work on deep bed graded media filters for use with LMFBR systems ${ }^{(26)}$ was performed with smal1 beds $\left(<1 \mathrm{ft}^{2}\right.$ surface area). A $4 \mathrm{ft}$ by $6 \mathrm{ft}$ by 14.5 inch deep $(1.2 \times 1.8 \times 0.37 \mathrm{~m})$ graded media filter is used at the EBR-II ${ }^{(34)}$, but large multiple banks, such as proposed for system SR-2, have not been constructed. Some scaleup problems can be anticipated, but these are not expected to be serious. Rating $=2.3$.

- Criterion 5a. "The EACS is effective for the entire particle size spectrum expected during the DBST."

The Harvard work with graded media filters ${ }^{(26)}$ used sodium and sodium oxide fume with particle sizes ranging from 1.0 to $3.0 \mu \mathrm{m} \mathrm{MMD;}$ og ranging from 1.9 to 4.5. Their test aerosols were approximately the same size as that expected for the LMFBR DBST. Larger particles are collected with greater efficiency. The effect of larger particles on loading is not clear at this time. Since the system SR-2 design is based on the Harvard work, it should adequately handle any particle size encountered in the DBST. Rating $=3.0$. 
- Criterion 5b. "The system performance is not highly sensitive to the atmosphere temperature, pressure and relative humidity."

The structural features of system SR-2 are not highly sensitive to the environmental conditions to which they are exposed. The fans and fan motors are designed for continuous operation in the maximum temperature expected $\left(300^{\circ} \mathrm{F}\right.$ or $\left.150^{\circ} \mathrm{C}\right)$. The system sees only the differential pressure caused by fan operation. However, the rate of chemical attack of the filter media would be accelerated at higher temperatures and humidities. Proof testing of this aspect would be necessary, including tests with media that are chemically inert to $\mathrm{Na}_{2} \mathrm{O} / \mathrm{NaOH}$. Rating $=3.8$.

- Criterion 5c. "The system energy consumption is low."

The five fan motors require a total of $1000 \mathrm{HP}(745 \mathrm{~kW})$. This is a significant power requirement, but is not considered impractical. Rating $=3.0$.

- Criterion 5d. "The system can be modified to add halogen removal components, hydrogen recombiners and containment coolers."

Al1 of these add-on devices require an efficient prefilter to remove aerosol particles. The graded media filter is only about 90 percent efficient at early times, hence the downstream components would be contaminated by aerosol particles penetrating the filter. This could be overcome by incorporating a HEPA filter as the last stage of the graded media filter bank. The other components would require space downstream, which would probably require a complete new design, but is possible. Rating $=3.5$.

- Criterion 5e. "The post-accident recovery is facilitated by the EACS." System SR-2 would collect approximately 97 percent of the released aerosol mass on the graded media filters, which can be designed for remote removal. The entire recirculation duct system, including fans, would be severely contaminated. On balance, it seems that the benefit achieved in the RCB is offset by the added problems in the filter system itself. A rating of 2.9 is assigned. 
- Criterion 6a. "The system cost is low. Capital cost is less than $\$ 10$ million; operating costs are low."

The installed cost is estimated at $\$ 8.9$ million. It is entirely possible that a more economical design could be developed. Rating $=2.2$.

- Criterion 6b. "Materials and techniques used in construction are readily available and easily fabricated.

The fans, motors and ducts are standard equipment, but fabrication of the graded media filter banks will require new techniques and possibly new fiber materials. Rating $=3.0$.

- Criterion 6c. "Components and equipment are readily available."

The graded media filter banks are of special design and not presently commercially available as modular units. However, the components from which the filters are fabricated are readily available. Rating $=1.5$.

7.1.2.6 Mandatory Criteria (SR-2). All of the mandatory criteria 1isted in Table 15 are satisfied with acceptable ratings. However, compliance with criterion 1c (ability to handle dry or sticky particles) and 2d (reliable long-term operation) depend on filter loading characteristics which must be verified by prototype testing.

7.1.2.7 Rating (SR-2). The numerical rating of system $S R-2$ is as follows:

\begin{tabular}{lc}
\multicolumn{1}{c}{ Group Criterion } & Rating \\
\hline System Effectiveness & 86.5 \\
System Reliability & 83.4 \\
Containment Compatability & 61.0 \\
Technological Credibility & 38.6 \\
System Characteristics and Flexibility & 37.1 \\
Fabrication Effort & 15.5 \\
\multicolumn{1}{c}{ TOTAL } & 322.1
\end{tabular}

7.1.2.8 Development Requirements (SR-2). The development requirements for system SR-2 are similar to those of system SR-1, which deal with the 
filter performance under DBST conditions. In addition, the effect of contamination and possible solids buildup on the fan requires evaluation for system SR-2. The four general areas of development needs are as follows:

- Filter performance tests. Optimization of graded media design. Loading as a function of bed depth and gas velocity. Particle collection efficiency as a function of time. Effect of moisture on loading and efficiency.

- Long-term recirculation tests. Buildup on fan. Chemical attack of filter media. Resuspension. Effect of continued gas flow on loaded filters.

- Decay heat removal. Measurement (by electrical simulation) of equilibrium temperature attained in the deposited aerosol cake during loss of flow conditions.

- Large-scale demonstration tests in a large containment vessel under DBST conditions to prove effective aerosol removal from containment atmosphere.

\subsubsection{Direct Application - Acoustic Agglomerator (SD-17)}

7.1.3.1 Background (SD-17). This air cleaning system involves the agglomeration of aerosol particles in the containment building atmosphere by sound waves, with subsequent removal of the larger agglomerate particles by gravitational settling to the RCB floor. It has the obvious advantage over recirculating air cleaning systems in that recirculation of the containment gas through a treatment device is not required.

Coagulation of aerosol particles has been studied sporadically, dating from early investigations of Kundt in the late nineteenth century. A flurry of interest in sonic precipitation of dust arose in the United States in the late 1940s and early 1950s. Most of this work involved pilot-scale application of sonic cleaning to industrial air cleaning problems. For example, Stokes $^{(35)}$ studied the collection of carbon black aerosols by agglomeration. Removal efficiencies obtained were generally below about 80 percent, at an optimum sound frequency of $3000-5000 \mathrm{~Hz}$. Danser and Neumann ${ }^{(36)}$ reported that sulfuric acid mist particles could be grown to a large enough size so 
that 90 percent by weight could be removed by cyclones when a $24,000 \mathrm{cfm}(11.3 \mathrm{~m} / \mathrm{s})$ gas stream was exposed to $2.25 \mathrm{kHz}$ sound of $150 \mathrm{db}$ intensity for less than 4 seconds.

Neither of these two applications appears to have come to fruition. Boucher(37), in reviewing sonic aerosol precipitation, states that by 1961 , no sonic precipitators were in operation in the United States. Boucher surveyed foreign applications and described several apparently successfully operating sonic precipitators in Italy, Germany, Hungary, Czechoslovakia, and France. A comprehensive review of all aspects of acoustic coagulation of aerosols was published by Mednikov (38) in 1965.

It appears that acoustic agglomeration processes have several drawbacks which limit their application in many industrial applications. The prime obstacle is the high energy consumption compared to alternatives. Also, acoustic agglomeration is successful only for relatively concentrated aerosols. For very dilute aerosols sufficient agglomeration could not be expected. However, for the LMFBR EACS DBST accident conditions considered in this report, acoustic agglomeration offers some definite attractions.

The physical forces which operate to coagulate particles in an acoustic field are complex, and a fully adequate theory does not appear to be available. Heuter ${ }^{(39)}$ describes four forces which act on particles suspended in a sound field. First, radiation pressure exerts a net force on the side of the particle facing the source, hence causes particles to drift away from the source. Second, Stokes' force, caused by a compression wave moving past the particle, induces a net drag on the particle in the direction of the source. According to Heuter, this net drag occurs because gas viscosity increases with temperature. A third kind of driving force results from wave shape distortion. Heuter terms this an Oseen force, and states that the direction of particle motion induced by the Oseen force depends on the phase angle of the distorted sound waves. A fourth kind of force is termed the Bernoul1i force, which arises when a velocity increase occurs as air from the wave flows between two closely-spaced particles. The Bernoulli force is attractive between the two closely-spaced particles. The magnitude of the first two forces depends on the particle size, hence relative velacities 
are induced which tend to coagulate particles. The 0seen force would tend to concentrate particles in a region where the other three forces plus Brownian diffusion would cause them to coagulate.

While one can theoretically compute the rate of agglomeration in a welldefined sound field (e.g., standing waves), the sound field set up in a containment vessel would be highly complex, and an a priori prediction of the coagulation rate from theory alone does not appear to be possible at this time.

7.1.3.2 Design Parameters (SD-17). The design of a sonic agglomeration system for this study was based on a number of important simplifying assumptions. It is obvious that much more sophisticated engineering analyses could be carried out, and would be required if such a system were to be designed in detail. Key parameters and assumptions are outlined in the following paragraphs.

- Acoustic Power Required. Based on statements by St. Clair(40), rapid agglomeration requires an acoustic energy density of $100 \mathrm{erg} / \mathrm{cm}^{3}$ or greater. The acoustic power input used in the present study was based on this energy density in a containment vessel having a volume of $6.4 \times 10^{10} \mathrm{~cm}^{3}$ and a sound energy decay rate of $0.5 \mathrm{sec}^{-1}$. For these conditions, an acoustic energy generation rate of $3.2 \times 10^{5}$ joules/sec ( $\left.320 \mathrm{~kW}\right)$ is required.

- Sound Duration. From several references $(35-40)$ experiments show that typical treatment times are on the order of 5 to 10 seconds. We selected a treatment time of 10 seconds for each of many successive acoustic power pulses.

- Sound Power Generation. The only type of sound generation which can produce the high-powered sound required here appears to be the siren type in which compressed gas expands through orifices which are suddenly opened and closed. Sound generators based on electromagnetic and piezoelectric effects are suitable for lower power levels but generally are not capable of producing the many kilowatts of sound energy required for rapid aerosol coagulation. 
Sonic energy production by sirens was calculated as 50 percent of the work energy produced by the isentropic expansion of nitrogen gas assuming ideal gas behavior. A nitrogen flow rate of about $70 \mathrm{lb} / \mathrm{sec}$ $(32 \mathrm{~kg} / \mathrm{s})$ was found to be required to produce the required sound intensity. During the 10 second sound-generating period, 9000 SCF $\left(255 \mathrm{~m}^{3}\right)$ of nitrogen gas would be injected.

- Airborne Particle Removal. The rate of particle removal was calculated from a well-stirred gravity settling model, assuming that the agglomerate particle diameter was $100 \mu \mathrm{m}$. This particle size was reportedly observed by St. Clair ${ }^{(40)}$ for an ammonium chloride aerosol having an initial mass concentration of $2 \mu \mathrm{g} / \mathrm{cm}^{3}$. For particles having a material density of $2.7 \mathrm{~g} / \mathrm{cm}^{3}$ and a density modification factor of 0.25 , the settling velocity is calculated to be $20.4 \mathrm{~cm} / \mathrm{sec}$. This settling velocity corresponds to a removal rate, $\lambda$, of $21.4 \mathrm{hr}^{-1}$. In order to limit the quantity of nitrogen gas added to the containment atmosphere by the siren, the siren would be operated only during 10 -sec pulses, each pulse occurring once each 8 minutes. This sequence would last for 8 hours, and then pulses would occur once each hour for the next 16 hours. Operation of the agglomerator every 8 minutes results in a 2-hr DRF of 10, assuming that the aerosol source is a puff which reaches the containment vessel just after the previous pulse terminated. More optimum operating cycles could likely be designed which would result in higher dose reduction factors. Also, there is a possibility that the sound-generating gas could be vented from the siren without adding to the contained gases. The scope design selected here is thought to be reasonably conservative in terms of performance and system requirements, although the effective size of the agglomerated particles under EACS-DBST conditions needs to be verified by development tests.

- The design parameters used to develop the scope design of the acoustic agglomerator air cleaning system, SD-17, are summarized in Table 21. 
DESIGN PARAMETERS FOR ACOUSTIC AGGLOMERATOR, SYSTEM SD-17

\section{Parameter}

Acoustic power intensity required

Sound intensity decay rate

Sonic pulse duration

Efficiency of sonic energy conversion

Agglomerate particle diameter

Effective particle density

Equilibrium aerosol concentration ( $2 \mathrm{hr}$ )

Interval between sonic pulses

$\mathrm{N}_{2}$ flow rate during sonic pulse
Value Used

100 ergs $/ \mathrm{cm}^{3}$

$0.5 \mathrm{sec}^{-1}$

$10 \mathrm{sec}$

$50 \%$

$100 \mu \mathrm{m}$

$0.7 \mathrm{~g} / \mathrm{cm}^{3}$

$1 \%$ of puff release concentration

8 min for $\mathrm{t}<8 \mathrm{hr}$;

$1 \mathrm{hr}$ for $8 \mathrm{hr} \rightarrow 24 \mathrm{hr}$

$70 \mathrm{lb} / \mathrm{sec}(32 \mathrm{~kg} / \mathrm{s})$

7.1.3.3 Conceptual Design (SD-17). A schematic diagram of an acoustic agglomerator for use in a single containment scheme is shown in Figure 11 .

- Description of Important System Components. This system coagulates suspended particles by sound waves transmitted from each of 5 identical siren-type generators. The generators would be located near the outer wall of the containment shell, and would be supplied with gaseous nitrogen by means of a ring header. The header is supplied with gaseous nitrogen from an accumulator tank. Pressurized gaseous nitrogen is produced from liquid nitrogen by means of ordinary atmospheric vaporizors. Coagulated particles would fall out on the floor of the containment vessel.

Discussion of the design approach used to size some of the most important components is provided in the following paragraphs. 

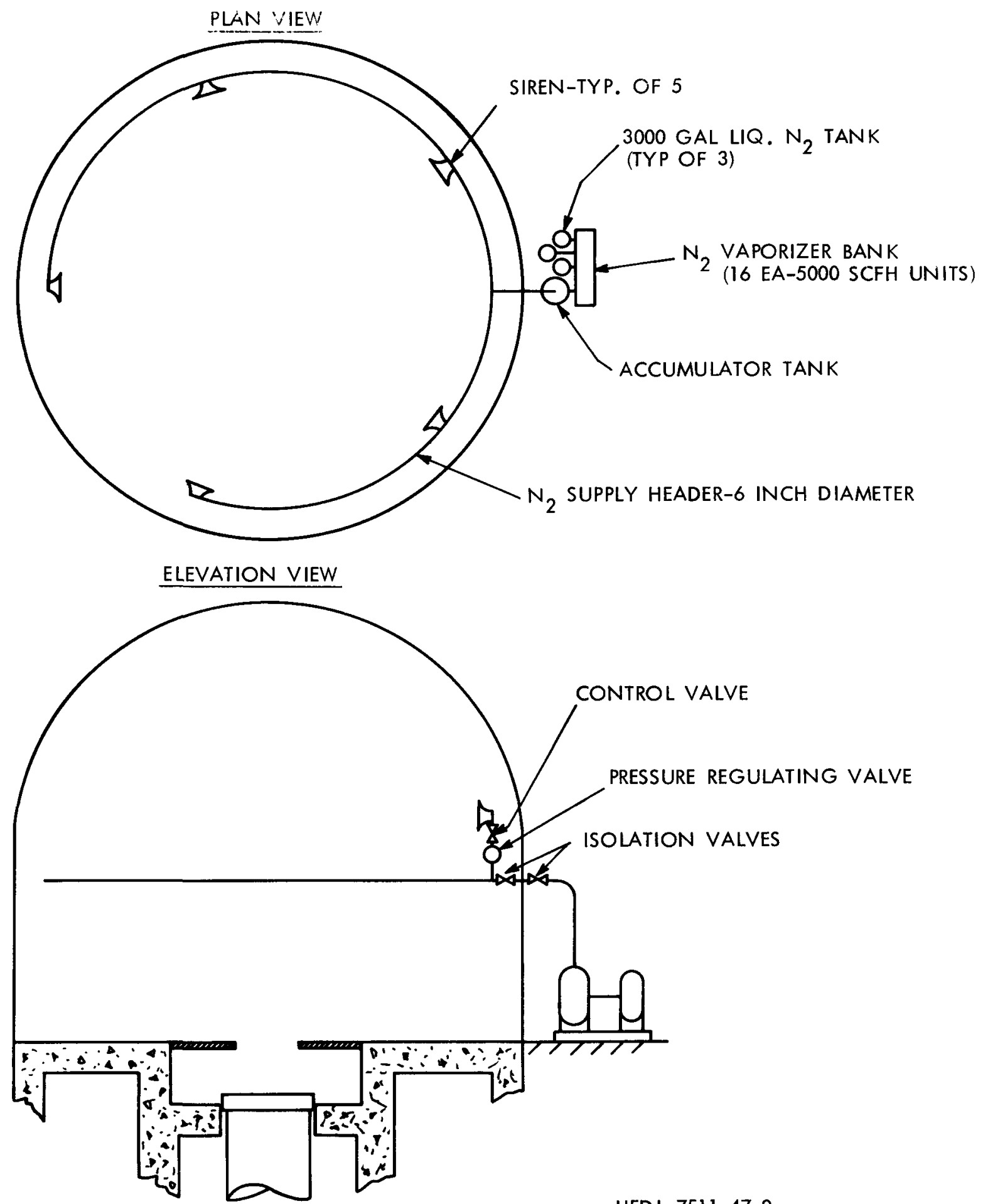

HEDL $7511-47.2$

$7510300-11$

FIGURE 11. Schematic Diagram of Acoustic Agglomerator for System SD-17. 
- Liquid Nitrogen Storage Tank. The size of the Tiquid nitrogen storage tank required is dictated by the quantity of nitrogen used over an assumed accident course. A total of 76 pulses, each using $700 \mathrm{lb}$ of $\mathrm{N}_{2}$, is specified, resulting in a total nitrogen mass of $53,200 \mathrm{lb}(24,000 \mathrm{~kg})$. The volume of the tank required is $1050 \mathrm{ft}^{3}$ (7900 gal or $30 \mathrm{~m}^{3}$ ). Three standard liquid nitrogen tanks, each with 3000 -gal $\left(11.4 \mathrm{~m}^{3}\right)$ capacity, are provided in the present design. Liquid nitrogen is used for other purposes in LMFBR plants, hence it is possible that separate storage tanks for the acoustic generator would not have to be provided. Anchors for the nitrogen storage tanks would have to be designed to accommodate appropriate seismic loads.

- Nitrogen Vaporizer. Liquid nitrogen would be converted to gas in a system of atmospheric vaporizers. The required capacity for these vaporizers is equal to the nitrogen flow per pulse spread over 8 minutes, $88 \mathrm{lb} / \min (0.67 \mathrm{~kg} / \mathrm{s})$. This vaporization rate corresponds to a gas flow rate of $880 \operatorname{SCFM}\left(0.47 \mathrm{~m}^{3} / \mathrm{s}\right)$. Fourteen standard commercial atmospheric vaporizer units (5000 SCFH capacity) would be adequate. Sixteen vaporizers were included in the present study to provide redundancy and conservatism.

Each vaporizer occupies a cubical volume $4 \mathrm{ft} \times 5 \mathrm{ft} \times 1.5 \mathrm{ft}$. The train of vaporizers would therefore oscupy a cubical $4 \mathrm{ft} \times 5 \mathrm{ft} \times$ $24 \mathrm{ft}$, or a total volume of abnut $480 \mathrm{ft}^{3}\left(13.6 \mathrm{~m}^{3}\right)$.

Nitrogen gas would be warmed to near ambient outdoor temperature in the vaporizer. The temperature of the gaseous nitrogen is not critical for the purposes of this study, and a temperature of $50^{\circ} \mathrm{F}$ was assumed. Anchors and structural supports for the vaporizers would have to be designed to accommodate appropriate seismic loads.

- Gaseous Accumulator. A nitrogen gas accumulator is needed to store the nitrogen gas vaporized between pulses. If the maximum pressure of the tank is 200 psia (1.4 MPa), and the minimum drawdown is to 100 psia, a minimum tank volume of $1400 \mathrm{ft}^{3}\left(40 \mathrm{~m}^{3}\right)$ is needed for a pulse frequency of one per 8 minutes. An $8-\mathrm{ft}$ diameter by $28-\mathrm{ft}$ long cylindrical tank is specified. The anchors and supporting 
structure for the accumulator tank are designed to accommodate appropriate seismic loads.

- Nitrogen Header Pipe. Nitrogen gas is delivered to each siren by means of a pipe routed near the periphery of the containment vessel, as shown in Figure 11. In order to minimize the size of the delivery pipe, gas pressure would be reduced at each siren, allowing the gas to be transported through the delivery line at the maximum density. This arrangement is pictured schematically in Figure 12.

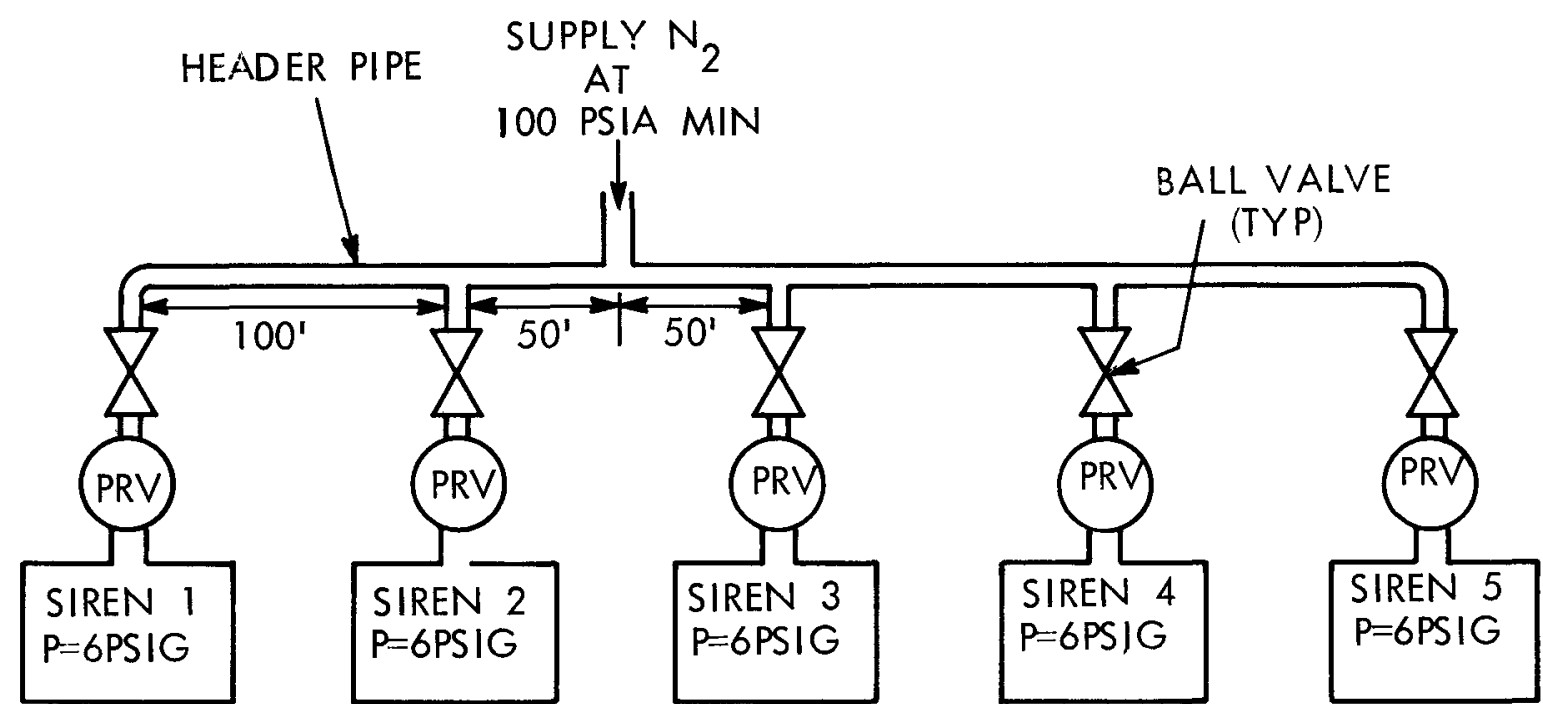

HEDL $7511-47.1$

FIGURE 12. Schematic Diagram of Nitrogen Delivery Pipe (SD-17).

A six-inch pipe would deliver the nitrogen flow with only a modest pressure drop. The pressure regulating valve (PRV) for siren 5 would receive nitrogen at about $75 \mathrm{psia}(0.52 \mathrm{MPa})$.

In addition to the PRVs, a fast-acting isolation valve would be required to turn the nitrogen flow on and off for each 10-second putse. 
- Siren Generator. The sound generators are envisioned to be very large sirens. Air at 6 psig $\left(4 \times 10^{4} \mathrm{~Pa}\right)$ would expand through holes in two concentric cylinders. One of these cylinders would be rotated at high speed, rapidly covering and uncovering the holes in the cylinders.

A crude estimate of the size of the sirens required was made as follows. For a siren which has 20 percent open area, the instantaneous flow rate was calculated to be $53,600 \mathrm{SCFM}\left(25 \mathrm{~m}^{3} / \mathrm{s}\right)$. The gas velocity through the holes was predicted from Bernoulli's equation to be $860 \mathrm{ft} / \mathrm{sec}\left(260 \mathrm{~m}^{3} / \mathrm{s}\right)$. Thus, an open area of $150 \mathrm{in.}^{2}\left(0.1 \mathrm{~m}^{2}\right)$ would be required for each siren. A total of 3100 holes, 0.25 -inch diameter $(6.4 \mathrm{~mm})$ would be required. These holes could be located in cylinders 6 inches $(0.15 \mathrm{~m})$ in diameter by 38 inches long $(0.96 \mathrm{~m})$. The rotating cylinder would have to spin at about $8000 \mathrm{rpm}$ to give a sound frequency of $5000 \mathrm{~Hz}$. While this siren design is probably not optimum, it serves to show that such a siren is feasible.

The sound produced by the siren would be ducted away from the generator by means of horns designed to optimize the volumetric coverage of the containment space.

For the purposes of this design, it was assumed that the sirens would be driven by a universal electric motor. Other drive motors which could be considered are gas turbines and induction motors with a step-up belt drive.

\subsubsection{Cost of Acoustic Agglomerator System (SD-17). In order to} establish a cost number for comparison with other systems considered in this study, a rough cost estimate for an installed system was prepared. This estimate is useful in establishing an overall feasibility of the concept, and for rating the concept against others. Such an estimate must be considered a crude first guess with potentially large inaccuracies. The cost estimate is as follows: 
Construction, Equipment, and Building

Engineering (20\%)

Contingency $(100 \%)$

Subtotal

TOTAL $\frac{\$ 000}{1180}^{(a)}$

$\frac{235}{1415}$

$\underline{1415}$

2830

(a) 1975 dollars

\subsubsection{Conformity with Criteria (SD-17).}

- Criterion 1a. "A dose reduction factor (2 hr) of $10 \mathrm{can}$ be achieved for aerosol particles."

A minimum value of 10 for the $2 \mathrm{hr}$ DRF was calculated for this system, based on the time-concentration history portrayed in

Figure 13. The dose reduction factor for this case is defined by Equation 5.

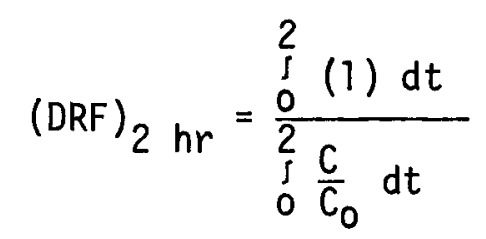

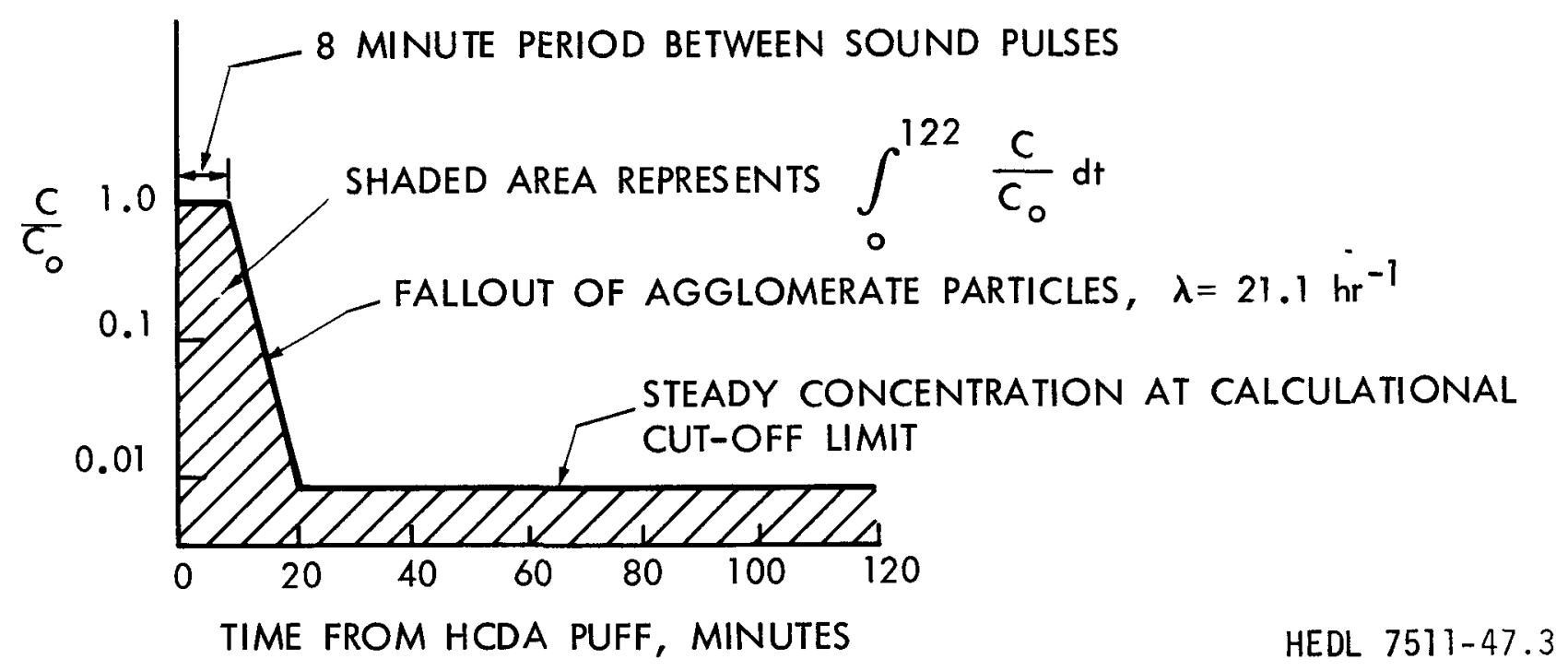

FIGURE 13. Aerosol Behavior Assumed for Dose Calculation (SD-17). 
Most of the dose integral comes during the 8-minute period when $C / C_{0}=1$. If it were assumed that the sound pulse occurred immediately after the puff release, the calculated $2 \mathrm{hr}$ DRF is 30 , much higher than the design value of 10 . On the other hand, it is possible that the agglomerate size will be smaller than the 100-um diameter observed by St. Clair $(40)$, and lower dose reduction factors would be obtained for smaller particles. The predicted dose reduction factor was calculated for a range of agglomerate particle sizes. Results of these calculations are presented in Figure 14. As expected, smaller agglomerate particles lead to lower dose reduction factors for both the base case assumed here ( 8 minute delay between sonic pulse and aerosol puff) and for an optimum case where the delay between the sonic pulse and the puff is zero. However, a dose reduction factor of 10 can be obtained for agglomerate particle diameters as small as 50-um diameter for optimized timing of the sonic pulse.

From this brief look at obtainable dose reduction factors, it is concluded that a DRF of 10 could likely be achieved in a we11-designed system, and a rating factor of 3.9 is assigned.

- Criterion 1b. "Decay heat can be dissipated adequately."

Following coagulation and settling, the bulk of the radioactive material would be expected to be distributed uniformly over the floor of the containment building. The temperature rise across this $0.13-$ inch thick dust layer caused by decay heat was estimated for uniform heat generation, assuming a powder density of $201 \mathrm{~b} / \mathrm{ft}^{3}\left(320 \mathrm{~kg} / \mathrm{m}^{3}\right)^{(41)}$, a powder mass of $4400 \mathrm{~Tb}(2000 \mathrm{~kg})$, and a thermal conductivity of $0.52 \mathrm{Btu} / \mathrm{hr}-{ }^{\circ} \mathrm{F}-\mathrm{ft}\left(0.90 \mathrm{~W} / \mathrm{m}-{ }^{\circ} \mathrm{C}\right) .(41)$ A temperature rise of only $5^{\circ} \mathrm{F}\left(2.8^{\circ} \mathrm{C}\right)$ was predicted. This calculated temperature rise is an overestimate because the calculation neglected heat transfer into the floor. The very small temperature rise predicted here shows that decay heat is well dissipated in this system. Rating $=4.0$.

- Criterion 1c. "Either dry or sticky particles can be treated effectively." 


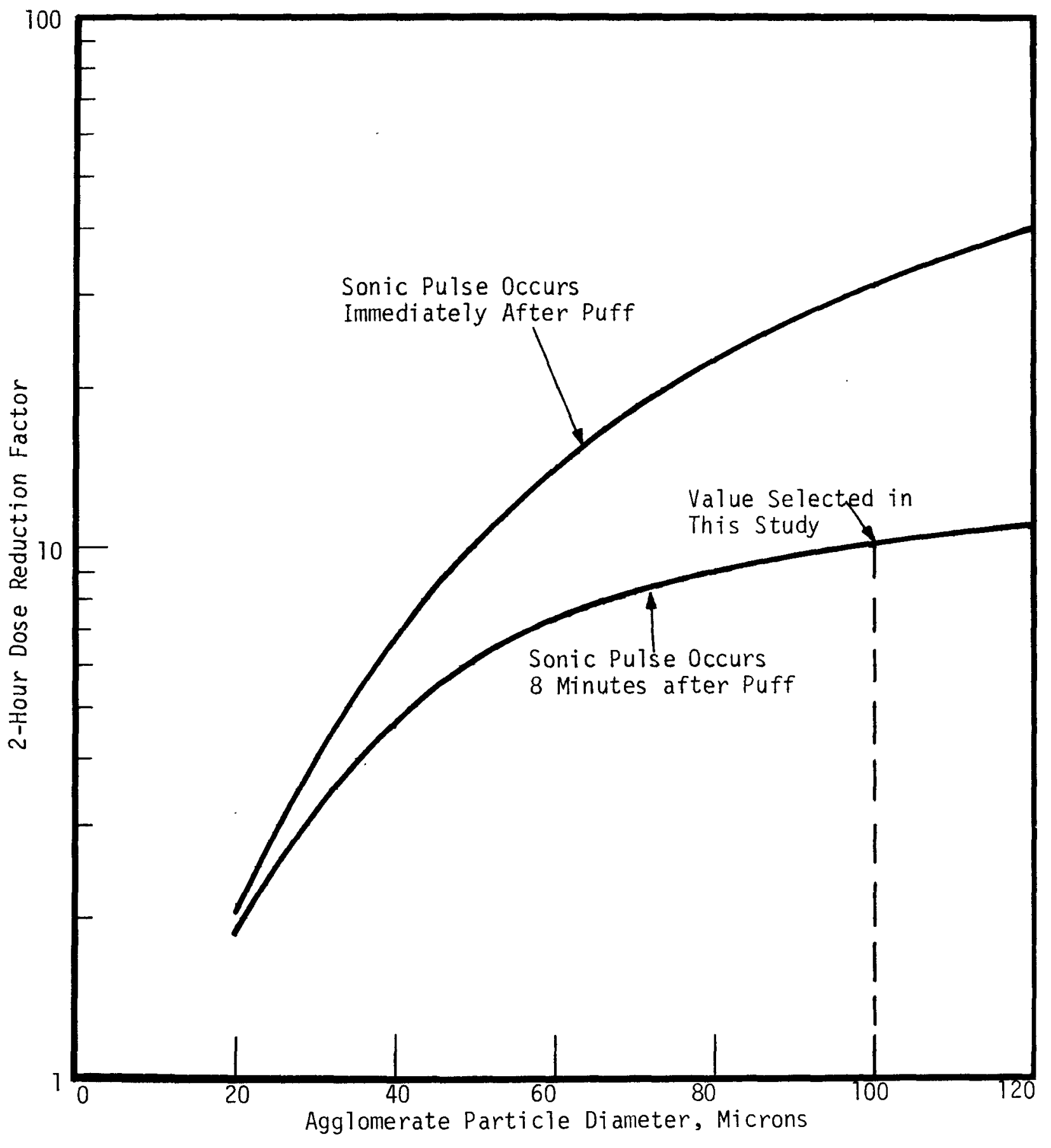

FIGURE 14. Dose Reduction Factor Calculated for Sonic Agglomeration in Single Containment (SD-17). 
The adhesive properties of an aerosol particle would not be expected to influence particle behavior prior to agglomeration. After the particles are coagulated, it is conceivable that sonic energy could redisperse very fragile particles. Fragile particles might be formed from very dry, open chain agglomerate particles. The presence of water should produce particles with adhesive surfaces which would not break up after agglomeration. St. Clair ${ }^{(40)}$ reports that some dust particles are temporarily flocculated while in the sound field and are dispersed immediately after leaving the field, a condition he reports to be curable by addition of a liquid aerosol. In the accidents considered here, sufficient water would probably be present to prevent re-dispersion of flocculated particles. However, until more experimental data become available, a doubt exists. Rating $=3.7$.

- Criterion 1d. "System effectiveness is not degraded by the radiation dose caused by the accident over the required operating period."

The physical factors which cause acoustic agglomeration appear to be entirely independent of the nuclear radiation field. Any influence of the radiation field would be indirect, such as material degradation of the acoustic generators. Since the sirens will be fabricated of steel and other metals, no significant structural degradation in the sirens would be expected. If greased bearings were used, the design would have to recognize the potential radiation polymerization of grease. In summary, the radiation field is not expected to have a significant adverse impact on sonic agglomeration. Rating $=4.0$.

- Criterion 2a. "The EACS shall have a high probability of startup after initiation of the DBST."

The nitrogen gas supply system for the sirens is simple, and is typical of present-day practice. Its reliability would be high, probably comparable to the opening of a valve. The siren itself has a moving part, and bearing failure would probably be the most likely failure mode. The reliability of bearings in such an application is high, as demonstrated by experience with jet engines and 
electric motors. Periodic testing of the sirens would provide a means for detecting degradation due to corrosion or man-caused loads. This system appears highly reliable. Rating $=3.4$.

- Criterion 2b. "The system shall be capable of withstanding the pressure pulse associated with the DBST."

The only component of this system which will be exposed to the pressure pulse would be the sirens. They are mechanically strong enough to easily withstand the pressure loading forces without damage. It is possible that blow-off covers would be used to prevent sodium smoke from reaching the rotor. Large quantities of dirt could not be tolerated inside the moving parts of the siren, but the outwardflowing nitrogen would prevent entry of dust during operation. No significant adverse impacts of the pressure pulse are obvious. Rating $=4.0$.

- Criterion 2c. "The system does not degrade during periods of unuse." Two components of this system would require periodic surveillance to assure operability over long time periods. One is the liquid nitrogen storage tank which would have to be refilled occasionally to make up for evaporation. The other system is the sirens, which have moving parts. Periodic testing would be required to show that corrosion or foreign material did not interfere with movement of the rotor, and that bearing performance was adequate. These aspects of degradation do not offer unusual maintenance problems. Rating $=3.7$.

- Criterion 2d. "The system sha11 be capable of dependable operation over the required period of time under the DBST conditions of temperature, pressure, humidity and aerosol loading."

A limitation to prolonged operation of this system appears to be the maximum quantity of nitrogen which one would want to add to the containment vessel. As designed, sound pulses would continue for $24 \mathrm{hr}$. The components of this system are readily adaptable to duplication in order to provide redundancy typically required of safety systems. 
The system as designed includes redundant vaporizers and multiple liquid nitrogen storage tanks, but uses a single accumulator tank. A detailed design analysis would identify the least reliable components of this system and show where redundancy would be helpful. Rating $=2.7$.

- Criterion 2e. "The system requires simple components and conservative design stress."

The sirens have fast-moving and closely-spaced parts and therefore are not considered simple. On the other hand, only one part is moving, so the degree of complexity is not high. Materials requirements are not expected to be unusual, and design of all components to modest stress limits should be possible. Rating $=3.0$.

- Criterion 3a. "Inadvertent operation of the EACS shall not harm plant equipment or constitute a hazard to personnel."

No harm to plant equipment would be done by operation of the sirens, but potential damage to ears of personnel would occur if the system sounded accidentally. Beranek ${ }^{(43)}$ states that immediate damage to exposed ears occurs at sound levels of the order of $160 \mathrm{db}$. This sound intensity is of the same order of magnitude required to give rapid particle coagulation. It appear; that damage to personnel would be non-fatal, but would result in a degree of loss of hearing. Compared to other systems, this one rates fairly low. Rating $=2.2$.

- Criterion 3b. "Operation of the EACS sha11 not significantly increase the pressure within the containment building by gas injection, energy release or other means."

Addition of $53,200 \mathrm{lb}(24,000 \mathrm{~kg})$ of $\mathrm{N}_{2}$ called for in this design is calculated to increase the pressure in the containment vessel by about 3.7 psi $(25,000 \mathrm{~Pa})$. While this pressure rise is undesirable, it does not represent an intolerable problem. Also, it is possible that an optimized design would use much less nitrogen gas, resulting in a much lower pressure rise. Rating $=2.0$. 
- Criterion 3c. "The size of the EACS shall be compatible with installation within or adjacent to the containment building."

This criterion is very well met by the acoustic precipitator. The total volume occupied by the nitrogen header pipe, acoustic siren, and horns appears to be less than $3000 \mathrm{ft}^{3}\left(85 \mathrm{~m}^{3}\right)$. This space would be along the outer diameter of the containment vessel, some $50 \mathrm{ft}$ $(15 \mathrm{~m})$ above the floor, and hence its use should not interfere with normal operations in the containment vessel. Outside the containment vessel, the liquid nitrogen tank, the vaporizers, and the accumulator tank would occupy a concrete slab having an area of about $450 \mathrm{ft}^{2}$ $\left(42 \mathrm{~m}^{2}\right)$. For head room of $20 \mathrm{ft}(6 \mathrm{~m})$, the spatial volume required would be about $9000 \mathrm{ft}^{3}\left(250 \mathrm{~m}^{3}\right)$. Rating $=3.9$.

- Criterion 3d. "The EACS shall maintain the collected aerosol in a subcritical configuration."

This criterion is easily met because the average aerosol depth on the floor of the containment vessel is only 0.13 inches $(0.8 \mathrm{~mm})$. Rating $=4.0$.

- Criterion 4a. "The air cleaning concept is based on highly developed technology."

Although many papers have been published on acoustic coagulation of particles, a truly solid base of technology does not exist. This lack of base technology is one of the weak points of system SD-17. Rating $=1.5$.

- Criterion 4b. "The EACS can be tested in-place for operability and efficiency."

Operability of the sonic generators could be tested in-place, but it would not be possible to prove the removal efficiency in-place. Overa11, the sonic agglomerator could be tested in-place as extensively as spray systems currently used in light water reactors. Since LWR spray systems are acceptable, sonic agglomerators should also be acceptable if operability can be tested in-place. Rating $=2.0$. 
- Criterion 4c. "The EACS performance can be predicted by verified mathematical models."

This criterion is a must for this system, and before it is used in LMFBR plants its performance must be predictable. However, today it would not be possible to reliably predict sonic precipitator performance. Rating $=2.0$.

- Criterion 4d. "The EACS equipment scaleup from currently available sizes to LMFBR plant application is small."

This system requires the use of sirens which are somewhat larger than those we have seen. However, the scaleup appears to be simply a matter of increasing the size of the rotor and stator so that more gas expansion holes are provided. A11 other system components are well within presently used size scales. Rating $=2.0$.

- Criterion 5a. "The EACS is effective for the entire particle size spectrum expected during the accident."

While it is often stated in the literature that sonic agglomerators work for all particle sizes, it is possible that the particle size spectrum could play a role in the agglomeration rate. Hard experimental evidence which would be required to fully evaluate this criterion is not available. Rating $=3.5$.

- Criterion 5b. "The system performance is not highly sensitive to the atmosphere temperature, pressure, and relative humidity."

The rate of sonic agglomeration should vary only slightly with the atmospheric composition. Rating $=2.7$.

- Criterion 5c. "The system energy consumption is low."

This system is powered mainly by liquid nitrogen, hence energy requirements are only those for the siren drive motors and for instrumentation and control which would total a few kilowatts. Liquification of nitrogen gas is by heat exchange with the atmosphere and does not require electrical energy. Rating $=4.0$. 
- Criterion 5d. "The system can be modified to add halogen removal components, hydrogen recombiners and containment coolers."

The direct application acoustic agglomerator is not amenable to adding of other removal devices, except by adding complete independent systems. Rating $=0.0$.

- Criterion 5e. "The post-accident recovery is facilitated by the EACS."

The disposition of aerosol material when this system operates would be much the same as if no EACS operated. Wall plateout would be reduced compared to natural processes alone, and this might aid cleanup. Rating $=2.0$.

- Criterion 6a. "The system cost is low. Capital cost is less than $\$ 10$ million; operating costs are low."

The installed cost of system SD-17 is estimated to be $\$ 2.8$ million, lowest of all the EACS judged to be feasible. Rating $=3.6$.

- Criterion 6b. "Materials and techniques used in construction are readily available and easily fabricated."

Fabrication of the sirens will require close tolerance machine work. Until a detailed design becomes available, it should be assumed that a moderate degree of difficulty will be involved. Rating $=3.5$.

- Criterion 6c. "Components and equipment are readily available." All components except the sirens are readily available commercially. The sirens would have to be specially made from readily available materials. Rating $=1.2$.

7.1.3.6 Mandatory Criteria (SD-17). A11 of the numerical ratings for the mandatory criteria are equal to 2 or better. The mandatory criterion with the lowest score is criterion $3 b$, which specifies a low pressure buildup in the containment vesse1. For this system a pressure rise of $3.7 \mathrm{psi}$ is calculated to result from the injection of nitrogen gas used to generate sound energy. It might be possible to eliminate this pressure rise 
by using a sound transfer membrane which would duct the gas from the containment vessel, or by using electromechanic means for generating sound. However, neither of the latter two systems is as likely to succeed as the direct gaseous injection system design used here.

7.1.3.7 Rating. The numerical rating of system SD-17 is as follows:

\begin{tabular}{lr}
\multicolumn{1}{c}{ Group Criterion } & Rating \\
\cline { 1 - 2 } System Effectiveness & 105.0 \\
System Reliability & 77.4 \\
Containment Compatibility & 52.6 \\
Technological Credibility & 26.5 \\
System Characteristics and Flexibility & 25.3 \\
Fabrication Effort & 22.7 \\
\multicolumn{1}{c}{ TOTAL } & 309.5
\end{tabular}

7.1.3.8 Development Requirements (SD-17). Two broad areas require development before a sonic agglomerator system could be designed with assurance that it would operate reliably.

(1) Base technology needs to be developed so that the degree of agglomeration (as measured by agglomerate aerodynamic diameter) can be predicted as a function of particle characteristics (concentration, size, density) and sound energy characteristics (frequency, power level, wave shape). A series of experiments would be required at several size scales, up to and including the CSE vesse1. (43) A strong theoretical effort would also be needed to make sure the results could be applied to postulated LMFBR accident conditions.

(2) Methods for generating high intensity need to be explored experimentally. Goals would be to develop methods for generating sound at high intensity without injecting appreciable quantities of gas, and to develop large generators which could be used in a ful1scale containment system. 


\subsubsection{Recirculating - Bag Filter (SR-4)}

7.1.4.1 Background (SR-4). Bag filters fahricated of various types of fabrics are often used for industrial gas cleaning applications. They typically have high efficiency and can handle high dust loadings of a wide range of particle sizes and types. (44) Multiple cloth tubes are assembled into vertical arrays in the bag houses. Periodically the accumulated dust is removed from the bags by shaking or reversing the air flow, and the dislodged dust is collected in hoppers for disposal.

Experience using bag filters for nuclear applications and for sodium smoke is limited. The HALLAM Nuclear Power Facility air treatment system included a $5000 \mathrm{CFM}\left(2.4 \mathrm{~m}^{3} / \mathrm{s}\right)$ bag filter for use in the event of a sodium fire in the confinement building. ${ }^{(45)}$ The Harvard Air Cleaning Laboratory studied the use of bag filters with dry sodium oxide fumes using both silicone treated glass fabrics $(46)$ and Teflon. $(47,48)$ The glass fabrics proved to be fragile and MACL recommended the Teflon bags because more vigorous cleaning (by shaking) is possible. It should be noted, however, that glass fabrics are commonly used in industry. ${ }^{(44)}$ For the HACL tests the Teflon bags were preflocked before use with asbestos fibers to improve the initial filtering efficiency of the cloth and to act as a parting agent to assist in dust removal during cleaning.

Teflon is chemically inert to the $\mathrm{Na}_{2} \mathrm{O}$ smokes but is limited to a temperature of $550^{\circ} \mathrm{F}$ for short time use. Glass fabrics can be used to $1000^{\circ} \mathrm{F}$, although the silicone lubricants are lost at $550^{\circ} \mathrm{F}$. Billings $(44)$ notes that experimental bags of ceramic and metal cloth have been made for higher temperature use. For the purpose of this design study, Tefion fabric is specified to conform to the HACL recommendation.

7.1.4.2 Design Parameters (SR-4). Design parameters are listed in Table 22 for this system.

7.1.4.3 Conceptual Design (SR-4). The recirculating bag filter system is arranged within the reactor containment building as shown in Figure 15. Each of the five loops is contained in a filter cell located below the operating floor. To accommodate the space required for the bag houses and fans, 
TABLE 22

\section{DESIGN PARAMETERS FOR BAG FILTER SYSTEM SR-4}

Total Flow, minimum

Number of loops

Flow rate per loop

\section{Filters}

Fabric material

Pre-flock material

Air velocity through fabric

Pressure drop, maximum

Efficiency, minimum

Cloth area, total all loops

Aerosol load, before cleaning

Cleaning method

Loop Bag House (each 1oop)

Cloth area

Bag size

Number of bags

Bag house size

Filter house size

Total collected dust

Shaker motors

Flow dampers, air operated

Inlet duct

\section{Fans}

Number per loop

Flow

Power required

Motor size

Discharge duct
220,000 CFM $\left(104 \mathrm{~m}^{3} / \mathrm{s}\right)$

5

44,000 CFM $\left(21 \mathrm{~m}^{3} / \mathrm{s}\right)$

Teflon

Asbestos

$5 \mathrm{ft} / \mathrm{min}(0.025 \mathrm{~m} / \mathrm{s})$

6 in. $\mathrm{H}_{2} \mathrm{O}(1500 \mathrm{~Pa})$

0.98

$44,000 \mathrm{ft}^{2}\left(4090 \mathrm{~m}^{2}\right)$

$3 \mathrm{~g} / \mathrm{ft}^{2}\left(32 \mathrm{~g} / \mathrm{m}^{2}\right)$

Mechanical shaker

$8800 \mathrm{ft}^{2}\left(820 \mathrm{~m}^{2}\right)$

5 in. dia $\times 10 \mathrm{ft}$ long $(0.13 \times 3.0 \mathrm{~m})$

670

$10 \mathrm{ft} \times 33 \mathrm{ft} \times 12 \mathrm{ft}$ high $(3 \times 10 \times 3.7 \mathrm{~m})$

$15 \mathrm{ft} \times 42 \mathrm{ft} \times 16 \mathrm{ft}$ high $(4.6 \times 13 \times 5 \mathrm{~m})$ $880 \mathrm{lb}(400 \mathrm{~kg})$

3 at 1 HP each

3 N.0., fail open

$1 \mathrm{ft} \times 10 \mathrm{ft} \times 60 \mathrm{ft}$ long $(0.3 \times 3 \times 18 \mathrm{~m})$

1

$44,000 \mathrm{CFM}$ at $10 \mathrm{in} . \mathrm{H}_{2} \mathrm{O}\left(21 \mathrm{~m}^{3} / \mathrm{s}\right.$ at $\left.2500 \mathrm{Pu}\right)$ $115 \mathrm{HP}(86 \mathrm{~kW})$

$150 \mathrm{HP}(112 \mathrm{~kW})$

42 in. dia $\times 100 \mathrm{ft}$ long $(1.1 \times 30 \mathrm{~m})$ 


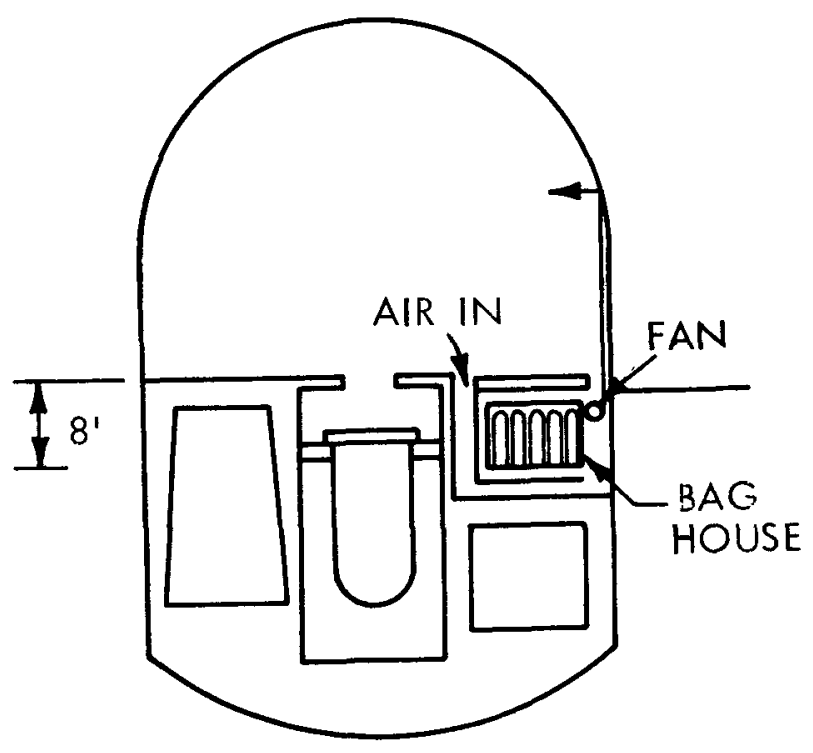

PLAN

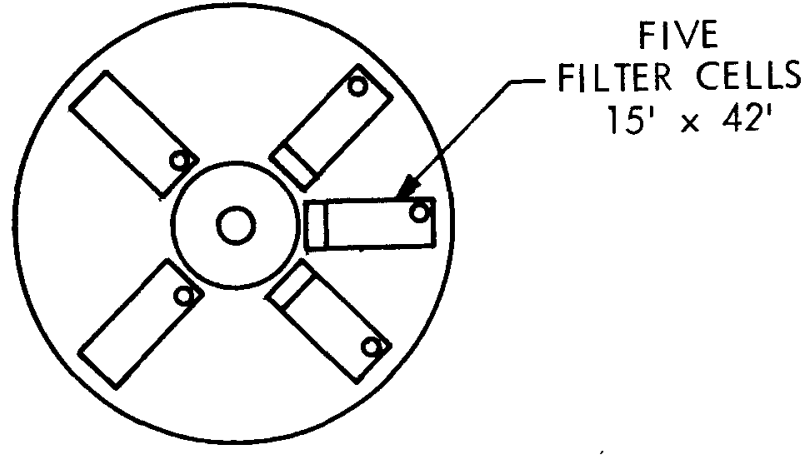

ELEVATION

FIGURE 15. Equipment Orientation for Bag Filter system SR-4.

the reactor containment building will be made 8 feet $(2.4 \mathrm{~m})$ higher than normal. While this is less than the $16 \mathrm{ft}(4.3 \mathrm{~m})$ of head space required for the bag house, the total volume added within the RCB is triple that used by the bag filter cells, which will allow relocation of other equipment within the containment building. An alternate location outside the RCB is possible.

Each of the five bag houses will be compartmented into three sections as shown in Figure 16. In this manner the flow to each section can be stopped by the flow damper during the 1 -minute cleaning cycle, which allows 30 seconds to shake and 30 seconds to settle the cake without interruption of the loop air flow. The pressure drop across the bags in the other two compartments will increase somewhat during this time because of increased flow in these two sections. Figure 16 also shows the inlet air flow under and over the fission product hearth. This air flow will provide cooling of the collected material. Air from the filter bags is routed to the fan and then to an outlet duct and is discharged in the main containment space near the polar crane. 

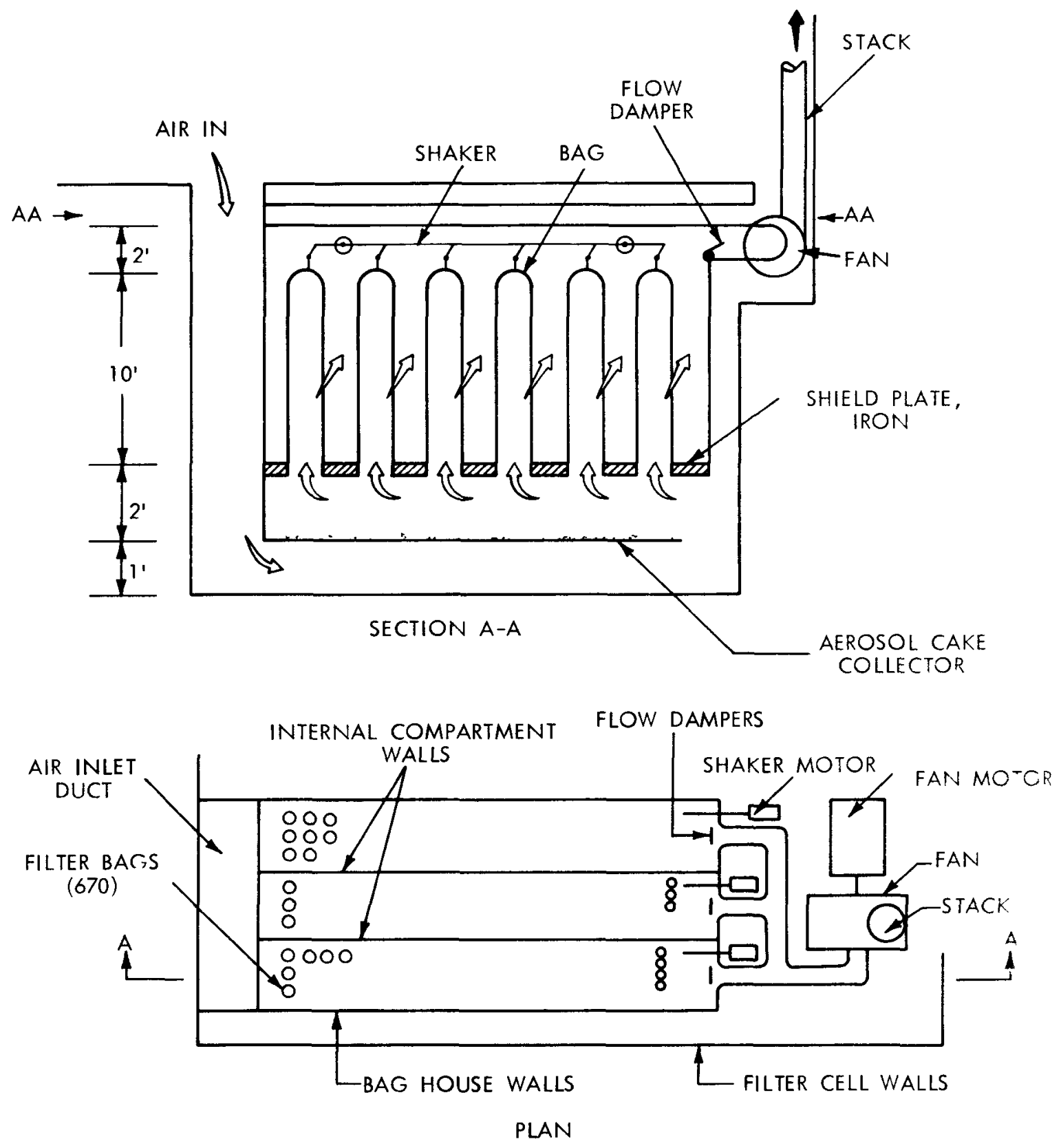

7510336-1

FIGURE 16. Bag House Arrangement for System SR-4. 
The filters will be exposed to beta and gamma radiation from the cake on the bags and from the material collected on the hearth. To keep the adsorbed doses to tolerable levels for the Teflon fabric, a shielding plate is located below the bags over the hearth.

Cleaning of the bags will be independently controlled by the pressure drop at each bag house and will start at 5 in. $\mathrm{H}_{2} \mathrm{O}(1250 \mathrm{~Pa})$. The three compartments will be cleaned sequentially and the loop fans will remain on line during the cycle. The fractional loss of air flow during cleaning will reduce the system effectiveness to approximately 86 percent of the full flow rate during the cleaning period.

\subsubsection{Cost Estimate (SR-4).}

$\begin{array}{lr}\text { Construction and equipment } & \frac{\$ 000(\mathrm{a})}{1,560} \\ \begin{array}{l}\text { Engineering (20\%) } \\ \text { Subtota1 }\end{array} & \frac{310}{1,870} \\ \begin{array}{c}\text { Containment Incremental Cost } \\ \text { Subtota1 }\end{array} & \frac{1,460}{3,330} \\ \text { Contingency (80\%) } \\ \text { TOTAL }\end{array}$

(a) 1975 dollars. 


\subsubsection{Conformity with Criteria (SR-4).}

- Criterion 1a. "A dose reduction factor (2 hr) of ten can be achieved for aerosol particles."

The DRF can be calculated as shown previously in Section 7.1.1.5. For the SR-4 system, $\lambda$ is $5.05 \mathrm{hr}^{-1}$ and the 2-hr DRF is 10.1. The criterion is met. Rating $=3.5$.

- Criterion 1b. "Decay heat can be dissipated adequately."

The decay heat source from the collected fission products is $1 \times 10^{7}$ BTU/hr $(3000 \mathrm{~kW})$ during the first three hours of the loop operation. This will heat the air flowing through the system $43^{\circ} \mathrm{F}\left(24^{\circ} \mathrm{C}\right)$ above the inlet temperature, which is $240^{\circ} \mathrm{F}\left(116^{\circ} \mathrm{C}\right)$ maximum for the first 12 hours, giving a maximum exit temperature of $283^{\circ} \mathrm{F}\left(140^{\circ} \mathrm{C}\right)$. This is well below the shortterm Teflon temperature limit of $550^{\circ} \mathrm{F}\left(288^{\circ} \mathrm{C}\right)$. During the bag cleaning cycle, the flow to each compartment will be stopped and the cake on the bags will self-heat at a maximum rate of $128^{\circ} \mathrm{F} / \mathrm{min}\left(1.2^{\circ} \mathrm{C} / \mathrm{s}\right)$. Natural convection heat transfer will limit the maximum temperature rise of the bags during the one-minute cleaning time to $50^{\circ} \mathrm{F}\left(28^{\circ} \mathrm{C}\right)$ above the bag house ambient temperature. These temperatures will not cause material problems, but if the fan power is lost for more than 25 minutes the bags may overheat and fail.

Cooling of the collected fission product and sodium oxide aerosol material is provided by air flow under and over the floor of the bag house. The maximum surface temperature of the deposit will be $745^{\circ} \mathrm{F}\left(396^{\circ} \mathrm{C}\right)$ and the centerline temperature wi11 be $1140^{\circ} \mathrm{F}\left(616^{\circ} \mathrm{C}\right)$.

In the event of fan failure the natural stack effect will induce a flow of about 10 percent of normal and the air exit temperature would be a manageable $750^{\circ} \mathrm{F}\left(400^{\circ} \mathrm{C}\right)$. It is concluded that decay heat removal is adequate during normal operation, but that extended loss of power would lead to severe filter bag failure. However, power loss would not endanger the integrity of the containment building. Rating $=2.8$.

- Criterion 1c. "Either dry or sticky particles can be treated effectively." 
The basis for this system design is the Harvard data (47) which measured glass and Teflon cloth filtering of $\mathrm{Na}_{2} \mathrm{O}$ particles produced by oxidation of sodium in dry air. Tests in humid air or with damp aerosols were not made. Billings ${ }^{(44)}$ noted that damp particles can cling and produce a cake difficult to remove from the cloth and that normal practice is to avoid condensation and damp dusts. The presence of the asbestos pre-flock and the fact that Teflon is nonwetting should assist in the cleaning of the damp aerosol, but tests are needed to demonstrate this. It is concluded that damp aerosols will give an increased pressure drop and may be less effectively removed from the fabric, but that the filter will be operable. More frequent cleaning cycles will reduce the overall effectiveness of the system. Rating $=2.0$.

- Criterion 1d. "System effectiveness is not degraded by radiation caused by the accident over the required operating period."

Radiation damage causes Teflon to become brittle and weak. Tests at Savannah River Laboratory (SRL) ${ }^{(49)}$ show severe damage at $2 \times 10^{8}$ rads to Tefion fiber demisters; no degradation was observed at $2 \times 10^{7}$ rads. The dose to the cloth from the cake accumulated between cleanings is estimated to be $5 \times 10^{6} \mathrm{rad} / \mathrm{hr}$ during the initial 2-hour collection period. The dose to the bags from the fission products on the hearth will reach $2.6 \times 10^{6} \mathrm{rad} / \mathrm{hr}$ at $2 \mathrm{hrs}$, hence the total dose to the bags at 2 hrs will be $1.5 \times 10^{7}$ rads. At three hours (allowing for decay) the accumulated dose to the bags will be $2 \times 10^{7}$ rads. It is concluded that the radiation resistance of the SR-4 system using Tefion bags is marginal, but probably satisfactory for at least 3 hours. Rating $=3.0$.

- Criterion 2a. "The EACS shall have a high probability of startup after initiation of the DBST."

This system uses electric motors for the fans and bag shakers. An emergency power source will be supplied. Flow interrupting dampers must stop air flow to the compartment being cleaned. Such equipment 
has long been used successfully in industrial plants where less stringent requirements for reliable startup after long outages are needed. The types of mechanical and electrical equipment involved are highly reliable, but the multiplicity of devices reduces the rating to a rather low value. Rating $=2.5$.

- Criterion 2b. "The system shall be capable of withstanding the pressure pulse associated with the DBST."

The system is open at all times (no isolation valves) and is protected by the inlet duct labyrinth and exhaust fan. The relatively slow pressure pulse should not cause any problems. Rating $=3.2$.

- Criterion 2c. "The system does not degrade during periods of unuse." The filter cloth is pre-flocked with asbestos to assist in increasing the early filtering efficiency and to act as a parting agent during cleaning. Natural aging may impair the quality of the pre-flock, however routine checks would be made and corrective action taken as needed. Any degradation of the bags or equipment would be very slow and detectable by routine maintenance. Rating $=3.4$.

- Criterion 2d. "The system shall be capable of dependable operation over the required period of time under the DBST conditions of temperature, pressure, humidity and aerosol loading."

Dependable operation of the relatively simple components for a minimum period of 2 hrs seems quite sure. However, the bags are subject to plugging by wet aerosols and to damage by excessive temperature, hence long-term operation is not assured. Rating $=2.9$.

- Criterion 2e. "The system requires simple components and conservative design stress."

The system is basically simple and has a long history of satisfactory industrial use. The bags are the weakest component of the system and bag materials with improved temperature and radiation resistance are needed. Rating $=2.0$.

- Criteria 3a. "Inadvertent operation of the EACS shall not harm plant equipment or constitute a hazard to personnel." 
Operation of the system would not harm or damage either personnel or equipment or the EACS. Rating $=4.0$.

- Criterion 3b. "Operation of the EACS shall not significantly increase the pressure within the containment building by gas injection, energy release or other means."

The fan and shaker motors will require $590 \mathrm{HP}(440 \mathrm{~kW})$ which is 15 percent of the maximum fission product decay heat. This is a significant but tolerable energy addition to the system. Air operated flow dampers will contribute a negligible amount of gas to the containment vessel contents. Rating $=3.6$.

- Criterion 3c. "The size of the EACS shall be compatible with installation within or adjacent to the containment building."

The overall height of the reactor containment building is extended 8 feet $(2.4 \mathrm{~m})$ to accommodate the space needs of the EACS 1oops. Some changes in the layout of the normal RCB equipment will be necessary, but the operating deck is left free. Alternatively, the EACS system could be located exterior to the RCB within its own leak-tight containment building. Rating $=2.6$.

- Criterion 3d. "The EACS shall maintain the collected aerosol mass in a subcritical configuration."

The system SR-4 meets this requirement due to the spread of the collected aerosol material on the $330 \mathrm{ft}^{2}\left(30 \mathrm{~m}^{2}\right)$ hearth. Rating $=3.5$.

- Criterion 4a. "The air cleaning concept is based on highly developed technology."

Industrial bag filter systems are widely used in the chemical process, agricultural chemical, aluminum reduction, fossil fuel and many other industries. (44) Some of the applications involve environments equal to or more severe than the present case. Air filtering within containment is recognized as an acceptable method for LWR plants by Regulatory Guide 1.52. (21) Improved filter cloth materials are needed for the application, however. Rating $=3.8$. 
- Criterion 4b. "The EACS can be tested in-place for operability and efficiency."

In-place testing of the SR-4 filter system for operability and DOP particle collection efficiency is possible. Loading and environmental testing must be performed in large-scale ex-vessel facilities rather than in place. Rating $=3.3$.

- Criterion 4c. "The EACS performance can be predicted by verified mathematical models."

The theory of filtration mechanisms is well known ${ }^{(50)}$ and the technology well applied. (44) Performance models are simple and suitable for verification by large-scale testing. Rating $=3.8$.

- Criterion 4d. "The EACS equipment scaleup from currently available sizes to LMFBR plant application is small."

Large bag filter systems are not uncommon in industry and systems of the size specified for the SR-4 design are currently available. Rating $=4.0$.

- Criterion 5a. "The EACS is effective for the entire particle size spectrum expected during the accident."

For recirculating system purposes, the fabric filters with the asbestos pre-flock have essentially constant collection efficiency regardless of particle size and loading. The pressure drop increase caused by the collected cake on the bags may be somewhat dependent on the aerosol particle size. The system will accommodate any expected particle size. Rating $=3.9$.

- Criterion 5b. "The system performance is not highly sensitive to the atmosphere temperature, pressure and relative humidity."

Bag filters have not been tested with sodium oxide smoke in high humidity environments. Sodium oxide is hygroscopic and will rapidly convert to $\mathrm{NaOH}$ in the presence of moisture. The cake pressure drop and cleaning characteristics of bag filters are known to be affected 
by the presence of moisture. The extent of change expected from moisture must be determined by tests, but moisture can be expected to affect the system performance to some extent. Rating $=2.7$.

- Criterion 5c. "The system energy consumption is low."

The fans and shaker motors will require $590 \mathrm{HP}(440 \mathrm{~kW})$. This is a significant, but manageable energy requirement. Rating $=3.4$.

- Criterion 5d. "The system can be modified to add halogen removal components, hydrogen recombiners and containment coolers." System SR-4, being a recirculating flow system, is readily adaptable to addition of other air treatment components. Added space and larger fans and motors would be required. Rating $=3.8$.

- Criterion 5e. "The post-accident recovery is facilitated by the EACS."

This system will collect 97 percent of the aerosol material in the filter cells. Removal of the material and equipment from the cells and from containment would be difficult. The current design has not incorporated any remote handling techniques, but this ability could be added. The presence of this EACS system will facilitate cleanup in other regions of the RCB. Rating $=2.3$.

- Criterion 6a. "The system cost is low. Capital cost is less than $\$ 10$ million; operating costs are low."

This system is estimated to cost $\$ 6,000,000$. Operating and surveillance costs will be low. Rating $=2.8$.

- Criterion 6b. "Materials and techniques used in construction are readily available and easily fabricated."

All materials and techniques for this system are standard. Rating $=3.2$.

- Criterion 6c. "Components and equipment are readily available."

A11 the components and equipment are standard. Rating $=3.5$. 
7.1.4.6 Mandatory Criteria (SR-4). A11 the mandatory criteria listed in Table 15 are satisfied. Criterion 1c (dry or sticky particles) has only a 2.0 rating and is based on judgment rather than test results. The effects of moisture on the system behavior must be investigated.

7.1.4.7 Rating (SR-4). The numerical rating of this system is:

$\begin{array}{lr} & \frac{\text { Rating }}{77.1} \\ \text { System Effectiveness } & 66.0 \\ \text { System Reliability } & 62.4 \\ \text { Containment Compatability } & 51.1 \\ \text { Technological Credibility } & 35.8 \\ \text { System Characteristics and Flexibility } & 20.7 \\ \text { Fabrication Effort } & 313.1\end{array}$

7.1.4.8 Development Requirements $(S R-4)$. The design of this system made use of the Teflon fabric filter bags because of the Harvard experience which demonstrated the durability and cleanability of the bags for use with dry, non-radioactive sodium oxide aerosols. The bags are the key to the entire system and are the "weak link" in the system. Teflon lacks the desired radiation and temperature resistance. It is chemically compatible with sodium oxide but not with molten sodium. The following development is needed:

- Identify suitable radiation and temperature-resistant bag materials from such candidates as fiberglass, high-temperature plastics, ceramics, carbon or metal felts or fibers, or others.

- Demonstrate bag cleaning methods, including mechanical shaking, reverse gas flow, and pulse jets.

- Determine the filtering and cleaning behavior of moist aerosols.

- Investigate the use of $\mathrm{CO}_{2}$ as a "filter aid" by converting the wet $\mathrm{NaOH}$ aerosol to dry $\mathrm{Na}_{2} \mathrm{CO}_{3}$. 


\subsubsection{Direct Application - Powder Discharge (SD-15)}

7.1.5.1 Background (SD-15). Gravitational coagulation of the DBST aerosol particles can, in theory, be greatly accelerated by supplying a source of relatively large inert particles (powder) near the ceiling of the RCB. The settling velocity of the powder particles is significantly greater than that of the DBST particle and a portion of the fine particles is collected by the larger inert particle as it settles through the fine aerosol cloud. Not all of the fine particles within the volume swept by the larger particle are collected because the smaller particles tend to follow the streamlines and move aside as the large particle passes. Considerable analysis and experimental investigation of this coagulation mechanism has been done. $(31,51)$

If it is assumed that the containment atmosphere is well mixed, the particles are spherical, the velocities of the small particles are negligible compared to the large powder particle, and that any particles which touch remain agglomerated, the following expression can be derived for $\lambda_{p}$, the exponential removal coefficient for a powder dispersal system: ${ }^{(51)}$

$$
\lambda_{p}=\frac{3 h W E}{2 V d_{p} \rho_{p}}
$$

where: $\quad h=$ average fall height of powder particle, ft or $m$

$W=$ mass flowrate of powder injection, $1 \mathrm{~b} / \mathrm{min}$ or $\mathrm{g} / \mathrm{min}$

$V=$ volume of contained gas space, $\mathrm{ft}^{3}$ or $\mathrm{m}^{3}$

$d_{p}=$ mean particle diameter of powder, ft or $m$

$E=$ total single particle collection efficiency, dimensionless

$\rho_{p}=$ density of powder particle, $1 \mathrm{~b} / \mathrm{ft}^{3}$ or $\mathrm{g} / \mathrm{m}^{3}$.

For the case of an instantaneous release of aerosol particles, the mass concentration of suspended aerosol particles, $C$, is related to $\lambda_{p}$ by Equation (7).

$$
c=c_{0} e^{-\lambda} p t
$$

where: $C_{0}=$ concentration of aerosol particles at time zero, $\mu \mathrm{g} / \mathrm{cm}^{3}$

$t=$ time after instantaneous aerosol release, min. 
All of the terms in the right hand member of Equation (6) are easily quantified except $E$. By neglecting all the collection mechanisms except inertial impaction and interception, a conservative value for $E$ can be calculated as a function of the DBST aerosol particle size. ${ }^{(31)}$ By using the particle size distribution calculated by HAA-3B (e.g., Figure A-2) the mean effective value of $E$ can be calculated.

Containment spray systems for LWR plants are similar to the SD-15 powder discharge system except liquid drops are used in place of solid particles. Postma, et al., (52) recently evaluated the removal of particles from containment atmospheres by water sprays and concluded that a 2-hr DRF of 9 is attainable for the LWR accident conditions. They also showed that the results predicted by Equations (6) and (7) were in good agreement with those predicted by HAA-3B and with large-scale experiments.

7.1.5.2 Design Parameters (SD-15). The key assumptions and design parameters for system SD-15 are listed in Table 23.

TABLE 23

DESIGN PARAMETERS FOR POWDER DISCHARGE - SYSTEM SD-15

Parameter

Powder

Type

Bulk density

Particle density

Particle size

Powder storage location

Method of dispersal

Number of hoppers

Weight of powder per hopper

Total powder weight

Powder dispersal radius

Powder fall distance, minimum

Delay time before start of powder dispersal

Powder flowrate per hopper

Total powder flowrate

Powder flow duration
Value

Treated anhydrous $\mathrm{Na}_{2} \mathrm{CO}_{3}$ $1.0 \mathrm{~g} / \mathrm{cm}^{3}$

$2.4 \mathrm{~g} / \mathrm{cm}^{3}$

$100 \mu \mathrm{m} \mathrm{MMD}$

Elevated hoppers in RCB

Gravity-fed rotating disc spreaders

9

$25,0001 \mathrm{~b}(11,000 \mathrm{~kg})$ $225,000 \mathrm{lb}(100,000 \mathrm{~kg})$ $25-30 \mathrm{ft}(7.6-9.1 \mathrm{~m})$ $100 \mathrm{ft}(30 \mathrm{~m})$

5 minutes

$4400 \mathrm{lb} / \mathrm{min}(33 \mathrm{~kg} / \mathrm{s})$ $40,000 \mathrm{lb} / \mathrm{min}(300 \mathrm{~kg} / \mathrm{s})$

5 minutes 


\subsubsection{Conceptual Design (SD-15). The type of powder selected was}

based on the requirement to use a material that was suitable for exposure to a sodium pool fire. Commercially available sodium carbonate base sodium fire extinguishing powder ${ }^{(53)}$ was selected, with the added specification of smaller particle size (100-200 mesh) than presently supplied. This powder has the advantage of being inert to sodium, contains additives to keep the powder dry and flowable, and it is relatively inexpensive. Another powder material which appears suitable is carbon microspheroids produced either from petroleum coke or pitch. Schmitt ${ }^{(54)}$ reported that such material is suitable for extinguishing sodium and other metal fires. The mass median diameter of the petroleum coke material is $172 \mu \mathrm{m}$, the true density $2.0 \mathrm{~g} / \mathrm{cm}^{3}$, bulk density $1.8 \mathrm{~g} / \mathrm{cm}^{3}$, and the cost is reported to be low (six cents/1b). The major-to-minor axis ratio averaged 1.25 , making this a very flowable material. The non-combustibility of the carbon microspheroid material must be proven for all DBST conditions, including large sodium pool fires. The material was reported to be only 92 percent carbon. Because the impurities may cause pressure in the containment building, the sodium carbonate material was selected for the present design.

A]ternative methods of dispersing the powder were examined. Pneumatic fluidization from commercial fire extinguishing powder dispersing systems with transport through a fixed pipe distribution system appears feasible. Ground-level storage with mechanical lift to upper containment elevations appears cumbersome. A system of storage in elevated hoppers within the RCB and mechanical discharge through a rotating disc spreader was selected on the basis of lower cost and higher reliability.

The arrangement of the hoppers in the RCB is shown in Figure 17. A platform (not shown) is provided for maintenance and inspection purposes. Nine hoppers are provided, with each containing 25,000 $1 \mathrm{~b}(11,000 \mathrm{~kg})$ of powder. The hoppers are located so that the powder fall distance is a minimum of $100 \mathrm{ft}(30 \mathrm{~m})$.

A schematic diagram of the hopper and rotating spreader is shown in Figure 18. The spreader disperses the powder to a radius of 25-30 ft $(7.6-9.1 \mathrm{~m})$. A nitrogen gas injection nozzle is provided near the bottom of the hopper to insure powder flow. The powder is kept dry by hermetically sealing the hopper outlets. 

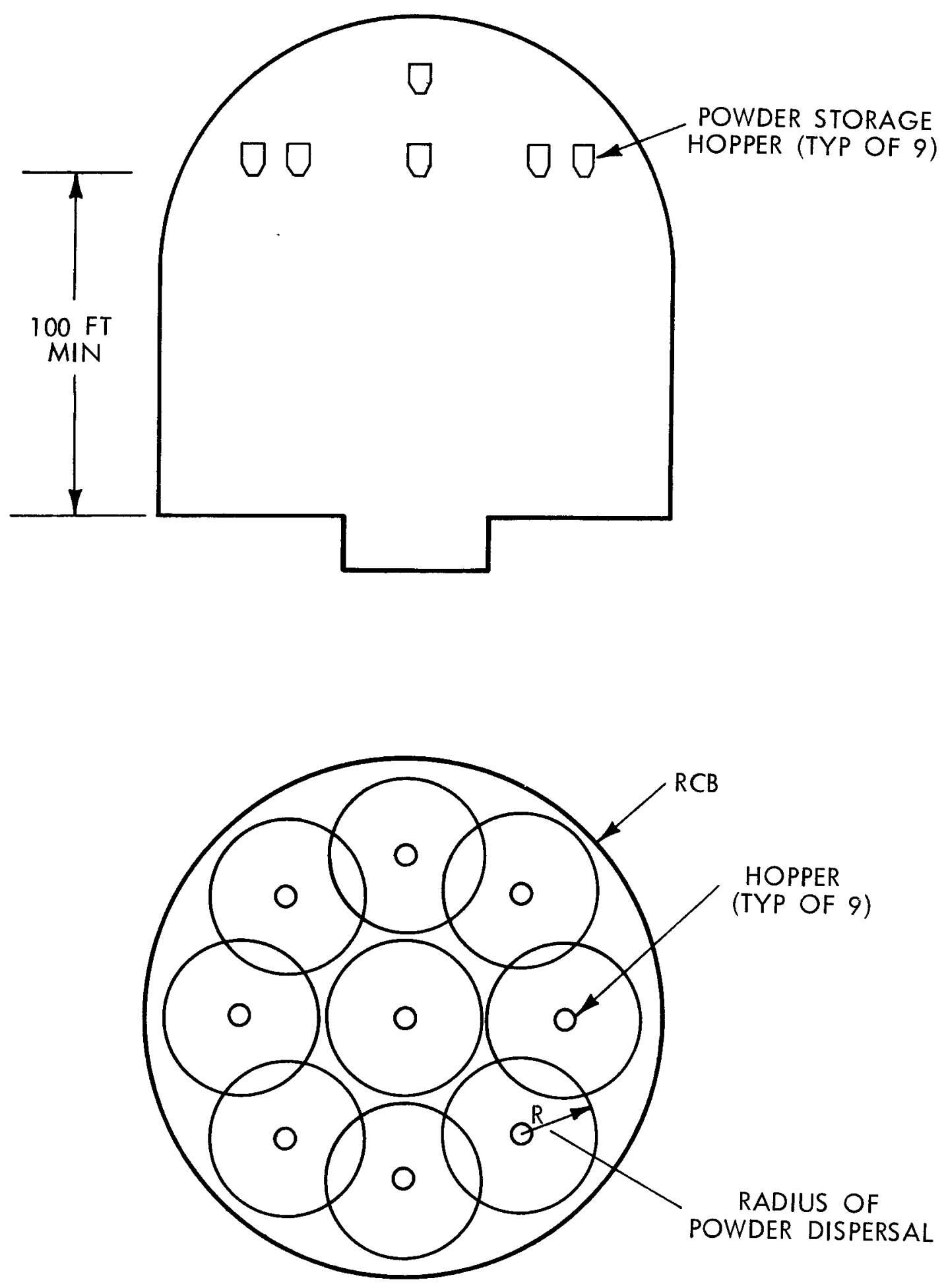

HEDL $7511-66.3$

FIGURE 17. Arrangement of Powder Storage Hoppers in the RCB for System SD-15. 


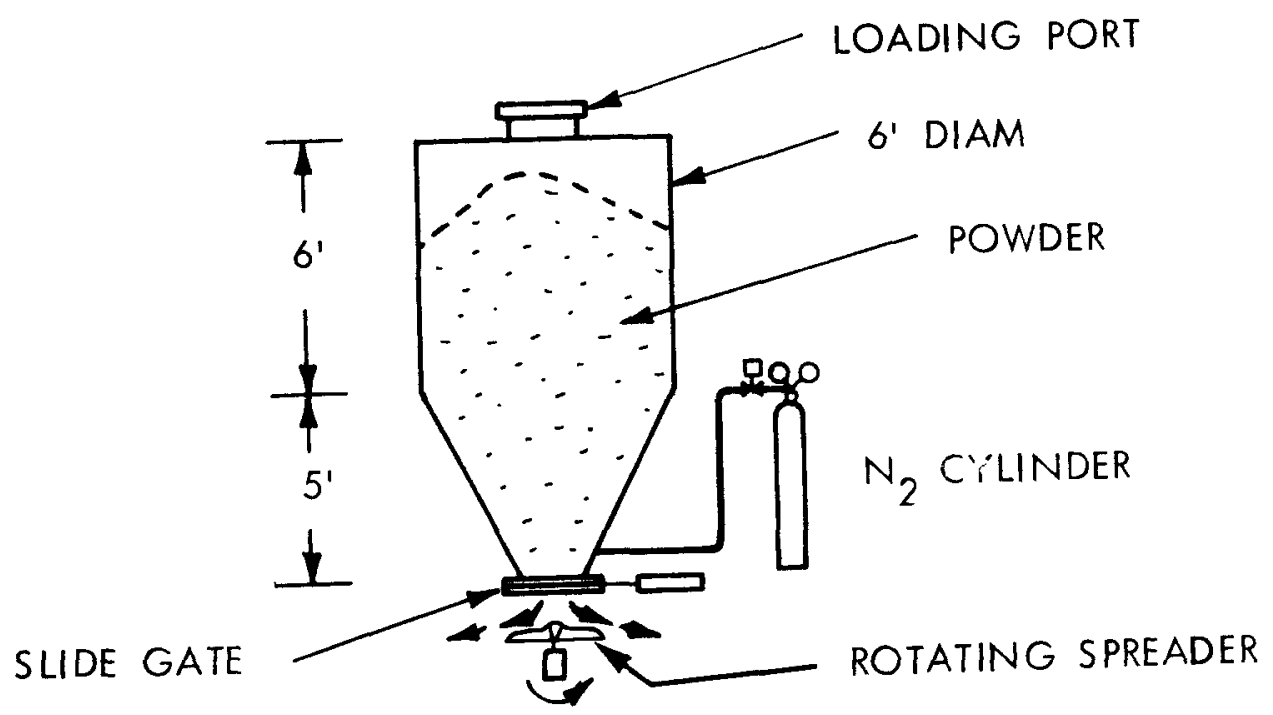

HEDL 7511-66.2

FIGURE 18. Powder Storage Hopper and Rotating Spreader (SD-15).

7.1.5.4 Cost Estimate (SD-15). The following cost estimate for system SD-15 includes the costs of the elevated maintenance platform, reinforcement of the RCB walls at support points, and incremental seismic analyses.

Construction and equipment

$$
\begin{aligned}
& \$ 000^{(a)} \\
& 1,632 \\
& 328 \\
& 1,960 \\
& 1,960 \\
& 3,920
\end{aligned}
$$$$
\text { Engineering (20\%) }
$$$$
\text { Subtotal }
$$$$
\text { Contingency }(100 \%)
$$

TOTAL

(a) 1975 dollars

\subsubsection{Conformity with Criteria (SD-15).}

- Criterion 1a. "A dose reduction factor (2 hr) of ten can be achieved for aerosol particles." 
A 2-hr dose reduction factor of 22.5 is predicted for the SD-15 design using Equations (6) and (7) and the aerosol particle size distribution 1isted in Table 24, which was taken from a HAA-3B computer run. The key parameters for this calculation are the powder particle size (100 $\mathrm{\mu m}$ diameter), weight of powder dispersed $(200,000 \mathrm{lb}$ or $90,000 \mathrm{~kg})$, and time delay before start of powder flow $(\theta=5 \mathrm{~min})$.

\section{TABLE 24} IN-CONTAINMENT AEROSOL PARTICLE SIZE DURING DELAY PERIOD
BEFORE POWDER DISCHARGE

$\begin{array}{crc}\begin{array}{c}\text { Time, } \\ \text { min }\end{array} & \begin{array}{c}\text { MMD, } \\ \frac{\mu \mathrm{m}}{0}\end{array} & \frac{\sigma_{\mathrm{g}}}{2.00} \\ 5 & 1.00 & 1.70 \\ 10 & 1.72 & 1.80 \\ 15 & 2.02 & 2.00 \\ 20 & 2.60 & 2.52 \\ 25 & 5.00 & 2.95 \\ 30 & 10.15 & 2.94\end{array}$

For the SD-15 design powder $(100 \mu \mathrm{m})$, the DRF is sensitive to the time delay, with the highest value being for immediate start of powder flow $(\theta=0)$ and low values of DRF for long delay times. However, the DRF is greater than ten for delay times shorter than 12 minutes, which gives a large safety factor for startup. Delay time has less effect for larger powder particle sizes. The effect of delay time on the DRF is shown by Figure 19.

The size of the powder particles is fairly important, as shown by Figure 20. Any real powder will have a particle size spectrum and, furthermore, may not be dispersed to its primary size. Figure 20 also shows that a 2-hr DRF can still be attained if the effective powder size is as large as $200-\mu \mathrm{m}$ diameter. 


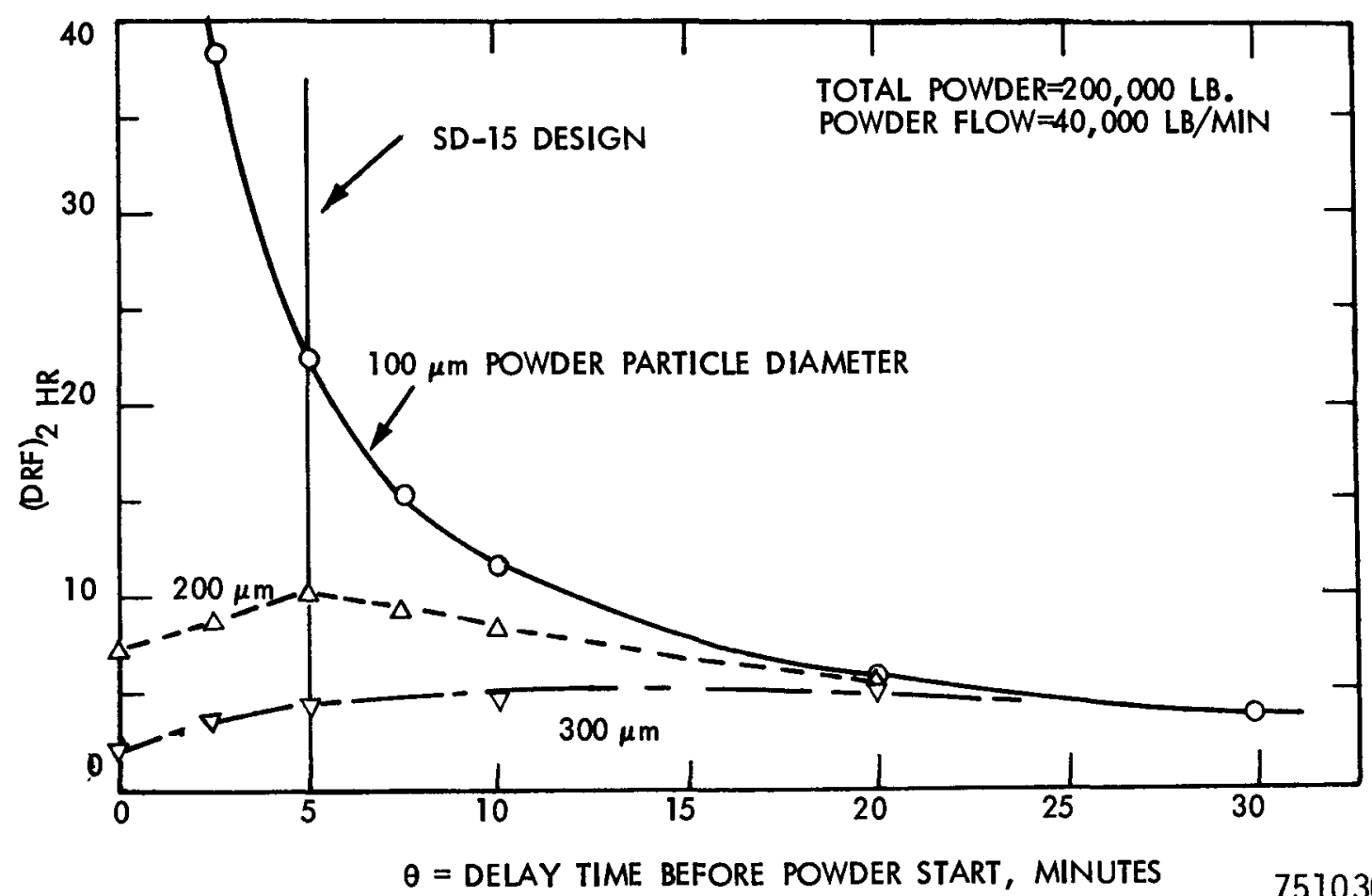

$7510300-8$

FIGURE 19. Effect of Delayed Powder Start on DRF (SD-15).

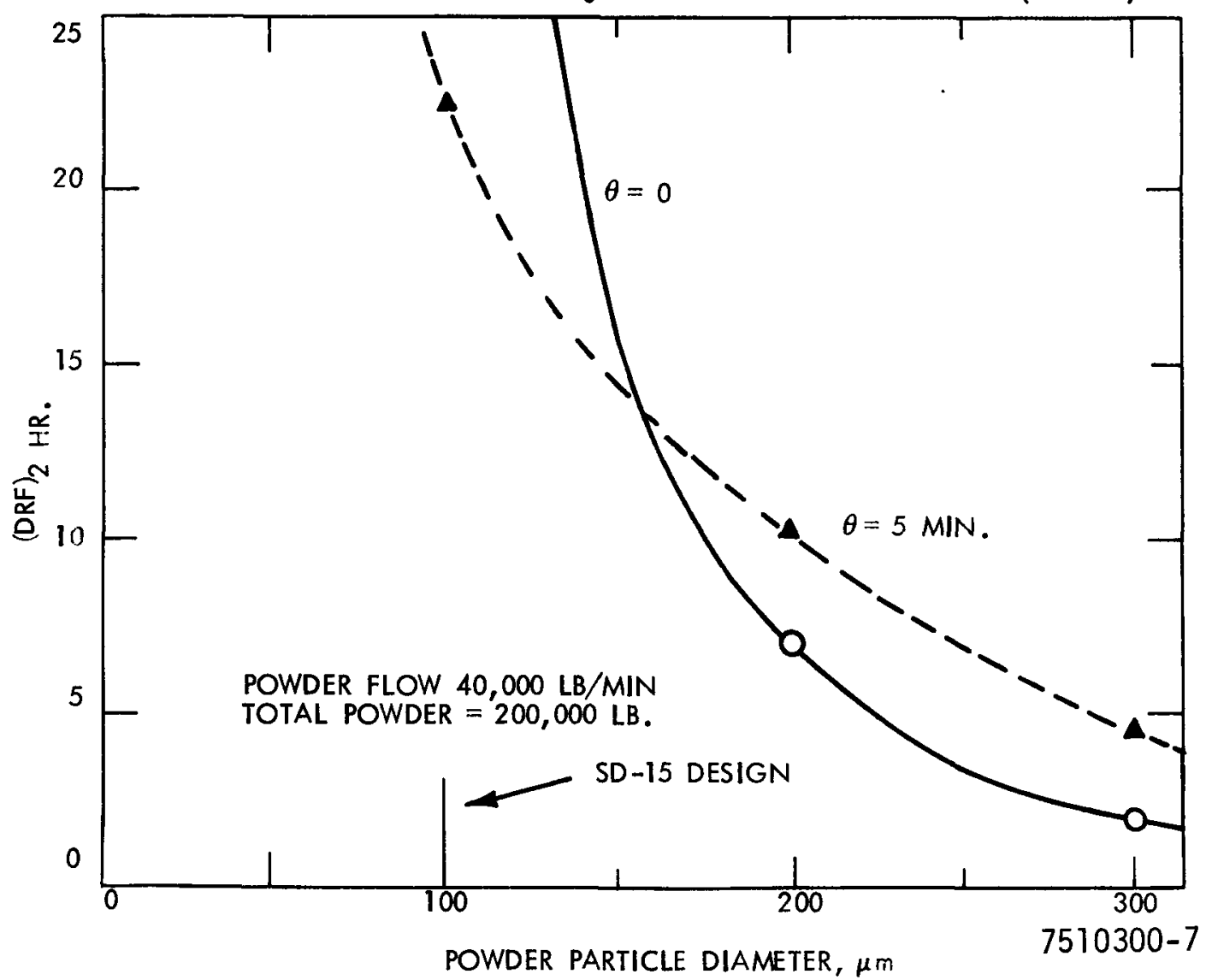

FIGURE 20. Effect of Powder Particle Size on DRF (SD-15). 
The rate at which the powder is discharged into the containment atmosphere does not affect the DRF significantly as long as the same quantity of powder is dispersed. This is shown by Figure 21. For a $100 \mu \mathrm{m}$ powder size, a powder flowrate of only $1 / 10$ of the SD-15 design rate would give a DRF of 15 . If the $200,000-16$ design powder mass were injected at a uniform rate over the entire 2-hr period (after an initial 5-minute delay), the design objective DRF of 10 would still be met.

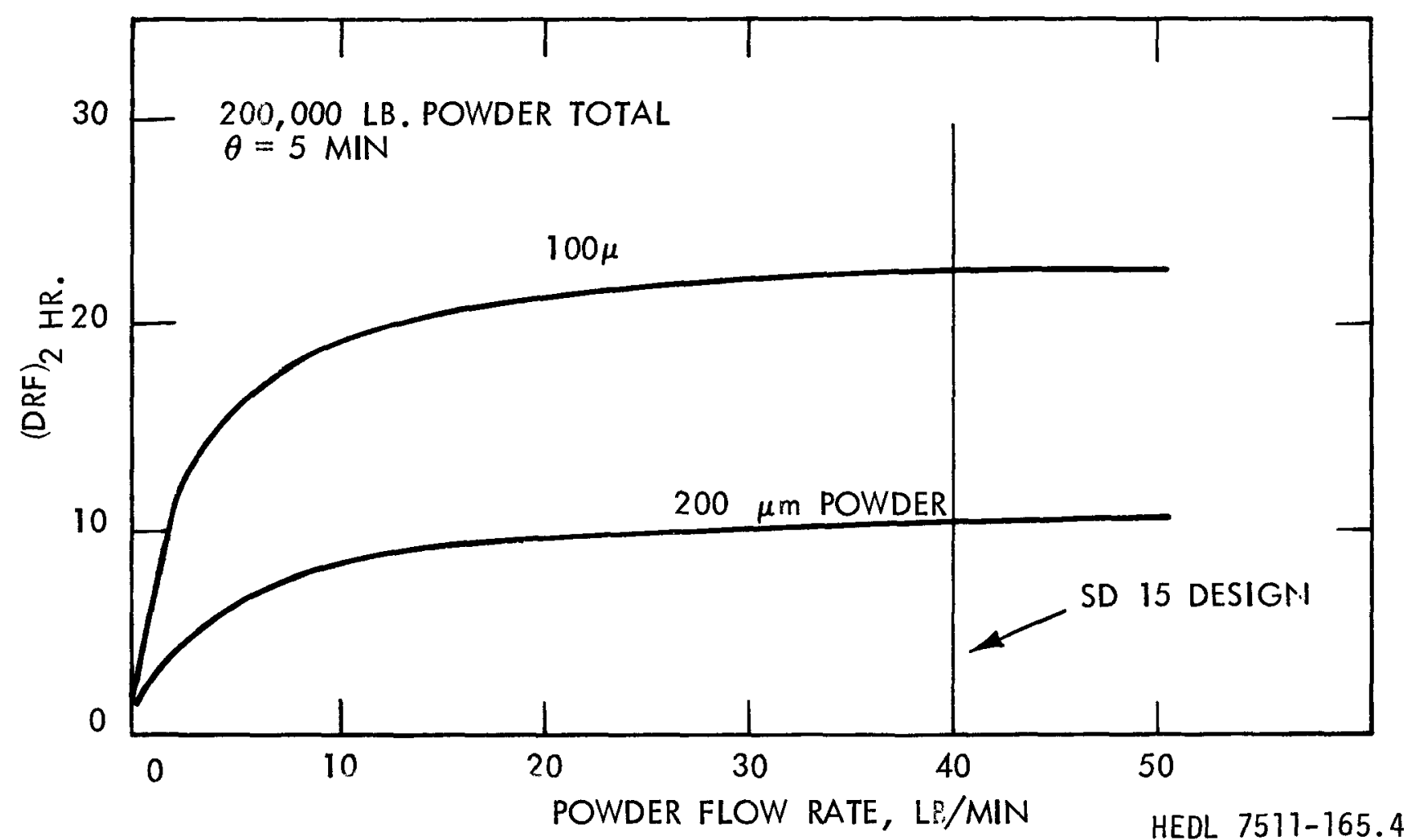

FIGURE 21. Effect of Powder Flow Rate on DRF (SD-15).

For the SD-15 design powder size and delay time, the DRF is not critically dependent on total mass of powder dispersed, as shown by Figure 22. The design objective DRF of 10 is attained with only $4000 \mathrm{lb}(1850 \mathrm{~kg})$ of powder. However, for powders with larger particle size, the DRF is more sensitive to the mass of powder discharged. An alternate operational method is suggested by Figure 22 , in which the powder would be dispersed intermittently throughout the 2-hr period to assure removal of radioactive aerosol particles released 


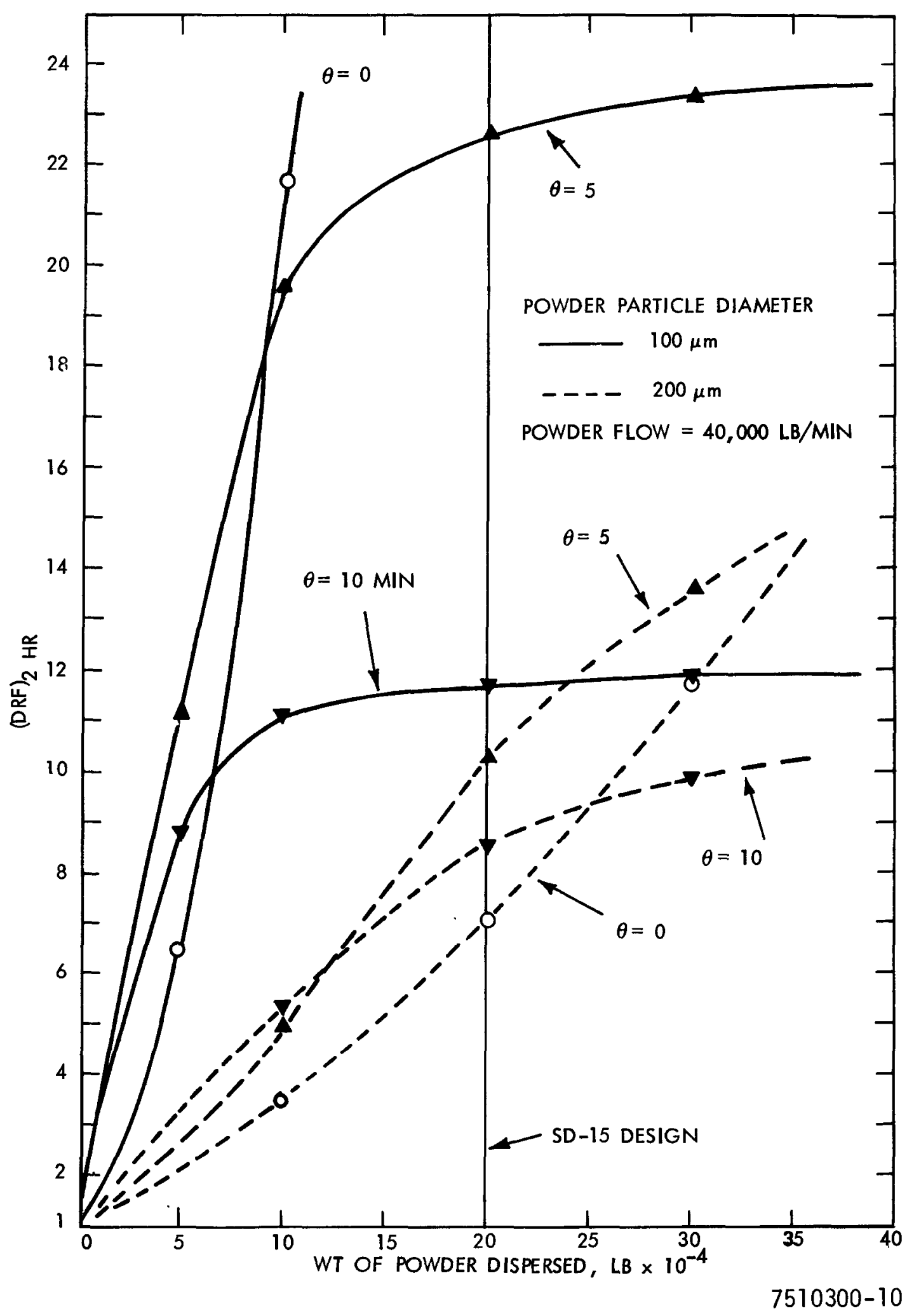

FIGURE 22. DRF as a Function of Mass of Powder Dispersed (SD-15). 
as a continuing source rather than as a prompt release. Experimental demonstration of the efficiency of the powder system would be necessary.

It is concluded that the SD-15 powder dispersed system completely meets the DRF criterion, and may significantly surpass the minimum requirement. Rating $=3.9$.

- Criterion 1b. "Decay heat can be dissipated adequately."

The maximum temperature in the aerosol-powder layer on the floor of the RCB is less than $800^{\circ} \mathrm{F}\left(427^{\circ} \mathrm{C}\right)$ if a 11 of the heat flux is upward to the air. If downward heat flux into the concrete equals the upward heat flux, a maximum temperature of $300^{\circ} \mathrm{F}\left(165^{\circ} \mathrm{C}\right)$ would occur after about 24 hours. The net effect of the powder would be to cause a higher concrete temperature but a lower atmosphere temperature. This is a beneficial effect in that a lower RCB pressure results, which gives a lower driving force for leakage from the RCB. Rating $=4.0$.

- Criterion 1c. "Either dry or sticky particles can be treated effectively."

The gravitational collision efficiency is dependent on the aerosol particle size, density and adhesiveness. When the DBA aerosol is exposed to water vapor, the $\mathrm{Na}_{2} \mathrm{O}$ is first converted to $\mathrm{NaOH}$, and then water of hydration is added. The overall effect is to increase the mass of the particle and its adhesiveness, both effects being favorable to removal by inertial mechanisms. However, the particle size may actually be reduced by collapse of its initial agglomerated open chain structure to a shape more nearly approximating a sphere. Since the efficiency of collection by the interception mechanism is directly proportional to the radius of the aerosol particle, the interception efficiency may be reduced. It is not known at this time whether the net effect of addition of moisture would increase or decrease the overall removal rate of aerosol by powder dispersal. Since the calculations for predicting the DRF in Criterion la were based on the assumption that aerosol particles are spherical, sufficient conservatism may already have been provided. Rating $=3.5$. 
- Criterion 1d. "System effectiveness is not degraded by the radiation dose caused by the accident over the required operating period." The operation of the powder dispersal equipment is not affected by radiation during the brief period of operation. The effectiveness of gravitational agglomeration would be improved by the radiation field, according to Koontz, et al. (55) This is true if the aerosol particles acquire a bipolar charge, which appears to be a reasonable assumption for the DBST conditions. It is concluded that the powder collection efficiency is not degraded by the radiation field and that it may be improved. Rating $=4.0$.

- Criterion 2a. "The EACS shall have a high probability of startup after initiation of the DBST."

The reliability of the electrically operated valves and rotating disc spreaders is high. The probability that the powder will flow out of the hopper and be completely dispersed by the disc spreaders is less certain. The SD-15 design features which improve the probability of powder dispersion are the use of a non-caking powder, hermetically sealed hoppers to avoid moisture addition or other adverse effects of long-term exposure to the RCB atmosphere, and a gas injection system within the hopper to agitate and fluidize the powder. Development testing would be required to confirm the reliability of this or other dispersal systems. Rating $=3.4$.

- Criteria 2b. "The system shall be capable of withstanding the pressure pulse associated with the DBST."

The powder storage hoppers are designed for $10 \mathrm{psi}$ internal or external pressure, considerably above the maximum expected during the accident. The electric motors, powder spreaders, hopper outlet valves and gas injection system can all easily withstand the pressure pulse. Rating $=4.0$.

- Criterion 2c. "The system does not degrade during periods of unuse." All of the mechanical components are not subject to degradation during long periods of unuse. The only potential problem in meeting 
this criterion is the possibility of powder caking with age. Anticaking agents are blended into the powder and the material must pass RDT Standard and Underwriter's Laboratories tests on caking and flowability. Verification testing under normal RCB operating conditions would be necessary. Rating $=2.0$.

- Criterion 2d. "The system shall be capable of dependable operation over the required period of time under the DBST conditions of temperature, pressure, humidity and aerosol loading."

The mechanical operation of the SD-15 powder system over its intended operating period is very reliable. The present design calls for all the powder to be dispersed within 10 minutes after start of the DBA, during which time the environmental conditions should have essentially no effect on the system. However, if an alternative mode of intermittent operation is specified, the temperatures and humidity might have adverse effects for longer periods. Any detrimental effect could be alleviated by operating each hopper system sequentially, keeping the remaining hoppers sealed until they are activated. The system is judged to meet the criterion satisfactorily. Rating $=2.5$.

- Criterion 2e. "The system requires simple components and conservative design stress."

The components are simple and can be fabricated with ample conservatism for any expected stresses. A seismic analysis must be performed to assure that incorporating the system into the RCB structure does not degrade containment capability or cause any other adverse effect. Rating $=3.3$.

- Criterion 3a. "Inadvertent operation of the EACS shall not harm plant equipment or constitute a hazard to personnel."

Inadvertent operation of any one of the nine powder-dispersing systems would spread the powder over all surfaces exposed to the RCB atmosphere. Personnel caught in the deluge would not be seriously harmed, although discomfort to the eyes and respiratory system is likely. The effect on equipment and instrumentation would be serious 
and a significant reactor downtime would probably be required for cleanup. The damage would be similar to that of inadvertent operation of caustic sprays in LWR plants, which is an accepted risk in many current LWR plants. Rating $=1.0$.

- Criterion 3b. "Operation of the EACS shall not significantly increase the pressure within the containment building by gas injection, energy release or other means."

Energy addition by the electric motors in SD-15 is negligible, being $<0.05$ percent of the FP decay heat during the initial 2-hr period. The maximum pressure increase due to gas injection is also negligible $(0.015 \mathrm{psig})$. Containment atmosphere cooling by sensible heat exchange with the falling powder is capable of quickly reducing the RCB atmosphere temperature by $30^{\circ} \mathrm{F}\left(16^{\circ} \mathrm{C}\right)$, or nearly 1 psig $(6900 \mathrm{~Pa})$. Further, the heat producing aerosol particles are quickly deposited on the floor of the RCB and covered with a layer of insulating powder. The heat flux to the RCB atmosphere is approximately half of what it would be in the absence of the powder system, which results in a significant reduction in RCB pressure. One point which needs laboratory checking is the determination of the extent of gas formation by decomposition of the additives to the powder. It is concluded that, barring unexpectedly bad results from the latter investigation, the powder system completely meets the criterion and may even provide a beneficial effect on reducing the containment pressure. Rating $=3.9$.

- Criterion 3c. "The size of the EACS shall be compatible with installation within or adjacent to the containment building."

The powder system occupies only about $500 \mathrm{ft}^{3}\left(140 \mathrm{~m}^{3}\right)$ of space in the $\mathrm{RCB}$, and the components can be installed near the ceiling of the RCB above the polar crane, an area which is normally unused. Rating $=4.0$.

- Criterion 3d. "The EACS shall maintain the collected aerosol mass in a subcritical configuration."

System SD-15 completely satisfies this criterion by spreading the fuel aerosol particles over $20,000 \mathrm{ft}^{2}\left(1850 \mathrm{~m}^{2}\right)$ of floor surface, or approximately $0.2 \mathrm{~g}$ of fissionable material per $\mathrm{m}^{2}$. Rating $=4.0$. 
- Criterion 4a. "The air cleaning concept is based on highly developed technology."

The technology of air cleaning by a powder spray is not as highly developed as is air cleaning by liquid sprays. Some work has been done in the field of atmospheric physics to advance the understanding of scavenging of naturally occurring aerosols by snow and ice crystals $(56)$, but powder spraying is not a normal industrial air cleaning concept. Rating $=1.0$.

- Criterion 4b. "The EACS can be tested in-place for operability and efficiency."

The SD-15 powder dispersal system cannot be tested in-place for efficiency, but the operability of individual hopper-spreader systems can be checked by installing a bag around the spreader to contain the dispersed powder. Alternatively, a hopper unit could be removed to an ex-containment area for testing, although this would involve a significant operating cost. It is concluded that this system only marginally satisfies the criterion. Rating $=1.2$.

- Criterion 4c. "The EACS performance can be predicted by verified mathematical models."

Existing computer models such as $\operatorname{HAA-3B}(4)$ and HAARM-1 ${ }^{(57)}$, which describe aerosol behavior due to Brownian agglomeration, gravitational agglomeration, settling, wall plating, leakage, and source term, can be modified to incorporate a removal term for powder removal. This has already been done to HAA-3B for liquid sprays. (52) Hand calculational models, such as described in Section 7.1.5.1 of this report and in Reference (52), are also available. In all of these models, the key uncertainty is the magnitude of $E$, the particle collision efficiency. Theoretical values of $E$ are available $(37,50)$, and thus the validity of the mathematical models is subject to verification by large-scale testing. Rating $=2.4$.

- Criterion 4d. "The EACS equipment scaleup from currently available sizes to LMFBR plant application is small." 
System SD-15 involves a unique air cleaning concept which is not used currently. Consequently, there is no scaleup. However, powder handling equipment is available in the required size scale for use in the mineral and agricultural chemical industries. Equipment size is not considered to be a serious problem. Rating $=2.5$.

- Criterion 5a. "The EACS is effective for the entire particle size spectrum expected during the accident."

The rate of aerosol particle removal by powder is dependent on the aerosol particle size. However, a 2-hr DRF of 10 can be achieved with the SD-15 design even if the aerosol particles were uniform sized (monodisperse) at $0.4 \mathrm{\mu m}$ diameter with an effective density of $0.7 \mathrm{~g} / \mathrm{cm}^{3}$. Since the DBST aerosol is expected to be considerably larger than this, the criterion is met. Rating $=2.0$.

- Criterion 5b. "The system performance is not highly sensitive to the atmosphere temperature, pressure and relative humidity."

As discussed for Criterion ic (ability to treat sticky particles), moisture probably has a minimal effect on system performance. The atmosphere temperature and pressure have negligible effects on the particle collision efficiency. Caking of the powder may be somewhat accelerated by the higher temperature, but this is unlikely to occur during the 5-minute delay period while the powder is still in the hoppers or during dispersal by the rotating disc spreaders. It is concluded that the system performance is not highly sensitive to the atmospheric conditions. Rating $=4.0$.

- Criterion 5c. "The system energy consumption is low."

Only $20 \mathrm{HP}(15 \mathrm{~kW})$ is required to operate the valves and spreaders. The criterion is completely met. Rating $=4.0$.

- Criterion 5d. "The system can be modified to add halogen removal components, hydrogen recombiners, and containment coolers."

System SD-15 is not adaptable to incorporation of hydrogen recombiner or containment atmosphere cooling components. However, it may be 
very well suited for halogen removal by the addition of activated charcoal to the powder. Only a small percentage of the powder weight ( $<1$ percent) as charcoal would be sufficient to remove nearly all the elemental iodine and organic iodides. The halogen removal rate would be much more rapid than by conventional recirculating charcoal adsorber systems. The presence of a powder system would not preclude the use of separate systems for hydrogen recombination and containment cooling. Rating $=0.5$.

- Criterion 5e. "The post-accident recovery is facilitated by the EACS."

Post-accident cleanup is not facilitated by system SD-15. For minor accidents the cleanup and recovery problems would be magnified by the spread of powder. For major accident conditions, the presence of powder would probably cause minor additional problems due to disposal of the large volume of powder $\left(3600 \mathrm{ft}^{3}\right.$ or $\left.100 \mathrm{~m}^{3}\right)$. Rating $=1.0$.

- Criterion 6a. "The system cost is low. Capital cost is less than $\$ 10$ million; operating costs are low."

The installed cost is estimated at $\$ 3.9$ million. Annual operating costs are estimated at $\$ 0.1$ million. Rating $=3.2$.

- Criterion 6b. "Materials and techniques used in construction are readily available and easily fabricated."

A11 materials used in SD-15 are readily available and easily fabricated. However, if development testing should show that the sodium carbonate powder material is not suitable, a search for a satisfactory powder would be necessary. Also, if testing should show that the powder is not properly dispersed by the rotating disc spreader technique, pneumatic fluidization may be required, and equipment of the size needed here is not presently available commercially. Rating $=2.8$.

- Criterion 6c. "Components and equipment are readily available." The hoppers and rotating disc spreaders are of special design, but fabricators of this type of equipment are plentiful. Rating $=2.5$. 
7.1.5.6 Mandatory Criteria (SD-15). A11 of the mandatory criteria are satisfied by acceptable ratings. However, the interpretation of Criteria $2 \mathrm{~d}$ (reliable operation over the required operating period) for system SD-15 is that the system is only required to operate for a period sufficient to give a 2-hr DRF of ten. Long-term operation over a 30-day period is not feasible with the powder system.

7.1.5.7 Rating (SD-15). The numerical rating of system SD-15 is as follows:

\begin{tabular}{lcc}
\multicolumn{1}{c}{ Group Criteria } & Rating \\
\cline { 1 - 1 } System Effectiveness & & 103.6 \\
System Reliability & 63.4 \\
Containment Compatibility & 56.5 \\
Technological Credibility & 23.6 \\
System Characteristics \& Flexibility & 28.0 \\
Fabrication Effort & 21.3 \\
\cline { 2 - 2 } TOTAL & 296.4
\end{tabular}

7.1.5.8 Development Requirements (SD-15). Improved knowledge of system SD-15 performance characteristics which can be obtained by development tests includes:

- Verification of mathematical model capability for predicting aerosol removal by powder. Confirmation of the effects of powder fall distance, powder flow rate, powder particle size, and quantity of powder dispersed on the aerosol removal rate and lower limit of reduced aerosol concentration.

- Evaluation of powder candidates, including the sodium carbonate fire extinguishing material, for long-term storability. Parameters are age, temperature, vibration, pressure due to powder weight, and relative humidity of atmosphere in the storage hopper.

- Evaluation of the flowability and dispersal characteristics of candidate powders, using prototype hopper-spreaders and fixed pipe pneumatic fluidization system.

- Determination of stability of powder falling into burning sodium or exposed to FP decay heat, especially as to evolution of vapors and gases. 


\subsubsection{Recirculating - Electrostatic Precipitator (SR-12)}

7.1.6.1 Background (SR-12). High voltage electrostatic precipitators (ESP) are a very common air cleaning device for large installations. These devices have been used successfully for collection of liquids and solids from a variety of industrial sources, such as smelters, steel furnaces, coal-fired power plants, acid plants and petroleum refineries. (17) Electrostatic precipitators are especially suited to the removal of particles from large volumes of hot gases. Existing industrial installations handle 50,000 to $2,000,000 \mathrm{cfm}\left(24\right.$ to $\left.940 \mathrm{~m}^{3} / \mathrm{s}\right)$ and can accommodate temperatures of $700^{\circ} \mathrm{F}$ $\left(370^{\circ} \mathrm{C}\right)$ or more. Typical removal efficiencies range from 85 to 99 percent.

Electrostatic precipitators are of many types and configurations; all, however, operate on the same basic principles. Separation of the particles from the gas stream requires three fundamental steps:
a) Electrical charging of the particles
b) Collection of the charged particles in an electric field
c) Removal of the collected material from the collecting electrodes.

Particles may be naturally charged, but except in special cases the natural charge levels are low and low removal efficiencies result. The most common means of particle charging in industrial practice is the use of the high-voltage corona. A corona is established between a fine wire maintained at a high (usually negative) voltage and a grounded collecting surface. The corona produces large numbers of ions. The positive ions are collected at the wire and the negative ions are attracted to the grounded collecting surface. Hence, the main space in the precipitator contains only negative ions. The suspended particles in the gas passing through this space are bombarded by the negative ions and become highly charged. These charged particles, influenced by the direct current field between the wire and the collecting plate, migrate to the plate, are deposited, and fall into a hopper for removal The action is quite fast; charging may take only $0.01 \mathrm{sec}$ and collection of the charged particles may be completed in 0.1 to 2 seconds. 
Use of electrostatic precipitators in the nuclear industry has been limited, primarily because the highly efficient particle removal needed at the typically low particle burden is better met by other air cleaning systems. (58) Removal of humidified nonradioactive alkali metal fumes from air by a "modified" Cottrell electrostatic precipitator was reported by LeMar (33) to be 98 percent efficient. Details of the test conditions were not given. Dennis ${ }^{(25)}$ tested low voltage two-stage precipitators with $20 \mathrm{mg} / \mathrm{m}^{3}$ concentrations of NaK fumes and found removals of 56 to 97 percent, depending on the air velocity. Problems were noted with insulator fouling. In addition, deposits on the close plate spacing of the two-stage precipitator necessitated reduced collection voltages. Dennis thought these problems would be overcome by the single-stage (Cottrell) design.

Based on this meager experience, but encouraged by the long time industrial success, a single-stage electrostatic precipitator was scope designed, using the parameters recommended by white. ${ }^{(59)}$ The design values chosen are believed to be conservative, and have been found to give satisfactory industrial performance.

7.1.6.2 Design Parameters (SR-12). The design parameters for this system are given in Table 25.

7.1.6.3 Conceptual Design (SR-12). The single-stage type electrostatic precipitators are located within the containment building below the operating deck in five cells. The containment building height is extended $8 \mathrm{ft}$ to accommodate the increased volume requirement of the equipment. The high voltage power supplies are located outside the containment vessel.

The precipitator size is determined by the gas flow to be treated, the expected particle migration velocity at the operating conditions, and the required degree of decontamination. The expression for efficiency is given by Equation (8).

$$
E_{R}=1-e^{-\frac{A_{E} w}{Q_{E}}}
$$


DESIGN PARAMETERS FOR RECIRCULATING-ELECTROSTATIC PRECIPITATOR

(SYSTEM SR-12)

Total flow (all loops operating)

Number of loops

Flow per loop

Particle removal efficiency

Loop Precipitators

Number per loop

Pressure drop

Collector area

Collector length

Collector height

Number of collector plates

Overall precipitator width

Corona wire-to-plate space

Gas velocity

Voltage

Voltage sections

Corona current (approx.)

Ion collecting current

Power (at $100 \%$ rectifier efficiency)

Average deposit thickness

Plate cleaning method
200,000 CFM $\left(94 \mathrm{~m}^{3} / \mathrm{s}\right)$

5

40,000 CFM $\left(19 \mathrm{~m}^{3} / \mathrm{s}\right)$

94 percent

1

2 in. $\mathrm{H}_{2} \mathrm{O}(500 \mathrm{~Pa})$

$4000 \mathrm{ft}^{2}\left(370 \mathrm{~m}^{2}\right)$

$18 \mathrm{ft}(5.5 \mathrm{~m})$

$10 \mathrm{ft}(3.0 \mathrm{~m})$

12

$9 \mathrm{ft}(2.7 \mathrm{~m})$

$4.5 \mathrm{in.}(114 \mathrm{~mm})$

$480 \mathrm{ft} / \mathrm{min}(2.4 \mathrm{~m} / \mathrm{s})$

$50 \mathrm{kV}$

4

0.06 to 0.2 amps

0.9 amps

$55 \mathrm{~kW}$

0.13 in. (3.3 mm)

None

Fans

Number per loop

Pressure drop at 40,000 CFM

Fan power (each loop)

Motor size

Discharge duct diameter
1

3 in. $\mathrm{H}_{2} \mathrm{O}(750 \mathrm{~Pa})$

$32 \mathrm{HP}(24 \mathrm{~kW})$

$50 \mathrm{HP}(37 \mathrm{~kW})$

42 in. $(1.07 \mathrm{~m})$ 
where: $\quad A_{E}=$ collector area, $\mathrm{ft}^{2}$

$Q_{E}=$ gas flow rate, $\mathrm{ft}^{3} / \mathrm{sec}$

$W=$ particle migration velocity, $\mathrm{ft} / \mathrm{sec}$.

Obviously, high removal efficiency is obtained at the cost of exponentially increasing size. Determination of the particle mobility, $w$, is made by considering the particle size distribution, the air viscosity, and the charging and collection parameters of the precipitator. ${ }^{(60)}$ For typical EACS operating conditions of $5 \mathrm{kV} / \mathrm{cm}$ and air at $300^{\circ} \mathrm{F}\left(150^{\circ} \mathrm{C}\right)$, the mobility can be estimated as shown in Table $26 .{ }^{(60)}$

TABLE 26

ELECTROSTATIC PRECIPITATOR PARTICLE MOBILITIES

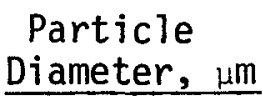

$<0.5$

$0.5-1$

$1-2$

$2-4$

$>4$
Mass

Fraction

0.04

0.17

0.39

0.29

0.11
Average Mobility, $\mathrm{ft} / \mathrm{sec}(\mathrm{mm} / \mathrm{s})$

$0.18(55)$

$0.25(76)$

0.60 (183)

$1.2(366)$

$2.3(700)$

Once the particle removal efficiency has been calculated, the optimum loop gas flow rate for a 2-hr DRF of 10 can be determined in the manner previously used for other systems [Equations (2) and (3)]. Parameters can be selected from white ${ }^{(59)}$, and for several $A_{E} / Q_{E}$ ratios the gross collector size can be determined. These are given in Table 27.

The designer has the flexibility of selecting the value of certain parameters, such as height, width, plate spacing and gas velocity, within practical limits. For example, a wire-to-plate spacing of 3 to 10 inches (76-254 mm) is satisfactory and this determines the volume occupied by the precipitators. To prevent particle reentrainment, gas velocities should not exceed $30 \mathrm{ft} / \mathrm{sec}(9.4 \mathrm{~m} / \mathrm{s})$. This critical velocity determines the length of the collection electrodes. 
TABLE 27

PRECIPITATOR SIZE AS A FUNCTION OF $A_{E} / Q_{E}$ RATIO

\begin{tabular}{|c|c|c|c|c|c|c|c|}
\hline \multirow{2}{*}{$\begin{array}{l}A_{E} / Q_{E} \\
\mathrm{sec} / \mathrm{ft} \\
\end{array}$} & \multirow{2}{*}{$\begin{array}{c}\text { Removal } \\
\text { Efficiency }\end{array}$} & \multirow{2}{*}{$\begin{array}{c}\text { Total } \\
\text { Gas Flow, } \\
\mathrm{ft}^{3} / \mathrm{min} \\
\end{array}$} & \multirow[t]{2}{*}{$\begin{array}{c}\text { Collecfor } \\
\text { Area }(a), \\
\mathrm{ft}^{2} \\
\end{array}$} & \multicolumn{3}{|c|}{ Size ${ }^{(b)}, \mathrm{ft}$} & \multirow[t]{2}{*}{$\begin{array}{c}\text { ESP } \\
\text { Volume, } \mathrm{ft}^{3} \\
\end{array}$} \\
\hline & & & & W & $\mathrm{H}$ & $L$ & \\
\hline 1 & 0.52 & 360,000 & 1200 & 8.25 & 18.2 & 3 & 450 \\
\hline 2 & 0.73 & 256,000 & 1710 & 8.25 & 13.0 & 6 & 640 \\
\hline 3 & 0.83 & 226,000 & 2260 & 8.25 & 11.4 & 9 & 850 \\
\hline 5 & 0.90 & 208,000 & 3470 & 8.25 & 10.6 & 15 & 1300 \\
\hline 6 & 0.94 & 199,000 & 3980 & 8.25 & 10.1 & 18 & 1500 \\
\hline 8 & 0.97 & 193,000 & 5140 & 8.25 & 9.7 & 24 & 1930 \\
\hline
\end{tabular}

(a) For each of five loops.

(b) For each of five loops with a gas velocity of $8 \mathrm{ft} / \mathrm{sec}$ and a wire-to-plate spacing of 4.5 inches.

Table 27 shows that the smallest precipitator volume is provided by a low-efficiency ESP operating at the higher flow rates. The actual space requirements, however, do not decrease proportionally as larger fans are needed and the extreme aspect ratio of height-to-length will require larger inlet and outlet plenums to insure uniform gas flow through the precipitator. For the system SR-12 design, a value of $6 \mathrm{sec} / \mathrm{ft}(19.6 \mathrm{sec} / \mathrm{m})$ for $A_{E} / Q_{E}$ is specified, giving an overall ESP efficiency of 94 percent. Table 28 presents the values chosen and also shows the range of normal industrial practice. The precipitator, as designed, falls within the normal range of design parameters.

The arrangement of the precipitators within the RCB is shown in Figure 23. Other arrangements are obviously possible, as are alternate precipitator dimensions within the limits of Tables 27 and 28 . Such alternates could be adapted to meet containment space and shape restrictions. Figure 24 shows the precipitator details.

Normal industrial precipitators are designed with hoppers to receive the collected dust and with electrode rappers to periodically clean the electrodes. 
TABLE 28

\section{ELECTROSTATIC PRECIPITATOR PARAMETERS}

\begin{tabular}{|c|c|c|c|}
\hline Basic Parameter & Symbol & $\begin{array}{l}\text { Industrial Practice } \\
\text { Normal Range(a) } \\
\end{array}$ & System SR-12 \\
\hline Precipitation rate & $w, f t / s e c$ & 0.05 to 1.0 & 0.18 to 2.3 \\
\hline Collection surface & $A_{E} / Q_{E}, \mathrm{sec} / \mathrm{ft}$ & 3 to 60 & 6 \\
\hline Plate separation & $2 S$, in. & 6 to 15 & 9 \\
\hline Gas velocity & $v, \mathrm{ft} / \mathrm{sec}$ & 3 to 15 & 8 \\
\hline Corona power & $\begin{array}{l}\mathrm{P}_{\mathrm{C}} / Q_{\mathrm{E}}, \text { watts } \\
1000 \text { CFM }\end{array}$ & 50 to 500 & $70(a)$ \\
\hline $\begin{array}{l}\text { High tension } \\
\text { sectionalization }\end{array}$ & $\begin{array}{l}N / Q_{E} \text { sections/ } \\
100,000 \mathrm{CFM}\end{array}$ & 0.5 to 10 & 10 \\
\hline
\end{tabular}

(a) Assumed from operating experience, Reference (58), Page 359.

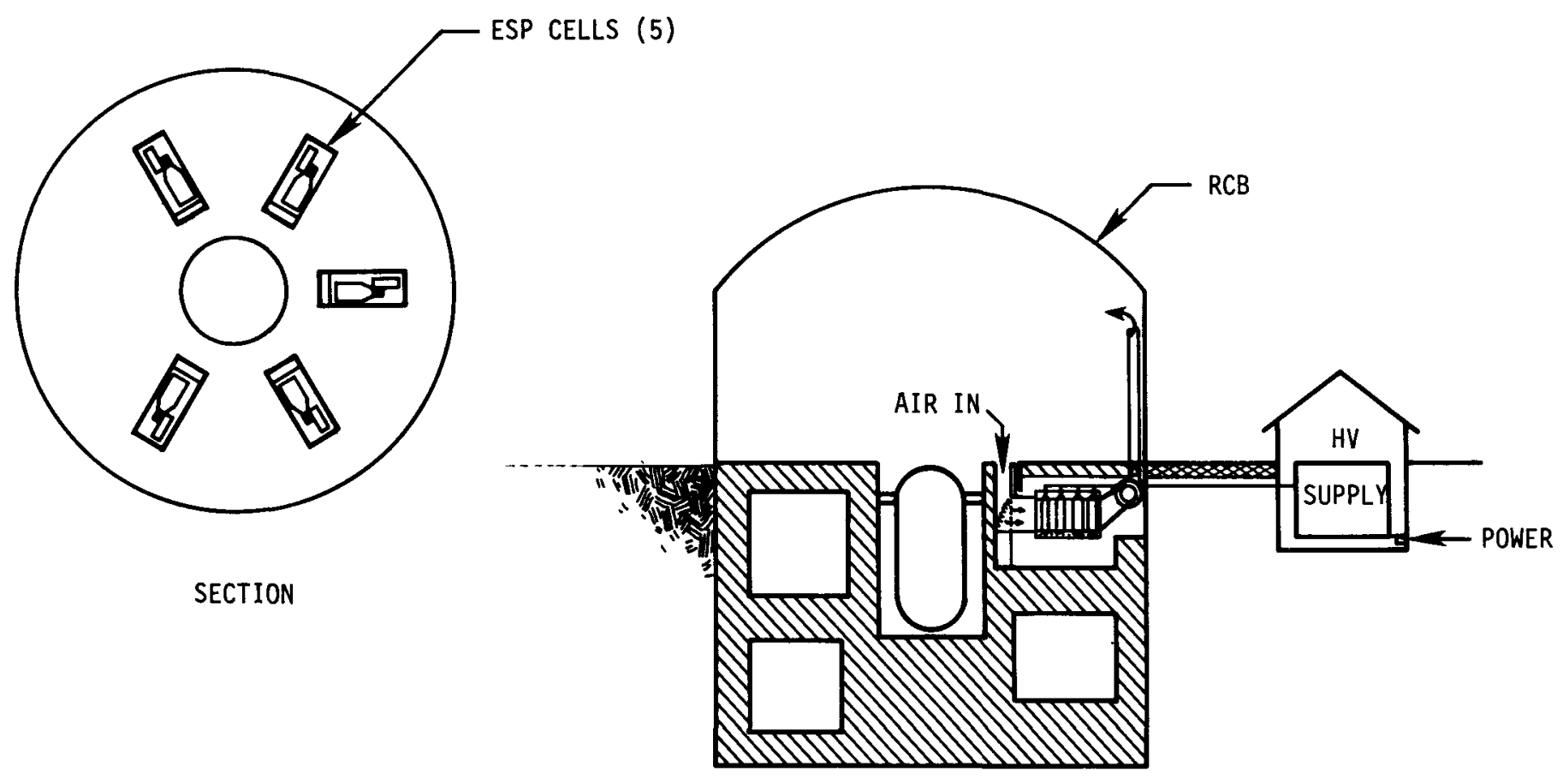

ELEVATION

$7510300-9$

FIGURE 23. Electrostatic Precipitator Arrangement Within the RCB for System SR-12. 


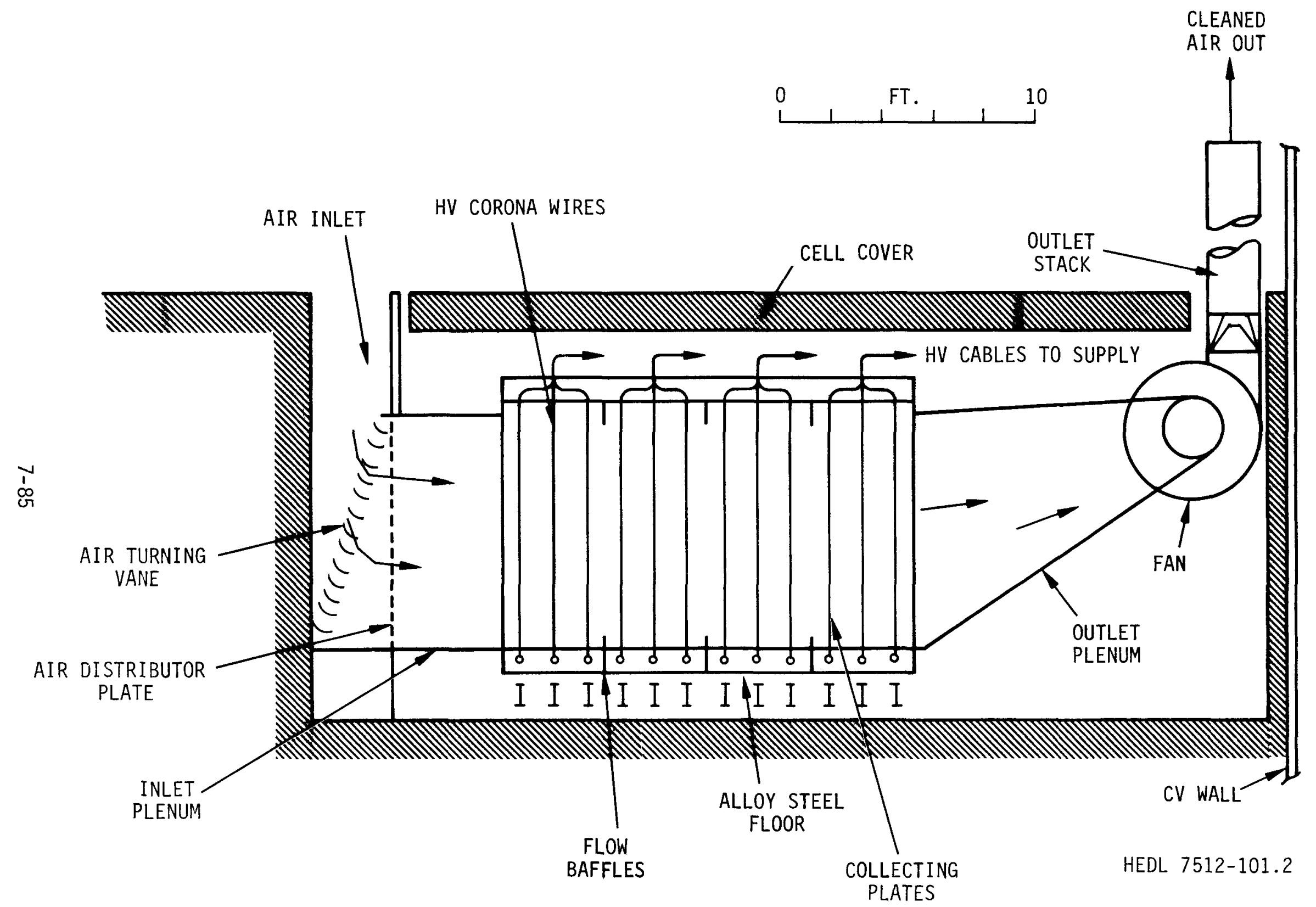

FIGURE 24. Schematic Section of Electrostatic Precipitator and Cell (SR-12). 
The volume of collected material for the DBST would provide a dust layer only 0.13 inches $(3.3 \mathrm{~mm})$ thick on the collecting electrodes. The maximum inlet deposit will be only about $0.3 \mathrm{in}$. $(7.6 \mathrm{~mm})$ thick. Rapping to dislodge this thin deposit is not needed. If all the dust falls to the floor, a layer about 10 inches $(0.25 \mathrm{~m})$ thick could accumulate at the inlet end and decay heat would lead to centerline melting of the $\mathrm{Na}_{2} \mathrm{O}$. Convection cooling of the underside of the floor and fabrication of alloy steel to withstand the $1400^{\circ} \mathrm{F}\left(760^{\circ} \mathrm{C}\right)$ surface temperature is needed. Air flow is not critical to the cooling as the natural stack effect will draw about $8000 \mathrm{CFM}\left(3.8 \mathrm{~m}^{3} / \mathrm{s}\right)$ through each loop, which would maintain adequate cooling.

Dust conductivity is a potential problem in electrostatic precipitators. Back voltage caused by the IR drop through the deposit on the electrodes can reduce the precipitator performance. No data on the electrical conductivity of dry $\mathrm{Na}_{2} \mathrm{O}$ dust was found. However, the normal moisture content of the RCB atmosphere is sufficient to convert the $\mathrm{Na}_{2} \mathrm{O}$ to $\mathrm{NaOH}$, which should help keep the resistivity below the critical value of $10^{10} \mathrm{ohm}-\mathrm{cm}$. The high sodium hydroxide content of the dust should also help lower the resistivity of the core material aerosols. White ${ }^{(61)}$ reports that the normal fly ash resistivity of $3 \times 10^{13} \mathrm{ohm}-\mathrm{cm}$ at 0.1 percent $\mathrm{Na}$ is reduced to $1 \times 10^{9} \mathrm{ohm}-\mathrm{cm}$ for ash with 10 percent $\mathrm{Na}$. In addition, the effect of the radiation field within the collected material is expected to assist the conductivity. ${ }^{(62)}$ The dust resistivity must be measured, but it does not seem likely to be of concern.

The effects of high level radiation fields on the action of the ESP are not clear. The maximum beta and gamma doses in the ESP occur after all of the aerosol has been collected and are on the order of $2 \times 10^{6} \mathrm{rad} / \mathrm{hr}$. This will ionize the air to the extent that a current of 0.9 ampere would be needed to collect the ions. That this is a significant additional current can be seen by comparing it with the expected normal corona current of 0.06 to 0.2 ampere. These radiation produced ions may interfere with the particle charging process. It is well known, for example, that radiation is used to discharge static charges. Schultz ${ }^{(62)}$, however, operated an electrostatic precipitator in a $1.5 \times 10^{5} \mathrm{R} / \mathrm{hr}$ field, and was able to obtain 98 percent removal of fly ash without a corona. In this mode of operation the radiation field is apparently beneficial. 
The conclusion made from this design effort is that an ESP can provide a means of air cleaning which would be satisfactory for use as an EACS. The main questions relate to the particle resistivity and to the effects of intense radiation fields on the collection efficiency. These must be investigated experimentally.

\subsubsection{Cost Estimate (SR-12).}

\begin{tabular}{lr} 
Construction and equipment & $\frac{\$ 000(\mathrm{a})}{2,850}$ \\
$\begin{array}{c}\text { Engineering (20\%) } \\
\text { Subtotal }\end{array}$ & $\frac{570}{3,420}$ \\
RCB Incremental Cost & $\frac{1,460}{4,880}$ \\
$\quad$ Subtota1 & $\underline{2,920}$ \\
Contingency (60\%) & 7,800 \\
TOTAL & \\
\hline o 1975 dollars
\end{tabular}

\subsubsection{Conformity with Criteria (System SR-12).}

- Criterion 1a. "A dose reduction factor $(2 \mathrm{hr})$ of ten can be achieved for aerosol particles."

A 2-hr DRF of 10 is calculated by Equations (2) and (3). This meets the criterion exactly. Rating $=3.4$.

- Criterion 1b. "Decay heat can be dissipated adequately."

Decay heat will produce a maximum temperature rise of $43^{\circ} \mathrm{F}\left(24^{\circ} \mathrm{C}\right)$ in the air flowing through the precipitator. If a 11 the collected aerosol material remains on the collector plates, only a small temperature drop through the deposit would be produced. If all the material falls from the plates to the floor of the ESP, a cake about 10 inches $(0.25 \mathrm{~m})$ thick could be obtained near the inlet end. Heat generation in this thickness would lead to partial melting of the $\mathrm{Na}_{2} \mathrm{O}$ cake. A surface temperature of $1400^{\circ} \mathrm{F}\left(760^{\circ} \mathrm{C}\right)$ could be attained. The floor design must, and can, accommodate this temperature. Convection cooling at the lower floor surface is provided by the design. 
In the event of fan failure the low pressure drop through the ESP and the natural draft induced by the stack effect will provide continued air flow and cooling. The ESP need not employ temperature sensitive materials in its fabrication and can tolerate the expected condition without damage or danger to the system or to the RCB. Rating $=3.4$.

- Criterion 1c. "Either dry or sticky particles can be treated effectively."

The performance of electrostatic precipitators is strongly dependent on the electrical properties of the aerosol particles. No data could be found on the performance of electrostatic precipitators for the $\mathrm{Na}_{2} \mathrm{O} / \mathrm{NaOH}$ at the expected accident condition. A moist, sticky aerosol would have a low electrical resistance and thus be beneficial. It is possible that a critical resistance exists at some low moisture content. Any sticky (moist) particles are likely to be conductive and their retention on the collector plates would not alter the precipitator effectiveness. This, however, must be tested. Rating $=3.6$.

- Criterion 1d. "System effectiveness is not decreased by radiation caused by the accident over the required operating period."

The effects of ionizing radiation fields on the operation of an ESP is uncertain. Some evidence exists ${ }^{(62)}$ that gamma radiation enhances the collection of aerosol particles and the present design would be readily adaptable to this type of collection. On the other hand, the power requirement would be increased by the ionization caused in the ESP systems from a normal 14-50 kW to about $225 \mathrm{~kW}$ for all five loops, and it can be calculated that the mixed ion fields would lead to reduced particle charges and hence reduced collection efficiency. The power supplies would be external to the containment and not affected by the radiation fields, but the high-voltage cables and insulators must be of radiation resistant materials. 
Work needs to be done to refine the calculations of the expected radiation and to measure the performance of ESP in these radiation fields. Rating $=2.0$.

- Criterion 2a. "The EACS shall have a high probability of startup after the initiation of the DBST."

This system uses electric motors to drive the fans which should have good probability of starting. The HV power supplies are less likely to be trouble free but could be kept "idling" on the line and hence the state of readiness would be known. In addition, the sectionalization of the ESP provides redundancy. It is concluded that the startup reliability can be kept high through proper design and checking. Rating $=3.0$.

- Criterion 2b. "The system shall be capable of withstanding the pressure pulse associated with the DBST."

The ductwork is open and the ESP is basically an open box. Hence the slow pressure change following the DBST should not cause any problems. Rating $=3.3$.

- Criterion 2c. "The system does not degrade during periods of unuse." The system contains no perishable items. The cables, power supplies, corona wires and insulators would require routine cleaning and checking. Rating $=3.4$.

- Criterion 2d. "The system shall be capable of dependable operation over the required period of time under the accident conditions of temperature, pressure, humidity and aerosol loading." Industrial ESP units commonly operate for long periods of time under conditions of temperature, humidity and aerosol loading similar to the DBST conditions. The fan motors and HV electrical insulation will need to be selected for the $300^{\circ} \mathrm{F}$ ambient temperature and radiation fields which will exist in the containment vessel. Operation after 2 hours is not required to meet the EACS needs, but longer time operation may be desirable and would be possible. Rating $=2.9$. 
- Criterion 2e. "The system requires simple components and conservative design stress."

Electrostatic precipitators have a long history of satisfactory use in industry but they do require high voltage and fine corona wires ( 0.1 in. diameter). Excessive dust buildup on the wires, plates or insulators can lead to spark-overs which will decrease the performance. Rating $=2.0$.

- Criterion 3a. "Inadvertant operation of the EACS shall not harm plant equipment or constitute a hazard to personnel."

The operation of this EACS would not cause harm or damage of any kind. Long term operation, however, could lead to ozone buildup in the containment building and personnel protection may be required during testing. Rating $=3.9$.

- Criterion 3b. "Operation of the EACS shall not significantly increase the pressure within the containment building by gas injection, energy release or other means."

Operation of the ESP and fans will require about $340 \mathrm{~kW}$, which is about 9 percent of the maximum fission product decay heat generation. This energy release within containment would increase the containment pressure; however, the design provides an additional containment volume of about 9 percent and the peak pressure would be unchanged. Rating $=3.5$.

- Criterion 3c. "The size of the EACS shall be compatible with installation within or adjacent to the containment building."

The design will require five cells with a total volume of $42,000 \mathrm{ft}^{3}$ $\left(1200 \mathrm{~m}^{3}\right)$. The designer of an ESP system can trade off air flow, efficiency, and shape, as indicated in Table 27, to optimize the design to equipment space needs. Any such system, however, will occupy a sizable space and may require an enlarged containment vessel. Rating $=2.6$.

- Criterion 3d. "The EACS shall maintain the collected aerosol mass in a subcritical configuration." 
The electrostatic precipitator system meets this requirement by spreading out the collected material on the collection plates and on the precipitator floor in the five units. Rating $=3.8$.

- Criterion 4a. "The air cleaning concept is based on highly developed technology."

Electrostatic precipitators have long been used in industry for air cleaning under a wide variety of conditions. $(17,59)$ The physics of electrostatic fields and of particle charging is well established, but much is still empirical, especially the arrangement of flow patterns. The determination of the particle conductivity is best based on tests, and, as noted, work needs to be done on the effect of radiation fields. Rating $=3.9$.

- Criterion 4b. "The EACS can be tested in-place for operability and efficiency."

The ESP system can be tested for flow and voltages with or without aerosol particles. If tests with high concentrations of particles are desired, special arrangements would be needed to trap the 6 percent of the test dust which would normally exit from the precipitator. The influence of radiation would not be readily field testable. Rating $=3.3$.

- Criterion 4c. "The EACS performance can be predicted by verified mathematical models."

The basic theory is well in hand, but as noted above, the field or laboratory tests are often needed in the case of unusual particle compositions and flow patterns. ESP designs often employ model tests and field adjustments. Rating $=3.3$.

- Criterion 4d. "The EACS equipment scaleup from currently available sizes to LMFBR plant application is small."

Industrial ESP systems range in size up to $3,000,000$ CFM $\left(1400 \mathrm{~m}^{3} / \mathrm{s}\right)$. The LMFBR air cleaning size needs can be readily met. Rating $=4.0$. 
- Criterion 5a. "The EACS is effective for the entire particle size spectrum expected during the accident."

The particle migration velocity in an ESP is size-dependent and reaches a minimum with $0.2 \mu \mathrm{m}$ diameter particles. The precipitators can be designed to collect these particles with any desired efficiency, but the overall ESP efficiency will depend on the particle size spectrum. Rating $=3.5$.

- Criterion 5b. "The system performance is not highly sensitive to the atmosphere temperature, pressure and relative humidity." Atmospheric temperature and pressure will have only minor effects on the precipitator efficiency, this being due to mobility changes caused by viscosity and drag effects. The effects of relative humidity could be important and tests of particle conductivity must be made to determine this. Rating $=3.5$.

- Criterion 5c. "The system energy consumption is low." The system fans will require $120 \mathrm{~kW}$ (160 HP) and the normal corona power will be $50 \mathrm{~kW}$ or less. An added amount of power is needed due to the ionization caused by the radiation field and for this design is estimated at $220 \mathrm{~kW}$. Assuming a rectifier efficiency of 75 percent, the total emergency power needs will be $480 \mathrm{~kW}$. Rating $=3.6$.

- Criterion 5d. "The system can be modified to add halogen removal components, hydrogen recombiners and containment coolers."

This system, as with any recirculating system, can readily be adapted for the addition of these devices with proper motor, fan, and space changes. Rating $=3.6$.

- Criterion 5e. "The post-accident recovery is facilitated by the EACS."

This system will collect and retain 97 percent of the aerosol material within the electrostatic precipitators. This will assist 
in post-accident cleanup in the RCB. The design does not include any remote handling for cleanup of the ESP itself. Rating $=2.6$.

- Criterion 6a. "The system cost is low. Capital cost is less than $\$ 10$ million; operating costs are low."

System SR-12 is estimated to cost $\$ 7.8$ million. Operation and surveillance costs will be moderate. Rating $=2.4$.

- Criterion 6b. "Materials and techniques used in construction are readily available and easily fabricated."

All materials and techniques used in this system are standard. Rating $=3.5$.

- Criterion 6c. "Components and equipment are readily available."

A11 the components and equipment are standard. Rating $=3.5$.

7.1.6.6 Mandatory Criteria (SR-12). Al1 the mandatory criteria 1isted in Table 15 are satisfied. The minimum rating was for criterion 1d (radiation field effects) at 2.0, which is due to the uncertainty of the radiation effects on the precipitator action. This and the effects of moisture on the particle properties (criterion 1c) must be investigated experimentally.

7.7.6.7 Rating (SR-12). The numerical rating of the recirculating electrostatic precipitator (System SR-12) is as follows:

\begin{tabular}{lc} 
System Effectiveness & 87.6 \\
System Reliability & 69.5 \\
Containment Compatibility & 62.6 \\
Technological Credibility & 49.4 \\
System Characteristics and Flexibility & 37.6 \\
Fabrication Effort & $\underline{19.0}$ \\
\multicolumn{1}{c}{ TOTAL } & 325.7
\end{tabular}


7.1.6.8 Development Requirements (SR-12). Three development needs are evident for this system:

- It is necessary that the electrical properties of the aerosol particles (and the deposited cake) be determined. This should be done for both dry and moist conditions and over the expected temperature range in the precipitator. If particle properties are not satisfactory, the possible use of conditioning agents such as $\mathrm{CO}_{2}$ should be considered.

- The effects of radiation fields on the electrostatic precipitator performance need to be clarified. Several levels of radiation up to $2 \times 10^{6} \mathrm{R} / \mathrm{hr}$ should be used. These tests can be performed at small scale.

- A large-scale proof test should be performed, using scale modeled parameters but realistic atmospheric conditions (except for radiation field).

\subsubsection{Other Systems}

A11 twenty candidate systems for single containment plants 1 isted in Table 27 were given a complete preliminary evaluation, but only the six systems discussed in the previous sections are reported in detail. The remaining fourteen systems are either variations of arrangement of components used in the six reported systems or were judged to be unfeasible and only the conclusions of the evaluation are reported here. Failure of a system to meet the design criteria specified in this study does not necessarily deny $i$ ts potential usefulness for air cleaning under different conditions and requirements. Also, future developments and discoveries may cause some method or component presently judged unfeasible to become a viable air cleaning concept for LMFBRs. For example, system SD-14, In-Containment Liquid Sprays, is judged unfeasible because no practical working liquid is known for use under LMFBR accident conditions. If a suitable liquid were found, in-containment sprays would become a favored air cleaning concept.

The conclusions of the preliminary evaluations of the remaining fourteen systems are presented in the following sections. 


\subsubsection{Recirculating - Sand Bed Filter (SR-3).}

- System Description - One large sand and gravel bed filter is provided with five inlet ducts and five exhaust ducts with fans. The filter building has $45,000 \mathrm{ft}^{2}\left(4200 \mathrm{~m}^{2}\right)$ of horizontal sand surface and occupies $50,000 \mathrm{ft}^{2}\left(4650 \mathrm{~m}^{2}\right)$ of floor area, including plenums and ducts. The entire system is built to the same leakage and pressure requirements as the RCB. The sand bed filter is graded from approximately 0.5 -inch $(13 \mathrm{~mm})$ gravel to 0.025 -inch $(0.64 \mathrm{~mm})$ sand and is 24 inches $(0.61 \mathrm{~m})$ thick. It is based on German test data using $\mathrm{Na}_{2} 0$ aerosol which gave a maximum loading of $0.1 \mathrm{lb} / \mathrm{ft}^{2}\left(0.5 \mathrm{~kg} / \mathrm{m}^{2}\right)$.

- System Effectiveness - System SR-3 is effective in cleaning the containment atmosphere, and a 2-hr DRF of 10.5 is achieved by recirculating the gas at a rate of $200,000 \mathrm{CFM}\left(94 \mathrm{~m}^{3} / \mathrm{s}\right)$. The aerosol removal efficiency ( 99 percent) is higher than required for a recirculating mode of operation. More information is required on the flow resistance as a function of loading, especially for high humidity atmospheres.

- System Reliability - The sand bed filter system is highly reliable. The only moving parts are the recirculating fans. The system is not degraded by long periods of unuse or operation at accident conditions.

- Containment Compatibility - The system rates poor on criteria related to containment compatibility. It is very large, requiring 500,000 $\mathrm{ft}^{3}$ $\left(14,000 \mathrm{~m}^{3}\right)$ of space and $50,000 \mathrm{ft}^{2}\left(4650 \mathrm{~m}^{2}\right)$ of horizontal bed area. Maintaining the boundary of such a large volume to the same pressure and leakage standards as the main RCB would be difficult to assure.

- Technological Credibility - The system rates good on these criteria. Sand bed filters have been used in fuel reprocessing plant exhaust gas systems for many years. In-place testing is possible and scaleup does not create a credibility problem. However, only small-scale testing has been performed under simulated LMFBR accident conditions(27), and no sand or gravel bed filters have been used in a recirculating mode. 
- System Characteristics and Flexibility - The sand bed filter can handle the full spectrum of aerosol particle sizes and containment environmental conditions expected. The system can be adapted to add halogen removal, hydrogen recombiner and containment cooling features. However, the energy consumption is fairly high (670 kW).

- Fabrication Effort - The system components and materials are available, although a local supply of properly graded and sized sand and gravel might not be available. The system initial cost is high (\$13.8 million) but operating costs are low.

- Conclusions (SR-3) - Although the sand bed system scores second highest of the 20 systems (338) and has many good features, it fails the mandatory criterion $3 c$ on size. It is judged to be impractical for use in the recirculating mode because of $i$ ts large size and potential reduction in containment leak tightness.

\subsubsection{Recirculating - Cyclone Separator (SR-5).}

- System Description - This system would use a bank of high efficiency cyclone separators located in a room adjacent to the RCB. Five loops with one fan and ten cyclones in parallel are provided for each loop. The collected particles would be held in the cyclone dust hoppers. The major conclusions from the rating of the preliminary design are summarized below for each criteria group.

- System Effectiveness - Cyclones are simple, rugged air cleaning devices commonly used in industry for removal of large sized particles. Since they depend on inertial effects for removal, they are inefficient for small particle removal. A range of removal characteristics is possible depending on the cyclone design. Typical removals for two rather extreme designs (taken from Reference 63) are shown in Figure 25. The upper curve was used in the design of system SR-5. This performance is probably about the best that could be expected for a large scale cyclone system.

A 2-hr DRF of 10 can be obtained for the DBST aerosol size (AED = $1.4 \mu \mathrm{m}, \sigma_{g}=2.0, \rho=1.0$ ) using these high efficiency cyclones if 
the flow rate is 460,000 CFM $\left(217 \mathrm{~m}^{3} / \mathrm{s}\right)$. This high flow rate is needed to overcome the low average removal efficiency of 40 percent and has obvious penalties for equipment size and power needs.

Sticky particles may tend to deposit at the cyclone inlet, but the large size chosen combined with the high inlet velocity should minimize this problem. The collected dust will fall to the bottom of the cyclone hoppers or stick to the rather large cyclone wall surfaces. The radiation field and FP decay heat will not have any appreciable effect on the operation or effectiveness of the system.

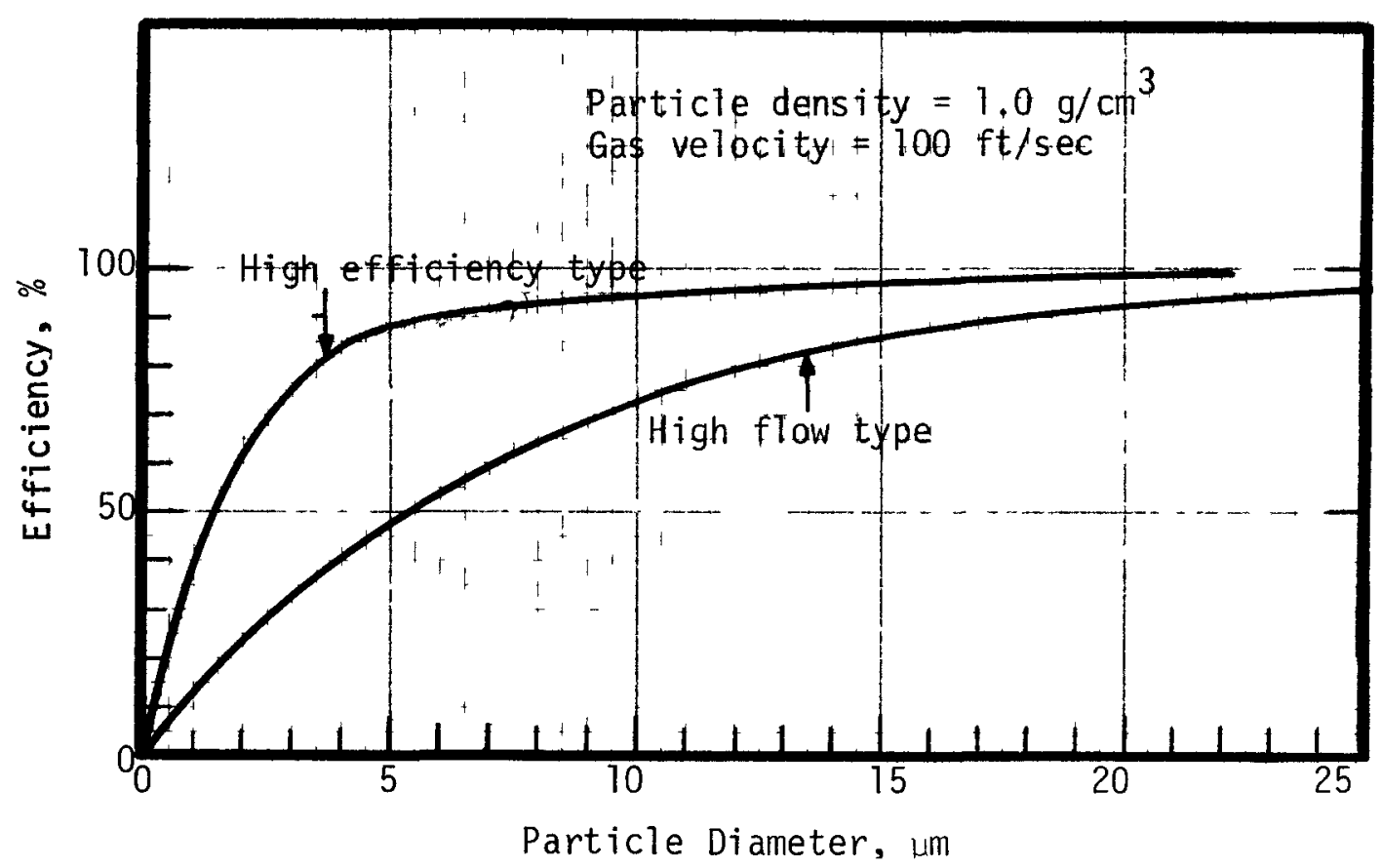

FIGURE 25. Cyclone Particle Removal Efficiency as a Function of Particle Size.

- System Reliability - Cyclone systems are very simple, needing only a fan and motor to provide the air motion, hence the starting and operating reliability is high. The particle removal efficiency is not very dependent on gas pressure, temperature or humidity, and very high mass loadings can be attained. 
- Containment Compatibility - Operation of the cyclone system or inadvertent operation will not degrade or harm personnel or equipment in any manner. No energy sources except the fan motors are present. A disadvantage is the large number of units needed for the required air flow. To house such a large battery of cyclones and the associated fans and ductwork an addition to the RCB similar to, but smaller than, that used for system SR-1 would be needed.

- Technological Credibility - The performance of cyclones of standard proportions has been determined $(19,63)$ and is predictable. $(20)$ The long-time industrial experience with cyclones of the sizes needed, combined with the ability to perform in-place testing of the system performance, leads to good scores for technological credibility.

- System Characteristics and Flexibility - In this rating group the major shortcoming of cyciones is the poor removal efficiency obtained with small particles. The performance of the system is very dependent on particle size and density. Other aspects of the system receiving low ratings are the need for additional particle cleanup before installing halogen or hydrogen recombiners downstream of the cyclone and the significant fan motor energy needed because of the large air flows.

- Fabrication Effort - The cost for the cyclone system, including containment quality building space is $\$ 6.0$ million, and materials and components are readily available.

- Conclusion (SR-5). In general, the cyclone has many desirable characteristics, including simplicity, high loading capacity, good reliability, and tolerance of the accident environment. Serious shortcomings are the poor removal of small particles and the large power requirements. The overall rating is 324 , fifth highest of the 20 systems studied.

\subsubsection{Recirculating - Cyclone Separator Plus Filter (SR-6).}

- System Description - This system combines a cyclone precleaner with a HEPA filter backup. Four recirculating loops are provided with $5 \mathrm{cy}$ clones and 220 HEPA filters per loop. The air flow rate is 48,000 CFM $\left(23 \mathrm{~m}^{3} / \mathrm{s}\right)$ per loop, or $192,000 \mathrm{CFM}\left(90 \mathrm{~m}^{3} / \mathrm{s}\right)$ total. The cyclones are 
of the same type used in system SR-5 and operate at 40 percent particle removal efficiency for the DBST conditions. The 60 percent penetration of the cyclones causes the filters to be loaded at $3.01 \mathrm{~b}$ $(14 \mathrm{~kg})$ per filter unit $(2 \mathrm{ft} \times 2 \mathrm{ft} \times 1 \mathrm{ft})$, which is 75 percent of the loading capacity used in the SR-1 filter system design. The pressure drop across the cyclones is 12 in. $\mathrm{H}_{2} \mathrm{O}(3000 \mathrm{~Pa})$; across the filters it is $10 \mathrm{in} . \mathrm{H}_{2} \mathrm{O}(2500 \mathrm{~Pa})$ fully loaded. The fans require $1100 \mathrm{HP}$ $(820 \mathrm{~kW})$ total power. All of the equipment is located in a building adjacent to the RCB, similar to the arrangement used in system SR-2. The building is a horizontal cylinder $40 \mathrm{ft}(12 \mathrm{~m})$ diameter by $150 \mathrm{ft}$ $(46 \mathrm{~m})$ long and is designed to the same containment specifications as the RCB.

- Conclusions (SR-6) - The purpose of adding a filter system as a backup to the cyclone was to eliminate the dependence on aerosol particle size. This is only partially accomplished, because the filters will become plugged if the cyclone efficiency drops below 20 percent. Figure 25 shows that the cyclones are 20 percent efficient for $0.5 \mu \mathrm{m}$ AED particles. It seems likely that any major accident having a maximum radiological impact would involve particles much larger than this and with higher density. For example, $0.5 \mu \mathrm{m}$ diameter fuel particles $(\rho=11)$ have an aerodynamic equivalent diameter (AED) of $1.65 \mu \mathrm{m}$, for which the cyclones are 65 percent efficient. If sodium accompanies the fuel and fission product particles, as assumed for the DBST, the particle sizes should be increased. Therefore, the SR- 6 combination system appears to be self-balancing. For high aerosol mass concentrations in the RCB the cyclone efficiency is high and a large fraction of the mass is collected in the cyclones. For accidents involving lower aerosol mass concentrations, the cyclone efficiency is decreased but a lower total mass penetrates to the filters.

System SR- 6 rates high (328), being third among the 20 systems studied. The fact that it does not rate even higher above the cyclone system (SR-5, score 324$)$ is due to the higher cost $(\$ 6.8 \mathrm{million})$ and added complexity. The validity of this high rating depends strongly on the values for cyclone 
efficiency and filter loading capacity used. These need to be confirmed by development testing, with relative humidity (sticky particles) as a parameter. The strong points of this system are its high reliability and insensitivity to particle size. A two-hour DRF of 10.1 is calculated for the postulated DBST.

\subsubsection{Recirculating - Wet Scrubber, Demister (SR-7).}

- System Description - Four loops recirculate air at a rate of $70,000 \mathrm{CFM}\left(33 \mathrm{~m}^{3} / \mathrm{s}\right)$ through two venturi scrubber-cyclone demister units in each loop. The scrubbing liquid, dilute aqueous sodium borate solution, is recirculated at $200 \mathrm{gpm}$ (760 //min) per venturi. The fans and liquid system are located exterior to the RCB in a low leakage building meeting the same containment criteria as the RCB.

- System Effectiveness - The calculated overall particle removal efficiency is 70 percent for the DBST conditions, which provides a 2-hr DRF of 10.5. Actual performance is expected to exceed this due to particle growth by moisture addition. Decay heat is removed by water-cooled heat exchangers in the water recirculating system. The system handles dry or sticky particles equally well.

- System Reliability - The reliability of system SR-7 was rated about the average of all the systems studied. It ranked low (but acceptable) in criterion $2 a$ for startup reliability due to the complexity of valving and pumps for the liquid system.

- Containment Compatibility - This system fails mandatory criterion 3b which states that operation of the EACS shall not increase the pressure within the RCB. A water scrubber system can potentially increase the pressure in two ways: by the partial pressure of water vapor and by the formation of $\mathrm{H}_{2}$ by reaction of water vapor with sodium which may be released during the accident. A significant quantity of water may be released from concrete surfaces within the RCB, but the engineered safety feature should not add to the potential problem. If a suitable nonvolatile liquid other than water can be identified, this drawback could be overcome and a net gain could be accomplished by cooling the atmosphere by cold scrubber liquid. 
- Technological Credibility - The system rates high in all credibility criteria.

- System Characteristics and Flexibility - The system rates high in all aspects of this criteria group except dependence on particle size. Its efficiency for submicron particles is $<50$ percent, although higher efficiencies can be obtained at the expense of higher pressure drop and higher water rates. It rates very high for ability to handle large aerosol mass loadings.

- Fabrication Effort - Al1 system SR-7 components and materials are readily available. The initial cost ( $\$ 8.7$ million) is slightly above the average for all the systems studied.

- Conclusions (SR-7) - The system is disqualified because of potential pressure and $\mathrm{H}_{2}$ buildup in the $\mathrm{RCB}$ atmosphere. If a suitable nonvolatile liquid could be identified, the system would rate favorably.

\subsubsection{Recirculating - Fluidized Bed (SR-8).}

- System Description - Four loops recirculate air at a rate of 50,000 CFM $\left(24 \mathrm{~m}^{3} / \mathrm{s}\right)$ through one fluidized bed in each loop. Each fluidized bed has a nominat $2000 \mathrm{ft}^{2}\left(185 \mathrm{~m}^{2}\right)$ bed surface area and the bed is 30 inches $(0.76 \mathrm{~m})$ deep when settled. The beds are composed of $400-\mu \mathrm{m}$ diameter beads of activated $\mathrm{Al}_{2} \mathrm{O}_{3}$. The fans are rated at sufficient head to initiate and maintain fluidization. All equipment is located in a lowleakage building exterior to the RCB which meets the same containment criteria as the RCB.

- Conclusions (SR-8) - The fluidized bed system rates high in effectiveness but low in all other criteria categories. Its overall rating is 273. It fails mandatory criterion $2 d$ for dependable operation over the required time period because of potential plugging at the inlet support screen. It has a very high initial cost (\$16.1 mil1ion) and offers no outstanding advantage over other systems. The one potential advantage of very high aerosol mass loading capacity in the bed (10-100 times greater than sand bed) is negated by plugging problems with the bed inlet support screen. 


\subsubsection{Recirculating - Acoustic Agglomerator, Cyclone (SR-9).}

- System Description - Four loops recirculate air at a rate of 50,000 CFM $\left(24 \mathrm{~m}^{3} / \mathrm{s}\right)$ through one agglomerator chamber and two cyclones in parallel for each loop. Each agglomerator chamber has two sirens capable of producing $100 \mathrm{erg}$ of acoustic energy per $\mathrm{cm}^{3}$ of gas treated. Gas residence time in the agglomerator chamber is 4 seconds, which is sufficient to agglomerate the particles to a size where the cyclones are 90 percent efficient ( $>10 \mu \mathrm{m}$ AED).

- Conclusions (SR-9) - This system has the disadvantages common to all recirculating systems of large size and cost and, in addition, rates low in the technological credibility criteria because of the unproven acoustic agglomeration feature. However, if development testing and analyses should confirm the effectiveness of the acoustic process, the latter shortcoming would be eliminated and the system would be attractive because of its high mass loading capability. Suitable sirens are not in standard industrial supply and would likely have to be custom fabricated. The overall rating is 306 , tenth highest of the 20 candidate systems. The cost is $\$ 8.7$ million.

\subsubsection{Recirculating - Mechanical Separator, HEPA Filter (SR-10).}

- System Description - Four loops recirculate air at 50,000 CFM (24 $\left.\mathrm{m}^{3} / \mathrm{s}\right)$ through two mechanical centrifugal separators and 60 HEPA filters per loop. The mechanical separators are of the dry centrifugal impeller type, which provide the motive force for gas recirculation. Efficiencies of 88 percent for $1.7 \mu \mathrm{m}$ AED particles have been reported ${ }^{(17)}$, but the SR-10 design is based on 80 percent efficiency. The HEPA filters are rated at $0.9 \mathrm{lb}(0.4 \mathrm{~kg})$ per unit loading at 10 inches $\mathrm{H}_{2} \mathrm{O}(2500 \mathrm{~Pa})$. All equipment is located in a rectangular cell adjacent to the RCB which has the same containment criteria as the RCB.

- Conclusions (SR-10) - The mechanical separator-HEPA system is disqualified by failure of two mandatory criteria: $1 c$, ability to handle sticky particles, and 2d, capability of performance during entire accident period. The latter deficiency arises due to 
the possibility of plugging of the impeller dust outlet. It also rates low on criterion $5 \mathrm{a}$, dependence on particle size. Its overall rating is 293 . The cost estimate is $\$ 6.6$ million.

\subsubsection{Recirculating - Settling Chamber, HEPA (SR-11).}

- System Description - Four loops recirculate air at 50,000 CFM $\left(24 \mathrm{~m}^{3} / \mathrm{s}\right)$ each through a settling chamber and 160 HEPA filter units per loop. Each settling chamber is $60 \mathrm{ft} \times 50 \mathrm{ft} \times 36 \mathrm{ft}(18 \mathrm{~m} \times 15 \mathrm{~m} \times 11 \mathrm{~m})$ and contains 100 shelves with 4 -inch $\left(100 \mathrm{~mm}\right.$ ) spacing, giving $300,000 \mathrm{ft}^{2}$ $\left(28,000 \mathrm{~m}^{2}\right)$ of horizontal surface. The settling chamber is 50 percent efficient for removal of the DBST aerosol particles $(1.4 \mu \mathrm{m}$ AED, $\sigma \mathrm{g}=2)$. A11 of the equipment and the settling chambers are located within a $114 \mathrm{ft} \times 230 \mathrm{ft} \times 40 \mathrm{ft}(35 \mathrm{~m} \times 70 \mathrm{~m} \times 12 \mathrm{~m})$ room adjacent to the RCB, designed to containment specifications.

- Conclusions (SR-11) - This system is not acceptable because of its very large space requirement $\left(1 \times 10^{6} \mathrm{ft}^{3}\right)$ or $28,000 \mathrm{~m}^{3}$ and cost (\$19.0 million). It also rates low on credibility and flexibility. Its overall rating is 304,12 th among the 20 systems studied.

\subsubsection{Recirculating - Steam Conditioner, Demister (SR-13).}

- System Description - Four loops recirculate air at 50,000 CFM $\left(24 \mathrm{~m}^{3} / \mathrm{s}\right)$ each through one heat exchanger and two Brink fibrous demisters $(64,65)$ per loop. Steam is released slowly through throttling valves from two 3000 -gallon $\left(11 \mathrm{~m}^{3}\right)$ high-temperature water storage tanks and blended with the dirty air upstream of the vertical heat exchangers. Some of the entrained water ( $\mathrm{NaOH}$ solution) is removed in a settling drum at the heat exchanger outlet, and the air with the remaining wet aerosol is sent to the high efficiency demisters (98 percent particle removal efficiency $\left.{ }^{(65)}\right)$. All of the equipment is located within a cylindrical building, $75 \mathrm{ft}(23 \mathrm{~m})$ diameter by $50 \mathrm{ft}(15 \mathrm{~m})$ high, which is designed to containment specifications.

- Conclusions (SR-13) - This system is unacceptable for the same reasons as the wet scrubber system (SR-7). Pressure increase by the partial pressure of water and potential $\mathrm{H}_{2}$ generation cause the 
system to fail mandatory criterion $2 b$. It also rates unacceptable for criteria $2 e$ (complexity), $4 a$ (undeveloped technology) and $6 a$ (high cost - $\$ 12.6$ million). Its favorable performance attributes include independence of particle size and stickiness and insensitivity to the atmosphere environmental conditions. The overall rating is 277 , which ranks 17 th among the 20 candidates.

7.1.7.10 Direct Application - Liquid Sprays (SD-14).

- System Description - This system is similar to the containment spray systems used in many current LWR plants for the purpose of cooling the containment atmosphere and scrubbing fission products from the RCB atmosphere. Fresh dilute sodium borate solution is stored in a 60,000 -gallon $\left(230 \mathrm{~m}^{3}\right)$ tank in the service building. Two identical but separate pumping systems, lines and spray headers are provided. After the fresh spray solution has been injected at a total rate of $3000 \mathrm{gpm}(190 \mathrm{l} / \mathrm{s})$, recirculating pumps are valved in and the fresh spray line is valved off. The recirculating pumps and heat exchangers are located in a cell adjacent to the sump at the low point of the RCB. Strainers are provided to prevent plugging of the spray nozzles. Hollow cone spray nozzles located near the RCB roof produce $700 \mu \mathrm{m}$ MMD drops with a minimum fall distance of $100 \mathrm{ft}(30 \mathrm{~m})$.

The choice of the spray liquid used is of paramount importance to the suitability of this system as an EACS in a LMFBR plant. After considering various types of liquids (aqueous, silicone oil, hydrocarbons, Dowtherm, molten metals, molten salt) it was concluded that there is no liquid known at this time which is satisfactory for this use. However, in order to determine the merit of a liquid spray system if a suitable liquid could be identified, system SD-14 was designed with aqueous sodium borate as the spray liquid. The sodium borate has no influence on the aerosol removal process and is added only to assure subcriticality in the RCB sump or other places where fuel particles could accumulate.

- System Effectiveness - The spray system is very effective in removing the DBST aerosol, with a 2-hr DRF of 14 being calculated for the 
conditions specified. It can handle sticky particles and decay heat very satisfactorily.

- System Reliability - The system ranked about average for reliability, with its weakest point being the possibility of nozzle plugging during recirculation. The nozzles are of the hollow cone type with orifices greater than 0.25 inch $(6.4 \mathrm{~mm})$, so proper strainers should minimize this potential problem.

- Containment Compatibility - The system rated nearly last among the 20 candidates for compatibility with the RCB environment. This is due to the use of water as the spray liquid. If a nonreactive, nonvolatile liquid were used, this rating would increase significantly, but would still be downgraded because of the possible damage due to inadvertent operation.

- Technological Credibility - The system ranks about average for credibility. It cannot be completely tested in-place for operability and effectiveness. However, the fact that similar systems are provided for LWR plants gives credence to this system.

- System Characteristics and Flexibility - The spray system has both good and bad features for flexibility of performance. Its efficiency for particle removal is sensitive to particle size. However, a 2-hr DRF of 6 can be achieved even with $1 \mu \mathrm{m}$ diameter particles $(\rho=0.7)$. The system is not sensitive to the RCB environmental conditions and, in fact, cools the containment atmosphere to $2120^{\circ} \mathrm{F}$ $\left(50^{\circ} \mathrm{C}\right)$. It is not directly adaptable to hydrogen recombination or rapid organic iodide removal, but is excellent for rapid removal of elemental iodine and long-term removal of organic iodides. $(50)$

- Fabrication Effort - This system rates good for fabrication effort. The initial cost is estimated at $\$ 4.4$ million, fifth lowest of the 20 systems studied. All materials and components are readily available (except a suitable spray liquid).

- Conclusions (SD-14) - Although the liquid spray system has many good features, it is unacceptable for use in LMFBR plants because water 
spray liquid has the potential for $\mathrm{H}_{2}$ formation and a suitable alternate liquid is not known at this time. Its score is 297.

7.1.7.11 Direct Application - Foam Dispersal (SD-16).

- System Description - Water and foaming agents are stored in tanks outside the RCB. Upon activation, the two liquids are blended into a pipeline leading to a fan on the RCB floor (or sub-floor) where it is injected into the fan intake. The fan takes dirty air from near the RCB ceiling at 50,000 CFM $\left(24 \mathrm{~m}^{3} / \mathrm{s}\right)$ and discharges the airfoam mixture onto the RCB floor. Two redundant systems provide a total air flow of 100,000 CFM $\left(48 \mathrm{~m}^{3} / \mathrm{s}\right)$ and the foam fills the containment gas space within a half hour. Aerosol particles diffuse or settle to the foam bubble surface within a few minutes. It is not necessary to maintain the foam after the RCB has been filled, since the particles will stay with the liquid produced by collapsing foam. Tests have been performed in the United Kingdom with sodium oxide aerosol using a rapid-collapse foam which show that soluble particles, at least, are not re-aerosolized. ${ }^{(66)}$ About 25,000 gallons (95 $\mathrm{m}^{3}$ ) of water are required.

- Conclusions (SD-16) - The foam system suffers from the same shortcomings as the wet scrubber and the liquid spray systems in that water is required, with its attendent $\mathrm{H}_{2}$ formation problem. This system is low cost ( $\$ 2.1$ million) and may be suitable for excontainment applications but is judged unacceptable for the proposed EACS use in LMFBR plants. Its overall rating is 238 , lowest of all 20 systems studied.

\subsubsection{Direct In-Containment Electrostatic Precipitator (SD-18).}

- System Description - This system is one in which an electrostatic precipitator is formed by placing an open grid of corona wires spaced about 6 inches $(150 \mathrm{~mm})$ from the inner wall of the RCB. It is an attempt to combine the advantages of direct-acting air cleaning in containment with electrostatic particle removal. Its effectiveness depends upon aerosol particles being carried past the RCB walls by 
natural convection currents induced by the accident energetics, charged by the corona at the wire grid and caused to migrate to the collecting surfaces by the impressed voltage gradient. The removal efficiency for particles depends on the particle charge, the voltage gradient, the air velocity, the electrode spacing and the wall contact length. A11 of these can be defined except the air velocity and contact length; both depend on the temperature differences and the flow characteristics of the atmosphere, and both are essential to predicting the system particle removal efficiency.

- Conclusions (SD-18) - It was concluded that convection velocities of the magnitude expected during the accident ( $200 \mathrm{ft} / \mathrm{min}$ or $1.0 \mathrm{~m} / \mathrm{s}$ ) would be unable to provide an assured 2-hr DRF of 10. For example, at an average convection velocity of $200 \mathrm{ft} / \mathrm{min}$ in the gas space between the corona wires and the wall and a particle removal efficiency of 70 percent, a 2-hr DRF of 2.2 is calculated. Although some improvement on efficiency and amount of wall surface used can be made, it is unlikely that a 2-hr DRF of 10 could be assured. Therefore, this system fails mandatory criterion la for effectiveness. In addition, the lack of a demonstrated technology leads to low scores in criterion groups 1,2, 4 and 5 . An overall rating of 225 was determined for this system, second lowest of the 20 systems studied.

7.1.7.13 Combination - Containment Acoustic Agglomeration Plus Recirculating Cyclone (SC-19).

- System Description - This system uses cyclones similar to those in system SR-5 in combination with the acoustic agglomerators of system SD-17. In the event that system SD-17 cannot provide particle growth to a size large enough for in-containment gravitational settling to be an effective air cleaning method, then the addition of cyclones may offer advantages. Cyclones such as used in system SR-5 would have an efficiency of $>90$ percent for aerosol particles $10 \mu \mathrm{m}$ in diameter $(8.7 \mu \mathrm{m}$ AED). This particle size is much smaller (and probably more obtainable) than the 50-100 $\mu \mathrm{m}$ diameter size range assumed for system SD-17, and is a more favorable size for use with cyclones than the natural DBST particle size (1.4 $\mu \mathrm{m} \mathrm{AED).}$ 
Such a combination system would require an acoustic system identical to that used in system SD-17 plus the recirculation of 200,000 CFM $\left(94 \mathrm{~m}^{3} / \mathrm{s}\right)$ of RCB air through twenty cyclones. All of the recirculation system equipment would be housed in an attachment to the containment building similar to, but smaller than, that needed for system SR-5.

- Conclusions (SC-19) - This system has an overall score of 305 and ranks 11 th among the 20 systems studied. It rates high in the effectiveness and reliability criteria groups and low in the containment compatability and technological credibility groups. Addition of the recirculating cyclone system provides a means of benefiting from acoustic agglomeration processes in the event that only moderate particle growth is attained by the acoustic system. The cyclones are inherentiy simple and reliable but they are bulky and their performance is dependent on the particle size. Figure 25 shows, however, that any particle size greater than $4 \mu \mathrm{m}$ AED can be effectively removed with a high efficiency type of cyclone. An important unknown at this time is, of course, the extent of particle agglomeration that can be provided by an acoustic system. The cost is $\$ 7.0$ million.

\subsubsection{Combination - Containment Powder Discharge plus} Recirculating Filter (SC-20).

- System Description - A powder discharge system identical to system SD-15 is provided. In addition, a recirculating system is provided similar to SR-1, except only 200 prefilters and 200 HEPA filters are provided in a 4-10op system. The total air recirculation rate is $200,000 \mathrm{CFM}\left(94 \mathrm{~m}^{3} / \mathrm{s}\right)$.

- Conclusions (SC-20) - The advantages of the two-system combination are that its effectiveness is independent of aerosol particle size, it is capable of rapidly removing the aerosol particles (large DRF) and at the same time can operate efficiently for long periods of time. However, its greater complexity reduces its reliability and doubles the cost over a powder system alone (to $\$ 7.8 \mathrm{million}$ ). Although its numerical rating is low (289), it would be greatly improved if development testing should show that powder systems are effective but that a supplemental long-term cleanup system is required. 


\subsection{EACS for Double Containment Plants}

If a sealed inner containment barrier surrounding the entire primary sodium system (including the head area) is provided in addition to the outer low-leakage RCB, the benefit of an EACS is greatly diminished. Table 9 shows that very low masses of plutonium are leaked from a double containment plant even without an EACS. Caution should be used in making conclusions from the data of Table 9, however, because the plutonium leakage depends strongly on the assumed plant design characteristics, especially the gas leakage rate from inner to outer containment. The table also shows that considerably more benefit is achieved by an EACS for the 30-day dose than for the 2-hr dose. This is true because of the assumption that gas leakage continues indefinitely at the design leakage rates. If leakage is related to differential pressure, the 30-day dose would probably be much lower than shown in Table 9.

In any event, if it should be found advantageous to install an EACS in a double containment plant, the EACS performance would probably not be as demanding as for the single containment plant. For example, an EACS with an exponential removal coefficient, $\lambda$, of $2-h r^{-1}$ was used to provide the data in Table 9, while $5-\mathrm{hr}^{-1}$ was used for the single containment plant. The particle size is much larger for the double containment plant $(5 \mu \mathrm{m}$ MMD versus $1.7 \mu \mathrm{m}$ MMD) because of the large agglomeration occurring within the smal1 inner containment before the aerosol leaks to the outer RCB. The mass loading on the EACS is very small (2 $\mathrm{lb}$ or $1 \mathrm{~kg}$ ), and environmental conditions in the RCB are much milder for the double containment plant accident case.

A complete evaluation of EACS candidates for a double containment plant was not made because most of the discussions for the single containment plant apply. The low aerosol mass concentration probably el iminates the acoustic system, and the low EACS mass loading eliminates the need for high mass loading systems such as cyclones and deep bed graded media filters unless a concurrent sodium fire is postulated. A conventioanl prefilter-HEPA filter system with a total recirculation rate of $75,000 \mathrm{CFM}\left(35 \mathrm{~m}^{3} / \mathrm{s}\right)$ would be very adequate. Because the aerosol mass loading is insignificant, the number of filters can be reduced to 72 standard ( $2 \mathrm{ft} \times 2 \mathrm{ft} \times 1 \mathrm{ft}$ ) units, and the cost is lowered to $\$ 2.7$ million compared to $\$ 7.7$ million for the SR-1 system designed for single containment plant requirements. 


\subsection{EACS for Containment/Confinement Plants}

Four air cleaning systems were evaluated for use in containment/confinement plants. Schematic diagrams of these four systems are shown in Figure 26. The final three cleanup devices are the same for all four plants; the difference in the systems arises in the first stage removal device which traps the bulk of the aerosol mass.

In system CF-21, the prefilter was required to trap only the smal1 aerosol mass associated with the DBA as described in Section 4.0 of this report. Indeed, if no sodium fire occurs, EACS requirements for the containment/confinement plants are modest, and presently available filter-adsorber systems appear to be fully adequate. In some plants, however, postulated sodium fires may serve as an alternate design basis accident for emergency air cleaning systems not associated with an HCDA. In order to evaluate an EACS which would handle both the HCDA and sodium fire accidents, a design basis fire in the confinement building involving a spill of $8000 \mathrm{lb}(3600 \mathrm{~kg})$ of hot sodium onto a $100 \mathrm{ft}^{2}\left(93 \mathrm{~m}^{2}\right)$ surface was postulated in addition to the HCDA. It is assumed that the two accidents do not occur simultaneously.

A major difference in EACS requirements for confinement building ventilation as compared to recirculating systems in single containments is that very high efficiency is required because the exhaust is discharged to the environs. However, the air flow rate for the confinement building is less than 10 percent of that required for recirculating systems in single containments. As a result, the confinement building EACS systems are much smaller and less expensive.

The air flow rate required in the confinement building ventilation exhaust is just equal to the value of inflow required to prevent leakage of unfiltered air to the atmosphere. The minimum air flow is a design parameter for the confinement building itself, and reflects considerations of the following factors:

- pressure differential from wind flowing over building

- changes in external or internal air temperatures

- changes in barometric pressure 


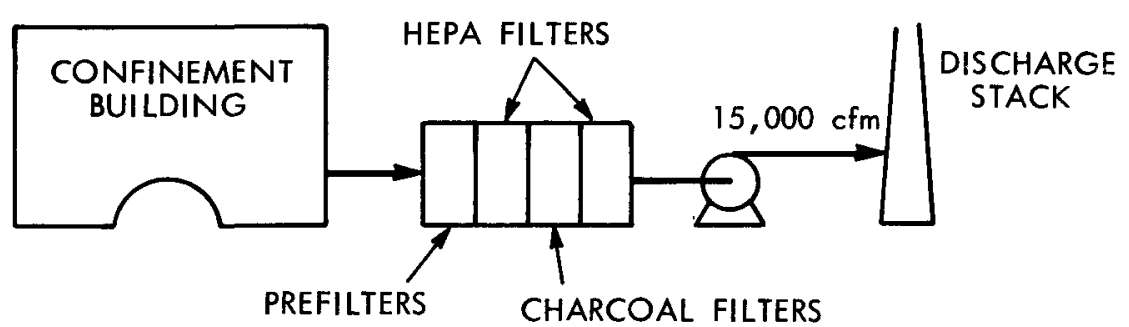

SYSTEM CF-21. PREFILTER, HEPA, CHARCOAL, HEPA

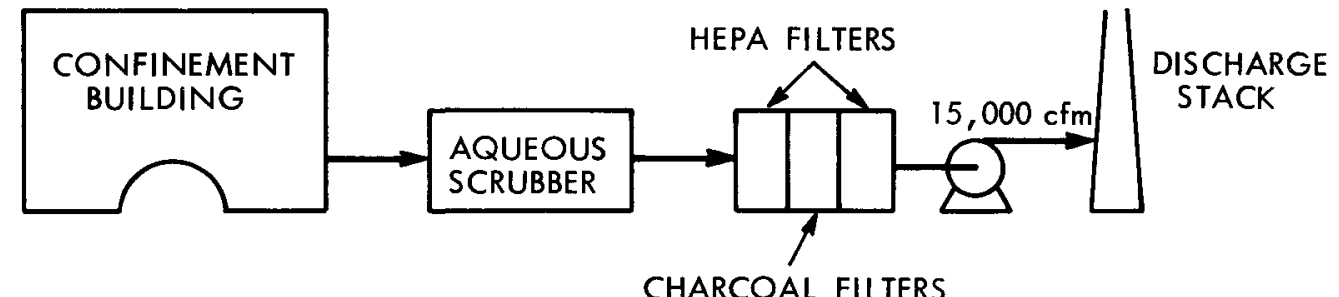

SYSTEM CF-22. SCRUBBER, HEPA, CHARCOAL, HEPA

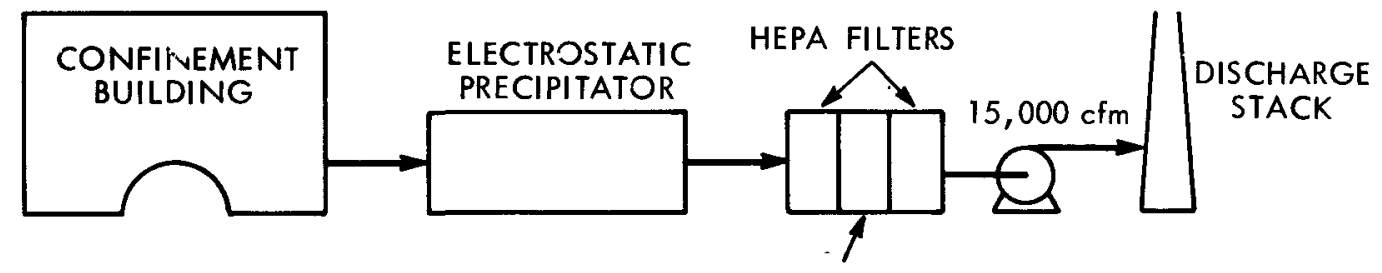

CHARCOAL FILTERS

SYSTEM CF-23. ELECTROSTATIC PRECIPITATOR, HEPA, CHARCOAL, HEPA

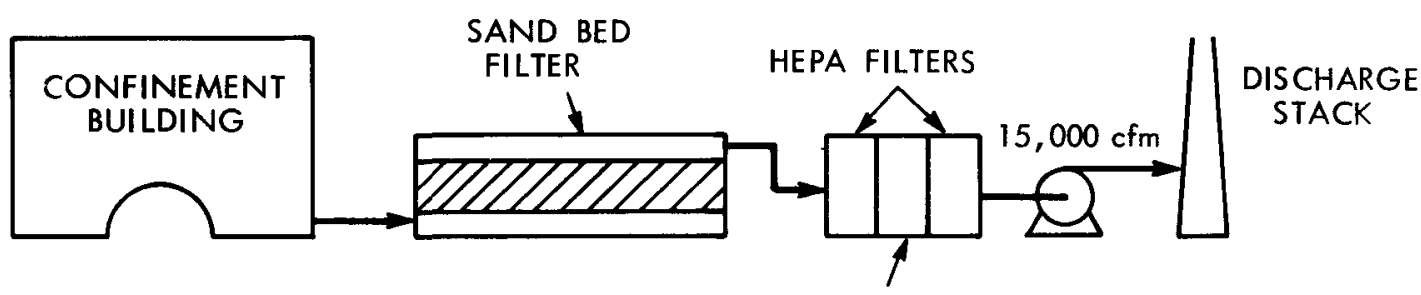

CHARCOAL FILTERS

FIGURE 26. Schematic Diagrams for Containment/Confinement Air Cleaning Systems Evaluated. (Photo No. 7510410-2) 
- gas released to confinement building during an accident

- size and location of effective leak paths in building walls and ducts.

After an accident signal is received by the control room, normal ventilation is shut down, and all major ducts and openings are closed. Startup of the EACS would lower building internal pressure compared to the outside atmosphere, causing all air leakage to be from the outside atmosphere into the containment building. The selected air flow rate, 15,000 CFM, $\left(7 \mathrm{~m}^{3} / \mathrm{s}\right)$, was obtained by rounding upward the value obtained from analysis of a conceptual design provided by the General Electric Company.

Two systems, CF-22 and CF-24, were analyzed in detail, and the other two were evaluated in a more cursory way. System CF-22 was selected because it uses an aqueous scrubber, a device not reported in detail for the single containment plant, and because the train of removal equipment appears to be feasible. System CF-24 was selected for detailed evaluation because it uses a sand bed filter which appeared to have favorable characteristics for single containment application as well as application to the confinement system. The two systems not described in detail are rated and discussed in Section 7.3.3 of this report.

Noble gas removal capability was not a design objective for the confinement EACS. However, removal of all other fission products and plutonium was a prime design objective.

\subsubsection{Scrubber - Demister, HEPA, Charcoal, HEPA (CF-22)}

7.3.1.1 Background. This air cleaning system is designed to exhaust a confinement building at an air flow high enough to ensure that all air leakage from the buildng goes through the air cleaning system. Two kinds of accidents may be postulated for the plant, and in order to avoid the need for two separate air cleaning systems, the system is designed to accommodate both. One postulated accident, involving a release through the reactor vessel head, requires a relatively high removal efficiency (99 percent), but involves the trapping of only very small aerosol masses. The other accident involves a large sodium fire in the confinement building, 
where very large masses of aerosol must be removed. Because of the large aerosol mass associated with the fire, the size and performance of the scrubber is dictated by the fire incident rather than the HCDA.

While a great deal of information is available in the literature on scrubber technology $(17,19,67)$, very little information is available on the removal of sodium smoke by scrubbers. LeMar ${ }^{(33)}$ reported results of tests of a "Pease-Anthony" scrubber and a "Peabody" scrubber. Both of these scrubbers are of the venturi type. The efficiency of the Pease-Anthony scrubber for fumes produced from a NaK fire was measured for a $5000 \mathrm{CFM}\left(2.4 \mathrm{~m}^{3} / \mathrm{s}\right)$ unit. A removal efficiency of about 90 percent was deduced from upstream and downstream samples collected by an impinger. The Peabody scrubber was also tested, and based on the visual appearance of the outlet plume, it was concluded that its performance was comparable to the Pease-Anthony scrubber. The observed removal efficiency was appreciably lower than the efficiency quoted by the manufacturers .

Smith ${ }^{(68)}$ reported that similar type scrubbers are used at Argonne National Laboratory to capture sodium oxide smoke. The scrubbers are sized to handle the smoke produced by burning $50 \mathrm{lb}(23 \mathrm{~kg})$ of metal per hour. After installation, the measured efficiency of both scrubbers was in the range of 96 to 99 percent.

While these few tests indicate that scrubber removal efficiencies of 90 to 99 percent can be obtained for sodium oxide smoke, the performance in particular applications would depend on the particle size and therefore on the concentration and time allowed for coagulation. Because of the lack of extensive information specific to scrubbing of sodium oxide aerosols, it will be necessary to design scrubbers using correlations between removal efficiency and particle properties developed for other kinds of aerosols.

7.3.1.2 Design Parameters. Key parameters used to develop the design of the CF-22 scrubber-filter system are derived primarily from three sources. First, the size and leakage features of the confinement building determine the system flow rate required to maintain negative pressure. Also, the quantity of aerosol plated and settled as well as degree of particle 
agglomeration would depend on confinement building design. Second, the decontamination factor required of the scrubber-filter system depends primarily on the postulated source term. Third, the loading capacity of the filterscrubber system is directly related to the burning area and duration of the postulated sodium fire. Important parameters and assumptions are outlined in the following paragraphs.

- Scrubber Loading Capacity. The design basis fire for the air cleaning system results from a spill of $8000 \mathrm{lb}(3600 \mathrm{~kg})$ of sodium onto a $1000 \mathrm{ft}^{2}\left(93 \mathrm{~m}^{2}\right)$ area, burning for 1 hour. Based on a burning rate of $8 \mathrm{lb} \mathrm{Na} / \mathrm{hr}-\mathrm{ft}^{2}\left(39 \mathrm{~kg} / \mathrm{hr}-\mathrm{m}^{2}\right)$, a fraction aerosolized of 0.3 , and 50 percent of aerosolized mass settled in the confinement building, some $2100 \mathrm{lb}$ of aerosol (as $\mathrm{NaOH}$ ) will enter the scrubber. Aerosol generated by the sodium fire is expected to enter the scrubber as $\mathrm{NaOH}$ since excess water vapor will be present in inleaked air to convert all $\mathrm{Na}_{2} 0$ to $\mathrm{NaOH}$. Residence time of the aerosol in the confinement building averages 2 hours, giving ample time for conversion to the hydroxide. For the DBST, only 560 grams of material (mostly insoluble) is expected to be delivered to the EACS.

- Scrubber Inlet Temperature. Temperature of air in the confinement building was estimated from a simple model in which the heat of reaction of sodium to form sodium hydroxide was equated to the sensible heat gain of air in the confinement building and the heat absorbing steel structure. The maximum temperature was calculated to be $300^{\circ} \mathrm{F}\left(150^{\circ} \mathrm{C}\right)$, and this would occur at 1 hour. At longer times, temperatures would decay roughly exponentially to the outside air temperature with a half time of several hours. For the HCDA, little temperature rise would be expected and the scrubber inlet temperature would be about the same as the outdoor ambient temperature. The lowest outside ambient temperature was assumed to be $-10^{\circ} \mathrm{F}\left(-23^{\circ} \mathrm{C}\right)$.

- Flow Rate. The flow rate required to maintain a suitable negative pressure inside the confinement building was based on design studies 
of others. (10) A value of $15,000 \mathrm{CFM}\left(7 \mathrm{~m}^{3} / \mathrm{s}\right)$ was used in the present scope design, but it should be recognized that system design might alter this flow requirement by factors of 0.5 to 2.0 .

- Aerosol Particle Size. For the postulated design basis sodium fire, concentrated aerosols would be produced and would be retained inside the confinement building for time periods long enough to produce large agglomerates. By comparison with HAA-3 runs, a maximum aerosol concentration of $25 \mu \mathrm{g} / \mathrm{cm}^{3}$ is expected, and the mean particle diameter is expected to increase from one micron initially to 25 microns at 1 hour. However, for smaller fires and for the DBST, smaller particles may be expected. In order to eliminate particle size as a sensitive parameter, the system was designed to operate satisfactorily with $0.3 \mu \mathrm{m}$ aerodynamic equivalent diameter particles.

- Removal Efficiency Required for Airborne Materials. The design removal efficiency of the EACS is 99 percent for particles and halogens resulting from the DBST. For the sodium fire accident, an additional constraint is that the scrubber must reduce the airborne particle load enough so that the HEPA filters will not become plugged. Assuming an allowable HEPA filter loading of 4 1b per 2-ft by $2-f t$ unit $\left(49 \mathrm{~kg} / \mathrm{m}^{2}\right)$, the required scrubber efficiency is calculated to be 97 percent.

- Summary of Design Parameters. Design parameters used to develop the scope design of the confinement building scrubber-filter EACS (System CF-22) are summarized in Table 29.

\subsubsection{Conceptual Scope Design.}

- Schematic Diagram of Proposed System. A schematic diagram of the confinement building scrubber-filter EACS is shown in Figure 27.

- Description of Important System Components. This system exhausts air from the confinement building through cleanup devices prior to its discharge from a 100-meter stack. At the time of an incident, the normal ventilation system would be shut off and the normal air intake openings would be closed. Startup of the EACS would maintain 
TABLE 29

DESIGN PARAMETERS FOR SCRUBBER-FILTER SYSTEM (CF-22)

Parameter

Sodium Aerosol Loading

Core Material Aerosol Loading

Maximum Inlet Temperature

Minimum Inlet Temperature

Overall Efficiency for Halogens and Plutonium

Scrubber Efficiency for Sodium 0xide Smoke

Minimum Aerosol Aerodynamic Equivalent Diameter

Maximum Sodium Aerosol Concentration

Air Exhaust Flow Rate from Confinement Building

Exhaust Stack Height
Value Used

$2100 \mathrm{lb}(950 \mathrm{~kg})$ as $\mathrm{NaOH}$

$21 \mathrm{~b}(0.91 \mathrm{~kg})$

$300^{\circ} \mathrm{F}\left(150^{\circ} \mathrm{C}\right)$

$-10^{\circ} \mathrm{F}\left(-23^{\circ} \mathrm{C}\right)$

$99 \%$

$97 \%$

$0.3 \mu \mathrm{m}$

$25 \mathrm{og} / \mathrm{cm}^{3}$

15,000 CFM $\left(7 \mathrm{~m}^{3} / \mathrm{s}\right)$

100 meters

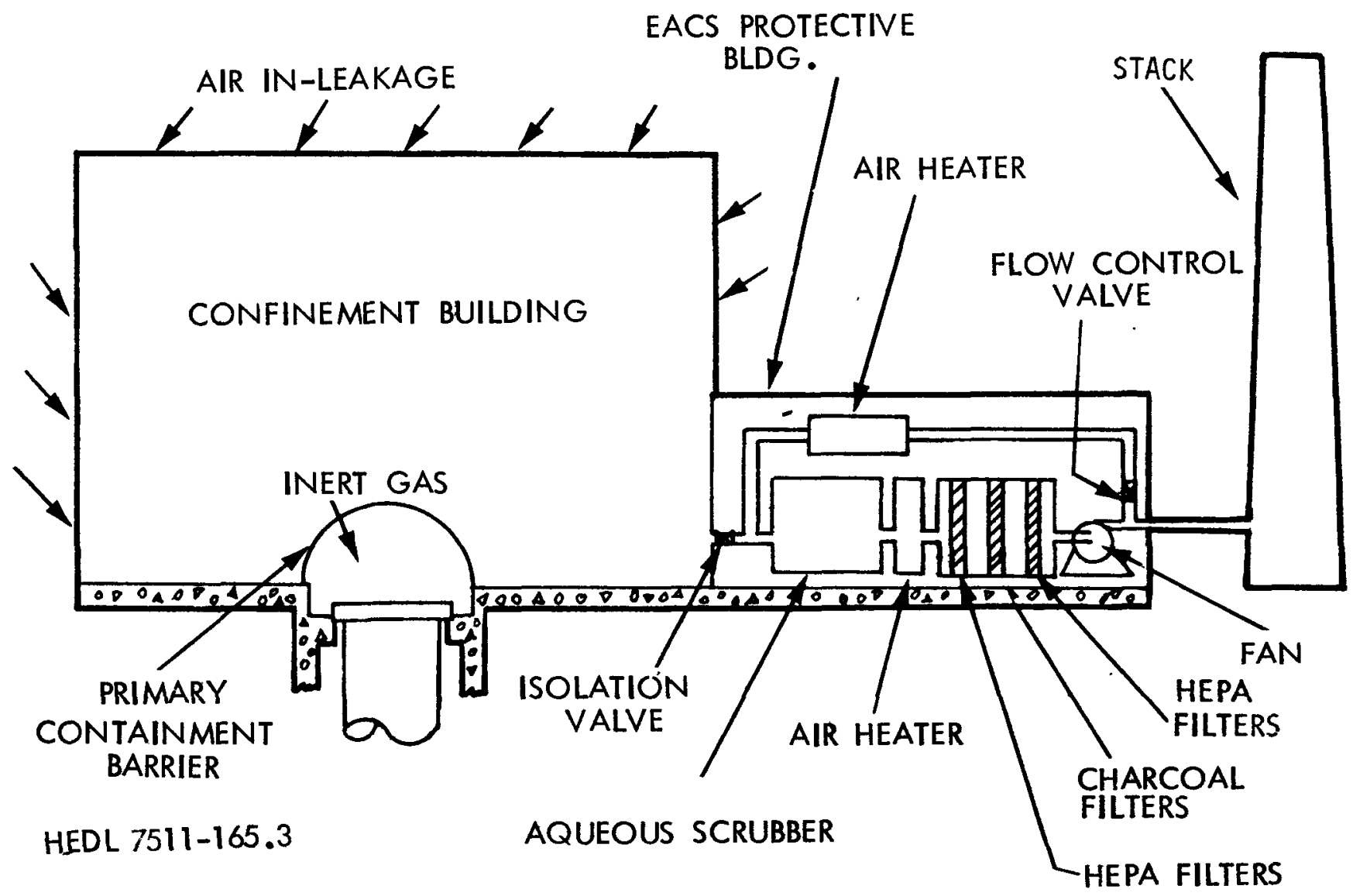

FIGURE 27. Schematic Diagram of Scrubber-Filter EACS for System CF-22. 
the building at a negative pressure. It was assumed that the heaters and coolers normally used in the confinement building were not available, and that the EACS would have to provide any heating and cooling required by the EACS. The scrubber is needed only because of the sodium fire accident, which would not occur concurrently with an HCDA. The first HEPA bank is provided to prevent potential fouling of the charcoal surface by aerosols penetrating the scrubber. The charcoal adsorber is provided to trap halogens, and the final HEPA filter bank prevents escape of charcoal powder which could carry entrained halogens from the system. The two HEPA filters in series provide aerosol decontamination factors (DF) much larger than required to attain the design DF of 100.

Discussion of the approach used to develop the scope design for this system and to size the most important components is provided in the following paragraphs.

- Aqueous Scrubber. Aqueous scrubbers usually employ inertial impaction to collect particles by water films and drops. They can be highly efficient for aerosol particles larger than a few microns, but typically become inefficient for particles smaller than $1 \mu \mathrm{m}$ in diameter. The most efficient types of scrubbers for small particles are venturi scrubbers, high velocity impingement scrubbers, and wetted fiber bed scrubbers. The design efficiency of 97 percent for $0.3 \mu \mathrm{m}$ particles eliminates venturi and impingement scrubbers from consideration because these scrubbers cannot practically achieve such high efficiencies for $0.3 \mathrm{\mu m}$ particles. Therefore, the irrigated packed fiber bed scrubbers appear to be the only choice available. It is probable that more detailed studies of required removal efficiency as a function of sodium smoke concentration and particle size would permit a lower removal efficiency for accidents involving small particle size, and such a relaxation in requirements would likely permit use of venturi scrubbers. Such a change would lower the cost and size of the scrubber compared to the wetted fiber scrubber system selected here. 
The scrubber flow rate is equal to the building exhaust rate plus the heated air recycle flow rate. For a minimum inlet temperature of $-10^{\circ} \mathrm{F}\left(-23^{\circ} \mathrm{C}\right), 2200 \mathrm{CFM}\left(1.0 \mathrm{~m}^{3} / \mathrm{s}\right)$ of air at $500^{\circ} \mathrm{F}\left(260^{\circ} \mathrm{C}\right)$ must be added, as shown in Figure 27 , resulting in a scrubber air flow rate of 17,200 CFM $\left(8.1 \mathrm{~m}^{3} / \mathrm{s}\right)$. Use of auxiliary heating would be necessary to prevent freezing of scrubbing liquid only for an accident which occurred on the coldest winter day, and at a time after the accident when the temperature in the confinement building had decayed to ambient.

Selection of fiber size, material, packing density, and air flow velocity was based on experimental tests with a wetted fiber bed demister reported by Postma. (65) The fiber bed scrubber design tested by Postma used polypropylene fibers of 20 microns diameter, packed at a density of $11.51 \mathrm{~b} / \mathrm{ft}^{3}\left(184 \mathrm{~kg} / \mathrm{m}^{3}\right)$ into a layer 3 inches $(76 \mathrm{~mm})$ thick. At an air velocity of $15 \mathrm{ft} / \mathrm{min}(0.08 \mathrm{~m} / \mathrm{s})$, the pressure drop across a clean bed was 5 in. $\mathrm{H}_{2} \mathrm{O}(1250 \mathrm{~Pa})$. The removal efficiency measured for $0.3 \mu \mathrm{m}$ uranine particles was 98 percent. This demister design is similar to fiber bed mist eliminators, whose performance is discussed by Brink. (64) The packed beds must be irrigated with water to dissolve deposited particles. The quantity of water required was calculated as 5 times that required to form a saturated solution of sodium carbonate. While reaction of the particles of sodium hydroxide with $\mathrm{CO}_{2}$ to form carbonate probably would not be complete, carbonate would require more water than hydroxide, hence the water application rate in this design was based on the lower solubility of sodium carbonate. In order to limit the amount of water applied to the packed bed, a spray scrubber section was provided in the lower part of the scrubber. The volume of the sump water was selected to insure that sodium carbonate concentration would not exceed 20 percent of saturation at $50^{\circ} \mathrm{F}\left(10^{\circ} \mathrm{C}\right)$. The scope scrubber design developed here is shown schematically in cross-section in Figure 28 .

Power would be required to run the recirculation pump and to supply compressed air for the misting spray nozzles. Both the pump and the air compressor would use 15-HP motors, requiring some $22 \mathrm{~kW}$ of electrical power. 


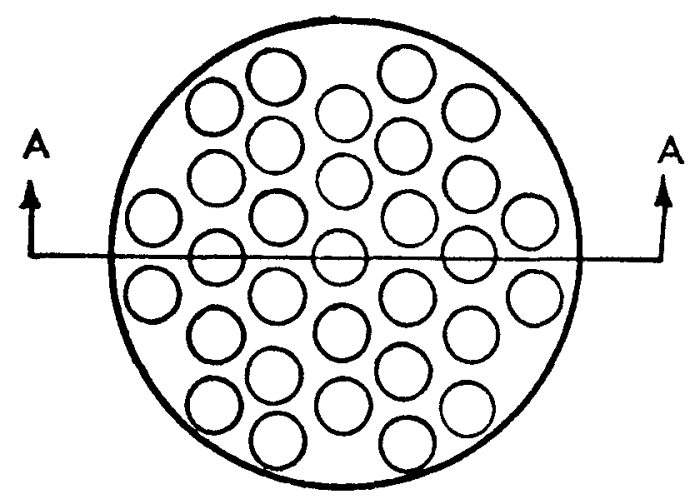

SECTION B-B

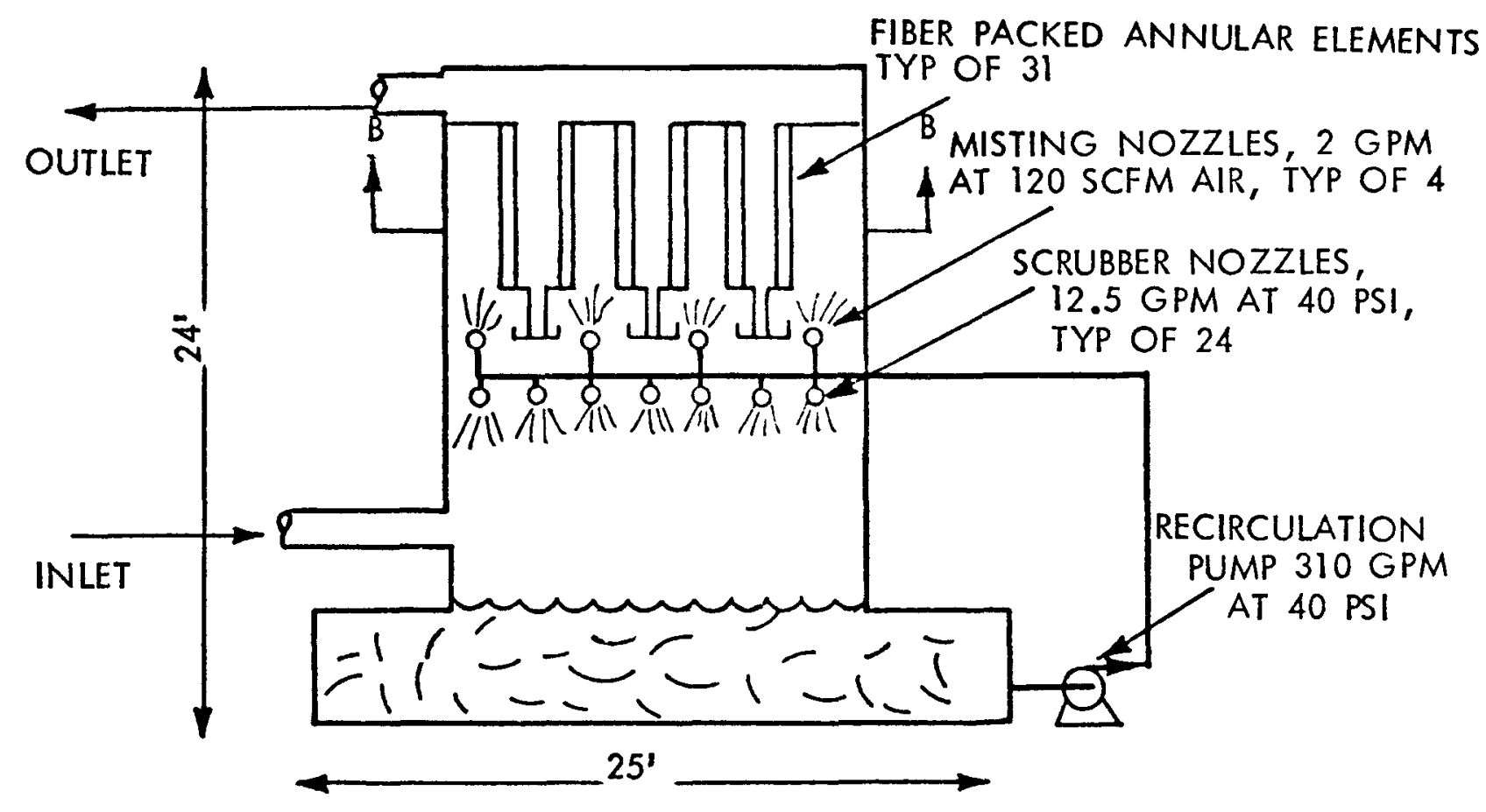

ELEVATION SECTION A-A HEDL 7511-165.7

FIGURE 28. Schematic Diagram of Scrubber Used in System CF-22. 
- HEPA and Charcoal Filter Pack. The final cleanup filters are of conventional design, and are operated under normal air flow conditions. For the $17,200 \mathrm{CFM}\left(8.1 \mathrm{~m}^{3} / \mathrm{s}\right)$ air flow, 18 standard $1000 \mathrm{CFM}\left(0.47 \mathrm{~m}^{3} / \mathrm{s}\right)$ units $(2 \mathrm{ft} \times 2 \mathrm{ft} \times 1 \mathrm{ft})$ are arranged in a $6 \times 3$ pattern. A schematic view of this arrangement is shown in Figure 29.
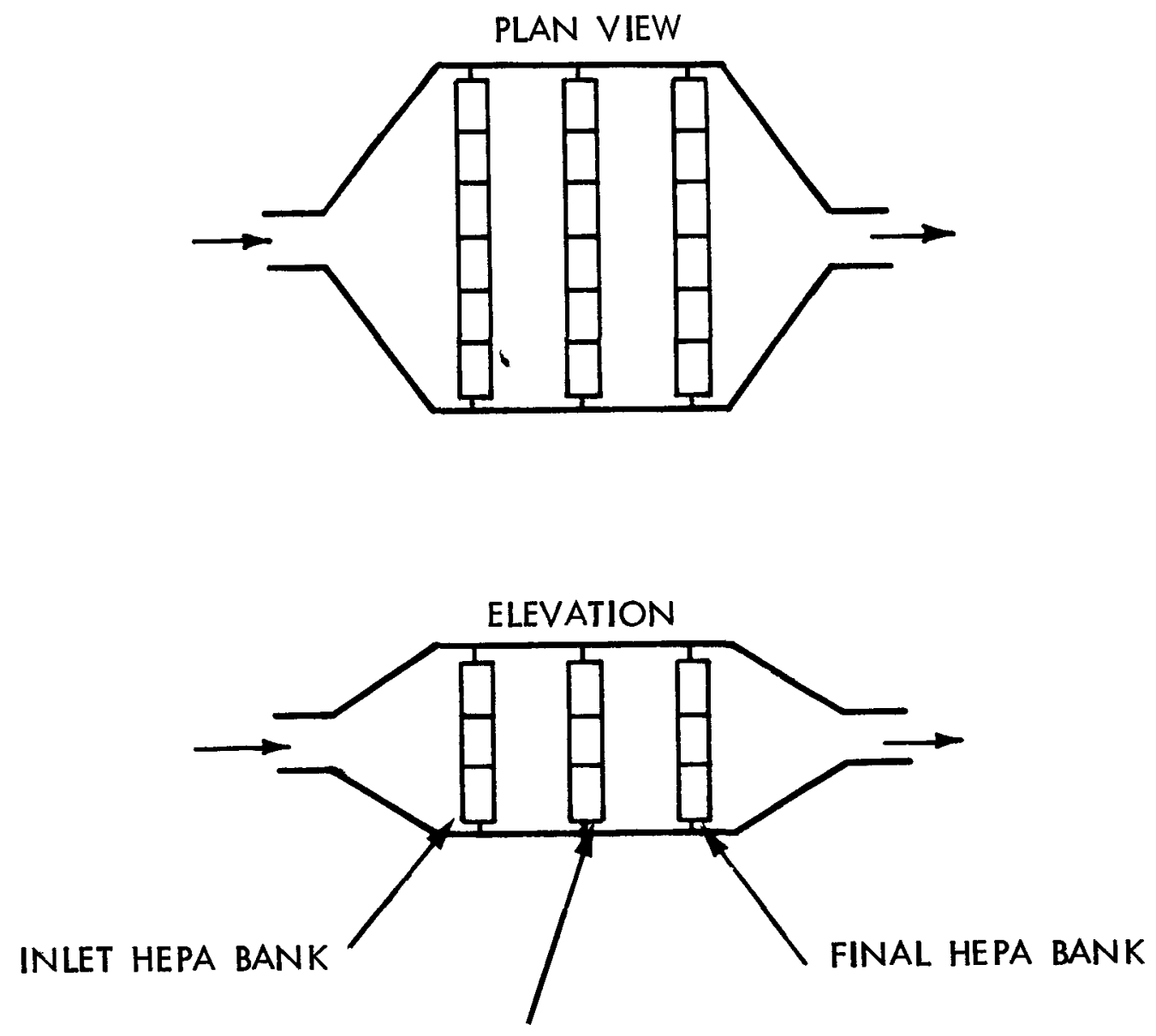

CHARCOAL ADSORBERS, 2" CHARCOAL $\mathrm{EFF}=95 \%$ FOR I $\mathrm{I}_{2}$ AND $\mathrm{CH}_{3} \mathrm{I}$

HEDL 7511-165.2

FIGURE 29. Schematic Diagram of Filter Pack for System CF-22. 
The inlet HEPA filters are provided to retain radioactive particles which penetrate the scrubber and to prevent blinding of the charcoal surface by sodium aerosols which penetrate the scrubber. A more detailed evaluation might show that this HEPA bank is not needed because of the high efficiency of the fiber bed scrubber. Charcoal adsorbers using 2 inches $(50 \mathrm{~mm})$ of impregnated charcoal are specified to obtain design credit of 95 percent removal of organic iodides. The final HEPA filter bank is provided to trap carbon fines which might be entrained from the charcoal. The filter pack would yield decontamination factors of at least $10^{4}$ for particles and 20 for gaseous iodine forms. A greater thickness of charcoal or multiple charcoal adsorbers in series could be provided for cases where a larger DF is required for iodine. Tests in the Containment Systems Experiment (CSE) with prototype charcoal adsorbers showed that additional decontamination of both elemental iodine and methyl iodide was obtained by secondary and tertiary adsorbers, even in saturated steam-air atmospheres. (69)

- Recirculating Air Heater. As shown in Figure 27, part of the exhaust air from the fan is heated and recycled back to the scrubber inlet. This heater is provided to assure that scrubber water does not freeze in the circumstance of an accident at a time when the outside air temperature was well below freezing. The heater design provided uses a propane flame to heat recycled air to $500^{\circ} \mathrm{F}\left(260^{\circ} \mathrm{C}\right)$. An air flow rate of $2200 \mathrm{CFM}\left(10.4 \mathrm{~m}^{3} / \mathrm{s}\right)$ was required to provide the needed heat energy at gas temperatures of no more than $500^{\circ} \mathrm{F}\left(260^{\circ} \mathrm{C}\right)$. The design temperature of the scrubber inlet air was selected as $40^{\circ} \mathrm{F}$ $\left(4.4^{\circ} \mathrm{C}\right)$. The minimum temperature of air exiting from the confinement building was assumed to be $-10^{\circ} \mathrm{F}\left(-23^{\circ} \mathrm{C}\right)$. At the maximum rate of use, about $1300 \mathrm{lb}(590 \mathrm{~kg})$ of propane would be burned per day.

Alternative heater designs which did not involve recycling of air were considered, but were discarded because they required either heat transfer or flame operation in an extremely dusty gas stream, 
where fouling would be a difficult problem to overcome. The use of a low freezing point liquid (or mixture) would eliminate the requirement for protection against freezing and a search for suitable liquids should be made before a firm design was made.

- Full flow Air Heater. In addition to the recirculating air heater, another air heater is required to maintain the relative humidity below 70 percent at the charcoal adsorber. Control of the gas relative humidity is required to obtain significant removal credit for methyl iodide. (21) The heater design selected involves combustion of propane with subsequent flow of the hot combustion gases through a series of vertical tubes located perpendicular to the EACS stream. Only about 30 tubes, each $4 \mathrm{ft}(1.2 \mathrm{~m})$ long and $1 \mathrm{in}$. (25mm) in diameter, are required. A maximum of $3901 \mathrm{~b}(177 \mathrm{~kg})$ per day of propane would be required for this use.

- Exhaust Fan. The exhaust fan will be required to deliver 17,200 CFM $\left(8.1 \mathrm{~m}^{3} / \mathrm{s}\right)$ at a static pressure of 18 in. $\mathrm{H}_{2} \mathrm{O}(4460 \mathrm{~Pa})$ when the filters and demister become loaded. Such a fan would deliver about 23,000 CFM $\left(10.8 \mathrm{~m}^{3} / \mathrm{s}\right)$ when all components are clean. A 75-HP electric motor would be required to drive the fan, and assuming 80 percent motor efficiency, an electric power supply of $70 \mathrm{~kW}$ would be needed.

7.3.1.4 System Cost. Estimated costs for system CF-22 are summarized below. Costs include acquisition of equipment items, installation of all pieces of equipment, and construction of a building to house the air cleaning system. The cost of the stack is not included.

$\begin{array}{lc}\begin{array}{l}\text { Construction, Equipment } \\ \text { and Building }\end{array} & \$ 000(\mathrm{a}) \\ \begin{array}{c}\text { Engineering (20\%) } \\ \text { Subtotal }\end{array} & \underline{253} \\ \text { Contingency (60\%) } \\ \text { TOTAL }\end{array}$

(a) 1975 dollars 


\subsubsection{Conformity with Criteria (CF-22).}

- Criterion 1a. "A decontamination factor of 100 can be achieved for aerosol particles."

The decontamination factor achieved by the system components would be at least 50 for the scrubber, 100 for the first HEPA bank, and 100 for the second HEPA bank. Thus the overal1 system decontamination factor of $5 \times 10^{5}$ is much higher than the criterion requires. This apparent over-design results from loading considerations imposed by a sodium fire, as discussed in Section 7.3.1.3 of this report. Rating $=4.0$.

- Criterion 1b. "Either dry or sticky particles can be treated effectively."

Aqueous scrubbers operate at 100 percent relative humidity, hence the aerosol to be scrubbed will uptake water vapor to a point of equilibrium with 100 percent relative humidity. The dry or sticky nature of the aerosol prior to its entry into the scrubber should have no appreciably adverse influence on system performance. Rating $=4.0$.

- Criterion 1c. "System effectiveness is not degraded by the radiation dose caused by the accident over the required operating period."

The most radiation-sensitive part of this system would be the organic materials used to fabricate the scrubber fiber beds. Moderate damage would be experienced by polypropylene at an exposure level of $10^{7}$ rads. Serious damage would begin at an exposure of $10^{8}$ rads. A conservative estimate of the radiation exposure indicated that the integrated radiation exposure would be less than $4 \times 10^{6}$ rads for the initial 8 -day period. The time-integrated exposure for infinite time would be less than $5 \times 10^{6}$ rads, hence the plastic fibers would not be influenced by the radiation dose. Due to the modest radiation doses, no appreciable damage to any part of the scrubber-filter system is expected. Rating $=3.7$. 
- Criterion 2a. "The EACS shall have a high probability of startup after initiation of the accident.

In order to start up properly, this system requires proper operation of a fan, a scrubber water pump, an air compressor, and possibly two propane gas heating systems. All of these unit operations are highly reliable, and have been extensively used in industrial operations. Also, redundant components could be included in the design to increase reliability if such an increase were needed. A less than perfect rating factor is assigned to account for the modest complexity of this system. Rating $=2.0$.

- Criterion 2b. "The system does not degrade during periods of unuse." The most probable source of system degradation during years of unuse would be corrosion by, or evaporation of, scrubbing water. Both of these problems can be handled adequately by design and periodic inspections, as attested to by emergency cooling water storage systems used in current light water reactors. The rating assigned reflects the fact that prevention of system degradation will require a deliberate design effort, but will not present a serious problem. Rating $=3.0$.

- Criterion 2c. "The system shall be capable of dependable operation over the required period of time under the accident conditions of temperature, pressure, humidity, and aerosol loading."

The scrubber-filter system could operate indefinitely under conditions imposed by the accident. Utilities which would have to be supplied include electric power, propane to fuel the heaters, and fresh water to make up for evaporation. No definite 1 imit exists to supplying these utilities, and therefore these requirements do not prohibit operation of the EACS for long time periods. Collection of normal atmospheric dust would ultimately plug either the fiber bed or first bank of HEPA filters. A long time period (many months) would be required before atmospheric dust could represent a serious problem, hence this system should be capable of dependable mechanical operation over the accident time period. Rating $=3.5$. 
- Criterion 2d. "The system requires simple components and conservative design stresses."

The CF-22 system uses 31 fiber bed scrubbing elements, 36 HEPA filter units, 18 charcoal adsorbers, propane heaters, isolation valves and an exhaust fan. While each component is readily available from industrial sources, the total number of system components is relatively high. Rating $=3.0$.

- Criterion 3a. "Inadvertent operation of the EACS shal1 not harm plant equipment or constitute a hazard to personnel."

Unplanned operation of this filter-scrubber system should pose no adverse problems to either personnel or equipment. Rating $=4.0$.

- Criterion 3b. "The size of the EACS shall be compatible with installation within or adjacent to the confinement building."

The scrubber and filter components of this system require an appreciable floor area, and therefore would probably be located outside the confinement building. A building 50-ft long by $36-\mathrm{ft}$ wide by 20-ft high $(15 \mathrm{~m} \times 11 \mathrm{~m} \times 6.1 \mathrm{~m})$ would provide ample space to house the system. The requirement to provide a separate building for the EACS is not considered a significant negative factor because it would be prudent to separate the EACS from the confinement building space in order to minimize common mode failure and to minimize emergency heating requirements for the EACS system; however a smaller system would be desirable. Rating $=3.5$.

- Criterion 4a. "The air cleaning concept is based on highly developed technology."

The air cleaning concepts used in this system include spray scrubbing, wetted fiber bed filtration, filtration in high-efficiency filters and adsorption on charcoal granules. All of these operations have been used extensively in industrial air cleaning problems, hence do not represent new or untried methodology. The operation which has the least amount of industrial experience is the trapping 
of solid, soluble particles in the wetted fiber bed. No particularly difficult problems are expected in this latter operation because ample water will be applied to dissolve the sodium aerosol, and the mass loading of insoluble material appears to be too small to be a problem, even if all insoluble aerosol material is assumed to remain in the fiber beds. Rating $=3.8$.

- Criterion 4b. "The EACS can be tested in-place for operability and efficiency."

This system would be well suited for testing of both operability and removal efficiency for DOP aerosol and iodine vapors. Rating $=3.0$.

- Criterion 4c. "The EACS performance can be predicted by verified mathematical models."

The performance of this system will be limited more by postulated leakage past gaskets than by particle trapping in the filters. Since the removal efficiency for the most penetrating test aerosol is expected to be much higher than the design DF of 100, no models wil1 be required to predict performance under accident conditions. Loading capacity for sodium aerosol is likewise not a problem because the aerosol is converted to a dissolved form rather than accumulated as a deposited solid. Rating $=3.0$.

- Criterion 4d. "The EACS equipment scaleup from currently available sizes to LMFBR plant application is smal1."

A11 of the equipment components required for this system are available commercially and, hence no size scaleup is required. The modest air flow rate for this system is appreciably smaller than existing industrial systems which employ the components of this system. Rating $=4.0$.

- Criterion 5a. "The EACS is effective for the entire particle size spectrum expected during the DBA."

This system was designed to attain the required performance even for aerosols of the most penetrating size $(0.3 \mu \mathrm{m}$ diameter). However, partial plugging of the scrubber fibers may occur with very small 
particles because insufficient water is provided to irrigate the fibers with very high mass loading. Large particles are easily handled. Rating $=2.5$.

- Criterion 5b. "The system performance is not highly sensitive to the atmosphere temperature, pressure and relative humidity."

This system design incorporates heaters which will control temperature to equal or exceed $40^{\circ} \mathrm{F}\left(4^{\circ} \mathrm{C}\right)$. The highest temperatures which could occur, around $300^{\circ} \mathrm{F}\left(150^{\circ} \mathrm{C}\right)$, present no problem because the hot air will be quenched by water spray before it enters the filters. Since temperature and relative humidity of incoming air are not important factors in the performance of the scrubber-filter system, a rating of 3.0 is assigned.

- Criterion 5c. "The system energy consumption is low." Operation of this system requires about $100 \mathrm{~kW}$ of electrical energy. The normal electrical power supply would have to be backed up by emergency diesels, hence the emergency power system would have to be sized to deliver an additional $100 \mathrm{~kW}$. In addition, $1690 \mathrm{lb} /$ day (770 kg/day) of propane fuel would be used during extremely cold weather. Rating $=2.5$.

- Criterion 5d. "The system can be modified to add halogen removal components and other air cleaning devices if needed."

This once-through system already contains a halogen adsorber. Other removal components could easily be added to the cleanup train. Rating $=4.0$.

- Criterion 5e. "The post-accident recovery is facilitated by the EACS."

About 50 percent of the aerosolized material is expected to settle out in the confinement building and the remainder will be trapped within the EACS. There will be a serious cleanup problem in the confinement building due to fallout, regardless of the specific type of once-through EACS used, and therefore it is not 
possible for the EACS to greatly influence post-accident recovery. As compared to strictly dry systems, the wet scrubber system is less desirable because the radioactive material would be distributed in $13,000 \mathrm{gal}\left(50 \mathrm{~m}^{3}\right)$ of water. Following an accident this water would have to be sent to a waste treatment facility where the radioactive materials would be converted to a solid form. Treatment and storage of contaminated water solutions is likely to be more expensive than treating solids, hence the present system would rate lower than the ideal system where all radioactive material was retained in compact, dry traps. Rating $=3.0$.

- Criterion 6a. "The system cost is low. Capital cost is less than $\$ 10$ million; operating and maintenance costs are low."

The estimated cost of this system, $\$ 2.4$ million, is well below the $\$ 10$ million limit; hence the system rates high on capital costs. Operating costs would be low, and would involve maintenance of the scrubber pumps, motors, valves, and heaters, as well as performance testing of the system. A few hundred man-hours per year spent on maintenance and testing should be sufficient to keep the system operable over its lifetime. Rating $=2.5$.

- Criterion 6b. "Materials and techniques used in construction are readily available and easily fabricated."

The materials and fabrication techniques incorporated in this system are commonly available and the system could be fabricated rapidly after a detailed design were made available. Rating $=3.5$.

- Criterion 6c. "Components and equipment are readily available." Much of the equipment required to build this system, such as pumps, motors, fans, nozzles, and filter units, are available commercially as shelf items. Specially fabricated items would include the scrubber chamber, the housing for the filter pack, and the EACS building. For the latter, requirements are standard. Rating $=3.5$. 


\subsubsection{Mandatory Criteria. This system easily meets all mandatory}

criteria, hence there does not appear to be any major problem with its use in a containment/confinement plant. Reliable operation of the system for a range of aerosol particle sizes would have to be demonstrated in large-scale tests before the system design could be used in full-scale applications.

7.3.1.7 Rating. The numerical rating of system CF-22 is as follows:

\begin{tabular}{lr}
\multicolumn{1}{c}{ Category } & Rating \\
\hline System effectiveness & 94.5 \\
System reliability & 82.0 \\
Containment compatibility & 26.5 \\
Technological credibility & 70.0 \\
System characteristics and flexibility & 35.5 \\
Fabrication effort & $\frac{19.5}{128.0}$ \\
\cline { 2 - 2 } TOTAL & 328.0
\end{tabular}

7.3.1.8 Development Requirements for System CF-22. Several questions need to be answered before a scrubber-filter system could be applied to fullscale containment/confinement LMFBR systems. First, the loading and cleaning characteristics of a wetted fiber bed scrubber need to be experimentally verified for soluble and insoluble aerosols typical of the DBST and sodium fire events. Such tests should be done with a full-scale fiber bed element so that no scaleup questions would remain. Test results would show how much spray was required to dissolve captured particles, the extent of pressure drop increase caused by the spray water and insoluble particles, and would verify the expected high removal efficiencies.

Another question which should be resolved experimentally is how much hydrogen is formed by reaction of unburned sodium with water. If 1 percent of the sodium aerosol were present as sodium metal, the hydrogen concentration is calculated to be 0.01 volume percent for the highest aerosol concentration $\left(23 \mathrm{~g} / \mathrm{m}^{3} \mathrm{Na}_{2} \mathrm{O}\right)$ projected here. If a 11 of the sodium reacted with $\mathrm{H}_{2} \mathrm{O}$ rather than $\mathrm{O}_{2}$, the maximum hydrogen concentration would be 1.0 volume percent, which is still well below explosive concentrations. ${ }^{(70)}$ Experiments to confirm the expected low hydrogen concentrations would be worthwhile. 
In addition to tests of the fiber bed scrubber, other scrubbers should be evaluated so that engineering data on performance of scrubbers would be available to system designers. Venturi scrubbers, with their lack of moving parts and small clearances, look promising and, if high efficiencies could be obtained, would provide a smaller and less costly scrubber alternative compared to the wetted fiber bed in the present design.

\subsubsection{Confinement - Sand Bed Filter, HEPA, Charcoal, HEPA (CF-24)}

7.3.2.1 Background. This air cleaning system is similar in function to the scrubber-filter system (CF-22) except that it uses a sand bed filter in place of the aqueous scrubber. The sand bed filter serves as a prefilter to protect the backup HEPA filters from being overloaded with sodium oxide smoke produced in the design basis sodium fire.

Filtration of particles from gas streams by means of beds of granular materials has been used in a broad range of industrial applications. Juvina11 ${ }^{(71)}$ published a comprehensive review of information on sand bed filtration which was available prior to 1970. As described by Juvinall, granular bed filters have been employed in a diversity of applications, including the trapping of sulfuric acid mists, the removal of dust from blast furnace gas, the removal of fly ash from flue gas, and the removal of radioactive aerosols from gas streams.

Large sand bed filters were built at the Hanford plant in the late 1940s and early 1950s. (71) An example is one installed at T-Plant (West Area) in 1948 which is still in operation. This bed is $110 \mathrm{ft}$ by $48 \mathrm{ft}$ $(33 \times 15 \mathrm{~m})$ and has a bed thickness of 2 feet $(0.6 \mathrm{~m})$ of 20-40 mesh sand. At an air flow rate of $25,000 \mathrm{CFM}\left(12 \mathrm{~m}^{3} / \mathrm{s}\right)$ the pressure drop is $4.0 \pm 0.1$ in. $\mathrm{H}_{2} \mathrm{O}(1000 \pm 25 \mathrm{~Pa})$ and the average collection efficiency is 99.5 percent.

Loading tests ${ }^{(71)}$ showed that only small quantities of aerosol could be collected before pressure drop increased significantly. Typical loading data for the Hanford sand filter (for methylene blue particles) are summarized in Table 30 .

The filter life for the Hanford sand filter has proven to be many years in spite of the low loading limits because the aerosol streams filtered are 
very dilute (approximately $2.3 \mathrm{mg} / \mathrm{m}^{3}$ ) and the filtration velocities are low. Much higher aerosol concentrations may be encountered for LMFBR emergency air cleaning application, and filter loading would be a limiting parameter in determining the filter size.

TABLE 30

LOADING CAPACITY OF HANFORD SAND BED FILTER*

\begin{tabular}{|c|c|c|c|c|c|c|}
\hline $\begin{array}{l}\text { Test } \\
\text { Unit } \\
\end{array}$ & $\begin{array}{l}\text { Sand Layer } \\
\text { Depth, in. }\end{array}$ & $\begin{array}{l}\text { Total Bed } \\
\text { Depth, in. }\end{array}$ & $\begin{array}{l}\text { Initial } \\
\text { Press. Drop, } \\
\text { in. } \mathrm{H}_{20} \mathrm{O} \\
\end{array}$ & $\begin{array}{l}\text { Final } \\
\text { Press. Drop, } \\
\text { in. } \mathrm{H}_{20} \mathrm{O} \\
\end{array}$ & $\begin{array}{l}\text { Dust } \\
\text { Loading, } \\
\text { lb/ft } 2 \\
\end{array}$ & $\begin{array}{l}\text { Gas } \\
\text { Velocity, } \\
\text { ft/min }\end{array}$ \\
\hline 1 & 3 & 17 & 3.17 & 8.80 & 0.0128 & 10 \\
\hline 2 & 3 & 45 & 1.88 & 7.83 & 0.0187 & 5 \\
\hline 3 & 2 & 45 & 1.29 & 7.65 & 0.0163 & 5 \\
\hline
\end{tabular}

*For methylene blue particles.

Kato, et al. (71), describe an emergency air cleaning system employing sand filters at the ZPR-6 and ZPR-9 critical facilities at Argonne National Laboratory. The sand bed filters are contained in 12-ft $(3.6 \mathrm{~m})$ diameter tanks with an $8-\mathrm{ft}(2.4 \mathrm{~m})$ depth of successively finer aggregate supporting a 2-ft $(0.6 \mathrm{~m})$ layer of 20-50 mesh sand. Each filter has a flow capacity of $12,000 \mathrm{CFM}\left(5.7 \mathrm{~m}^{3} / \mathrm{s}\right)$ of air at a pressure drop of $10 \mathrm{psi}(69,000 \mathrm{~Pa})$. The sand filters are backed up with two banks of HEPA filters to assure highly efficient removal of aerosols. This emergency filter system was designed to protect against radioactive aerosols generated by a criticality incident as well as a sodium fire. This sand filter application uses much higher air velocities (100 ft/min or $0.51 \mathrm{~m} / \mathrm{s}$ ) at higher pressure drops (10 psi) than the Hanford sand bed. This is possible because it serves as a pressurized gas vent rather than an in-line air cleaner whose air flow is induced by an ordinary fan. The postulated accident involves burning $1301 \mathrm{~b}(60 \mathrm{~kg})$ of plutonium and vaporization and rapid oxidation of $48 \mathrm{lb}(22 \mathrm{~kg})$ of sodium. A DF of 1000 is expected for the sand filter for submicron plutonium particles. The increase in pressure drop which would be caused by trapping of $48 \mathrm{lb}(22 \mathrm{~kg})$ of sodium oxide aerosol was not discussed by Kato, et al., hence no loading data are obtainable for this application. 
In his review, Juvinall ${ }^{(71)}$ cites several advantages of sand bed filters compared to alternatives:

- resistance to damage by shock wave loading

- resistance to damage by seismic disturbances

- large thermal sink for hot exhaust gases.

Unfortunately, these three advantages for sand filters do not mesh well with the needs of the containment/confinement system where compactness, high aerosol loading, and cost are the most important characteristics of a prefilter.

Schurr, et al. (73), discussed performance testing of a scale model of a sand bed filter designed to replace existing filters at the Savannah River Laboratory (SRL). A two-ft-square plywood box 8-ft high $(0.6 \mathrm{~m} \times 0.6 \mathrm{~m} \times 2.4 \mathrm{~m})$ was used to assemble a graded filter typical of a full-scale filter. Results of tests on this pilot scale test bed are summarized in Table 31 .

TABLE 31

PERFORMANCE DATA OF SAVANNAH RIVER SAND BED FILTER TESTS $(a)$

Parameter

Superficial Velocity, ft/min

Pressure Drop across Clean Filter, in. $\mathrm{H}_{2} \mathrm{O}$ DOP Efficiency, \%

Loading Capacity(b) (at 15 in. $\mathrm{H}_{2} \mathrm{O}$ )

Total Bed Depth

Sand Depth (20-50 mesh)

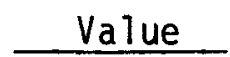

5

4.8

$99.95 \pm 0.02$

$1.26 \mathrm{lb} / \mathrm{ft}^{2}$

$8 \mathrm{ft}$

$3 \mathrm{ft}$

(a) Data taken from Reference 73 .

(b) Carbon black aerosol

The most noteworthy feature of the data presented in Table 31 is that the dust loading capacity of the SRL sand filter (measured with carbon black) is a factor of 50 higher than the dust loading capacity of the Hanford sand filters (measured using methylene blue). Since the two sand filters seem to be of similar construction, it is tempting to attribute the difference in loading capacity to the difference in aerosol material. 
Bohm, et al. (27), presented results of pilot scale tests of sand filters designed to trap aerosols of sodium oxide which are postulated in design basis accidents for the SNR-300 reactor. The fine sand layer was 6 inch (152mm) thick, and was a blend of 0/0.6 and 0.6/2 millimeter sand. Three times as much coarse sand was used as fine sand. The sand layer was supported by 7.5 inches of $2 / 5$ millimeter sand below, and was covered from above with a layer of $2 / 5$ sand 6 inches thick. Downflow was used in tests of loading versus pressure drop at several velocities. Results of experiments reported by Bohm, et al ${ }^{(27)}$, are summarized in Table 32

\section{TABLE 32}

SUMMARY OF SODIUM OXIDE LOADING TESTS OF SNR-300 SAND BED FILTER*

\begin{tabular}{|c|c|c|c|c|}
\hline $\begin{array}{c}\text { Gas Velocity, } \\
\mathrm{ft} / \mathrm{min} \\
\end{array}$ & $\begin{array}{c}\text { Initial } \\
\text { Pressure Drop, } \\
\text { in. } \mathrm{H}_{2} \mathrm{O} \\
\end{array}$ & $\begin{array}{c}\text { Final } \\
\text { Pressure Drop, } \\
\text { in. } \mathrm{H}_{2} \mathrm{O} \\
\end{array}$ & $\begin{array}{l}\mathrm{Na}_{2} \mathrm{O} \text { Dus } \\
\text { Loading } \\
\mathrm{lb} / \mathrm{ft}^{2} \\
\end{array}$ & $\left(\mathrm{~kg} / \mathrm{m}^{2}\right)$ \\
\hline 8.85 & 3.94 & 11.22 & 0.025 & $(0.12)$ \\
\hline 8.85 & 3.94 & 32.70 & 0.047 & $(0.23)$ \\
\hline 4.42 & 0.79 & 4.92 & 0.029 & $(0.14)$ \\
\hline 4.42 & 0.79 & 16.50 & 0.055 & $(0.27)$ \\
\hline 1.77 & 0.39 & 2.95 & 0.078 & $(0.38)$ \\
\hline
\end{tabular}

The loading data presented in Table 32 for the SNR-3000 sand bed filter agree reasonably well with those shown in Table 30 for Hanford filters. The SNR-300 tests used aerosols generated from burning sodium. The removal efficiency of the sand bed for the sodium oxide aerosol was greater than 99.9 percent.

Bohm, et al. (27), also tested HEPA filters made of fiberglass and concluded that sand filters were superior to fiberglass filters for a number of reasons. Points of comparison made by Bohm, et al., are the following:

- Sand bed filters are chemically inert against sodium oxide aerosols.

- Sand bed filters have efficiencies comparable to HEPA filters. 
- Sand bed filters are good heat sinks.

- Sand bed filters are somewhat more expensive than fiberglass filters but, due to longer life, may be less expensive in some applications.

Based on the favorable operating characteristics, Bohm reports that a sand filter, backed up with charcoal and HEPA filters, was selected for inclusion in the SNR-300 off-gas filter system.

Moyer, et al.(74), describe a large sand filter recently installed at SRL. The filter covers a rectangular area $103 \mathrm{ft}$ by $140 \mathrm{ft}(31 \times 43 \mathrm{~m})$, and consists of layers of rock, gravel, and sand to a depth of $7.5 \mathrm{ft}(2.3 \mathrm{~m})$. The design air flow rate is $74,000 \mathrm{CFM}\left(35 \mathrm{~m}^{3} / \mathrm{s}\right)$ at a velocity of $5.15 \mathrm{ft} / \mathrm{min}$ $(0.03 \mathrm{~m} / \mathrm{s})$. Pressure drop across the clean filter is 6.5 inches of water $(1620 \mathrm{~Pa})$. The sand filter was installed to provide additional protection against the release of radionuclides to the environment in the event of an accident, such as a fire or explosion, that could breach the containment provided by the existing HEPA filter systems. The laboratory air would be expected to contain low aerosol concentrations, hence bed loading is not expected to be a problem. Removal efficiency of the installed filter was measured to be 99.9 percent for $0.3 \mu \mathrm{m}$ DOP aerosol particles.

In summary, it may be stated that large sand bed filters have Deen employed quite successfully in the nuclear industry for 30 years. Most applications, however, involve treatment of gas streams having very low aerosol concentrations. Because loading capacity is a critical factor in the present study, it is likely that a large, expensive filter will be required to trap the large quantities of sodium oxide smoke postulated for a sodium fire accident. A much smaller filter would suffice if the DBST excluded a sodium fire in the confinement building.

7.3.2.2 Design Parameters. Most of the design parameters for the sand bed prefilter are the same as for the scrubber in system CF-23. One unique parameter for the sand bed is the assumed loading capacity at the required flow velocity. For the sand filter, the aerosol loading capacity is defined in terms of a "resistance coefficient." The resistance coefficient defined by Viles, et al. (26), is given in Eq. (4) as: 


$$
C_{R}=\frac{\Delta P}{H V}
$$

where: $C_{R}=$ resistance coefficient, in. $\mathrm{H}_{2} \mathrm{O} /\left(1 \mathrm{~b} / \mathrm{ft}^{2}\right)(\mathrm{ft} / \mathrm{min})$, $\Delta P=$ increased air flow resistance, in. $\mathrm{H}_{2} \mathrm{O}$,

$H=$ fume loading density, $1 \mathrm{~b} / \mathrm{ft}^{2}$ of filter surface, $v=$ superficial air velocity, $\mathrm{ft} / \mathrm{min}$.

Numerical values of $C_{R}$ for sand filters were computed from the data shown in Tables 30, 31, and 32. Results are summarized in Table 33.

TABLE 33

RESISTANCE COEFFICIENTS CALCULATED FROM EXPERIMENTAL MEASUREMENT OF SAND FILTER PERFORMANCE

\begin{tabular}{|c|c|c|c|c|}
\hline $\begin{array}{l}\text { Reference } \\
\text { Number } \\
\end{array}$ & $\begin{array}{l}\text { Gas } \\
\text { Velocity, } \\
\mathrm{ft} / \mathrm{min} \\
\end{array}$ & $\begin{array}{c}\text { Test } \\
\text { Aerosol } \\
\end{array}$ & in. ${ }^{\Delta P} H_{2} \mathrm{O}$ & $\frac{\mathrm{C}_{R}, \text { in. } \mathrm{H}_{2} \mathrm{O}}{\left(\mathrm{lb} / \mathrm{ft}^{2}\right)(\mathrm{ft} / \mathrm{min})}$ \\
\hline 71 & 10 & methylene blue & 5.6 & 44 \\
\hline 71 & 5 & methylene blue & 6.0 & 64 \\
\hline 71 & 5 & methylene blue & 6.4 & 78 \\
\hline 73 & 5 & carbon black & 10.4 & 1.7 \\
\hline 27 & 8.9 & sodium oxide & 7.3 & 33 \\
\hline 27 & 8.9 & sodium oxide & 28.7 & 69 \\
\hline 27 & 4.4 & sodium oxide & 4.1 & 33 \\
\hline 27 & 4.4 & sodium oxide & 15.8 & 64 \\
\hline 27 & 1.8 & sodium oxide & 2.6 & 19 \\
\hline
\end{tabular}

The most applicable data shown in Table 33 is the lowest velocity test reported in Reference 27, for which a $C_{R}$ of 19 was observed. For the present (system CF-24) filter design, it is expected that a still lower value for $C_{R}$ could be obtained by development, e.g., use of larger aggregate. For the purposes of this study, a $C_{R}$ value of 20 is assumed to apply because no other applicable data are available. It is entirely possible that a substantially lower value of $C_{R}$ would be possible, resulting in a smaller, more economical bed. Research is needed to better define applicable values of $C_{R}$ for sand 
beds whose efficiencies are in the 90-99 percent range, permitting use of larger, more uniformly-sized aggregate. The estimated cost and size of sand bed filters varies inversely with the allowable loading per unit area, and therefore a great incentive exists to develop units to operate at higher loadings.

Design parameters used to develop the scope design of system CF-24 are summarized in Table 34.

TABLE 34 .

DESIGN PARAMETERS FOR SAND BED, HEPA, CHARCOAL, HEPA SYSTEM CF-24

\section{Parameter}

Total sodium aerosol loading

Core material aerosol loading

Maximum inlet temperature

Minimum inlet temperature

Overall system efficiency for plutonium removal

Overall system efficiency for halogens removal

Sand filter efficiency for sodium oxide aerosol

Sand filter resistance coefficient

Maximum sodium aerosol inlet concentration

Air exhaust flow rate from confinement building Allowable increase in sand filter pressure drop Allowable pressure drop across first HEPA filter bank Allowable pressure drop across charcoal adsorbers Allowable pressure drop across second HEPA filter bank Relative humidity at inlet to charcoal adsorber
Value

$2100 \mathrm{lb}(955 \mathrm{~kg})$ as $\mathrm{NaC} !$

$2.21 \mathrm{~b}(1.0 \mathrm{~kg})$

$300^{\circ} \mathrm{F} \quad\left(150^{\circ} \mathrm{C}\right)$

$-10^{\circ} \mathrm{F} \quad\left(-23^{\circ} \mathrm{C}\right)$

$99 \%$

$95 \%$

$99 \%$

$20 \frac{\text { in } H_{2} \mathrm{O}}{\left(\mathrm{bb} / \mathrm{ft}^{2}\right)(\mathrm{ft} / \mathrm{min})}$

$25 \mu \mathrm{g} / \mathrm{cm}^{3}$ (as $\mathrm{NaOH}$ )

$15,000 \operatorname{CFM}\left(7.1 \mathrm{~m}^{3} / \mathrm{s}\right)$

5 in. $\mathrm{H}_{2} \mathrm{O}(1250 \mathrm{~Pa})$

8 in. $\mathrm{H}_{2} \mathrm{O}(2000 \mathrm{~Pa})$

2 in. $\mathrm{H}_{2} \mathrm{O}(500 \mathrm{~Pa})$

1.5 in. $\mathrm{H}_{2} \mathrm{O}(375 \mathrm{~Pa})$

$<70 \%$

\subsubsection{Conceptual Scope Design (CF-24).}

- Description of Important System Components. This system is comprised of a sand bed filter, an air heater, backup HEPA filters and charcoal adsorbers, an exhaust fan, and a 100-meter stack. The system is shown schematically in Figure 30. 


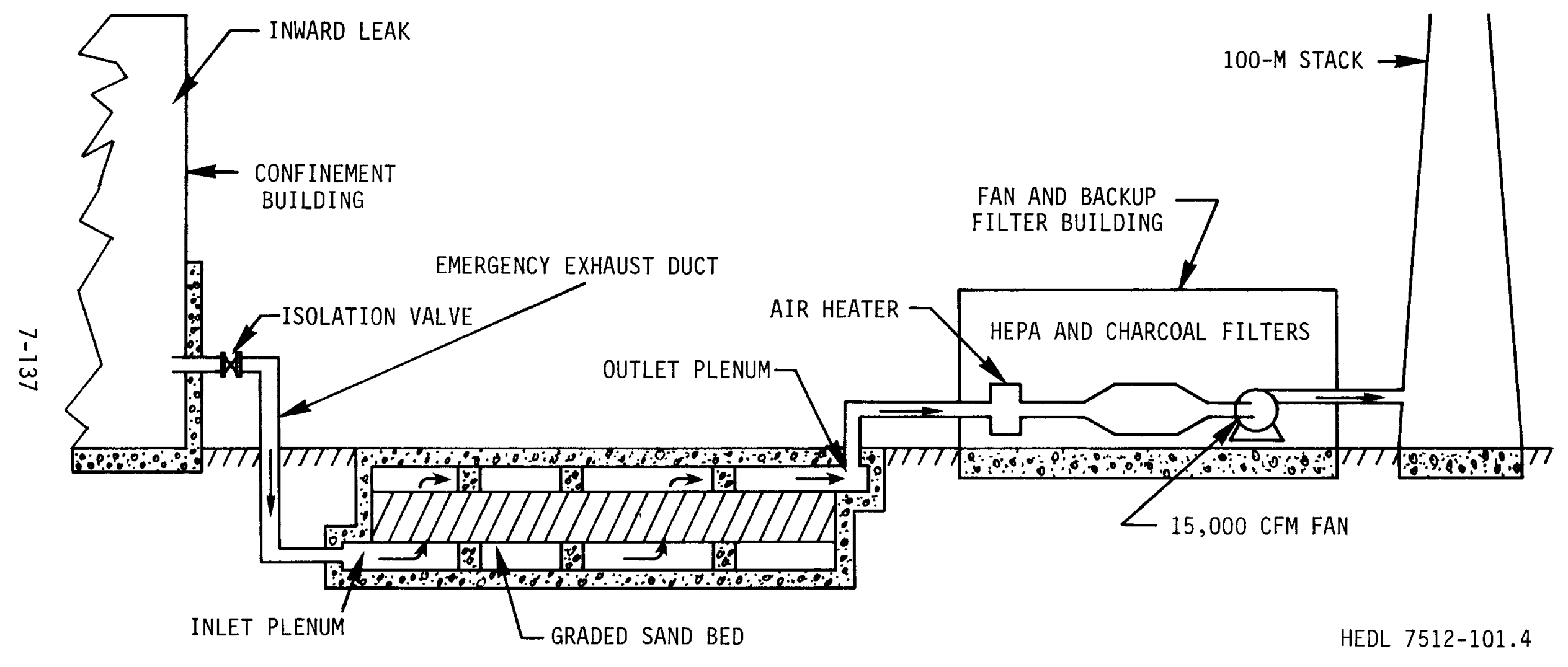

FIGURE 30. Schematic Diagram of Sand Bed Filter System CF-24 for Confinement Building Exhaust Air. 
It is envisioned that the sand bed housing would be built of concrete, with a roof supported by concrete columns. Backup HEPA filters, charcoal halogen adsorbers, air heater, and fans would be housed in a sheet metal building located between the sand filter and the discharge stack.

Not shown in Figure 30 are the intake ducts, fans, filters, and heat exchangers that comprise the normal ventilation system. Isolation valves would be provided on the normal ventilation system intake and exhaust ducts to prevent air from entering the building through these ducts when the emergency exhaust system operates.

This system exhausts air from the confinement building through filters prior to discharge to the atmosphere via a 100-meter stack. A sand bed filter is used as a roughing filter to trap the bulk of the mass of aerosol produced by a design basis sodium fire in the confinement building. The first HEPA filter bank is provided to prevent potential fouling of the charcoal halogen adsorbers by aerosols penetrating the sand filter. Charcoal filters to trap halogens are backed up by a final HEPA filter bank to prevent escape of charcoal powder which could carry entrained halogens from the system. The sand bed filter and two HEPA filters in series provide aerosol decontamination factors much larger than required to attain the design DF of 100 . It is possible that a more detailed study of this system would show that some components, such as the first HEPA filter bank, could be eliminated or reduced in size, resulting in a smaller, less costly system. Discussion of the approach used to develop the scope design for this system is provided in the following paragraphs.

- Sand Filter. The size of the sand filter required is determined by the loading capacity of the filter. The total area of the filter can be computed from the flow rate, the aerosol mass to be trapped by the filter, the allowable pressure drop, and the resistance coefficient defined in Eq. (4). Algebraic rearrangement of Eq. (4) leads to the following expression for the flow area required: 


$$
A=\left(\frac{C_{R} M Q}{\Delta P}\right)^{1 / 2}
$$

where: $\quad A=$ sand bed area required, $\mathrm{ft}^{2}$

$M=$ mass of aerosol to be retained in filter, $1 \mathrm{~b}$

$Q=$ air flow rate, $\mathrm{ft}^{3} / \mathrm{min}$

$\Delta \mathrm{P}=$ allowable pressure drop through filter, in. $\mathrm{H}_{2} \mathrm{O}$

$C_{R}=$ filter resistance coefficient, in. $\mathrm{H}_{2} \mathrm{O} /\left(\mathrm{lb} / \mathrm{ft}^{2}\right)(\mathrm{ft} / \mathrm{min})$.

For the present application, $C_{R}=20 \mathrm{in} . \mathrm{H}_{2} \mathrm{O} /\left(1 \mathrm{~b} / \mathrm{ft}^{2}\right)(\mathrm{ft} / \mathrm{min}), M=$ $2100 \mathrm{lb}, Q=15,000 \mathrm{CFM}$, and $\Delta P=5 \mathrm{in}$. $\mathrm{H}_{2} \mathrm{O}$, resulting in an area of $11,200 \mathrm{ft}^{2}\left(1000 \mathrm{~m}^{2}\right)$. If square in shape, the bed would be $106 \mathrm{ft}(32.3 \mathrm{~m})$ on each side. The gas velocity would be $1.3 \mathrm{ft} / \mathrm{min}(0.0067 \mathrm{~m} / \mathrm{s})$.

The composition and thickness of the several sand and gravel layers for the sand bed were taken to be the same as that of a sand bed recently installed at SRL. (74) The layers of material are identified in Figure 31.

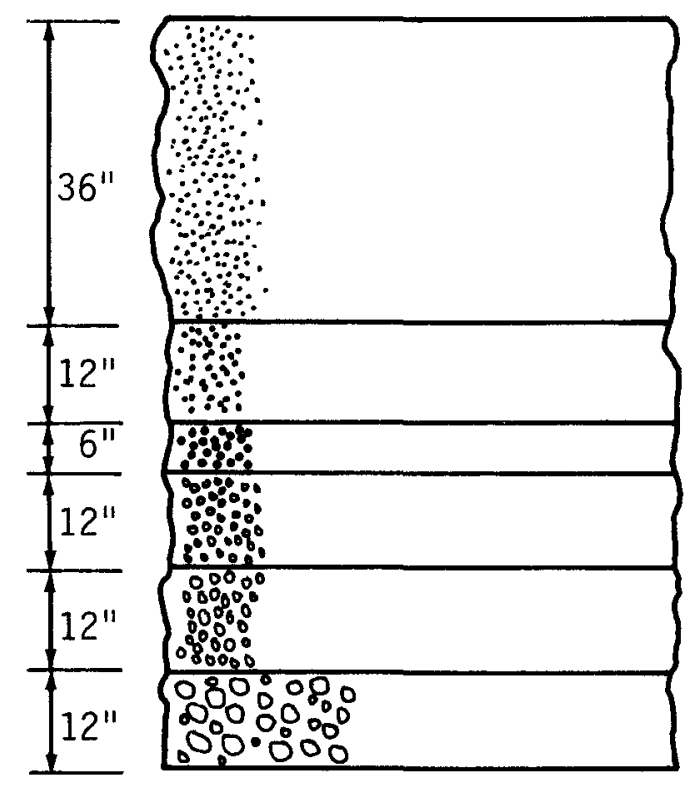

LAYER G, \#50 T0 \#30 SAND

LAYER $\mathrm{F}$, \#20 T0 \#8 SAND

LAYER E, \#8 TO 1/4-IN. SAND

LAYER C, 1/4-IN. TO 5/8-IN. GRAVEL

LAYER B , 5/8-IN. T0 1-1/2-IN. GRAVEL

LAYER A, 1-1/4-IN. TO 3 IN. GRAVEL

HEDL $7512-101.1$

FIGURE 31. Aggregate Used in Sand Bed Filter for System CF-24. 
The sand bed defined by the layers shown in Figure 31 represents an overkill in terms of particle removal efficiency because this bed design yielded a DOP particle removal efficiency of 99.9 percent. (74) When compared to the 99 percent design efficiency for system CF-24, this bed has a penetration only 10 percent of that allowable, showing that the DF is 10 times greater than required. It is obvious that this design is not optimized, and that smaller beds possibly could be used if a lower efficiency bed were developed to maximize the loading capacity.

- Backup Filters. A HEPA-charcoal filter pack is provided as a backup to the sand filter to trap particles penetrating the sand filter and to remove halogens. A standard series arrangement, consisting of a HEPA followed by a charcoal adsorber and a final HEPA, is used. This filter pack is of the same design provided for system CF-22, and is described more fully in Section 7.3.1.3 of this report.

- Air Heater. An air heater is required to maintain the relative humidity equal to or less than 70 percent at the inlet to the charcoal adsorbers. This air heater would be similar in design to the one provided in system CF-22, and is more fully discussed in Section 7.3.1.3 of this report.

- Exhaust Fan. The exhaust fan will be required to deliver 15,000 CFM $\left(7.1 \mathrm{~m}^{3} / \mathrm{s}\right)$ at a maximum pressure drop of 24 inches of water (6000 Pa). This fan will deliver about 21,000 CFM $\left(9.9 \mathrm{~m}^{3} / \mathrm{s}\right)$ when all components are clean. A 100-HP $(75 \mathrm{~kW})$ motor would be required to drive the fan.

\subsubsection{Cost Estimate (CF-24). Estimated costs for system CF-24 are} summarized below. Costs include acquisition and installation of al1 components described in Section 7.3.2.3. Relatively low factors for nuclear quality assurance and contingency have been applied because the costs were based on a recent sand filter installation of similar design at an operating nuclear plant (SRL). 


\begin{tabular}{|c|c|}
\hline Item & $\$ 000^{(a}$ \\
\hline $\begin{array}{l}\text { Construction, Equipment } \\
\text { and Building }\end{array}$ & 2525 \\
\hline Engineering $(20 \%$ & 505 \\
\hline Subtotal & 3030 \\
\hline Contingency $(50 \%)$ & 1515 \\
\hline TOTAL & 4545 \\
\hline
\end{tabular}

(a) 1975 dollars

\subsubsection{Conformity with Criteria (CF-24).}

- Criterion 1a. "A decontamination factor of 100 can be achieved for aerosol particles."

A realistic evaluation of this system would result in assignment of a DF of 100 for the sand filter, 100 for the first HEPA bank, and 100 for the final HEPA filter bank. Thus, the overall system decontamination for aerosol particles would probably exceed $10^{6}$, which is $10^{4}$ times higher than the value required by the design criteria. This over-design in removal efficiency results from design constraints imposed by aerosol loading requirements. The high DF achieved by the present system design suggests that containment/confinement plants can achieve a DF appreciably higher than 100. Rating $=4.0$.

- Criterion 1b. "Either dry or sticky particles can be treated effectively."

Particle capture mechanisms which operate in the sand filter include diffusion, interception, and impaction. None of these depend upon the adhesive properties of the aerosol, and therefore the efficiency of particle capture within the sand bed should be the same for dry and sticky particles, other factors remaining the same. The sand filter operation does not involve the removal of particle deposits. The physical properties of the deposited layer may affect the pressure drop to some extent, although no data on this are available. It is concluded that sand filter operation should be nearly independent of the adhesive properties of the aerosol. The backup HEPA performance is probabiy more dependent on the physical nature of the aerosol than is the sand bed. Rating $=3.5$. 
- Criterion 1c. "System effectiveness is not degraded by the radiation dose caused by the accident over the required operating period." The principal effects of radiation which are of potential importance are particle charging (or discharging) and material degradation. It is well known that nuclear radiation of an aerosol results in an equilibrium charge distribution. Low-level bipolar charging of aerosols is the equilibrium condition, and the rate at which equilibrium is achieved increases as the radiation level increases. Since electrical forces are not among the dominant particle capture mechanisms in sand bed filters, any influence of particle charge will be minor. However, since charge equilibrium in the aerosol will exist at all points in the bed as a result of the radiation field, particle capture by image forces should be enhanced. Image force deposition would be the dominant mechanism arising from electrical forces in a sand bed. Thus, it is concluded that the radiation field would slightly increase removal efficiency because it provides a means for maintaining charge equilibrium in the flowing aerosol.

Degradation of sand bed materials caused by the radiation field would be negligible. As noted in Section 7.3.1.5 of this report, the integrated dose for infinite time would be less than $5 \times 10^{6} \mathrm{rad}$, and this dose is orders of magnitude smaller than the doses which would be required to damage the sand filter. The charcoal would receive less than $4 \times 10^{7}$ rad at infinite time exposure, far below the $10^{9}$-rad resistance required for LWR charcoal systems.

In summary, the sand filter system CF-24 will be negligibly affected by the nuclear radiation dose. Rating $=4.0$.

- Criterion 2a. "The EACS shall have a high probability of startup after initiation of the DBST."

Startup of this system involves proper operation of isolation valves, an electric motor and fan, and a gas heater. These operations are simple and involve simple components. Therefore startup of a singly equipped system should be highly reliable. Addition of a 
redundant fan and motor to further increase the reliability of this already highly reliable system would be possible. Rating $=4.0$.

- Criterion 2b. "The system does not degrade during periods of unuse." It is difficult to pinpoint any cause for appreciable degradation of a properly designed sand bed. One possible degradation mode would be development of major cracks in the concrete walls of the sand bed, which could permit entry of ground water or air inleakage. Such degradation is considered improbable because: (1) major cracks would not develop in properly designed and fabricated concrete walls, (2) small cracks would not be a problem because all air leäkage would be inward when the system operated, (3) any inleaked water would end up in a sump in the floor of the sand bed, and (4) the current status of the system condition could be determined by periodic tests. The efficiency of the charcoal halogen adsorbers may decrease with time due to natural aging and periodic in-place testing. Their status would be well known by the in-place testing, however. Rating $=3.7$.

- Criterion 2c. "The system sha11 be capable of dependable operation over the required period of time under the accident conditions of temperature, pressure, humidity, and aerosol loading."

Experience with sand bed filters leads one to conclude that continuous operation for many years is feasible provided the design dust loading is not exceeded. Since the bed is passive, there appears to be no likely mechanical failures which could interfere with proper operation of the bed for months, and perhaps years.

In summary, the major factor in reliable operation of the bed is the aerosol loading. If the design aerosol load were exceeded, plugging of the bed could occur, with attendant reduction in air flow rate. Such plugging would be possible only for a major sodium fire accident, and even if the filter eventualiy plugged, off-site doses would be minor because of the very low dose potential of sodium. For the DBST, plugging will not occur because of the very low aerosol 
loading. The HEPA backup filters are also limited by loading and will plug if the sand filter efficiency decreases below 297 percent for the sodium fire case.

It is concluded that system CF-24 is highly reliable for long-term operation during the postulated DBST and reasonably reliable for the sodium fire accident. Rating $=3.4$.

- Criterion 2d. "The system requires simple components and conservative design stresses."

The major components of system CF-24 are very simple. The filter components are of conventional design and are readily available. Stress levels in this passive system can be designed to conservative levels. Rating $=3.5$.

- Criterion 3a. "Inadvertent operation of the EACS shall not harm plant equipment or constitute a hazard to personnel."

Unplanned operation of this sand filter system should pose no adverse problems to either personnel or equipment. Rating $=4.0$.

- Criterion 3b. "The size of the EACS shall be compatible with installation within or adjacent to the confinement building."

Perhaps the most obvious weak point of the sand bed filter is its large size. The sand bed itself will occupy a volume of $170,000 \mathrm{ft}^{3}$ $\left(4800 \mathrm{~m}^{3}\right)$. In addition, plenums, ductwork and a building $40-\mathrm{ft} \times 25-\mathrm{ft}$ $\times 20$-ft high $(12 \mathrm{~m} \times 7.6 \mathrm{~m} \times 6.1 \mathrm{~m})$ will be required to house the backup filters and the fan. The total volume of $195,000 \mathrm{ft}^{3}\left(5500 \mathrm{~m}^{3}\right)$ is very large for the moderate air flow rate of $15,000 \mathrm{CFM}\left(7 \mathrm{~m}^{3} / \mathrm{s}\right)$.

The large size of the sand filter is probably not a major deterrent to its use because it could be located at some distance from the confinement building. The site area occupied by the sand bed would be small compared to total area of a nuclear site. Therefore, no major problems are caused because of the large size of the sand bed. A rating of 2.0 is assigned which recognizes that a smaller system would be desirable. 
- Criterion 4a. "The air cleaning concept is based on highly developed technology."

From the discussion provided in Section 7.3.2.1 of this report, it is noted that large sand bed filters have been used in industry to some extent, but in only two nuclear plants in the United States (Hanford and SRL). At each plant only a few sand beds have been used, and thus large-scale sand bed installations number less than 10. The sand bed designs used to date have been based on empirical data related to particular applications, and we are unaware of comprehensive analytical design methods which would allow all important parameters to be factored into a proposed design. Therefore, sand bed filtration technology is in an intermediate state of development. Additional development would be necessary to permit optimization of a sand bed for the present requirements. It is believed that a smaller, less costly sand bed would work for the confinement application if the design were optimized for loading capacity at 99 percent efficiency.

A rating factor of 3.0 is assigned to account for the intermediate state in technological development of sand bed filters.

- Criterion 4b. "The EACS can be tested in-place for operability and efficiency."

This system is well suited for testing of both operability and removal efficiency for DOP aerosol and halogens. Therefore a rating of 4.0 is assigned.

- Criterion 4c. "The EACS performance can be predicted by verified mathematical models."

The particle removal efficiency of this system is very high, and will be limited more by postulated leakage than by filter performance. Direct measurement of DOP aerosol penetration will confirm that the removal efficiency for all particles will be higher than the design value of 99 percent, and therefore no detailed model of aerosol capture efficiency is needed. 
Loading capacity of the sand filter, an important aspect of performance, cannot be predicted by verified mathematical models. This gap in technological understanding can be bridged by an experimental program for a specific filter design, and so does not represent a serious obstacle to use of sand filters.

A rating factor of 4.0 is assigned to reflect the absence of a verified mathematical model for the loading capacity of sand filters.

- Criterion 4d. "The EACS equipment scaleup from currently available sizes to LMFBR plant application is small."

The sizes of both the sand bed and backup filter system required for this application are smaller than sizes currently in use.

Therefore no size scaleup is required. Rating $=4.0$.

- Criterion 5a. "The EACS is effective for the entire particle size spectrum expected during the DBST."

The particle removal efficiency of this system will greatly exceed the design requirement, even for the $0.3 \mu \mathrm{m}$ particles of DOP aerosol. Therefore, the design performance will be met or exceeded regardless of the actual particle size, and a favorable rating of 3.5 is assigned.

- Criterion 5b. "The system performance is not highly sensitive to the atmosphere temperature, pressure, and relative humidity."

The performance of the sand bed filter system is not sensitive to temperature per se, at least within the range specified for the design basis accidents. Hence, the temperature part of this criteria is fully met by the sand filter. Likewise, system performance is not sensitive to pressure within the narrow range possible in the confinement plant design.

The relative humidity of the incoming air would likely influence processes occurring in the system. For example, if air entering the EACS were saturated at $80^{\circ} \mathrm{F}\left(27^{\circ} \mathrm{C}\right)$ and the sand bed was initially at a temperature of $60^{\circ} \mathrm{F},\left(16^{\circ} \mathrm{C}\right)$, condensation of moisture within the bed would occur. The condensed water would drain to the bottom of the bed, 
carrying with it deposited aerosol material. This condensation process should cause no significant problems, since experience with steam injection into operating sand beds $(70)$ showed enhanced particle collection with no increase in pressure drop. Indeed, this result suggests that the loading capacity of a sand bed for sodium hydroxide aerosol would be greatly increased by wetting the bed with condensed steam or by water spray. Water drained from the bed would carry with it sodium hydroxide, and so would clean the bed.

Air leaving the sand bed would be expected to be saturated with water vapor at least for some time period in the accident cycle. A heater is provided to increase the air temperature by about $10^{\circ} \mathrm{F}\left(5.6^{\circ} \mathrm{C}\right)$, which will lower the relative humidity to 70 percent or less. This heater, if operated continuously at the maximum rate, would use less than 50 gallons (190l) of propane per day. The heater requirement is modest.

In summary, only the charcoal adsorber is expected to be sensitive to relative humidity, and a heater is provided to control relative humidity to 70 percent or less, regardless of that of incoming air. The system as designed satisfies this criterion. Rating $=4.0$.

- Criterion 5c. "The system energy consumption is low." Operation of the sand bed filter system would require about $75 \mathrm{~kW}$ of electrical power for the fan and up to 50 gal/day of propane. These energy requirements are modest and do not impose unacceptable demands on emergency diesels or propane storage facilities. Rating $=3.7$.

- Criterion 5d. "The system can be modified to add halogen removal components and other air cleaning devices if needed."

This once-through system already contains a halogen adsorber designed for a DF of 20. Improvement of the halogen adsorber or addition of other air cleaning devices could be easily done. Rating $=3.8$.

- Criterion 5e. "The post-accident recovery is facilitated by the EACS." About 50 percent of the aerosolized material is expected to settle out in the confinement building and the remainder will be trapped in 
the EACS. More than 99 percent of material entering the EACS will be trapped in the sand filter. Particles penetrating the sand filter will be effectively captured by the first HEPA filter. Some halogens will penetrate to the charcoal adsorbers.

Since half of the aerosolized material settles to the floor of the confinement building, there will be a serious cleanup problem in the confinement building regardless of the specific type of once-through EACS used. In the present case, the radioactive material would be distributed within many tons of sand and gravel. It seems unlikely that the sand could ever be quantitatively cleaned, and if a DBST release occurred, the sand filter would be abandoned in-place.

Sand filter disposal would be a minor problem compared to cleanup and disposal of the confinement building and inner containment zones.

While it does not fail this criterion, the sand filter is less desirable than an ideal system which would retain all radioactive material in compact, dry traps. Rating $=1.0$.

- Criterion 6a. "The system cost is low. Capital cost is less than $\$ 10$ million; operating and maintenance costs are low."

The estimated cost of this system, $\$ 4.5$ million, is well below the $\$ 10$ million limit, but is higher than other systems considered in this report. Operating costs would be minimal and would involve periodic in-place testing and occasional changes of HEPA filters and charcoal adsorbers. Due to its inherent simplicity, operating costs (due to maintenance) would be lower for the sand filter than for more complex systems involving scrubbers (CF-22) or electrostatic precipitators $(\mathrm{CF}-23)$. Based on the comparatively high capital cost and the low operating cost, a rating of 1.3 is assigned.

- Criterion 6b. "Materials and techniques used in construction are readily available and easily fabricated."

All of the materials required to build the sand filter system are readily available commercially. No unusual fabrication techniques are required. Rating $=3.5$. 
- Criterion 6c. "Components and equipment are readily available." Many components required to fabricate this system are available commercially as shelf $i$ tems. However, the sand filter itself would have to be constructed in-place of concrete, concrete block, sand and gravel. In some previous installations the fine sand fraction was shipped to the site from the Midwest. Because of the possibility of having to ship the sand aggregate via rail, an intermediate rating of 3.5 is assigned.

7.3.2.6 Mandatory Criteria (CF-24). The sand bed filter, backed up by HEPA filters and charcoal adsorbers, easily meets all mandatory criteria; hence there are no major problems associated with its use in a containment/ confinement plant. The major drawbacks to the system are its large size and high cost, and both of these could probably be greatly reduced by an optimized design based on both loading and removal efficiency.

7.3.2.7 Rating (CF-24). The numerical rating of system CF-24 is as follows:

\begin{tabular}{lr}
\multicolumn{1}{c}{ Criteria Group } & Rating \\
\hline System Effectiveness & 92.5 \\
System Reliability & 106.7 \\
Containment Compatibility & 22.0 \\
Technological Credibility & 79.0 \\
System Characteristics \& Flexibility & 42.5 \\
Fabrication Effort & 13.5 \\
\multicolumn{1}{c}{ Total } & 356.2
\end{tabular}

7.3.2.8 Development Requirements (CF-24). The development effort required before a sand bed filter is built for an LMFBR plant with containment/ confinement features falls into two areas. First, effort should be applied to increase the loading capacity for sodium oxide/hydroxide aerosol particles and to reduce the size and cost for a given mass loading and air flow rate. Optimization could probably be attained by using larger sizes for the aggregate and permitting some decrease in the particle removal efficiency. If the 
loading capacity can be increased by a factor of ten (to $\sim 1 \mathrm{lb} / \mathrm{ft}^{2}$ or $4.9 \mathrm{~kg} / \mathrm{m}^{2}$ ), the total cost of the CF-24 system would be reduced to approximately one-third of the cost estimated in this report.

The second area requiring development would be proof testing of a largescale module of the sand bed which has prototypic aggregate size and sand bed thickness but a reasonable superficial area for testing. The proof tests should be performed at a prototypic air velocity and should cover a range of temperatures and inlet relative humidities. The loading for sodium oxide/ hydroxide aerosol and the removal efficiency for $0.3 \mu \mathrm{m}$ DOP particles should be measured. Full-scale backup HEPA and charcoal adsorbers should be used in these tests.

\subsubsection{Other Systems for Use with Containment/Confinement Plants}

Many of the air cleaning concepts and devices evaluated for use in a single containment plant are obviously not suited for use in a containment/ confinement plant arrangement. For example, low-efficiency devices such as cyclones and settling chambers are at a disadvantage for use in a oncethrough mode of operation. Direct in-containment application methods such as liquid sprays, acoustic agglomeration and powder discharge are useful only if the contaminated air is contained for an appreciable period of time. Foam, steam conditioning, fluidized bed and mechanical separators appear to have too low reliability and flexibility for once-through, high-efficiency systems.

The wet scrubber (CF-22) and sand bed filter (CF-24) systems are discussed in Sections 7.3.1 and 7.3.2, respectively, of this report. The remaining four systems which appear to offer a reasonable chance for satisfactory performance in containment/confinement plants are prefilter-HEPA systems, electrostatic precipitators, bag filters and deep bed graded media filters. The latter three require HEPA backup filtration, but may be feasible. The bag filters are discounted because of the possibility of rupture of one or more of the bags, which would possibly allow the downstream components to become overloaded. Also, shaking the wet sodium hydroxide deposit from the bags appears to be a severe problem in the once-through mode where long-term operation is essential. The deep bed graded media filters appear to be more 
costly than alternate prefilters and would probably require more development effort. The prefilter-HEPA system (CF-21) and the electrostatic precipitator (CF-23) are discussed briefly in the following sections of this report.

\subsubsection{Confinement System - Prefilter, HEPA, Charcoal, HEPA (CF-21A,} for Sodium Fire or DBST.

- System Description. This air cleaning system is a filter and adsorber train designed for removal of either the radioactive DBST aerosol or the sodium fire aerosol defined in Table 12. In evaluating its performance and assigning rating factors, the dual accident capability is considered and the accident type which is most demanding is used for each criterion.

As discussed in previous sections of this report, the major design problem is the large quantity of sodium oxide/hydroxide which must be collected by the system while keeping a nearly constant air flow rate. To do this we have used a prefilter and HEPA filter combination similar to system SR-1, followed by charcoal trays and a final HEPA filter bank.

The loading capacity of both the prefilters and the HEPA filters are taken as $4 \mathrm{lb}(1.8 \mathrm{~kg})$ per standard filter unit (2-ft $\times 2-\mathrm{ft} \times 1-\mathrm{ft})$. If the efficiency of the prefilter is 50 percent, it would be expected that the 2100 pounds $(950 \mathrm{~kg})$ of sodium smoke could be held on a combination of 260 prefilters and 260 HEPAs. The system CF-21A design, however, allows for the possibility that changes in the aerosol particle size and prefilter efficiency may affect the loading of the prefilter. Hence, each bank is sized to hold 90 percent of the total sodium fumes. This arrangement of two filter banks in series is adequate for the removal of sodium smoke, but, for the DBST case, charcoal and final HEPA filters are needed to remove halogens.

It is necessary to provide an air heater so that the relative humidity is kept at 70 percent or less at the inlet to the charcoal beds for good $\mathrm{CH}_{3} \mathrm{I}$ removal. (21) The fan must be sized to handle $15,000 \mathrm{CFM}\left(7 \mathrm{~m}^{3} / \mathrm{s}\right)$ of air over a temperature range of $-10^{\circ} \mathrm{F}$ to $300^{\circ} \mathrm{F}\left(-23^{\circ} \mathrm{C}\right.$ to $\left.150^{\circ} \mathrm{C}\right)$. To allow for the effects of air density 
changes, a flow control damper will be used. Table 35 lists the important design parameters used for system $\mathrm{CF}-21 \mathrm{~A}$.

TABLE 35

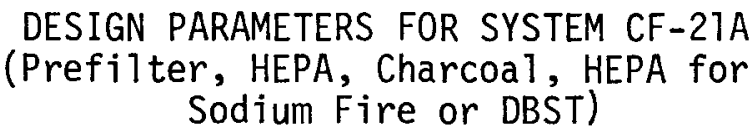

Parameter

Air Flow Rate

Prefilter

Quantity

Size

Collection Efficiency

Pressure Drop When Loaded

Loading Capacity per Unit

HEPA Filters (1st Bank)

Quantity

Size

Collection Efficiency

Pressure Drop When Loaded

Loading Capacity per Unit

Charcoal Beds (Tray Type)

Quantity

Flow

Thickness

Type

Residence Time

Maximum Humidity

Air Heaters

HEPA Filters (Final Bank)

Quantity

Size

Pressure Drop

Fan (Static Pressure)

Motor

Damper

Filter Building Size
Value

$15,000 \operatorname{CFM}\left(7.0 \mathrm{~m}^{3} / \mathrm{s}\right)$

480

$2-f t \times 2-f t \times 1-f t(0.61 \times 0.61 \times 0.3 m)$

$0.5 \pm 0.3$

4 in. $\mathrm{H}_{2} \mathrm{O}(1000 \mathrm{~Pa})$

$41 \mathrm{~b}(1.8 \mathrm{~kg})$

480

$2-f t \times 2-f t \times 1-f t(0.61 \times 0.61 \times 0.3 m)$

0.9995

6 in. $\mathrm{H}_{2} \mathrm{O}(1500 \mathrm{~Pa})$

$4 \mathrm{lb}(1.8 \mathrm{~kg})$

40 trays

$380 \operatorname{CFM}\left(0.18 \mathrm{~m}^{3} / \mathrm{s}\right)$ per tray

2 in. $(51 \mathrm{~mm})$

Impregnated

$0.2 \mathrm{sec}$

$70 \% \mathrm{RH}$

$60 \mathrm{~kW}$

15

$2-f t \times 2-f t \times 1-f t(0.61 \times 0.61 \times 0.3 m)$

1 in. $\mathrm{H}_{2} \mathrm{O}(250 \mathrm{~Pa})$

27 in. $\mathrm{H}_{2} \mathrm{O}(5200 \mathrm{~Pa})$

$80 \mathrm{HP}(60 \mathrm{~kW})$

Outlet Type

$25-\mathrm{ft} \times 75-\mathrm{ft} \times 22-\mathrm{ft}(7.6 \times 23 \times 6.7 \mathrm{~m})$ 
- System Effectiveness. The effectiveness of this system is judged to be quite good. The two banks of HEPA filters will provide a minimum DF for aerosol particles of 1000 each. The overall DF is well above the required value of 100 . The loading capacity of the prefilter and first HEPA filter bank may be sensitive to physical properties of the aerosol, but these filter banks are oversized and either bank can accommodate 90 percent of the total mass for the sodium fire accident. No loading problem exists for the postulated DBST. Radiation-resistant materials and gaskets are available and would be used to meet Regulatory Guide 1.52 requirements. ${ }^{(14)}$ Total group score $=75.5$.

- System Reliability. This system is quite simple and will start and run with very good reliability. The long-term integrity of the first HEPA filter bank may be decreased by chemical reaction of the sodium smoke with the glass fibers. However, the second HEPA filter bank will remain intact. For the DBST release, highly reliable long-term operation is required and can be achieved by this system because of the lower loading and lesser corrosion problem for this accident case. Total group score $=101.4$.

- Containment Compatibility. This is a large filter system, requiring a $2000 \mathrm{ft}^{2}\left(185 \mathrm{~m}^{2}\right)$ building. However, this should not be a problem for the confinement type of plant. The system is judged to be compatible with the normal plant operations. Total group score $=27.1$.

- Technological Credibility. This filter system is similar in all respects to the filter-adsorber systems used in many LWR plants, with the exception of the high mass loading requirement. Verification of the high mass loading ability of the filters for sodium smoke is needed. The system collection efficiency for aerosols and halogens can be tested in-place. Total group score $=77.2$.

- System Characteristics and Flexibility. With the possible exception of changes in filter flow resistance with humidity, this system can tolerate any expected particle sizes or atmospheric conditions. The CF-21A design does not address post-accident recovery, but remote 
handling and removal of components could be incorporated. Only 50 percent of the material released from the primary during the DBST would be held in the filter system and this would be only of minor assistance in cleanup operations. Total group score $=40.2$.

- Fabrication Effort. All the system components and materials are standard and commercially available. If development tests should show that the prefilter specifications are too demanding, some change in the design would be necessary in order to use standard units. The total system installed cost is estimated at $\$ 1.94$ mi1lion. Annual operating costs should be low. Total group score $=20.0$.

- Conclusions (CF-21A). It is concluded that this system could be built to handle effectively either a sodium fire or the DBST accident case with an overal1 DF greatly exceeding the design requirement of 100. The system size is much larger than a normal 15,000 CFM $\left(7 \mathrm{~m}^{3} / \mathrm{s}\right)$ air cleaning system because of the need to hold 2100 pounds $(950 \mathrm{~kg})$ of sodium smoke. The loading capacity of the prefilters and HEPA filters needs to be verified. The total system score is 341 , ranking 2 nd among the four systems evaluated for the confinement system plant.

7.3.3.2 Confinement System - Prefilter, HEPA, Charcoal, HEPA (CF-21B, for DBST Without a Sodium Fire).

- System Description. This air cleaning system is similar in design to system CF-21A, but is designed to handle only the postulated DBST accident. As was noted previously in this report, the design basis sodium fire in the confinement building determines the size and cost of an EACS because the aerosol mass generated by the sodium is much larger than would be evolved by the DBST postulated here. In order to show quantitatively what part of the system size and cost results from the requirement to handle both the DBST and a major sodium fire, system $C F-21 B$ was designed to handle only the DBST conditions described in Table 12.

The filter train is designed to process 15,000 CFM $\left(7 \mathrm{~m}^{3} / \mathrm{s}\right)$ of air 
at a temperature of $-10^{\circ} \mathrm{F}$ to $110^{\circ} \mathrm{F}\left(-23^{\circ} \mathrm{C}\right.$ to $\left.43^{\circ} \mathrm{C}\right)$, and to provide a DF of 100 for aerosol particles and a DF of 20 for halogens. In sequence, the components are:

18 Prefilters $(2-f t \times 2-f t \times 1-f t)$

18 HEPA filters $(2-\mathrm{ft} \times 2-\mathrm{ft} \times 1-\mathrm{ft})$

45 charcoal adsorber trays ( 2 in. thick)

18 HEPA filters (2-ft $\times 2-f t \times 1-f t)$

Fan $\left(15,000 \mathrm{CFM}\right.$ at 11 in. $\left.\mathrm{H}_{2} \mathrm{O}\right)$

Motor (50 HP).

In previous systems which had to filter air ranging from $-10^{\circ} \mathrm{F}$ to $300^{\circ} \mathrm{F}\left(-23^{\circ} \mathrm{C}\right.$ to $\left.150^{\circ} \mathrm{C}\right)$, an outlet damper was used to regulate the air flow variability which results from the air density (temperature) changes and filter flow resistance change with loading. No flow control is needed for the present, lower temperature range and low filter loading. Extra filters, however, are used to provide some extra capacity. To assure efficient removal of organic iodide, the inlet air is warmed to reduce the relative humidity to below 70 percent by recirculation of a $500 \mathrm{CFM}\left(0.23 \mathrm{~m}^{3} / \mathrm{s}\right)$ side stream of air heated to $500^{\circ} \mathrm{F}\left(260^{\circ} \mathrm{C}\right) ; 70 \mathrm{~kW}$ of electric power is needed for the heater. A protective filter building and the necessary ductwork and isolation valves complete the system.

- System Effectiveness. This system is highly effective in maintaining a DF of 100 minimum. Each bank of HEPAs will have a minimum tested removal of 99.95 percent. The low aerosol loading on the filters makes the system insensitive to the particle humidity. Heaters to reduce the air humidity to 70 percent wil1 insure 95 percent removal of organic iodides. Components of known radiation resistance for EACS service are available. Total group score $=85.0$.

- System Reliability. This is a very simple system using only a fan motor and air heaters, both of demonstrated reliability in LWR air cleaning systems. (2) The system may have to run for many weeks in the event of a DBST release, and is capable of doing so. Total group score $=113.3$. 
- Containment Compatibility. This system is compact and is able to make efficient use of the HEPA air flow capacity due to the low aerosol loadings. The filter building is only $750 \mathrm{ft}^{2}\left(70 \mathrm{~m}^{2}\right)$ and could be conveniently located near (or possibly within) the confinement building. Total group score $=27.7$.

- Technological Credibility. As noted before, this system is based on a well-developed technology and is conservatively designed using recommended guidelines. $(21,24)$ A1l components are readily testable in-place for operability and efficiency. Total group score $=84.0$.

- System Characteristics and Flexibility. The system's efficiency for particle removal is essentially independent of particle size. An additional thickness of charcoal can be provided if a higher DF for halogens is required. The aerosol removal processes are not deleteriously dependent on the expected accident atmospheric conditions. The humidity dependence of organic iodide adsorption has been allowed for in the design. Post-accident recovery could be facilitated by incorporation of remote handling capability into the system. Total group score $=46.7$.

- Fabrication Effort. The cost of this system is reduced considerably below that of system CF-21A because of the much reduced scope of the postulated accident. It is estimated at $\$ 870,000$. A11 components and techniques are standard and are commercially available. Total group score $=25.5$.

- Conclusions (CF-21B). This conventional filter-adsorber system fully satisfies all the criteria for use in a containment/confinement plant where a sodium fire in the confinement building is not assumed. It cannot be compared directly to the other systems which are designed to handle a sodium fire as well as a radiological DBST, but is a much more compact and less expensive EACS than any of the other systems evaluated. 
7.3.3.3 Confinement System - Electrostatic Precipitator, HEPA, Charcoal, HEPA (CF-23).

- System Description. This system uses an electrostatic precipitator (ESP) as a preliminary gas cleaning device to reduce the amount of sodium fire aerosol which would reach the first HEPA filter bank. Charcoal adsorbers for halogen removal and a final HEPA filter bank are provided to ensure a minimum DF of 100 overal1. Air heaters upstream of the charcoal will be used to keep the humidity below 70 percent for effective $\mathrm{CH}_{3} \mathrm{I}$ removal.

The ESP must remove the 2- $\mu \mathrm{m}$ MMD sodium oxide/hydroxide particles with a minimum efficiency of 97 percent in order to prevent overloading the HEPA filters during the sodium fire case. A singlestage Cottrell-type ESP with a ratio of electrode area to flow area of $10 \mathrm{sec} / \mathrm{ft}(33 \mathrm{sec} / \mathrm{m})$ is 98.5 percent efficient, as shown by a calculation similar to that described for system SR-12. The calculated efficiency for the DBST case would be higher than 98.5 percent due to the increased particle size expected from this accident.

The CF-23 ESP has eleven parallel channels, each 0.75-ft wide, 8-ft high and 15-ft long $(0.23 \mathrm{~m} \times 2.4 \mathrm{~m} \times 4.6 \mathrm{~m})$, which provide a total collector surface area of $2500 \mathrm{ft}^{2}\left(230 \mathrm{~m}^{2}\right)$. For the sodium fire case, approximately 32 pounds $(14.5 \mathrm{~kg})$ would escape the precipitator and would be collected downstream on the sixteen HEPA filters for a loading of $2.0 \mathrm{lb}(0.90 \mathrm{~kg})$ per filter unit. This is well below the loading capacity of $41 \mathrm{~b}(1.8 \mathrm{~kg})$ assumed for systems CF-21A and SR-1.

The dust loading in the ESP results ir, a deposit averaging 0.5 inches $(13 \mathrm{~mm})$ thick over the collector plate surfaces if the deposit is dry and fluffy. The deposit at the inlet will be thicker than this and it will be necessary to clean the plates to maintain consistent precipitator performance. This can be done either by rapping or by irrigating the plates with water or other liquid. For the present design, rapping is specified but tests may show that irrigation is necessary.

The entire CF-23 system can be housed in a $16-\mathrm{ft} \times 52-\mathrm{ft}$ $(4.9 \mathrm{~m} \times 16 \mathrm{~m})$ building. Design parameters are summarized in 
Table 36, and the aerosol parameters are the same as used in Table 12.

- System Effectiveness. The system is very effective in removing the radioactive DBST aerosol particles. Its calculated overall DF is greater than $10^{7}$. The charcoal beds will provide a hologen DF of 20 . Greater halogen DFs can be obtained, if required, by using deeper charcoal beds. For the sodium fire accident, the ESP performance can be affected by particle buildup on the electrodes. Radiation and decay heat are not problems with this system. Total group score $=85.1$.

- System Reliability. The reliability of this system is good although it is more complex than a simple filter system. Flow control and humidity control are both required. The reliable operation of the ESP will require redundant power supplies and frequent checks of cable, insulators, etc. However, precipitators are used in industry successfulty under more severe conditions. Total group score $=88.4$.

- Confinement Compatibility. The score for this criteria group is high. This is a compact system, relative to the alternates, and inadvertent operation causes no problems. Total group score $=27.4$.

- Technological Credibility. The ESP, filters and charcoal adsorbers are all well established air cleaning methods. In-place testing can be performed. This system is of typical industrial size. The cleaning (or the need for cleaning) of the $\mathrm{NaOH}$ from the precipitator plates must be verified. Total group score $=74.0$.

- System Characteristics and Flexibility. This system can accommodate the complete range of particle sizes which can be expected. Electrostatic precipitator performance can be influenced by particle conductivity if very high or very low and testing would be needed to evaluate the sodium smoke removal over the range of accident conditions. In a similar manner, the pressure drop at the first HEPA bank may also be influenced by the particle size and air humidity. Post-accident recovery is assisted to some extent in that some 50 percent of the released material will be retained in the EACS. Total group score $=38.7$. 
TABLE 36

DESIGN PARAMETERS FOR SYSTEM CF-23

(Electrostatic Precipitator, HEPA, Charcoal, HEPA)

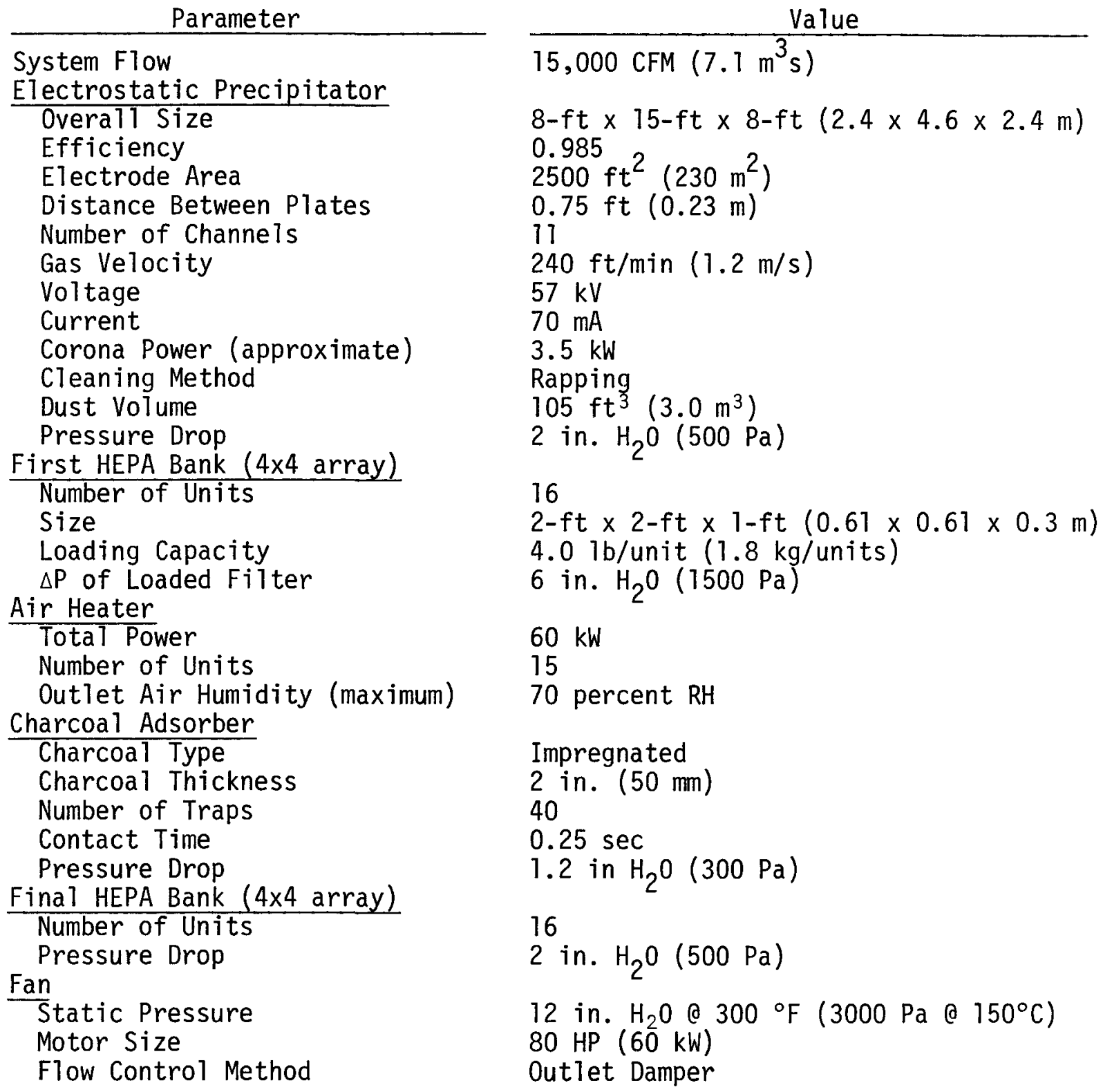

- Fabrication Effort. This system uses standard components and materials. The initial installed cost, including building, is estimated to be $\$ 1.7$ million. Total group score $=22.0$. 
- Conclusions (CF-23). This system can handle the confinement building exhaust during either a major sodium fire or the postulated DBST. Overall DF for aerosol particles is greater than $10^{7}$. The startup and long-term operating reliability of the ESP is lower than for the filter systems (CF-21 and CF-24), but operation of the ESP is not essential for the DBST case. The system is the most compact of the four systems which are capable of handling a sodium fire. It is also the least costly. The total system score is 336 , 3rd highest among the four systems evaluated for the confinement system plant.

\subsection{Selection of Most Promising Systems}

\subsubsection{Numerical Ratings for Single Containment Plant EACS}

The numerical ratings and weighted scores assigned in Section 7.1 for single containment plant systems are tabulated in Tables $\mathrm{Cl}-\mathrm{C} 3$ in Appendix $\mathrm{C}$. The ratings represent the best judgment of the authors and were arrived at after both independent and joint assessments of how well each criterion was satisfied on a system-by-system basis. Quantitative evaluations were possible for some of the criteria (e.g., cost, size, DRF, energy requirement), but many of the criteria ratings were assigned on a subjective basis.

The twenty EACS systems evaluated for use in single containment plants are ranked in Table 37 according to numerical score for the total system and also for each of the six criteria groups. As noted in Table 37, nine of the systems rated unacceptably low in the mandatory criteria defined in Table 15. The nine systems which failed the mandatory criteria are listed in Table 38. Two of the systems failed because of their large size (SR-3, sand bed, and SR-11, settling bed plus HEPA). Although the size criterion is somewhat arbitrary, it is felt that the added containment volumes required for the sand bed (22 percent of the RCB volume) and the settling bed ( 45 percent) are clearly excessive. Four systems failed because they used water which creates a potential hydrogen problem (SR-7, wet scrubber; SR-13, steam conditioner; SD-14, liquid spray; and SD-16 foam). If a suitable alternate liquid could be found to replace water in these systems they would rate much higher and the SD-14 liquid spray system would probably be the best overall system. 


\section{TABLE 37}

RANKING OF TWENTY EACS CANDIDATES BY TOTAL SCORE AND BY CRITERIA GROUPS - SINGLE CONTAINMENT PLANT

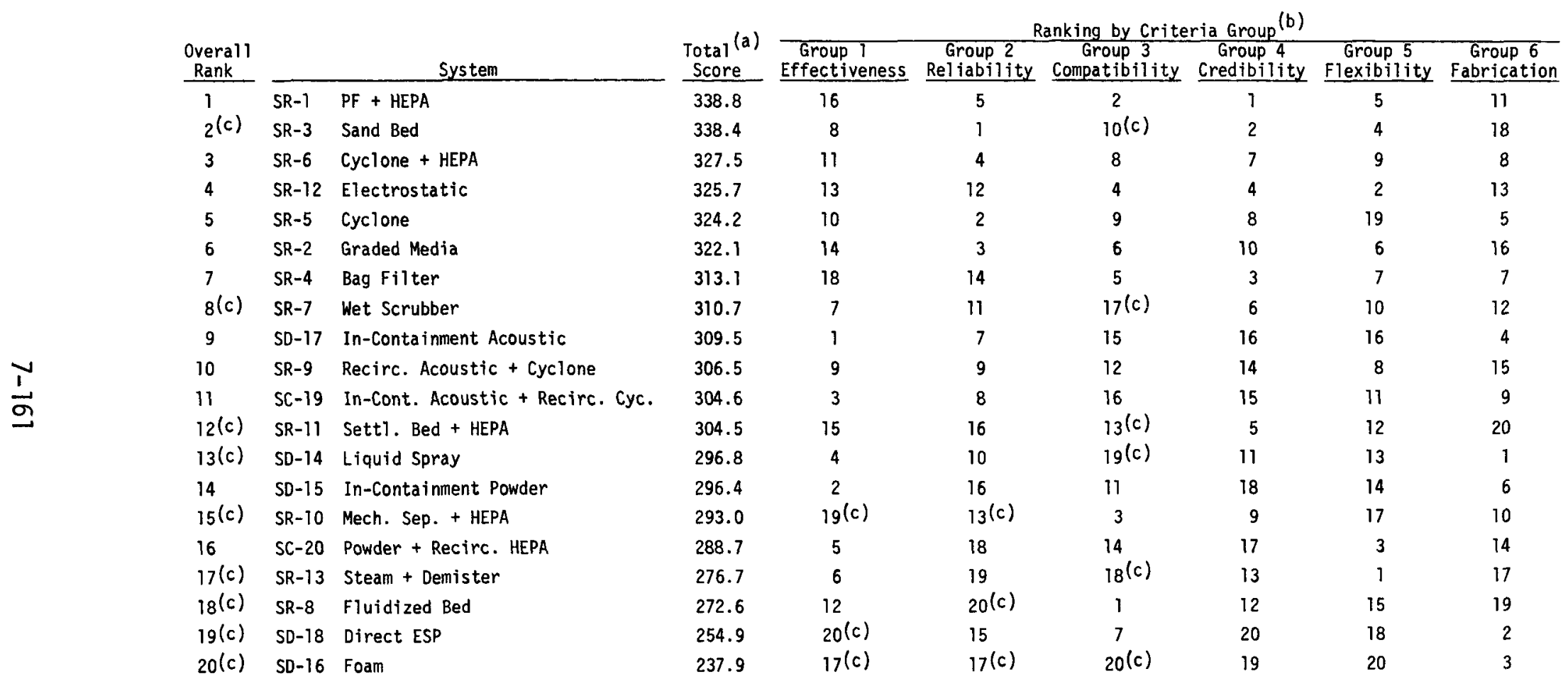

(a) See Tables $C-1$ through $C-3$ in Appendix $C$ for detailed ratings.

(b) See Table B-1 in Appendix B for complete definition of criteria.

(c) Denotes failure of one or more mandatory criteria as defined in Table 15. 
Two systems failed beccause of unacceptably low reliability for operating throughout the required period of time (SR-8, fluidized bed; and SR-10, mechanical separator plus HEPA filters). Both of these are sensitive to handling sticky particles. One system failed because it was ineffective in providing a reasonable dose reduction factor (SD-18, in-containment electrostatic precipitator).

The eleven EACS systems remaining after elimination of the failed systems are listed in Table 39 in order of decreasing total scores. The ranking within each of the criteria groups are also shown. The system with the highest overall rating is the recirculating-prefilter, HEPA system, SR-1.

TABLE 38

EACS CANDIDATES FAILING MANDATORY CRITERIA - SINGLE CONTAINMENT PLANT

\section{System}

\section{SR-3 Sand Bed}

SR-7 Wet Scrubber, Demister

SR-8 Fluidized Bed

SR-10 Mechanical separator, HEPA

SR-11 Settling Bed, HEPA

SR-13 Steam Conditioner, Demister

SR-14 Liquid Spray

SD-16 Foam

SD-18 In-Containment Electrostatic Precipitator
Mandatory Criteria Failed (a)

3c Size

3b No pressure buildup

2d Reliable operation

1c Dry or sticky particles

2d Reliable operation

3c Size

3b No pressure buildup

3b No pressure buildup

Ib Decay heat removal

2d Reliable operation

$3 b$ No pressure buildup

1a LoW DRF

(a) See Table B-1 in Appendix B for complete definition of criteria. 
TABLE 39

RANKING OF EACS AFTER ELIMINATION OF FAILED

SYSTEMS - SINGLE CONTAINMENT PLANT

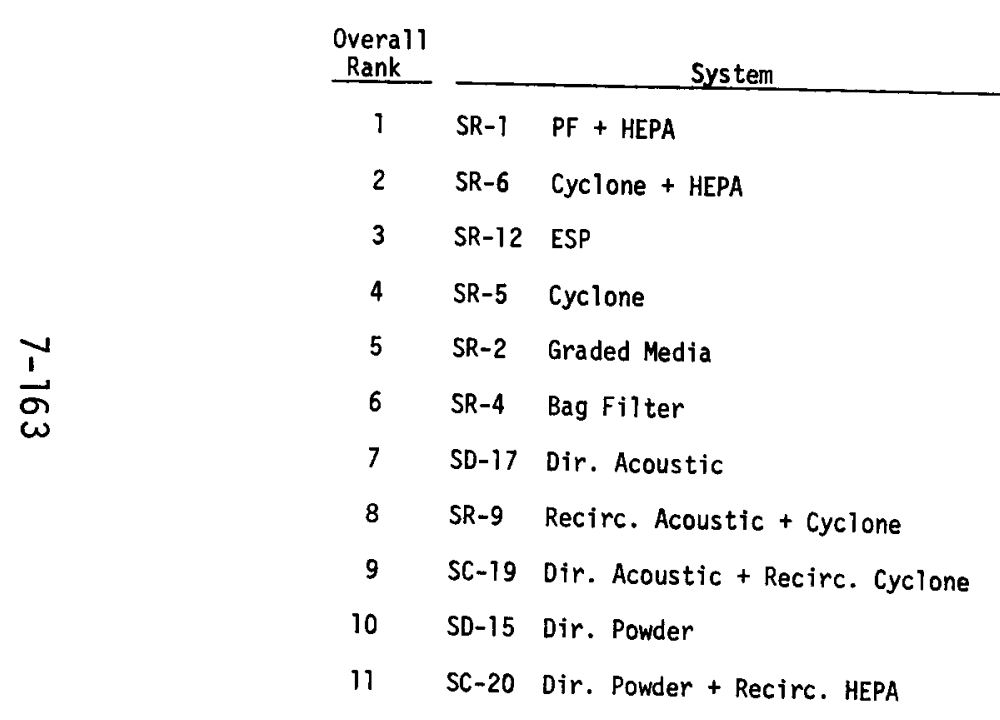

Total Group 1 Group 2 Rank by Criteria Group

Score Effectiveness Reliability Compatibility Group 4 Group 5 Group 6

$\begin{array}{lllllll}3 & 10 & 4 & 1 & 1 & 3 & 7\end{array}$

$\begin{array}{llllllll}328 & 8 & 3 & 5 & 4 & 7 & 5\end{array}$

$\begin{array}{lllll}326 & 7 & 8 & 5 & 7\end{array}$

$\begin{array}{lllll}8 & 3 & 1 & 8\end{array}$

$\begin{array}{llll}6 & 1 & 6\end{array}$

$\begin{array}{llll}322 & 9 & 2 & 4\end{array}$

$\begin{array}{llll}313 & 11 & 9 & 3\end{array}$

$\begin{array}{llll}310 & 1 & 9 & 3\end{array}$

$\begin{array}{lll}307 & 5 & 7\end{array}$

305

296

289

$3 \quad 6$

210

11

5
6
2
9
7
8
11
10

7
5
8
2
11
4
1
10
6
3
9




\subsubsection{Recommended Systems for Single Containment Plant}

Table 39 shows that the recirculating systems rank higher in total score than those which act directly in containment. Closer examination of Table 39 reveals that this is due to the generally low ratings given the concepts for reliability, compatibility, credibility and flexibility. The in-containment (acoustic agglomeration and powder dispersal, either singly or in combination with recirculating system) rate very high in effectiveness and fabrication. This suggests that if development effort can improve the credibility, reliability and compatibility of the two in-containment concepts they would probably become the best EACS candidates. It seems probable that the credibility group ratings, at least, could be improved considerably by proper development effort.

Figure 32 illustrates that the two in-containment concepts (SD-15, powder dispersal; and SD-17, acoustic agglomeration) or combination systems using these two concepts (SR-9, SC-19, SC-20) are generally low in credibility but high in effectiveness. The diagonal line in Figure 32 arbitrarily separates the systems into those which offer high and low incentive for improvement by development effort. The systems furthermost to the left of the line offer the most potential. Similarly, Figure 33 plots the reliability versus the credibility ratings.

Another criterion which can be used to select the most promising EACS for development is cost. In Figure 34 the numerical ratings are plotted versus the installed cost for all twenty systems evaluated. The nine systems which failed the mandatory criteria are designated by solid symbols, while the remaining eleven systems are plotted with open symbols. Since low cost and high numerical rating are desirable, systems lying to the left of the diagonal line are the more favorable candidates. On a cost basis, system SD-17 (in-containment acoustic agglomeration) is the best system, having a reasonably high rating with the lowest cost of any of the eleven feasible systems. The powder dispersal system, SD-15, and the two cyclone systems (SR-5 and SR-6) are also cost favorable.

Table 40 lists the systems that are favored by the four selection criteria of overall rating score, research and development potential based on 


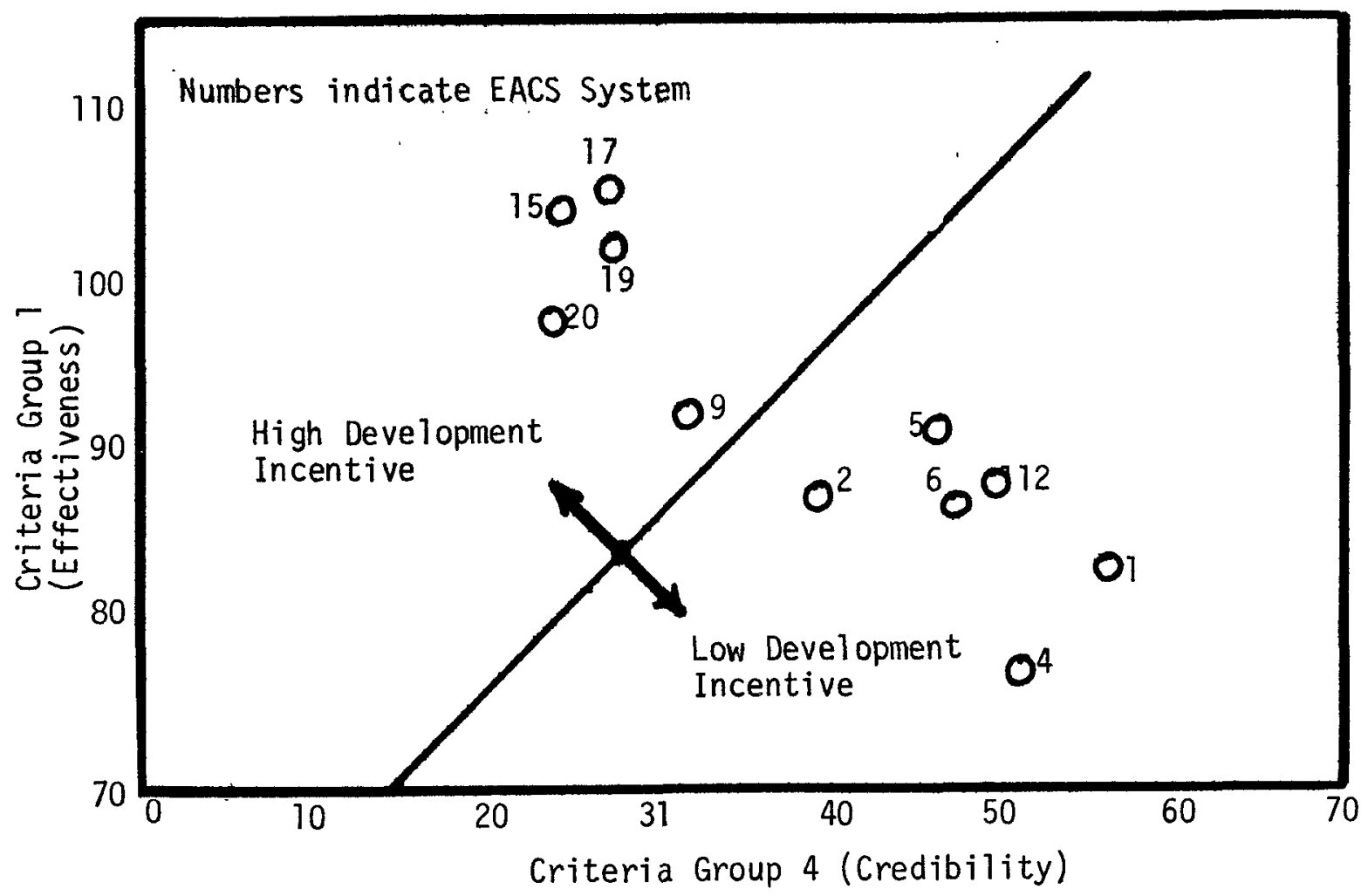

FIGURE 32. EACS Effectiveness Versus Credibility Ratings.

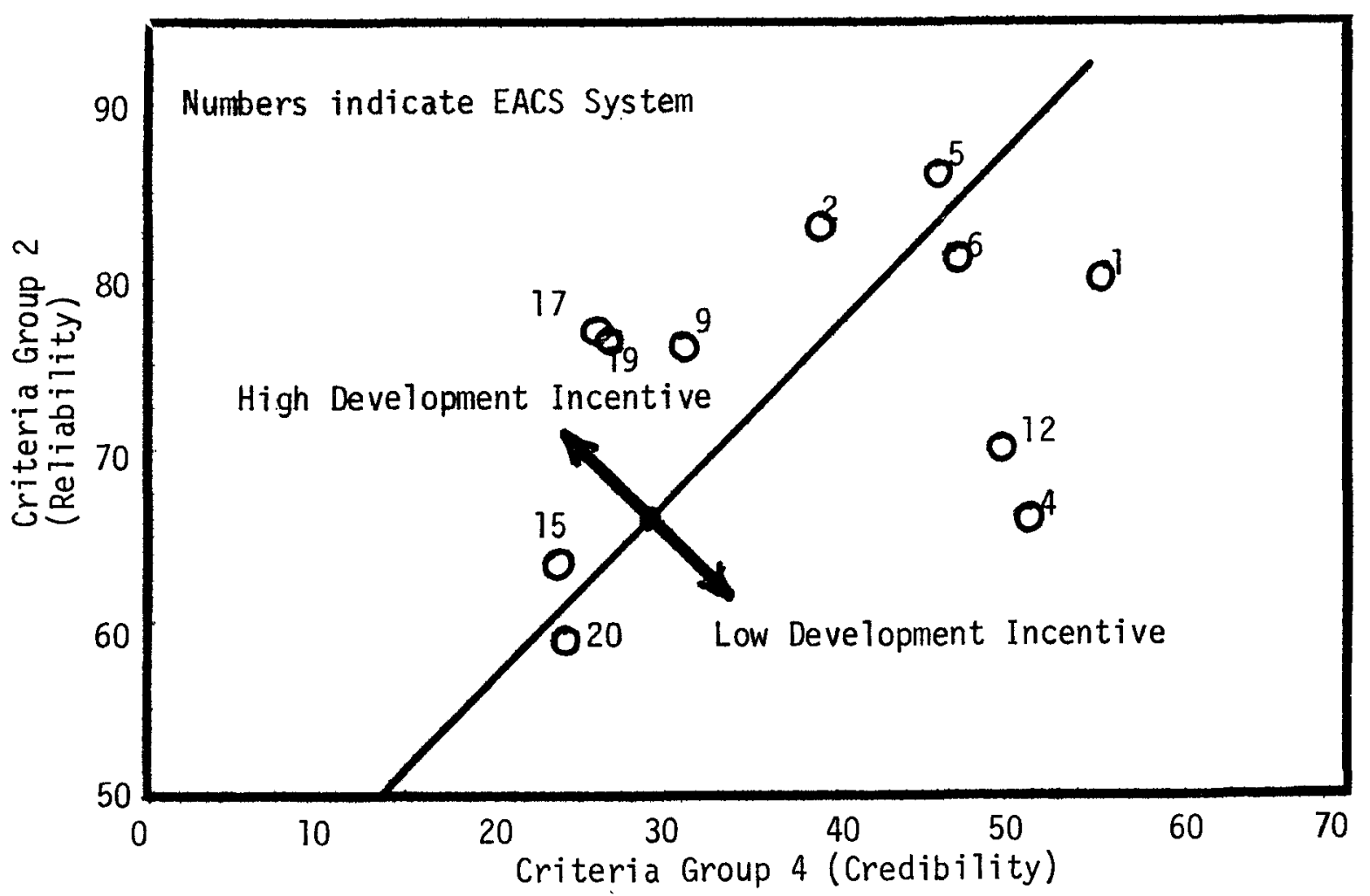

FIGURE 33. EACS Reliability Versus Credibility Ratings. 


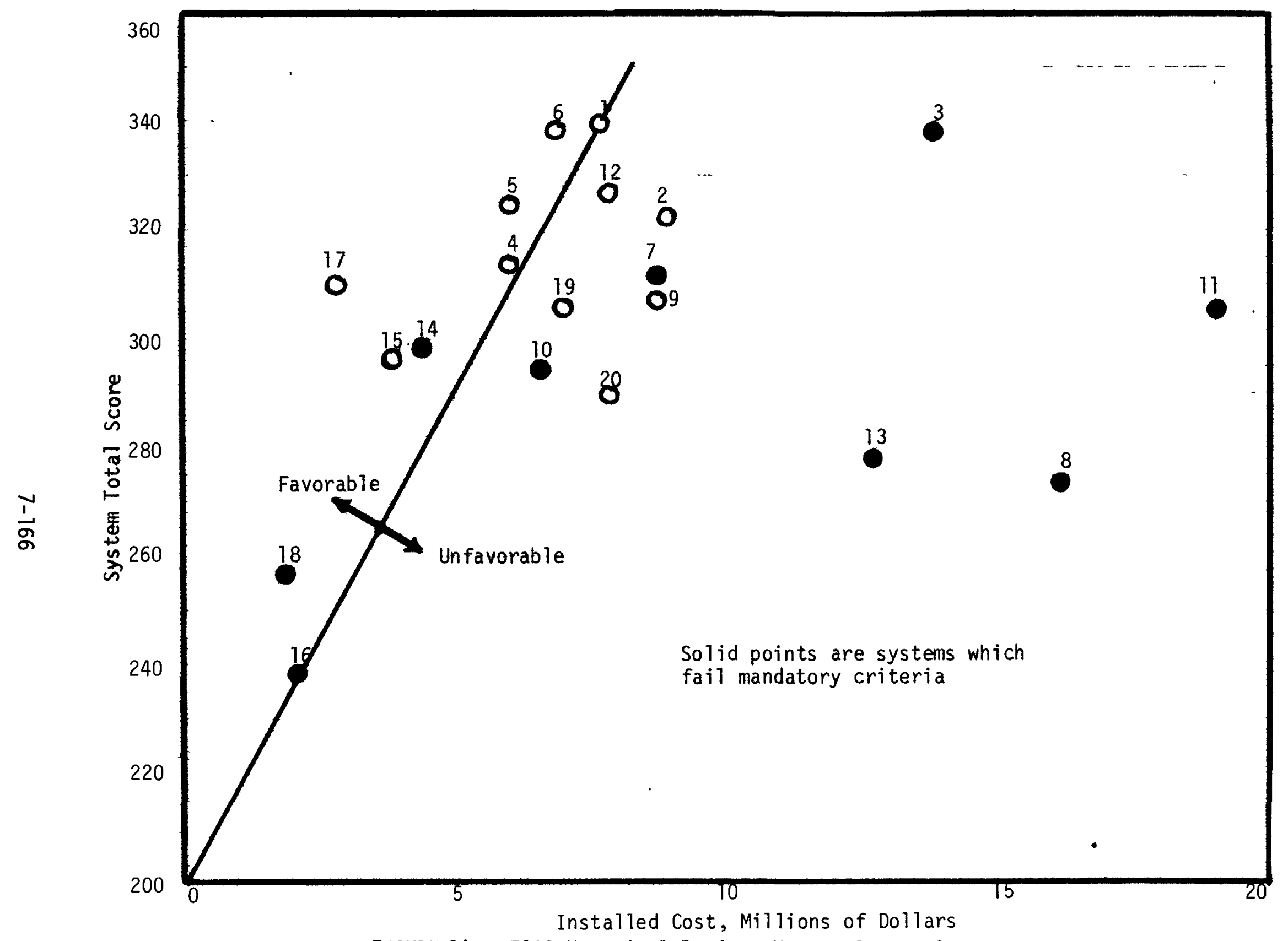

FIGURE 34. EACS Numerical Ratings Versus System Cost. 
reliability, and system installed cost. In Table 41, the systems are ranked by the number of times each is favored in Table 40 . The in-containment acoustic agglomeration, in-containment powder dispersal, and recirculating cyclone systems are each favored by three out of the four rating methods.

TABLE 40

SYSTEMS RATED BEST BY SEVERAL SELECTION

CRITERIA - SINGLE CONTAINMENT PLANT

\begin{tabular}{|c|c|c|c|}
\hline $\begin{array}{l}\text { Overal1 } \\
\text { Rating } \\
\text { Score (a) } \\
\end{array}$ & $\begin{array}{l}\text { R\&D Potential } \\
\text { Effectiveness- } \\
\text { Credibility (b) }\end{array}$ & $\begin{array}{l}\text { R\&D Potential } \\
\text { Reliability- } \\
\text { Credibility (c) } \\
\end{array}$ & $\begin{array}{l}\text { System } \\
\text { Cost } \\
\text { Basis (d) }\end{array}$ \\
\hline $\begin{array}{l}\text { SR-1 } \\
\text { SR-6 } \\
\text { SR-12 } \\
\text { SR-5 } \\
\text { SR-2 }\end{array}$ & $\begin{array}{l}\text { SD-15 } \\
\text { SD-17 } \\
\text { SC-19 } \\
\text { SC-20 } \\
\text { SR-9 }\end{array}$ & $\begin{array}{l}\text { SD-17 } \\
\text { SC-19 } \\
\text { SD-15 } \\
\text { SR-2 } \\
\text { SR-5 } \\
\text { SR-9 }\end{array}$ & $\begin{array}{l}\text { SD-17 } \\
\text { SD-15 } \\
\text { SR-5 } \\
\text { SR-6 } \\
\text { SR-4 }\end{array}$ \\
\hline
\end{tabular}

(a) From Table 39

(b) From Figure 32

(c) From Figure 33

(d) From Figure 34

For the purpose of defining areas of development needs, it is helpful to convert the preceding evaluation from a system basis to an evaluation of air cleaning concepts or equipment components. Only eight different air cleaning processes or types of equipment are used in the eleven systems ranked in Table 41. By counting the number of times each air cleaning concept or equipment component is used or favored in Table 41 a ranking by favored air cleaning concept is obtained and reported in Table 42. The latter table suggests that cyclones, acoustic agglomeration, and powder dispersal are the most promising areas for future development effort aimed at providing the best overal1 EACS for single containment LMFER plants. However, the best system at the present state of technology is the prefilter-HEPA filter system as described in system SR-1. Because the SR-1 design is very dependent upon 
TABLE 41

RANKING OF SYSTEMS FAVORED FOR SINGLE CONTAINMENT PLANTS

System

Number of Times Favored in Table

SD-17 In-Containment, Acoustic 3

SD-15 In-Containment, Powder 3

SR-5 Recirculating, Cyclone 3

SR-6 Recirculating, Cyclone + HEPA

SC-19 Combination, In-Containment Acoustic + Recirc. Cyclone

SR-2 Recirc., Graded Media Filter 2

SR-9 Recirc., Acoustic + Cyclone 2

SR-1 Recirc., Prefilter + HEPA 1

SR-12 Recirc., Electrostatic Precipitator 1

SC-20 Combination, In-Containment Powder

+ Recirc. HEPA

SR-4 Recirc., Bag Filter

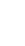

TABLE 42

\section{AIR CLEANING CONCEPTS FAVORED FOR DEVELOPMENT FOR LMFBR SINGLE CONTAINMENT PLANTS}

Air Cleaning Concept or Device

High Efficiency Cyclone Separator

Acoustic Agglomeration

Powder Dispersal

HEPA Filters

Deep Bed Graded Media Filter

Prefilter

Electrostatic Precipitator

Bag Filter
Number of times Favored (a)

9

(a) From Table 41 
the assumed filter loading capacities, it is also important that HEPA and prefilter loading capacities be verified for the EACS-DBST conditions.

\subsubsection{Numerical Ratings for Containment/Confinement EACS}

The numerical ratings and weighted scores assigned in Section 7.3 for the containment/confinement EACS systems are summarized in Table C-4 in Appendix $C$. As discussed in Section 7.3, the candidate systems were designed to handle the confinement building effluent from two postulated accident cases: a sodium fire and a radiological DBST release. Because the sodium fire releases one thousand times more mass to the EACS than does the DBST, the design and size of the systems were dominated by the considerations for high mass loadings for the sodium fire case.

The four systems that were designed to handle both types of accidents are compared and ranked by numerical score in Table 43 . The ranking by each of the six criteria groups is also given in the table. None of the systems fail any of the mandatory criteria listed in Table 15. Table 43 shows that system CF-24 (sand bed, HEPA, charcoal, HEPA) has the highest total score. Second highest is system CF-21A (prefilter, HEPA, charcoal, HEPA); third is CF-23 (electrostatic precipitator, HEPA, charcoa1, HEPA); and fourth is CF-22 (wet scrubber, HEPA, charcoal, HEPA).

It is not reasonable to compare system CF-21B (conventional prefilter, HEPA, charcoal, HEPA) with the other four systems because it is not designed to handle the sodium fire accident. However it was rated on an absolute basis against the DBST conditions and was assigned a total score of 382. A1though it was not given a perfect score of 400 , this system clearly met or exceeded every criterion for the DBST case.

\subsubsection{Recommended Systems for Containment/Confinement Plant}

7.4.4.1 Recommended EACS for DBST Only. For a containment/confinement plant where a sodium fire in the confinement building is not postulated, a conventional (21) filter-adsorber system (CF-21B) consisting of banks of prefilters, HEPA filters, charcoal adsorbers, and final-stage HEPA filters in series is completely satisfactory and the cost is relatively low $(\$ 870,000)$. 
TABLE 43

RANKING OF EACS FOR USE IN CONTAINMENT/CONF INEMÉNT

PLANTS WITH EITHER HCDA-DBA OR SODIUM FIRE

\begin{tabular}{|c|c|c|c|c|c|c|c|c|}
\hline \multirow[b]{2}{*}{ Rank } & \multirow[b]{2}{*}{ System } & \multirow[b]{2}{*}{$\begin{array}{l}\text { Total } \\
\text { Score* }\end{array}$} & \multicolumn{6}{|c|}{ Rank by Criteria Group ${ }^{\dagger}$} \\
\hline & & & $\begin{array}{c}\text { Group } 1 \\
\text { Effectiveness }\end{array}$ & $\begin{array}{c}\text { Group } 2 \\
\text { Reliability }\end{array}$ & $\begin{array}{c}\text { Group } 3 \\
\text { Compatibility }\end{array}$ & $\begin{array}{c}\text { Group } 4 \\
\text { Credibility } \\
\end{array}$ & $\begin{array}{c}\text { Group } 5 \\
\text { Flexibility }\end{array}$ & $\begin{array}{c}\text { Group } 6 \\
\text { Fabrication } \\
\end{array}$ \\
\hline 1. & CF-24 Sand Bed & 356 & 2 & 1 & 4 & 1 & 1 & 4 \\
\hline 2. & CF-21A PF, HEPA & 341 & 4 & 2 & 2 & 2 & 2 & 2 \\
\hline 3. & CF-23 ESP & 336 & 3 & 3 & 1 & 3 & 3 & 1 \\
\hline 4. & CF-22 Wet Scrubber & 328 & 1 & 4 & 3 & 4 & 4 & 3 \\
\hline
\end{tabular}

* See Table $C-4$ in Appendix $C$ for detailed ratings.

+See Table B-2 in Appendix B for complete definition of criteria. 
Although other systems were not specifically designed for this limited-mass case, it is the authors' opinion that any additional equipment would be unnecessary and add extra cost with no real benefit.

The realistic DF for aerosol particles achieved by this system is greater than $10^{6}$, greatly exceeding the EACS design requirement of 100 . Recent tests at Los Alamos Scientific Laboratory (LASL) ${ }^{(75)}$ using $\mathrm{PuO}_{2}$ aerosol and three sma11 (25 CFM or $0.7 \mathrm{~m}^{3} / \mathrm{min}$ ) HEPA filters in series showed that the first two HEPA filters gave a combined DF of $10^{8}$, even for particles as small as $0.22 \mu \mathrm{m}$ AED. Although these tests were performed under idealized conditions, it is reasonable to assume that a similar system properly installed and maintained would give a reliable DF exceeding $10^{6}$ for aerosol particles.

The DF for halogens for system DF-21B is $10^{3}$, assuming that 98 percent of the halogens are associated with aerosol particles and the charcoal adsorber is 95 percent efficient for gaseous and vapor forms. Higher DFs can be achieved, if needed, by using additional charcoal.

\subsubsection{Recommended EACS for DBST or Sodium Fire. A11 four of the sys-} tems evaluated achieved good scores and are entirely feasible for use against either the DBST or a sodium fire. This is not surprising since the systems with obvious shortcomings were weeded out beforehand on the basis of the evaluation of single containment EACS reported in Section 7.1. Consideration of the rating data presented in Tables 43 and C-4 provides the basis for the following conclusions:

- The sand bed system (CF-24) has the highest overall rating and is especially strong in reliability, credibility and flexibility. Its weakness is high cost ( $\$ 4.5$ million) and large size. Development effort has a high probability of reducing the size and cost.

- The prefilter HEPA system (CF-21A) ranks second overall and is consistently second in a 11 criteria groups except effectiveness, where it ranks last. The latter is due to concern that sticky particles might plug the filters, a question which can only be resolved by development testing. 
- The electrostatic precipitator system (CF-23) ranks third overall, but has the lowest initial cost $(\$ 1.7$ million) and space requirement.

- The wet scrubber system (CF-22) ranks last in total score, but first in effectiveness. It ranks last in technological credibility, flexibility, and reliability. It has the advantage over the other three systems in that it can handle very large masses without plugging. The latter asset is not important for the DBST case, where the aerosol mass is quite small, but is a very positive asset for cleaning the effluent from a large sodium fire.

It is concluded that on the basis of present knowledge the sand bed filter system, CF-24 (backed up by a HEPA, charcoal, HEPA), is the best system for cleaning the confinement building exhaust if the EACS must handle both the DBST and a sodium fire in the confinement building.

A conventional prefilter-HEPA-charcoal-HEPA system (CF-21B) is best if a sodium fire is excluded.

If two parallel, independent systems can be shown to be feasible, then the best combination is the CF-21B filter-adsorber system for handling the radiologically significant DBST and a separate system using only a wet scrubber (without backup filters) for handling the sodium fire accident effluent.

\subsubsection{Development Needs for Recommended Systems}

The development effort required for each system before it can be accepted as a reliable EACS was detailed at the end of each system evaluation in sections 7.1 and 7.3 of this report. A brief summary of the development needs of the recommended air cleaning concepts and components is presented in Table 44 . The development activities described in Table 44 do not constitute a coherent test program plan, but do represent a compilation of the necessary data and confirmatory information found to be lacking during the conceptual design and evaluation of the EACS systems. Completion of the recommended development would provide a sound basis for the design of the respective air cleaning systems. 
TABLE 44

\section{DEVELOPMENT NEEDS FOR RECOMMENDED EACS CONCEPTS}

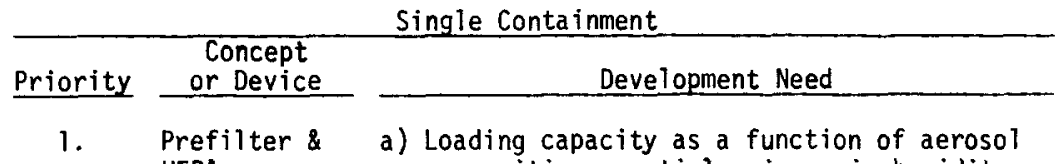

1. HEPA composition, particle size, air humidity.

b) Long-term performance--chemical attack, change in flow resistance, resuspension.

c) Large-scale demonstration under simulated DBA conditions.

2. Acoustic Agglomeration

3. Cycione Separator (HighEfficiency
Type)

4. Powder Discharge a) Measurement of agglomerated particle size and density as a function of sound intensity, frequency, wave shape; and particle concentration, size, density. Small-scale and large-scale tests.

b) Theoretical treatment of acoustic agglomeration process relating particle size to acoustic conditions.

c) Develop high intensity sound generator, minimizing gas requirement.

a) Large-scale demonstration tests in simulated DBA conditions:

1) Alone

2) Pretreatment for filter

3) Backup for in-line acoustic agglomera tor.

a) Develop suitable powder (storage, flowability, dispersibility, reaction with Na fire).

b) Demonstrate aerosol removal in a large vessel, verifying mathematical mo dictions of effects of powder size, flow rate and fall height.

c) Demonstrate full-scale equipment for storing and dispersing powder.
Conta inment/Confinement

\begin{tabular}{|c|c|c|}
\hline Priority & $\begin{array}{l}\text { Concept } \\
\text { or Device }\end{array}$ & Development Need \\
\hline \multirow[t]{3}{*}{1.} & Sand Bed & $\begin{array}{l}\text { a) Optimize sand and gravel layers to give } \\
\text { maximum } \mathrm{Na} 2 \mathrm{O} / \mathrm{NaOH} \text { loading capacity. }\end{array}$ \\
\hline & & $\begin{array}{l}\text { b) Characterize sand bed (la above) perfor- } \\
\text { mance. Efficiency, flow resistance as } \\
\text { function of aerosol particle size, concen- } \\
\text { tration and gas relative humidity. }\end{array}$ \\
\hline & & $\begin{array}{l}\text { c) Proof test large-scale section of prototype } \\
\text { sand bed under simulated DBA conditions. }\end{array}$ \\
\hline 2. & HEPA & Same as No. 1 for single containment. \\
\hline 3. & Wet Scrubber & $\begin{array}{l}\text { a) Measure efficiency for } \mathrm{Na} 2 \mathrm{O} / \mathrm{NaOH} \text { particle } \\
\text { removal as function of particle size, using } \\
\text { three types of scrubbers (wetted fiber bed, } \\
\text { Venturi, centrifugal wet fan) at large scal } \\
(5-10,000 \text { CFM). }\end{array}$ \\
\hline
\end{tabular}


Prefilters and HEPA filters have great utility in conventional air cleaning applications, but are not usually recommended for use in LMFBR installations because of their reputed low loading capacity. Firm information on this important point is not available. Data in the literature are conflicting and not representative of conditions required for an EACS as described in this report. This work should be performed at a size scale such that typical commercial filter units can be used.

Acoustic agglomeration is a high-incentive, high-risk development activity. There is no firm basis for predicting the agglomerate size attained. Most of the experimental data available provide only indirect evidence of particle growth, as inferred by improved downstream equipment performance. However, if acoustic agglomeration can be shown to be effective in rapidly agglomerating small particles in situ in the containment atmosphere, this would be a very valuable tool for the LMFBR safety program.

The cyclone separator is a simple, common air cleaning device that is used in several of the EACS systems with high ratings for the single containment case. Considerable information is available in the literature regarding cyclone performance, but none with the LMFBR DBST aerosol. of concern here is maintaining a high efficiency as the cyclone becomes loaded with dust, especially for the sticky aerosol possible in the DBST case.

Rapid addition of a large mass of inert powder or smoke was shown in system SD-15 to be capable (in theory) of quickly reducing the suspended aerosol concentration to very low levels. Dispersal of stored powder was chosen over creation of a smoke for the SD-15 design on the basis of practicability. Development needs include selection of the best powder material, verification of the mathematical model for aerosol removal, and proof testing of the powder storage and dispersal equipment.

For the confinement plant EACS required to handle both the DBST and a large sodium fire in the confinement building, the sand bed filter is recommended. However, the high cost provides an incentive to develop a sand and gravel bed filter with a much higher loading capacity than is used in the system CF-24 design. High particle removal efficiency is not a requirement, since backup HEPA filters will be provided. If a sand bed can 
be developed with 10 times the loading capacity for sodium oxide/hydroxide particles, the system cost would be reduced to approximately one-third.

For the confinement plant where an independent system is provided to handle the sodium fire accident effluent only, the wet scrubber has the advantage because of $i$ ts very large capacity for sodium smoke particles. However, experimental information on which to base the selection of scrubber type, efficiency and operating conditions is not available. Such information would significantly enlarge the options for designers of future LMFBR air cleaning sys tems .

Development of some of the other systems evaluated in this report may be worthwhile, but those listed in Table 44 deserve the highest priority. 


\subsection{ACKNOWLEDGEMENTS}

Significant contributions to this report were made by personnel at HEDL other than the authors. J. A. Hassberger ran the HAA-3B code cases. $P$. R. Shire ran the SOFIRE-II code and advised in setting up the HAA-3B cases. Valuable discussions and references on FFTF safety analyses were supplied by D. E. Simpson, J. W. Hagan and J. P. Hale of HEDL Safety Engineering. Likewise, information on CRBRP containment design and PSAR evaluations were supplied by personnel at General Electric Company, Energy Systems and Technology Division, and Westinghouse Advanced Reactors Division. The authors wish to acknowledge the guidance provided by L. D. Muhlestein, HEDL, and Carl Newton of the Fast Reactor Safety Branch, RRD, ERDA, whose comments and suggestions added appreciably to the usefulness of this work. 


\subsection{REFERENCES}

1. Carl Newton, "Program Planning for Development of Radiological Source Terms for Postulated LMFBR Accidents," Paper 1-1 in "Status of Safety Technology for Radiological Consequence Assessment of Postulated Accidents in LMFBRs," ERDA-56, JuTy 1975.

2. R. R. Bellamy and R. W. Zavadoski, "The AEC Regulatory View of the Reliability of Air Cleaning Systems in Nuclear Facilities," Proceedings of the Thirteenth AEC Air Cleaning Conference, CONF-740807, p. 41, San Francisco, California, August 1974.

3. P. Beiriger, et a., Sofire II User Report, AI-AEC-13055, Atomics. Internationa 1, Canoga Park, California, March 31, 1973.

4. R. S. Hubner, E. U. Vaughn and L. Baurmash, HAA-3 User Report, AI-AEC-13038, Atomics International, Canoga Park, California, March 30, 1973.

5. E. R. Appleby, Compilation of Data and Descriptions for United States and Foreign Liquid Metal Fast Breeder Reactors, HEDL TME 75-12, August 1975.

6. W. B. Cottrell and A. W. Savolainen, eds., U.S. Reactor Containment Technology, ORNL-NSIC-5, Oak Ridge National Laboratory, Oak Ridge, Tennessee, August 1965.

7. P. L. Hofmann, R. E. Peterson and D. E. Simpson, "Approaches to Reactor Safety," Education and Research in the Nuclear Fuel Cycle, edited by D. M. Elliott and L. E. Weaver, University of OkTahoma, Norman, OkTahoma, pp. 301-320, January 20, 1972.

8. R. E. Shaver and N. G. Wittenbrock, Review of Reactor Safety Analyses of Fast and Liquid Cooled Reactors, BNWL-477, Battelle Northwest Laboratory, Richland, Washington, 1967.

9. R. E. Aronstein, et al., 1000-MWe Liquid Metal Fast Breeder Reactor Follow-0n Study Conceptual Design Report, AI-12792 (Vol. IV) Atomics International, Canoga Park, California.

10. W. R. Gee, Jr., et al., Conceptual Plant Design, System Descriptions, and Costs for a 1000 Mwe Sodium Cooled Fast Reactor, GEAP-5678, General Electric Co., Sunnyvale, California, December 1968.

11. J. M. Laithwaite, "Containment Design in Fast Reactors," Proceedings of International Conference on Engineering of Fast Reactors for Safe and Reliable Operations, Karlsruhe, Germany, pp 454-469, October 9-13, 1972. 
12. Status of Safety Technology for Radiological Consequence Assessment of Postulated Accidents in Liquid Metal Fast Breeder Reactors, ERDA-56, July 1975 .

13. Regulatory Guide 1.3, Revision 2, "Assumptions Used for Evaluating the Potential Radiological Consequences of a Loss of Coolant Accident for Boiling Water Reactors," USAEC Directorate of Regulatory Standards, June 1974.

14. Regulatory Guide 1.4, Revision 2, "Assumptions Used for Evaluating the Potential Radiological Consequences of a Loss of Coolant Accident for Pressurized Water Reactors," USAEC Directorate of Regulatory Standards, June 1974.

15. A. S. Goldin, et a1., "Behavior of Iodine in Sodium Systems," CONF-700816, Proceedings of the Eleventh AEC Air Cleaning Conference, p. 356, December 1970 .

16. L. Baurmash, et al., "Behavior of Iodine in the Presence of Sodium Oxide Aerosols," CONF-700816, Proceedings of the Eleventh AEC Air Cleaning Conference, p. 373, December 1970.

17. "Control Techniques for Particulate Air Pollutants," U.S. Department of Health, Education and Welfare, National Air Pollution Control Administration Publication No. AP-5T, Washington D. C., January 1969.

18. Contamination Control Handbook, NASA SP-5076, National Aeronautics and Space Administration, Washington, D. C., 1969.

19. G. Nonhebel, ed., Gas Purification Processes for Air Pollution Control, Newnes-Butterworths, London, England, 1972.

20. A. C. Stern, ed., Air Pollution, Vol. II, Academic Press, New York, New York, 1962.

21. Regulatory Guide 1.52, "Design, Testing, and Maintenance Criteria for Atmospheric Cleanup System Air Filtration and Adsorption Units of Light Water-Cooled Nuclear Power Plants," Directorate of Regulatory Standards, June 1973.

22. T. H. Arnold and C. H. Chilton, "New Index Shows Plant Cost Trends," Chemical Engineering, pp. 143-152, February 18, 1963

23. U. S. Atomic Energy Commission, "Minimal Requirements for High Efficiency Air Filter Units," Health and Safety, No. 120.

24. C. A. Burchsted and A. B. Fuller, Design, Construction, and Testing of High-Efficiency Air Filtration Systems for Nuclear Application, ORNL-NSIC-65, p. 3.2, 8.16, January 1970. 
25. R. Dennis, et a 1., Fibrous Filters for NaK Fume Removal, NYO-4811, Harvard Air Cleaning Laboratory, May 1, 1960.

26. F. J. Viles, et al., High Capacity-High Efficiency Filters for Sodium Aerosols, NY0-841-10, Harvard Air Cleaning Laboratory, August 1967.

27. L. Bohm, et al., "The Off-Gas Filter System of the SNR-300," CONF-740807, Proceedings of the Thirteenth AEC Air Cleaning Conference, p. 620, August 12-15, 1974 .

28. R. Jorgensen, ed., Fan Engineering, Buffalo Forge Company, Buffalo, New York, 1961.

29. G. W. Keilholtz, et al., Air Cleaning as an Engineered Safety Feature in Light Water-Cooled Power Reactors, ORNL-NSIC-25, September 1968.

30. Efficiency Testing of Air Cleaning Systems Containing Devices for Removal of Particles, ANSI-N101.1-1972.

31. N. A. Fuchs, The Mechanics of Aerosols, The MacMillan Company, New York, New York, 1964.

32. J. D. McCormack, R. K. Hilliard and A. K. Postma, Removal of Airborne Fission Products by Recirculating Filter Systems in the Containment Systems Experiment, BNWL-1587, Battelle Pacific Northwest Laboratories, Richland, Washington, June 1971.

33. H. K. Lemar, Liquid Metal Smoke Abatement," PWAC-235, Pratt \& Whitney Aircraft, Middleton, Connecticut, November 1, 1957.

34. H. A. Morewitz, R. K. Hilliard and F. A Smith, "U.S. Position Paper, Sodium Combustion and Its Extinguishment--Techniques and Technology," TID-26076, International Working Group on Fast Reactors Meeting in Richland, Washington, p. 98, May 1972.

35. C. A. Stokes, "Sonic Agglomeration of Carbon Black Aerosols, "Chem. Engr. Prog., 46 (8), p. 423, 1950.

36. H. W. Danser and E. P. Neuman, "Industrial Sonic Agglomeration and Collection Systems," Ind. Engr. Chem., 41 (11), p. 2439, 1949.

37. R. M. G. Boucher, "UTtrasonics in Processing," Chem. Engr., 68, p. 83, October 1961 .

38. E. P. Mednikov, Acoustic Coagulation and Precipitation of Aerosols, Consultants Bureau Enterprises, Inc., New York, New York, 1965.

39. T. F. Heuter, and R. H. Bolt, Sonics, John Wiley and Sons, New York New York, 1954. 
40. H. W. St. Clair, Agglomeration of Smoke, Fog or Dust Particles by Sonic Waves," Ind. Engr. Chem., 41 (11), p. 2434, 1949.

41. M. First and H. Yusa, "Heat Transfer of Sodium Compounds Deposited on Surfaces from Aerosols," Proceedings of the Eleventh AEC Air Cleaning Conference, CONF-700816, Richland, Washington, p. 413, August 1970.

42. L. L. Beranek, Acoustics, McGraw-Hi11 Book Co., New York, New York, p. 397, 1954.

43. R. K. Hilliard et al., "Experimental Plans for Aerosol Behavior Tests in a Large Vesse1," Status of Safety Technology for Radiological Consequence Assessment of Postulated Accidents in LMFBR, ERDA-56, JuTy 1975.

44. C. E. Billings and J. Wilder, Handbook of Fabric Filter Technology, Vol, I, Fabric Filter Systems Study, PB 200-648, GCA Corporation, Bedford, Massachusetts, December 1970.

45. Final Summary Safeguard Report for the HALLAM Nuclear Power Facility, NAA-SR-5700, Atomics Internationa 1, Canoga Park, California, Apri1 15, 1961.

46. M. W. First, et al., Semiannual Progress Report, Harvard Air Cleaning Laboratory--March 1 to August 31, 1969, NY0-841-20, October 1969.

47. M. W. First and T. Baldwin, "Sodium Aerosol Filtration Studies," Proceedings of the Eleventh AEC Air Cleaning Conference, Richland Washington, CONF-700816, p. 445, December 1970.

48. M. W. First, et a]., Semiannual Progress Report, Harvard Air Cleaning Laboratory--September 1, 1969 to February 28, 1970, NY0-841-22, Apri1 1970.

49. L. R. Jones, "Effects of Radiation on Reactor Confinement System Materials," Proceedings of the Twelfth AEC Air Cleaning Conference, Oak Ridge, Tennessee, CONF-720823, p. 655, August 1972.

50. C. N. Davis, ed., Aerosol Science, Academic Press, New York, New York, 1966.

51. R. K. Hilliard, et al., Removal of Iodine and Particles from Containment Atmospheres by Sprays - Containment Systems Experiment Interim Report, BNWL-1244, Battelle Northwest Laboratory, February 1970.

52. A. K. Postma, R. L. Ritzman, J. A. Gieseke and E. W. Schmidt, Models for Predicting the Removal of Airborne Contaminants by Reactor Containment Sprays, BNWL-B-417, Battel1e Northwest Laboratory, June 27, 1975.

53. RDT Standard, Sodium Carbonate, Low-Chloride Fire Extinguishing Agent, RDT M 17-1T, December 1973. 
54. C. R. Schmitt, Carbon Microspheroids as Extinguishing Agents for Meta 1 Fires, Y-1890, Oak Ridge National Laboratory, Oak Ridge, Tennessee, August 28, 1973.

55. R. L. Koontz, et a1., Studies of the Distribution of Mass Released Into the FFTF Hot Cell After the DBA - Interim Report, AI-68-MEM0-53, Atomics International, Canoga Park, California, May 7968.

56. "Precipitation Scavenging - 1970," CONF-700601, Proceedings of a Symposium held at Richland, Washington, June 1970.

57. L. D. Reed and J. A. Gieseke, HAARM-1 Users Manua 1, BMI-X-658, Battelle Columbus Laboratories, Columbus, Ohio, May 15, 1975.

58. L. Silverman, Economic Aspects of Air and Gas Cleaning for Nuclear Energy Processes in Disposal of Radioactive Wastes, Volume I, international Atomic Energy Agency, Vienna, 1960.

59. H. J. White, Industrial Electrostatic Precipitation, Addison-Wesley Pub. Co., Reading, Massachusetts, 1963.

60. J. H. Perry, ed., Chemical Engineers' Handbook, Third Ed., McGraw-Hil1, New York, p. 1040, 1950.

61. H. J. White, "Resistivity Problems in Electrostatic Precipitation," J. Air Pol. Control Soc., 24 (4), p. 314, April 1974.

62. M. A. Schultz, et al., "Collection of Particulate Matter from Smoke Stacks Using Gamma-Ray Ionization," Nuclear Technology, 17, p. 38 January 1973.

63. C. J. Stairmand, "Design and Performanca of Cyclone Separators," Trans. Instn. Chem. Engrs., Vol. 29, p. 364, 1951.

64. J. A. Brink, "Phosphoric Acid Mist Eliminators," Gas Purification Processes for Air Pollution Control, G. Nonhebel, Ed., NewnesButterworths, London, England, 1972.

65. A. K. Postma, Laboratory Evaluation of De-Entrainers Made from Teflon and Polypropylene Fibers, BNWL-415, Battelle Northwest Laboratory, Richtand, Washington, 1967.

66. G. W. Hughes, The Use of High Expansion Foam in the Control of Airborne Contamination, TRG-MEM0-4406, U. K. Atomic Energy Authority, Risley, England, Apri1 1968.

67. S. Calvert, et al., "Scrubber Handbook," Vol. I, Wet Scrubber System Study, Prepared for the U. S. Environmental Protection Agency by Ambient Purification Technology, Riverside, California, July 1972. 
68. F. A. Smith, U. S. Position Paper--Sodium Combustion and Its

Extinguishment-Techniques and Technology, Paper No. 3, TID-26076, International Atomic Energy Agency, 1972.

69. J. D. McCormack, R. K. Hilliard and A. K. Postma, Removal of Airborne Fission Products by Recirculating Filter Systems in the Containment System Experiment, BNWL-1587, Battelle Northwest Laboratory, Richland, Washington, June 1971.

70. Regulatory Guide 1.7, "Control of Combustible Gas Concentrations in Containment Following a Loss of Coolant Accident," Directorate of Requlatory Standards, June 1973.

71. R. A. Juvinall, et al., Sand-Bed Filtration of Aerosols: A review of Published Information on Their Use in Industrial and Atomic Energy Facilities, ANL-7683, Argonne National Laboratory, Argonne, I11 inois, 1970.

72. W.Y. Kato, et al., Final Safety Analysis Report on the Use of Plutonium in ZPR-6 and -9, ANL-7442, Argonne National Laboratory, Argonne, I7linois, February 1970.

73. G. A. Schurr, D. B. Zippler, and D. C. Guyton, "Deep-Bed Filter Performance Tests," Proceedings of the 12th AEC Air Cleaning Conference, Oak Ridge, Tennessee, CONF-720823, pp. 597-618, August 28-31, 1972.

74. R. A. Moyer, J. H. Crawford, and R. E. Tatum, "Deep-Bed Sand Filter at Savannah River Laboratory," Proceedings of the Thirteenth AEC Air Cleaning Conference, San Francisco, CONF-740807, pp. 632-640, August 12-15, 1974.

75. M. Gonzales, et al., "Performance of Multiple HEPA Filters Against Plutonium Aerosols," Proceedings of the Thirteenth AEC Air Cleaning Conference, San Francisco, California, CONF-740807, p. 501, August 1974.

76. H. Hilsdorf, The Water Content of Hardened Concrete, DASA-1875, University of Illinois, Urbana, Illinois, February 1967.

77. R. D. Peak and D. D. Stepnewski, "Computational Features of the CACECO Containment Analysis Code," ANS Transactions, Vol. 21 , June 8-13, 1975. 
APPENDIX A

AEROSOL BEHAVIOR

CASE I (SINGLE CONTAINMENT)

For the single containment reference plant, two aerosol sources were present: first, an instantaneous release of mass from the reactor vessel as identified in Table 4, and second, a continuous source resulting from the sodium pool fire in the head compartment. Aerosol behavior was analyzed, using the HAA-3B computer code $(4)^{*}$ for eight variations of input parameters. The input parameters and salient output data are summarized in Table A-1. The base case assumes that all of the sodium vapor and 978 1b of liquid sodium released from the reactor vessel instantly react with all the oxygen in the head compartment to form $\mathrm{Na}_{2} \mathrm{O}$ aerosol which is mixed with the fuel and fission product materials and uniformly dispersed throughout the containment volume.

The sodium pool fire was assumed to burn at a constant rate of 5.2 1b $\mathrm{Na} / \mathrm{hr}-\mathrm{ft}^{2}$ until all the sodium was reacted. The rate of $\mathrm{Na}_{2} \mathrm{O}$ aerosol production was assumed to be 20 percent of the burning rate. Thermal conditions for the entire time period of $H A A-3 B$ application were calculated from a heat balance in which the thermal energy of the released core material and sodium combustion is equated to the increase in sensible heat of the containment gas space and assumed constant throughout the accident period. Thermal conditions were predicted by the SOFIRE-II code. (3)

The base case Tisted in Table A-1 includes the operation of an EACS $\left(\lambda=5 \mathrm{hr}^{-1}\right)$. The other computer cases were the same with the exception that one of the following key parameters changed in each case: no EACS operation, mass of liquid sodium ejected, magnitude of aerosol shape factor (ALPHA), and initial particle size. Selected results of these code cases are discussed in the following sections.

Airborne Mass Concentrations

The depletion of airborne mass by natural transport processes and by both natural processes and an air cleaning system $(\lambda=5 \mathrm{hr}-1)$ is pictured \#NOTE: References are listed in Section 9.0. 
TABLE A-1

HAA-3B COMPUTER CODE CASES FOR SINGLE CONTAINMENT

\section{Parameter}

\section{Input}

EACS $\lambda, \mathrm{hr}^{-1}$

Sodium Liquid Expelled, ib

Sodium Vapor Expelled, ib

Pool Fire Duration, sec

Initial Particle conc, $\mathrm{cm}^{-3}$

Particle Density, $\mathrm{g} \mathrm{cm}^{-3}$

Particle Source Rate, $\mathrm{cm}^{-3} \mathrm{sec}^{-1}$

Initial Particle Diam, MMD, um

Source Geometric Std Deviation

$\stackrel{3}{n}$

\section{Output}

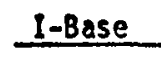

5
5,000
68
2317
$7.95 \times 10^{7}$

2.738
0.25
$2.28 \times 10^{4}$
1.0
2.0

\begin{tabular}{l}
$\quad I-A$ \\
\hline \\
5 \\
978 \\
68 \\
0 \\
$7.95 \times 10^{7}$ \\
2.738 \\
0.25 \\
0 \\
1.0 \\
2.0
\end{tabular}
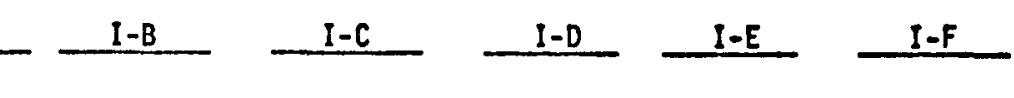

$I-6$

Initial Mass Conc, $\mu \mathrm{g} \mathrm{cm}^{-3}$

Max Mass Conc, $\mu \mathrm{g} \mathrm{\textrm {cm } ^ { - 3 }}$

Mass Conc $2 \mathrm{hr}, \mu \mathrm{g} \mathrm{cm}$

Total Mass Leaked o $2 \mathrm{hr}, 9$

Total Mass Leaked $0 \infty, g$

Maximum Milo, um

MMD at $2 \mathrm{hr}, \mathrm{um}$

Time of max MHD, hr

Total Mass Removed by EACS, kg

Pu Fraction in Aerosol (b)
Pu Mass Leaked o $2 \mathrm{hr}$,

$\begin{array}{lll}13.1 & 13.1 & 13.1 \\ 13.1 & 13.1 & 13.1 \\ 0.0028 & 5.8 \times 10^{-4} & 2.0 \\ 11.4 & 6.85 & 19.5 \\ 11.4 & 6.85 & 19.5 \\ & & \\ 1.7 / 2.3 & 2.45 & 1.7 / 1 / 8 \\ 2.3 & 2.4 & 1.6 \\ 0.35 / 1.3 & 1.5 & 0.35 / 3.4 \\ 1350 & 822 & 2440 \\ & & \\ 0.0402 \text { (a) } & 0.0402 & 0.0402(\mathrm{a}) \\ 0.27 & 0.27 & 0.27\end{array}$

13.1

17.0

5,000

68

68

6916
$7.95 \times 10^{7}$

2317
$7.95 \times 10^{7}$

0
978
68

68
0
$7.95 \times 1$

0
$7.95 \times 10^{7}$

0
0
68
0

5

6,000

2317

1. $46 \times 10^{7}$

$9.93 \times 10^{9}$

5,000

5,000

2317

$7.95 \times 10^{7}$

$\begin{array}{ll}2.738 & 2.738 \\ 0.25 & 0.25 \\ 2.28 \times 10^{4} & 2.28 \times 10^{4} \\ 1.0 & 1.0 \\ 2.0 & 2.0\end{array}$

2.738

5.565

0

2.783

0.25
$2.85 \times 10^{6}$

2.738

1.0
2.0

1.0

$2.85 \times 10^{6}$
0.2

$2.28 \times 10^{4}$

1.0
2.0

(a) Initial value. Fraction as Pu decreased during pool fire period.

(b) Not direct HAA-3B output -- hand calculated. 
in Figure A-1. For both cases, the initial concentration is $13.1 \mu \mathrm{g} / \mathrm{cm}^{3}$. As expected, the EACS causes a more rapid decrease in concentration than natural processes alone. At 1 hour, the concentration with EACS operation is lower by a factor of 13 than when only natural processes operate. The difference in concentration caused by EACS operation increases with time, and at 2 hours, the concentration with EACS operation is lower by a factor of 1000 than the concentration as depleted by natural processes alone.

Particle Size

The size of airborne particles changes with time as a result of coagulation and depletion processes. One would expect an initial increase in particle size due to agglomeration, and then a gradual decrease in particle size at long times because removal processes cause a more rapid depletion of the larger particles. This behavior is shown by the calculated particle sizes in Figure $A-2$.

The initial particle size is an assumed input to the HAA-3B code. Fortunately, the effect of this parameter is small, as shown by Table $A-1$ and by comparing cases $I-C$ and $I-F$ in Figure $A-2$. The only difference in the HAA-3B input for these two cases was that the initial particle size was $1.0 \mu \mathrm{m}$ mass median diameter (MMD) for case I-C and $0.2 \mu \mathrm{m}$ MMD for case I-F. The same aerosol mass was released in each case. As Figure A-2 shows, the smaller particles in case I-F agglomerated more rapidly and actually attained a larger mean size after 0.7 hours. Table A-1 shows that leakage to the environs was only 5 percent greater for the smaller initial size particles. This is negligible compared to other aspects of aerosol behavior.

The effect on particle size of operating an EACS is quite large. For the base case (I-base) with pool fire and EACS, the particles grew from $1 \mu \mathrm{m}$ to a maximum of $2.3 \mu \mathrm{m}$, while for the similar case without EACS (I-C) the particles grew to a maximum of $18 \mu \mathrm{m}$ at $1.2 \mathrm{hr}$, then decreased slowly to $10 \mu \mathrm{m}$ at 6 hours. The reason that more agglomeration did not occur with the EACS case was due to the rapid removal of particles by the EACS and consequent lower particle concentration.

The curves on Figure A-2 exhibit two maxima. The double maxima result from the two aerosol sources. The first peak results from agglomeration of 


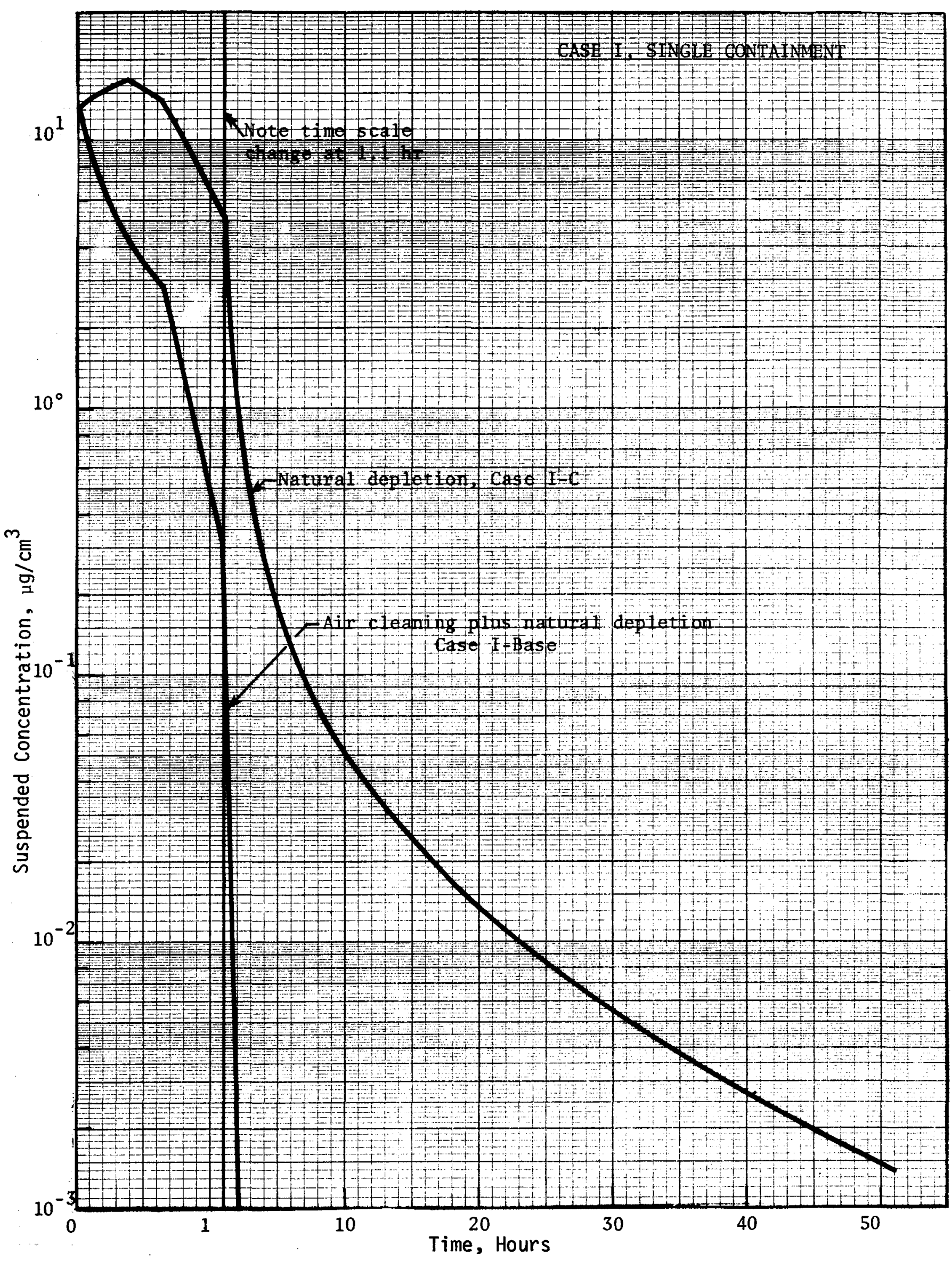

FIGURE A-1. Aerosol Concentration in Single Containment. 


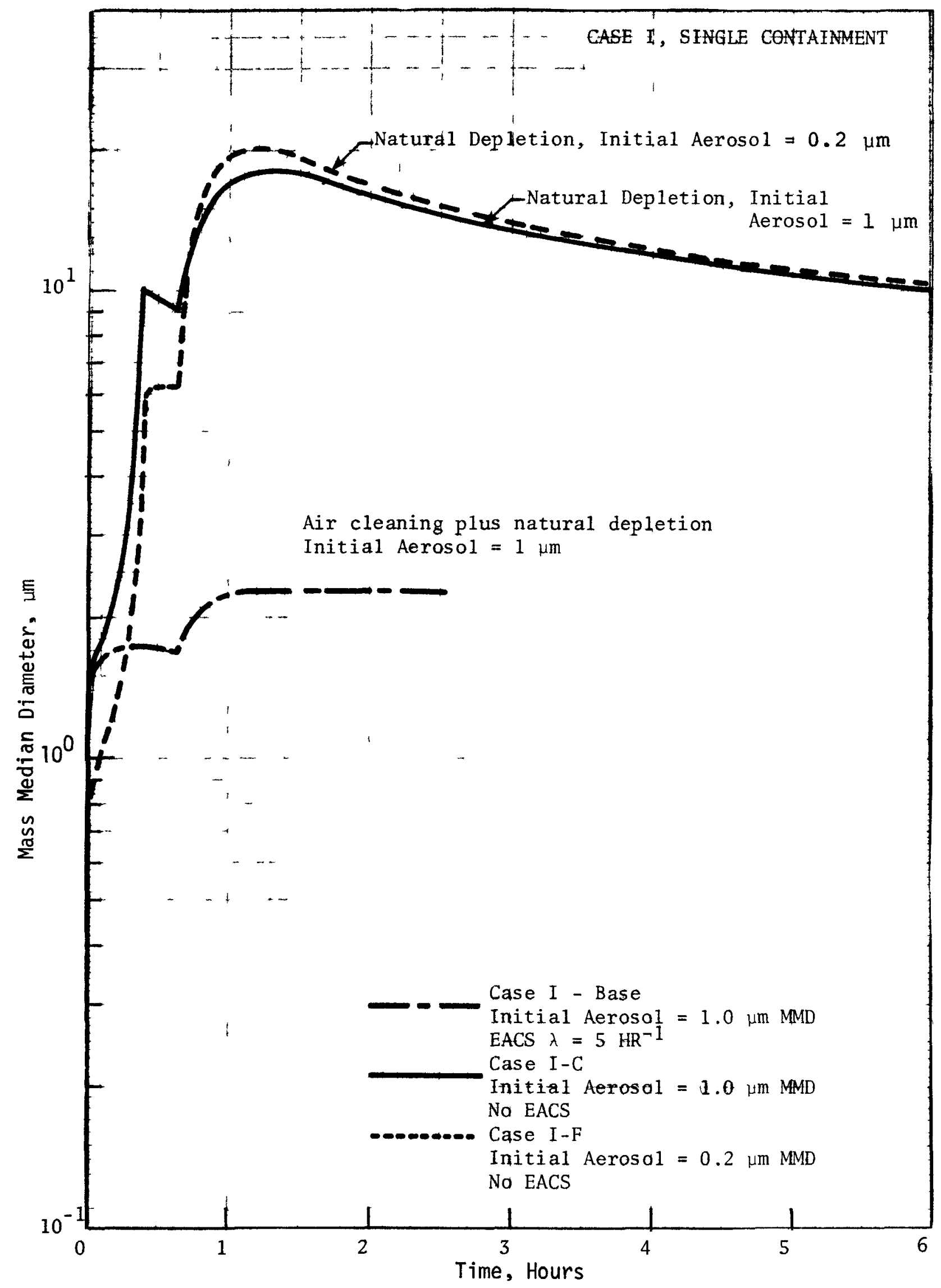

FIGURE A-2. Airborne Particle Size in Single Containment. 
the puff release at zero time, and the second results from coagulation of the sodium fire aerosol which generates aerosol from 0 to $0.64 \mathrm{hr}$.

\section{Plutonium Leaked to Environment}

For postulated accidents which involve only a puff release of radioactive material and no continuing source term, the ratio of $\mathrm{Pu}$ to total mass in the aerosol particles is constant and plutonium leakage can be calculated by multiplying the total leaked mass by the fraction which is released as $\mathrm{Pu}$. This was done for cases I-A, I-D and I-E and the mass of Pu leaked is listed in Table A-1. For postulated accidents which involve a puff release followed by a continuing source which has a different fraction of $\mathrm{Pu}$, this simple calculation is not valid because the fraction of $\mathrm{Pu}$ in the airborne particles is continually changing with time. Such is the situation with cases I-base, $I-B, I-C, I-F$ and $I-G$ in Table A-T. For these cases, an estimate of the plutonium mass leaked was made by performing numerical calculations by hand, using the HAA-3B total mass data. Errors introduced by these calculations of $\mathrm{Pu}$ leakage are believed to be less than 10 percent.

Results of these calculations are shown in Figure A-3, where the mass of leaked $\mathrm{Pu}$ is plotted as a function of time. If no depletion of airborne particles occurs, 2.8 grams of Pu would leak in two hours. Natural processes with $A L P H A=0.1$ (Case $I-G$ ), reduce the $P u$ leakage to 1.7 grams. For $A L P H A=$ 0.25 (Case I-C) 1.15 grams of $\mathrm{Pu}$ would leak. If the initial particle size is $0.2 \mu \mathrm{m}$ MMD (Case I-F) instead of $1.0 \mu \mathrm{m}$, the leakage is 1.20 grams. Finally, if an EACS is operated with $\lambda=5 \mathrm{hr}^{-1}$ (Case I-base), only 0.27 grams of $\mathrm{Pu}$ would leak, and the value of ALPHA and initial particle size is immaterial.

Compared with the case of constant containment mass concentration, the two-hour dose reduction factors (DRF) for these cases are 1.65 for natural depletion with ALPHA $=0.1,2.44$ for natural depletion with ALPHA $=0.25$, 2.34 for natural depletion with initial particle size of $0.2 \mu \mathrm{m} \mathrm{MMD}$, and 10.4 for the $\operatorname{EACS}\left(\lambda=5 \mathrm{hr}^{-1}\right)$ plus natural depletion.

The performance required by an air cleaning system can be assessed by comparing the leaked $\mathrm{Pu}$ mass with the $\mathrm{Pu}$ mass which would give a 2 -hr bone 


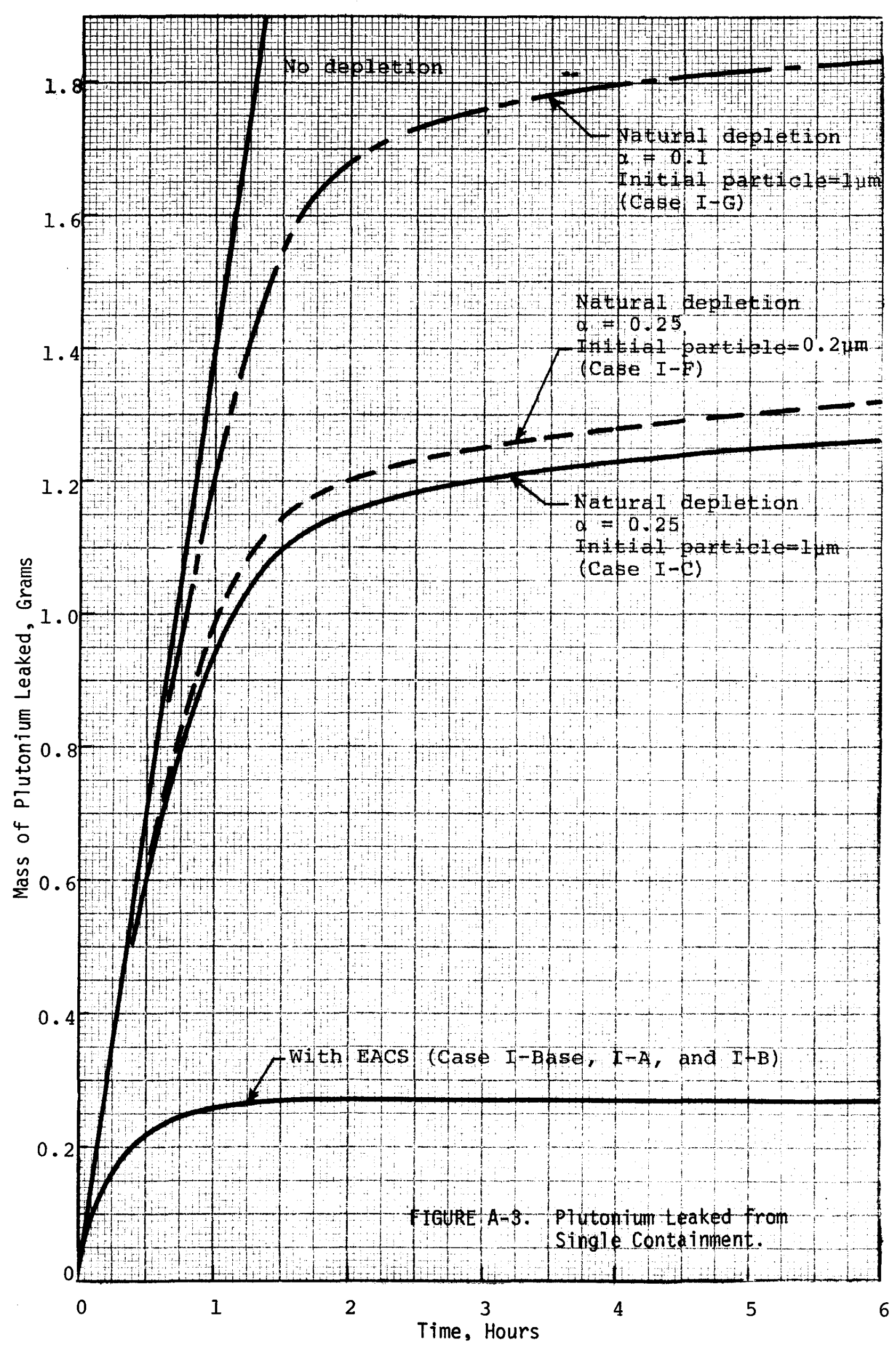

FIGURE A-3. Plutonium Leaked from Single Containment. 
dose of 150 rem at the site boundary. Pu masses released to the atmosphere which result in calculated bone doses of 150 rem at the site boundary were calculated, and are shown in Figure A-4. The dose calculations were based on atmospheric diffusion factors and breathing rates described in Regulatory Guide 1.4. (14) An F-factor of $2.9 \times 10^{9}$ rem/gram of $\mathrm{Pu}$ was used, which assumes LWR recycle fuel and soluble $\mathrm{Pu}$ forms.

The minimum site radius required when the EACS unit operates (leaked $\mathrm{Pu}$ $=0.27 \mathrm{~g}$ ) is about 0.41 miles. When only natural settling is credited (ALPHA $=0.25$, leaked $\mathrm{Pu}=1.15 \mathrm{~g}$ ), a minimum site radius of 1.65 miles is required. If sites of these two respective radii could be purchased for $\$ 2000$ per acre, the savings in land cost alone would be $\$ 10$ million. If ALPHA is taken as 0.1 , the minimum site radius would be 2.3 miles and the savings in land by using an EACS would be $\$ 20$ million. Other incentives for reducing the calculated plutonium leakage which are probably even more important are:

- A wider choice of sites is possible because they would not have to be as large.

- An existing site or limited site might become licensable if an EACS were used.

- Use of an EACS would allow higher degrees of conservatism in other parts of the HCDA analysis, thereby minimizing the degree of refinement required in analyses.

\section{Mass Removed by EACS}

The total mass of aerosol which enters the containment vessel may be categorized as: settled mass, plated mass, airborne mass, leaked mass, and mass collected by the EACS. The total aerosol mass collected by the EACS is shown in Figure $A-5$ as a function of time. After two hours, particle collection is essentially complete, and some $1350 \mathrm{~kg}$ of mass have been removed by the EACS system.

Removal of $1350 \mathrm{~kg}$ of particles in a way which does not cause plugging of the removal system is a system requirement which represents a significant challenge. This high loading tends to favor systems which are direct application, e.g., sprays or powders, for which the aerosol removed would be 


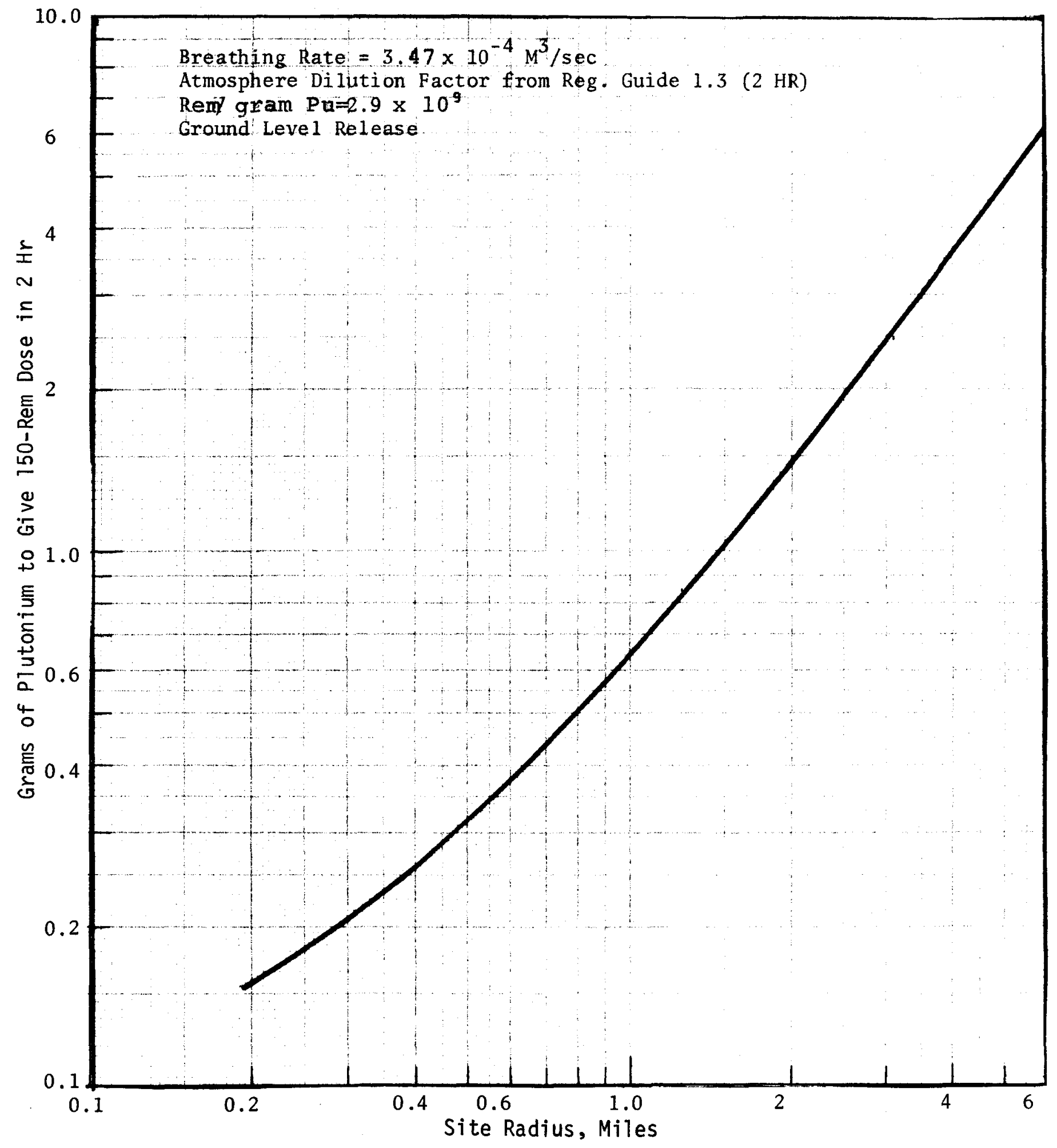

FIGURE A-4. Mass of Plutonium Calculated to Give Guideline Bone Dose at Site Boundary. 


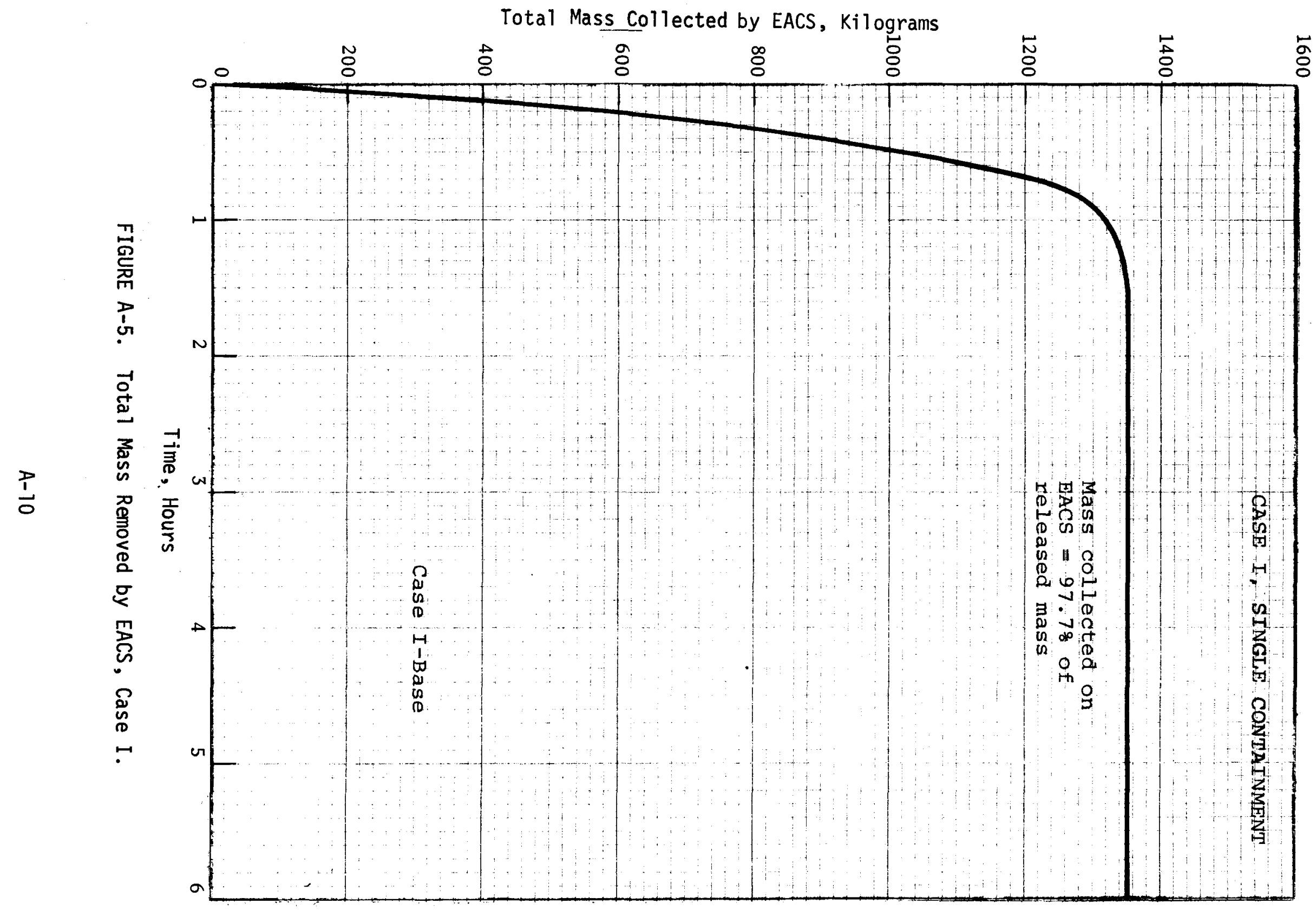


deposited on the floor of the containment vessel, or liquid scrubbers which would dissolve the predominantly sodium oxide material.

Effect of Sodium Release Mass on Aerosol Behavior

In the base case DBA, 5,000 1b of liquid sodium was assumed to be released from the reactor vessel. In order to evaluate how the assumed mass influenced the EACS requirements, $H A A-3 B$ code cases were also made for higher and lower quantities of released sodium, as listed in Table A-1. The masses of plutonium leaked for each of the six cases are plotted in Figure A-6. A significant feature of the assumed accident conditions is the start of a sodium pool fire at sodium releases above 1050 ib. Releases less than this quantity would be insufficient to burn all the oxygen in the head compartment; the initial aerosol concentration would be reduced and consequently the agglomeration rate would be reduced. At the limit of no sodium, only fuel and fission products would be released. Releases of sodium above 1050 lb result in a pool fire which burns for a progressively longer period of time, but at a constant rate.

For the natural depletion cases, the mass of $\mathrm{Pu}$ leaked is highest when no sodium is released and decreases to an approximately constant value after $1000 \mathrm{lb}$ of sodium has been released. This corresponds to the assumed condition that sodium quantities above $1000 \mathrm{lb}$ fall to the head compartment floor and burn as a pool fire. If an EACS is operated, fallout of $\mathrm{Pu}$ is insignificant compared to removal by the EACS $\left(\lambda=5 \mathrm{hr}^{-1}\right)$, therefore the quantity of sodium released is not important to the $\mathrm{Pu}$ leak rate. However, the total mass removed by the EACS increases proportionately and poses a loading problem on the EACS. The mass loading for case I-E (no sodium) would be small, but the heat generation due to fission product decay would be the same.

\section{Moisture Loss from Concrete}

The water content of concrete ranges from $7-141 \mathrm{~b} / \mathrm{ft}^{3}$ and averages $9 \mathrm{lb} / \mathrm{ft}^{3}(76)$ and is fairly independent of age. The equilibrium water content of concrete decreases with increasing temperature and with decreasing relative humidity in the gas exposed to its surface. For Case I geometry, the only concrete structure of appreciable volume subjected 


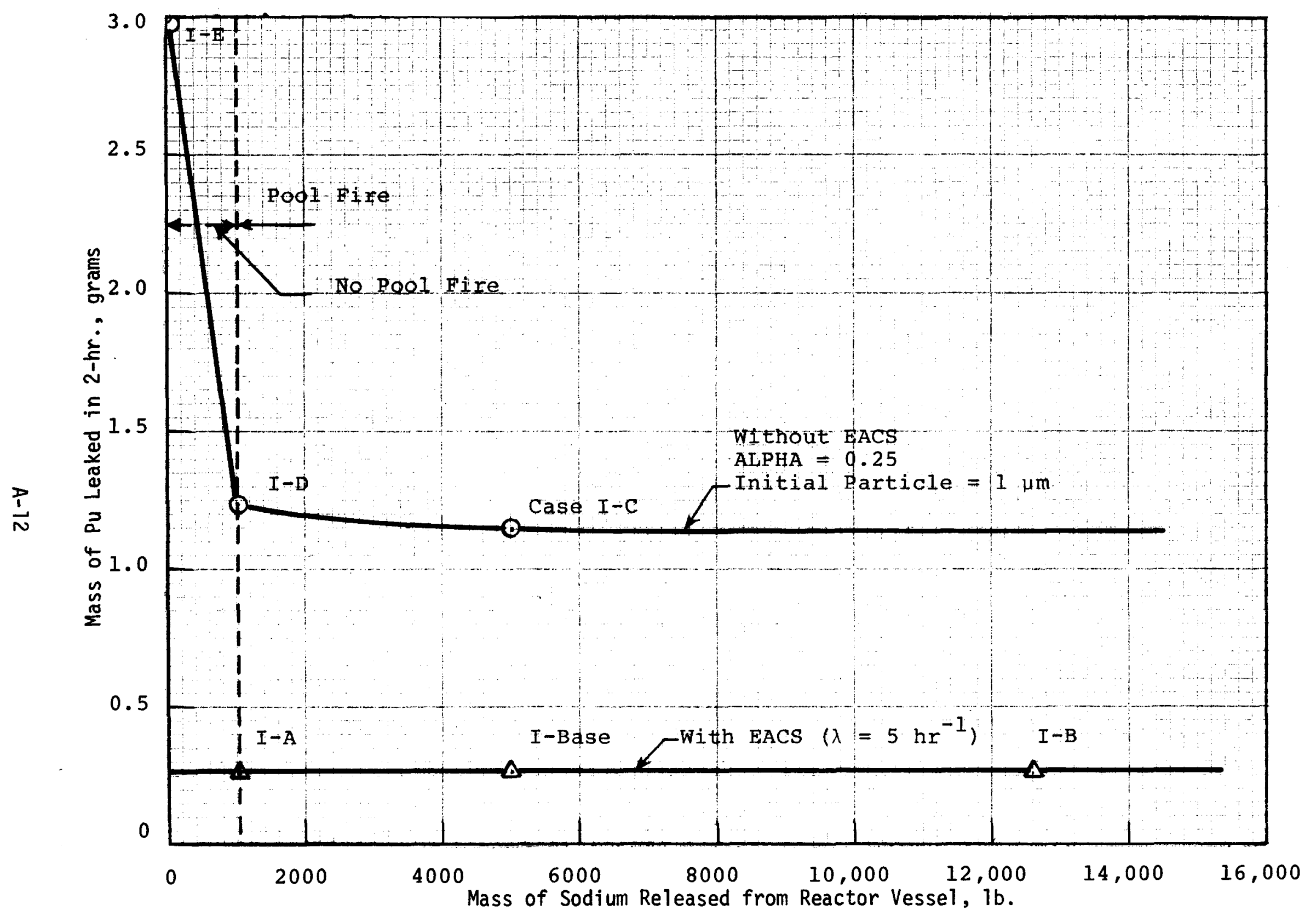

FIGURE A-6. Effect of Sodium Release on Mass of Plutonium Leaked. 
to heat following the DBA is the operating floor in the containment vessel. Temperatures in this floor were predicted as a function of time and depth below the surface, using an 8-node SOFIRE-II analysis. Results are shown in Figure A-7, where the node thicknesses are also presented. These data, when coupled with data on water release vs temperature, may be used to estimate the amount of water loss from heated concrete.

Water loss was computed using the equilibrium water loss vs temperature relationship used in the CACECO code. (77) The assumption was made that the concrete was in continuous equilibrium with dry air at each temperature. This assumption is consistent with the method of calculation used in the CACECO code, but probably overestimates the water release rates.

Total water released is shown as a function of time in Figure A-8. At 1 hour, 20,000 lbs of water is predicted to be released to the containment air. This amount of water is equivalent to a humidity of $0.12 \mathrm{lb} \mathrm{H}_{2} \mathrm{O} / \mathrm{lb}$ air, and at the predicted average gas temperature of $215^{\circ} \mathrm{F}$, would correspond to a relative humidity of about 17 percent, and a gas pressure of 3.6 psia. At 50 hours, some 250,000 lbs of $\mathrm{H}_{2} \mathrm{O}$ is predicted to be released. This amount of water, if vaporized at the temperature of the floor surface node, would result in a water partial pressure of more than $1 \mathrm{~atm}$ and 20,000 gal of liquid water on the containment floor.

This predicted massive release of water could not really happen because of several factors not included in the calculation. First, the energy required to evaporate the water $\left(9 \times 10^{7} \mathrm{Btu}\right)$ is comparable to all the energy released to the outer containment building. Second, if a layer of liquid water formed on the floor, the relative humidity would be 100 percent, which would greatly impede release of water. Third, the release was assumed to be instant, whereas in reality, it would be stretched out in time due to diffusional mass transfer limitations within the concrete. None of these three factors were accounted for in the simple release model, and therefore the predicted amount of water released is obviously much too high.

The calculation does illustrate two important factors: (1) appreciable water vapor may be present under accident conditions, leading to a sticky 


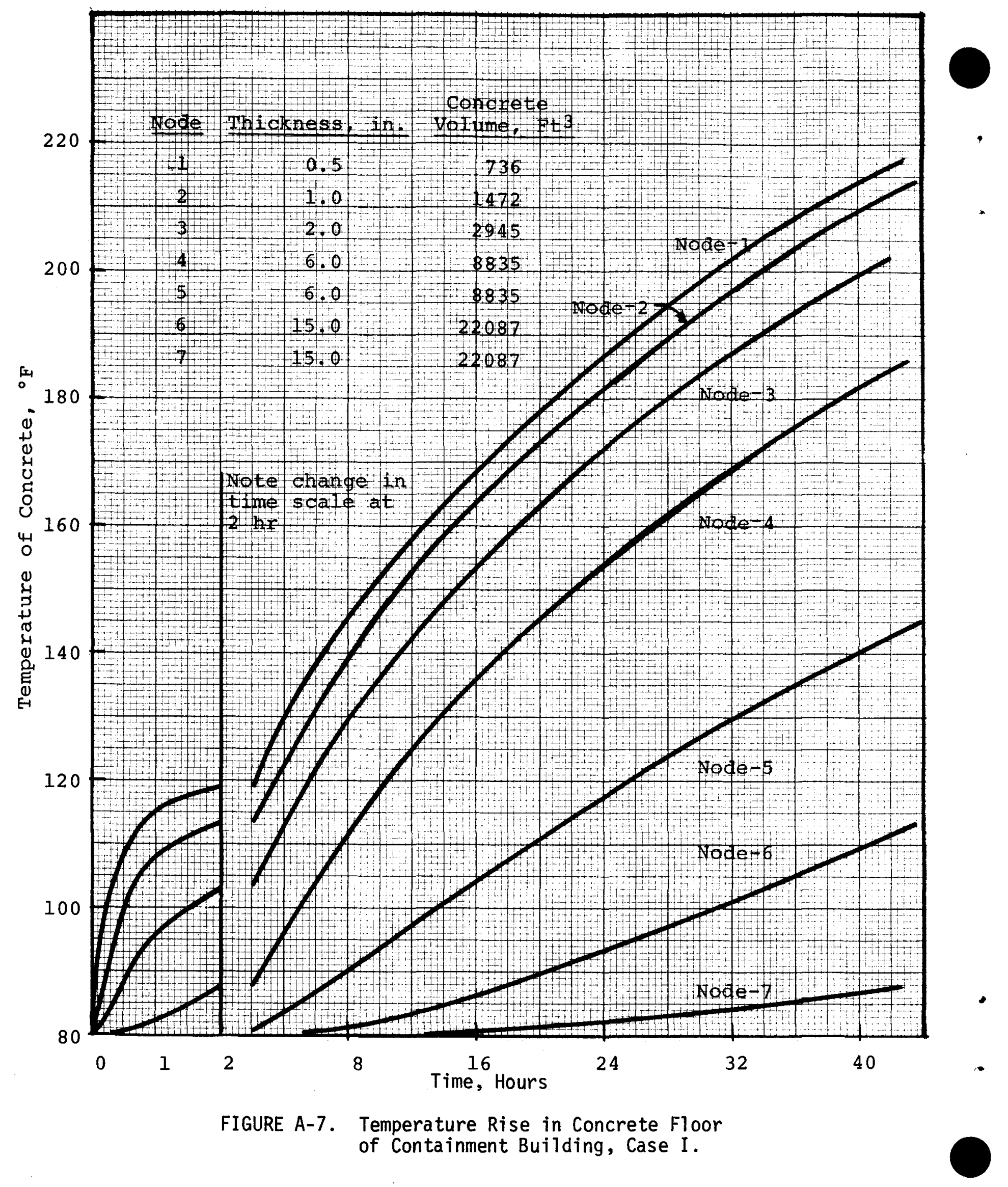




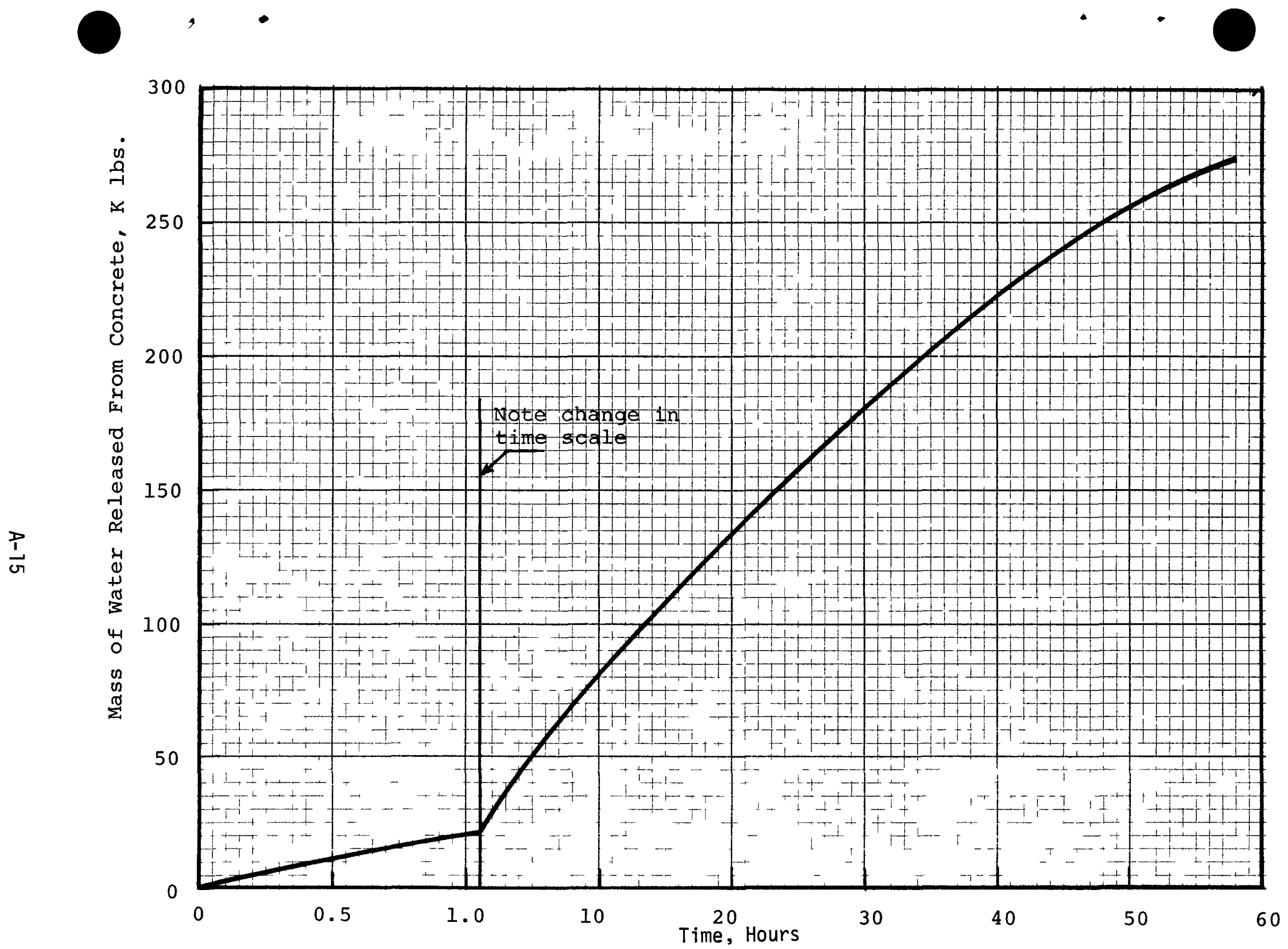

FIGURE A-8. Water Released from Operating Floor Concrete, Case I. 
sodium hydroxide aerosol rather than a dry, fluffy sodium oxide aerosol, and (2) calculational methods for predicting water release from concrete need to be improved and experimentally verified.

\section{CASE II (DOUBLE CONTAINMENT)}

Case II preserves the geometry of Case I with the exception that in Case II the head compartment is covered by a sealed dome, which becomes a portion (together with below-grade cavities) of the primary containment barrier. The inert gas enclosed in the primary volume prevents a sodium pool fire; hence, only one aerosol source exists for this case. Thermal conditions for HAA-3B operation were taken as constant in both the primary containment volume and in the secondary building. Gas temperature estimated for the $\mathrm{DBA}$ was $980^{\circ} \mathrm{K}\left(1305^{\circ} \mathrm{F}\right)$ in the primary volume. Air temperature in the secondary building was assumed to be $300^{\circ} \mathrm{K}\left(80^{\circ} \mathrm{F}\right)$.

Airborne Mass Concentration

Airborne mass concentrations predicted for both the inner and outer containment volumes are shown in Figure A-9. In the outer containment vessel, the concentration is shown both with and without an EACS.

Concentration in the inner containment starts from a maximum level of about $280 \mu \mathrm{g} / \mathrm{cm}^{3}$ at zero time, and then falls very rapidly due to plating and settling. At 2 hours, the concentration has decayed by a factor of 30,000 , showing how effective natural fallout is for relatively small vessels.

In the large, outer building, natural aerosol depletion is much less effective, as expected. The peak concentration level of $1.5 \times 10^{-2} \mu \mathrm{g} / \mathrm{cm}^{3}$ occurs at about 0.2 hour, and at 2 hour has decayed by natural depletion to $1.0 \times 10^{-2} \mu \mathrm{g} / \mathrm{cm}^{3}$. The aerosol depletion half-time increases with time, and for the period from 2 hour to 50 hour, the average half-time is about 20 hour.

Installation of an EACS in the outer containment vessel greatly enhances aerosol depletion. The concentration at 2 hour is about $1.0 \times 10^{-4} \mu \mathrm{g} / \mathrm{cm}^{3}$, which represents a reduction by a factor of 100 compared to when no EACS is 


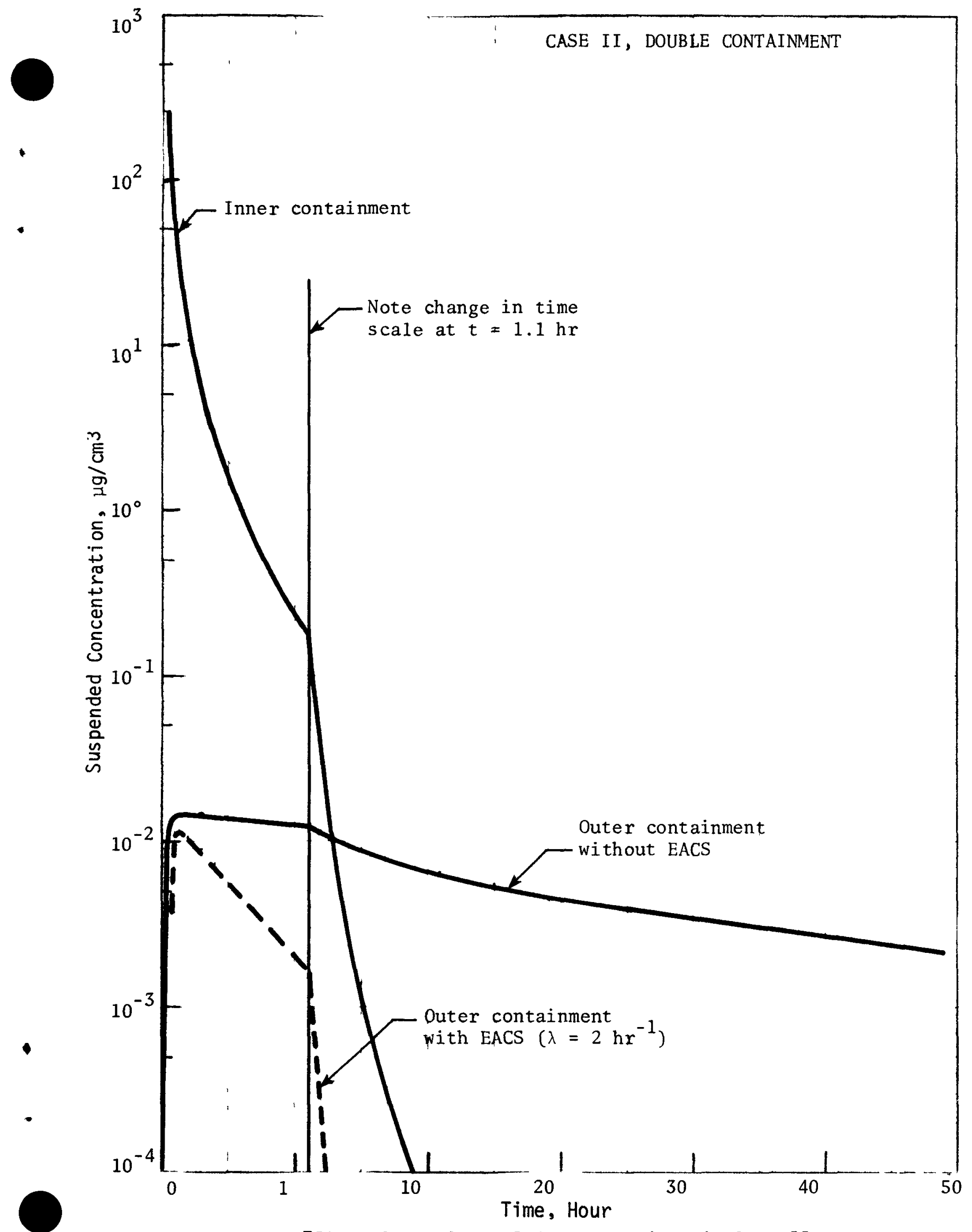

FIGURE A-9. Aerosol Concentrations in Case II. 
used. An EACS $\lambda$ of $2 \mathrm{hr}^{-1}$ was selected for this case. It was anticipated that smaller cleanup rates would be required for the double containment plant than for a single containment plant.

Particle Size

Aerosol particle mass median diameters are plotted as a function of time in Figure A-10. In the inner volume, a maximum particle diameter of 30 microns is attained at $0.1 \mathrm{hr}$. Particle size decreases with time because settling preferentially removes the largest particles. At $0.6 \mathrm{hr}$, when the concentration has been reduced by four orders of magnitude, the mass median particle diameter is predicted to be 16 microns, still rather large.

Particle sizes in the outer containment are predicted to be only a fourth as large as those in the inner containment. The small size occurs because an appreciable fraction of the mass which leaks from the primary volume does so before particles agglomerate to their maximum size in the primary volume. Concentrations in the secondary volume are too low to result in much additional agglomeration. In the secondary volume, a peak particle diameter of 7.6 microns occurs at $0.06 \mathrm{hr}$. At $0.6 \mathrm{hr}$, the size has decreased to four microns.

One unexpected feature shown in Figure $A-10$ is the decrease in particle size with time in the secondary volume. It is concluded that only the largest particles settle out, and their removal is enough to skew the particle size distribution toward the smaller sizes. No significant difference in particle size is predicted whether the EACS operates or not. This behavior is consistent with the expected lack of agglomeration in the secondary vessel.

Mass Collected by EACS

The total mass of aerosol material collected on the EACS located in the secondary building is shown as a function of time in Figure A-11. The ultimate mass collected is 696 grams, which is 79 percent of the mass leaked from the inner containment. This loading represents a very modest equipment requirement.

Final loading of the EACS is achieved in about $3 \mathrm{hr}$. For longer times, airborne concentrations are too low to add a significant loading. 


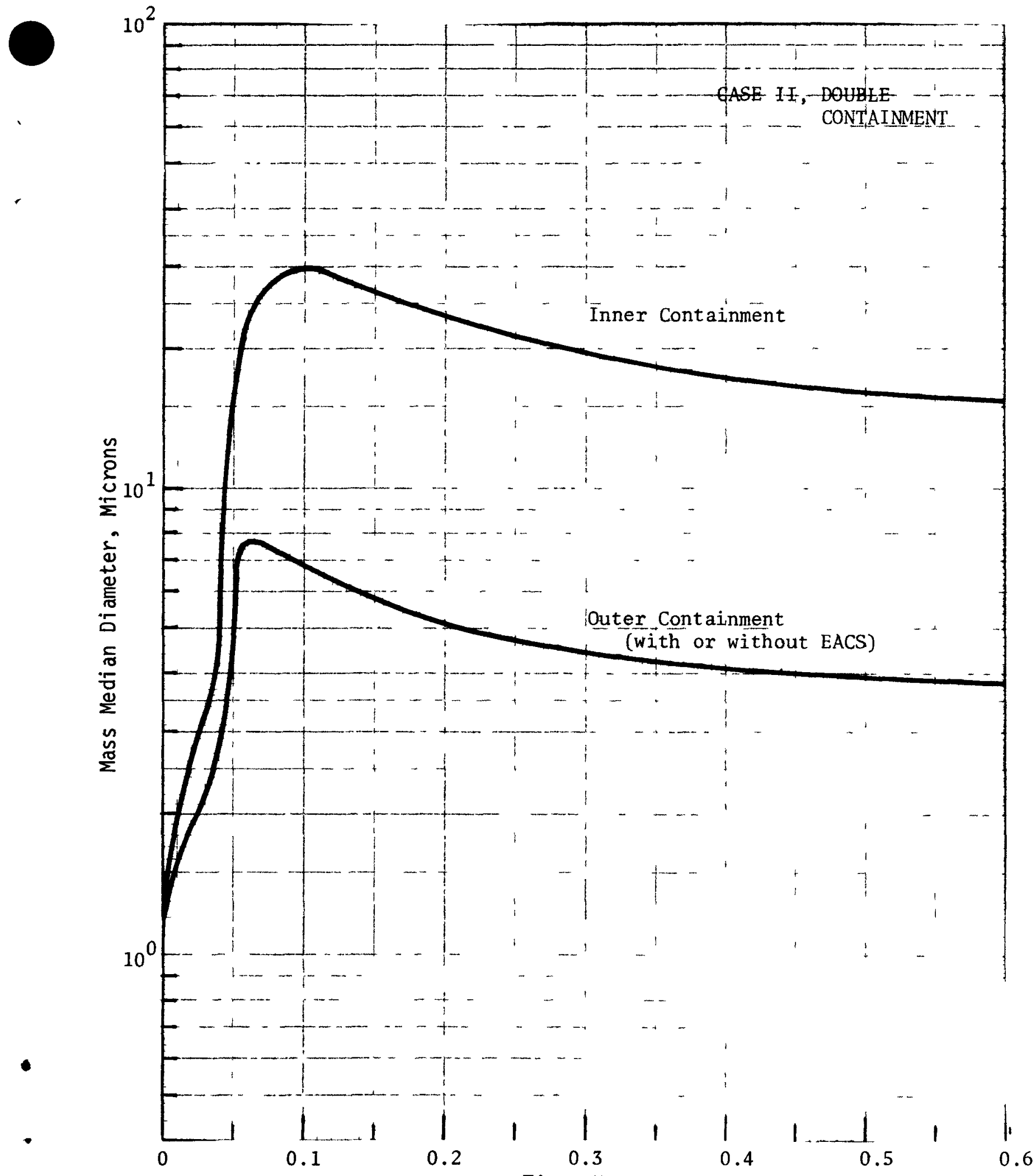

Time, Hours

FIGURE A-10. Airborne Particle Size in Case II. 


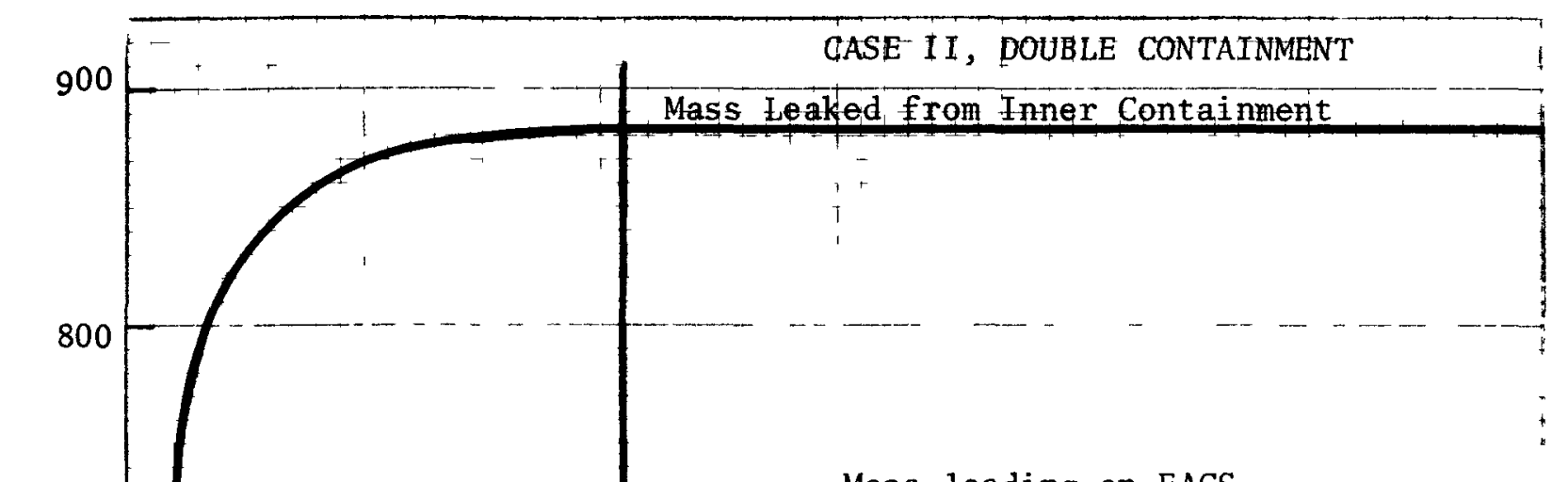

Mass loading on EACS

(79\% of total mass)

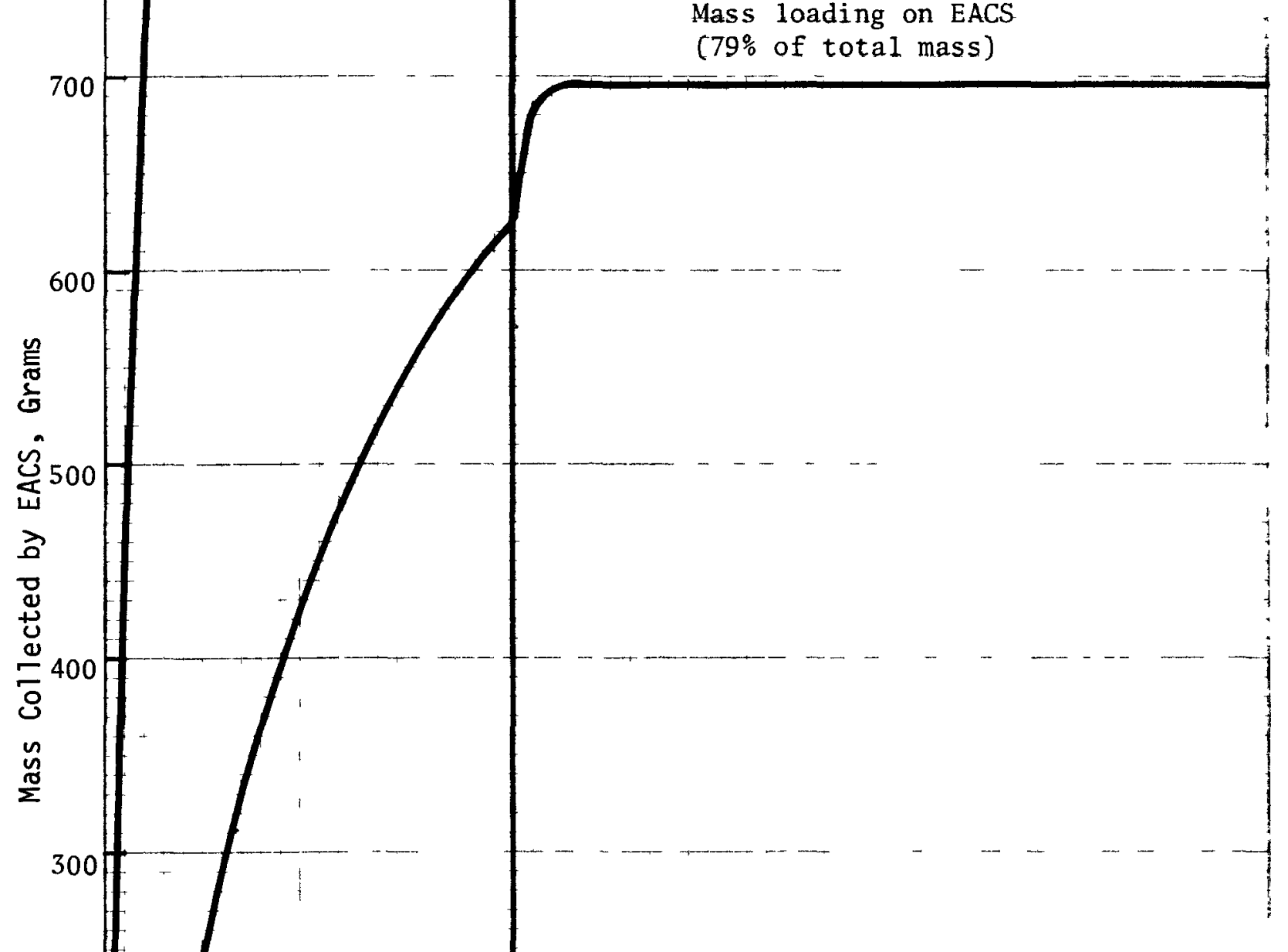

Note change in time

scale at $\mathrm{t}=1.05 \mathrm{hr}$

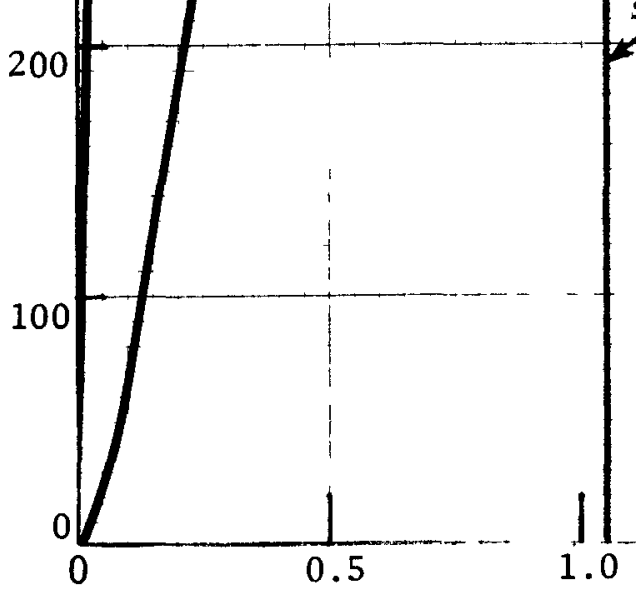

$\left.\prod_{1.0}\right|_{10}$

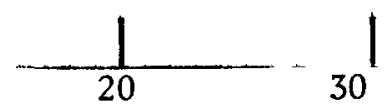

1

Time, Hours

FIGURE A-11. Aerosol Mass Collected by EACS in Case II. 
Also shown in Figure $A-11$ is the mass leaked from the primary volume. Leakage is essentially final at $1 \mathrm{hr}$ due to the rapid depletion of concentration in the primary volume by natural deposition.

\section{Mass Leaked to the Environment}

The mass leaked to the environment is greatly reduced by the presence of the inner containment region. Therefore, an air cleaning system may not be required to rapidly remove radioactive material in order to meet guideline doses for reasonably sized sites.

\section{Total Aerosol Mass Leaked}

The integrated mass leaked from the outer containment vessel is portrayed in Figure A-12 with and without EACS. For natural depletion alone, the mass leaked in two hours is $0.05 \mathrm{gram}$. Due to the slow natural deposition in the outer containment vessel, leakage continues at an appreciable rate for times beyond $50 \mathrm{hr}$. At $50 \mathrm{hr}$, about 0.5 grams of material is calculated to leak to the environment.

\section{Mass of Plutonium Leaked}

Plutonium accounts for 14.6 percent of the released aerosol mass and, assuming co-agglomeration of all materials, 14.6 percent of the leaked mass is plutonium. Therefore, only 0.0073 grams of $\mathrm{Pu}$ is predicted to leak in $2 \mathrm{hr}$ without EACS operation, and only one-fourth of this amount $(0.0020 \mathrm{~g})$ when EACS is used.

For the base case without EACS, plutonium leaked in two hours was reduced by a factor of 160 in Case II compared to Case I. This large gain in performance demonstrates the very large improvements which can be realized by using a more complex containment design. The 2-hr leakage of $\mathrm{Pu}$ in Case II without an EACS is only 3 percent of the leakage in Case I with an EACS.

\section{CASE III (CONTAINMENT/CONF INEMENT)}

Aerosol behavior in Case III was analyzed using the HEDL version of the HAA-3B code. Only one aerosol source term was present in Case III because a continuing sodium fire is not possible in the inerted primary containment zone. 


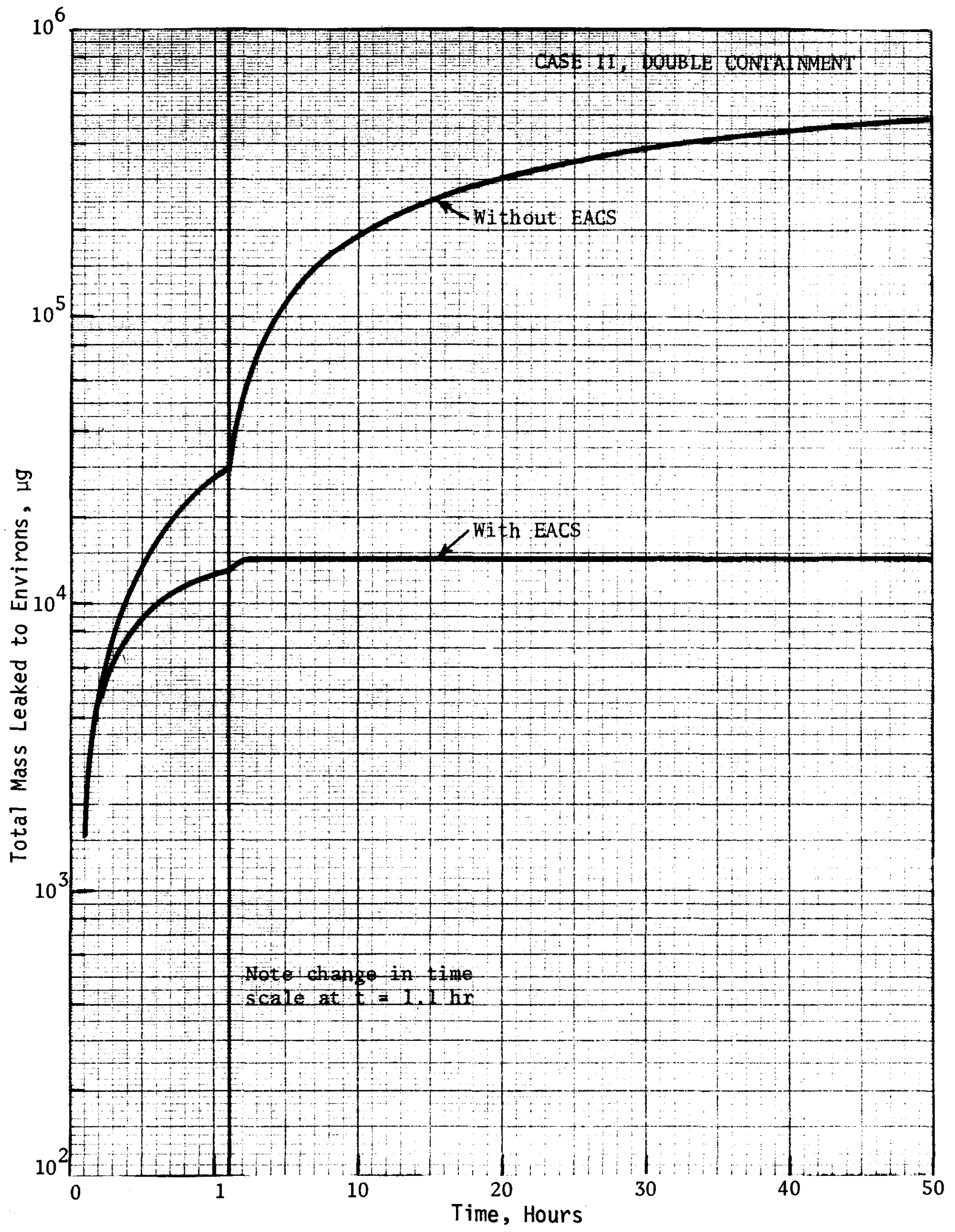

FIGURE A-12. Total Mass Leaked to Environment in Case II. 
Thermal conditions for HAA-3B operation were taken as constant, both in the primary containment volume and in the confinement building. Temperature estimated for the primary volume was $1305^{\circ} \mathrm{F}$, and in the confinement building temperature was assumed to be constant at $80^{\circ} \mathrm{F}$.

\section{Airborne Mass Concentration}

The airborne concentration in both the primary (inner) containment and in the confinement building is shown in Figure A-13. The concentration in the primary volume falls rapidly, by natural processes, from an initial concentration of $280 \mu \mathrm{g} / \mathrm{cm}^{3}$ to $0.12 \mu \mathrm{g} / \mathrm{cm}^{3}$ after one hour. Natural transport processes continue to deplete the airborne concentration in the primary, and at $4 \mathrm{hr}$ the concentration has been reduced by a factor of $10^{-5}$ from the initial value.

In the confinement building, the aerosol concentration builds to a maximum of $0.01 \mathrm{\mu g} / \mathrm{cm}^{3}$ at $0.1 \mathrm{hr}$ due to leakage from the primary volume. The concentration then is depleted by plateout, fallout, and by the ventilation flow of 15,000 CFM caused by the EACS.

\section{Particle Size}

Aerosol particle sizes predicted for the primary volume and for the confinement building are compared in Figure A-14. As expected, the particles in the primary volume grow to a much larger size than those in the confinement building. In the primary, a maximum particle size of $30 \mu \mathrm{m} \mathrm{MMD} \mathrm{is} \mathrm{at-}$ tained at about $0.1 \mathrm{hr}$. This size decreases with time, and at $0.6 \mathrm{hr}$, the mass median diameter is predicted to decrease to 15 microns.

Particle growth in the confinement building is minimal because of the very low concentration (maximum of $10^{-2} \mu \mathrm{g} / \mathrm{cm}^{3}$ ). The predicted diameter attains a maximum of 7.6 microns at $0.06 \mathrm{hr}$, and falls with time. At 0.6 $\mathrm{hr}$, the MMD is $4 \mu \mathrm{m}$. The magnitude of the decrease in particle diameter with time for the confinement building is greater than might have been expected since the only factor tending to reduce average particle size is fallout. 


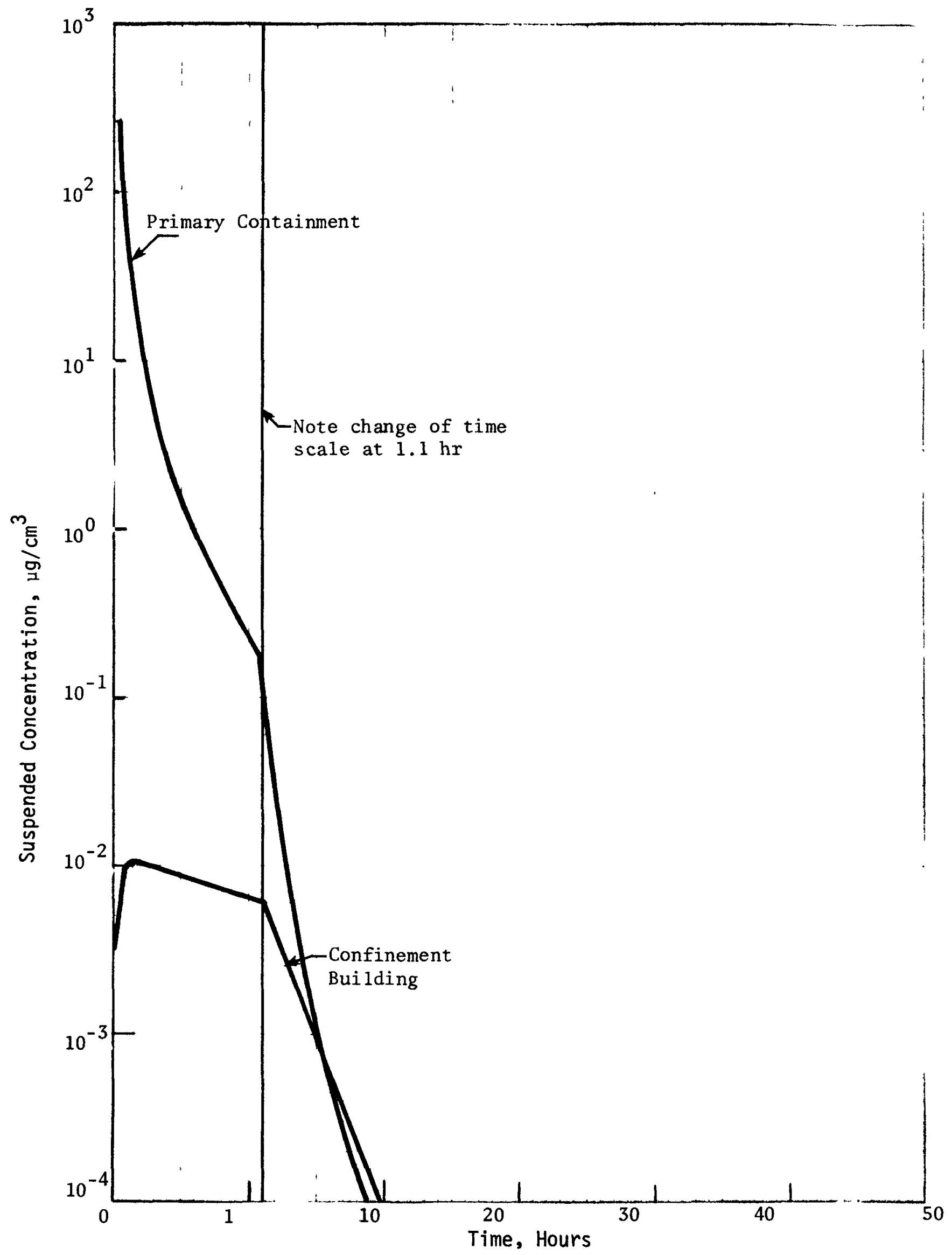

FIGURE A-13. Airborne Particle Concentrations in Containment/Confinement System Following DBA. 


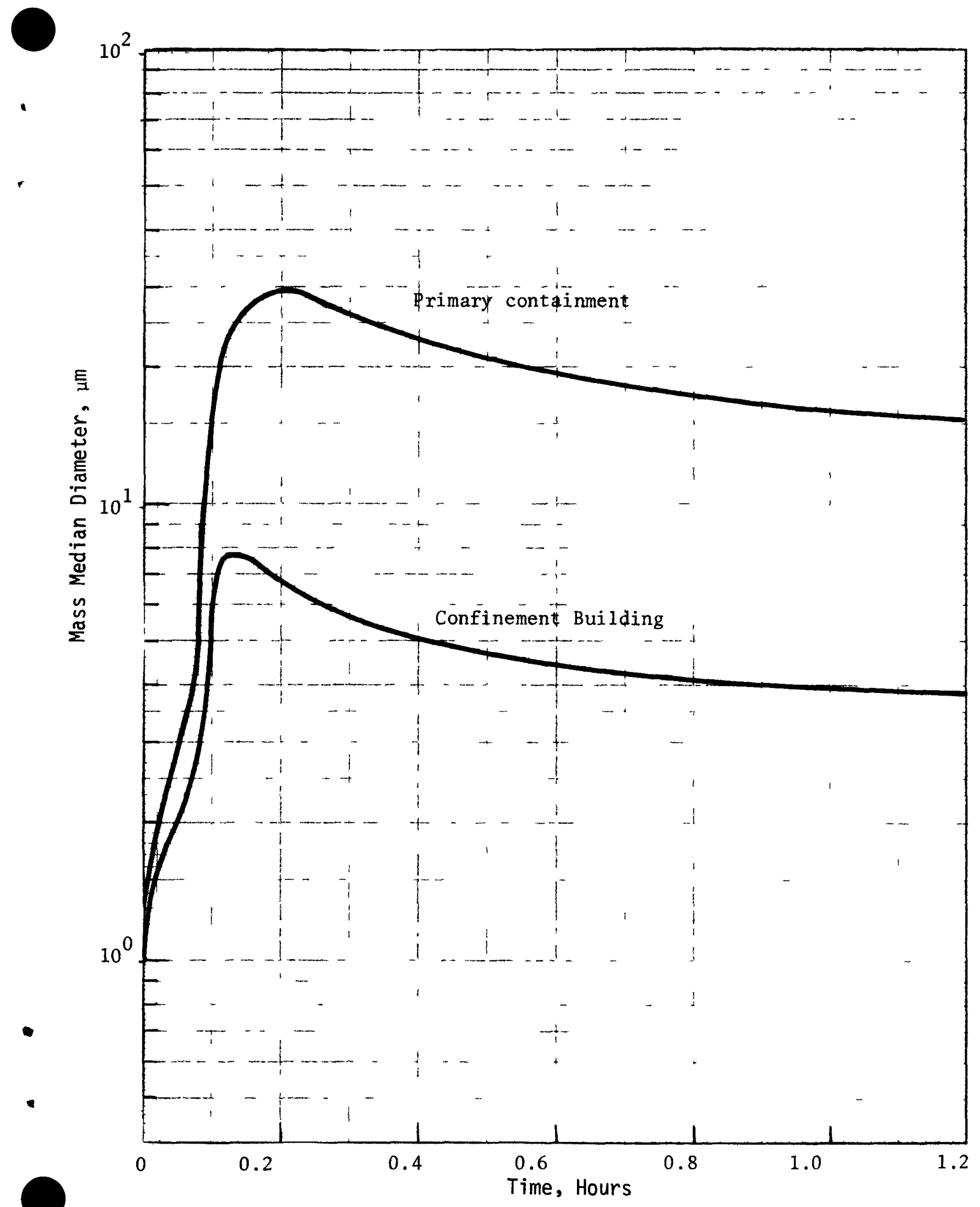

FIGURE A-14. Airborne Particle Size in Containment/Confinement System Following DBA. 
Aerosol Mass Leaked to the Environment

The airborne mass which reaches the environment through the EACS discharge stack was computed from the HAA-3B data on mass entering the EACS, assuming two values for the overall EACS collection efficiency, $E_{V}$, of 0.99 and 0.999 . The decontamination factor, $D F$, is related to the collection efficiency as shown by Equation (A-1):

$$
D F=\frac{1}{1-E_{v}} \text {. }
$$

Thus, decontamination factors of 100 and 1000 correspond to efficiencies of 0.99 and 0.999 , respectively. At the present time, a DF of 100 is accepted by NRC for properly designed filtration systems for LWR plants. ${ }^{\text {(14) It is }}$ possible that additional credit will be granted in the future with sufficient test verification.

\section{Total Aerosol Mass Leaked}

The total mass discharged to the environment as a function of time is plotted in Figure A-15 for each of the two assumed decontamination factors. The mass discharged was calculated by multiplying the mass entering the EACS by the penetration of the EACS, $\left(I-E_{v}\right)$. The mass discharged to the environs during the initial 2-hr period is 3.5 and 0.35 grams for a DF of 100 and 1000 , respectively.

\section{Mass of Plutonium Leaked to Environment}

Plutonium accounts for $\mathbf{1 4 . 6}$ percent of the released aerosol mass, and assuming co-agglomeration of all aerosol materials, 14.6 percent of the total leaked mass if Pu. If no EACS were used to attenuate the mass of leaked aerosol, 50 grams of Pu would be discharged through the stack in 2 hours. An estimate of the DF required of an EACS so that the guideline dose of 150 rem could just be met is shown in Figure A-16. The curve in Figure A-16 was calculated by Equation ( $A-2)$, using values of $X / Q$ and breathing rate from Regulatory Guide 1.3: ${ }^{(8)}$

$$
M_{\mathrm{Pu} 150}=\frac{150 \text { rem }}{\text { (F-Factor)(Breathing Rate })(X / Q)} .
$$




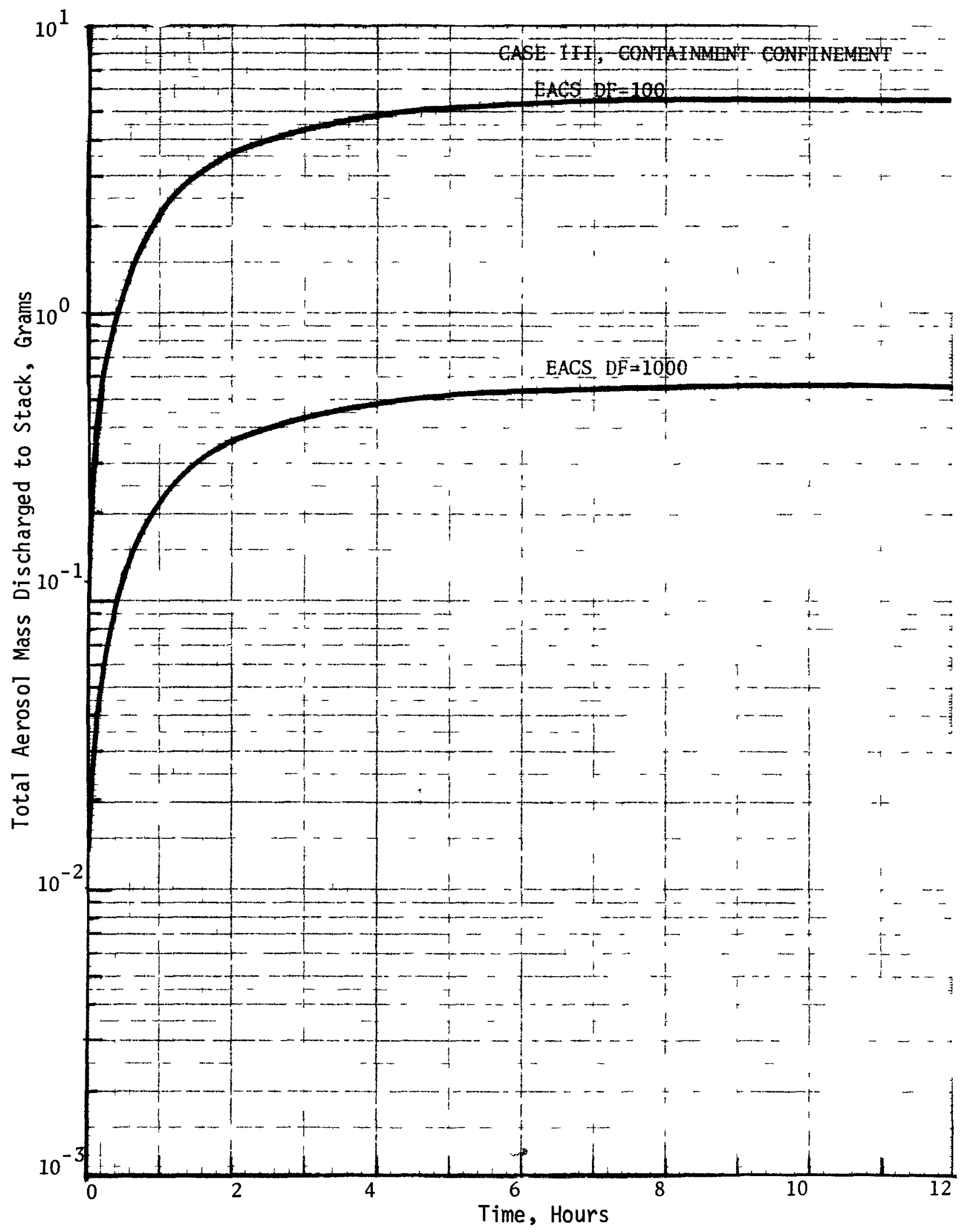

FIGURE A-15. Aerosol Mass Discharged to Stack from Containment/ Confinement System Following DBA. 


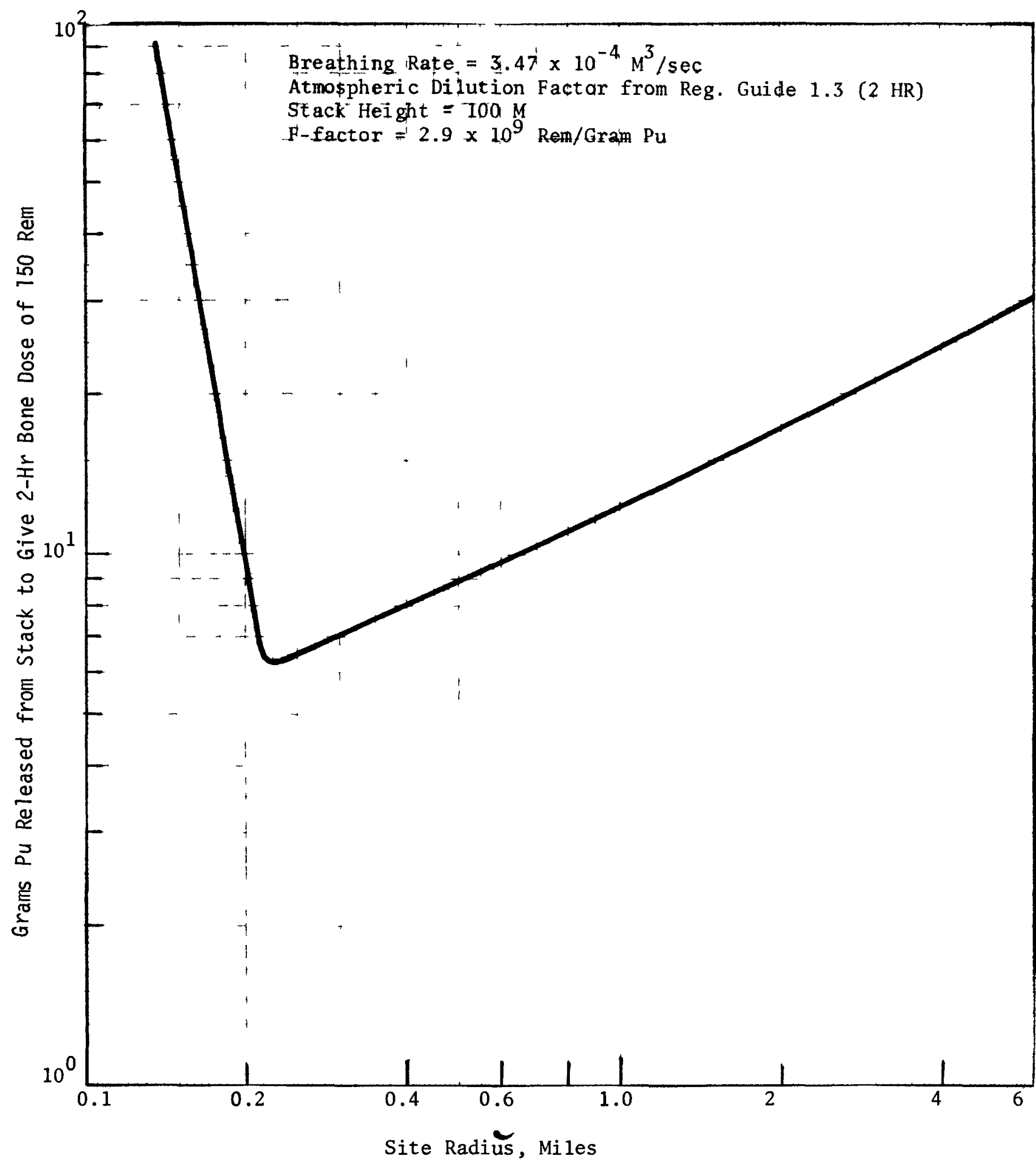

FIGURE A-16. Calculated Plutonium Release to Yield 150-rem Dose at Site Boundary. 
where: $\mathrm{M}_{\mathrm{Pu}} 150=$ mass of $\mathrm{Pu}$ released from stack in $2 \mathrm{hr}$ which gives $150-$ rem bone dose,

F-Factor $=2.9 \times 10^{9} \mathrm{rem} / \mathrm{g} \mathrm{Pu}$ inhaled,

Breathing Rate $=3.47 \times 10^{-4} \mathrm{~m}^{3} / \mathrm{sec}$,

$X / Q=$ atmospheric diffusion factor $=$ function of site radius.

Figure A-16 shows that the minimum quantity of Pu released from the stack which gives the 150 -rem guideline dose is $6.2 \mathrm{~g}$, and a site exclusion area radius of 0.23 mile is sufficient. Thus, the 51 grams of Pu discharged if no EACS were provided needs to be reduced by a factor of 8.2 (an EACS $D F$ of only 8.2) in order to just meet the minimum siting requirement with a 0.23-mile site boundary. The population center distance should be considered also, of course, but this exercise shows that a containment/ confinement type of containment system is feasible and has potential for reducing site boundary dose well below the 150-rem guideline. The mass loadings and required DF appear to be modest, and it is likely that such a system could be designed on the basis of the present state of the art. 
TABLE B-1

CRITERIA FOR EVALUATING LMFBR EMERGENCY AIR CLEANING SYSTEMS IN SINGLE CONTAINMENT PLANTS

Weight Factor

1. SYSTEM EFFECTIVENESS

The EACS shall be effective in reducing the release of radioactive substances to the environment under DBST conditions.

a. A dose reduction factor (2-hr) of ten can be achieved 9 for aerosol particles.

b. Decay heat can be dissipated adequately. 7

c. Either dry or sticky particles can be treated 7 effectively.

d. System effectiveness is not degraded by the radiation 4 dose caused by the accident over the required operating period.

2. SYSTEM RELIABILITY

The EACS shall have a high degree of reliability in startup and continuance of operation during the entire accident period.

a. The EACS shall have a high probability of startup after initiation of the DBST release.

b. The system shall be capable of withstanding the pressure pulse associated with the DBST.

c. The system does not degrade during periods of unuse. 4

d. The system shall be capable of dependable operation over the required period of time under accident conditions of temperature, pressure, humidity and aerosol loading.

e. The system requires simple components and conservative design stress.

3. CONTAINMENT COMPATIBILITY

The presence and operation of the EACS shall not degrade the normal effectiveness of the containment building.

a. Inadvertent operation of the EACS shall not harm plant 5 equipment or constitute a hazard to personnel.

b. Operation of the EACS shal1 not significantly increase 5 the pressure within the containment building by gas injection, energy release or other means. 
TABLE B-1 (Cont'd.)

c. The size of the EACS shall be compatible with instal(less than $10 \%$ of the volume of the RCB).

d. The EACS shall maintain the collected aerosol mass in a subcritical configuration.

4. TECHNOLOGICAL CREDIBILITY

The effectiveness of the EACS shall be clearly demonstrable by experience, mathematical models and testing.
a. The air cleaning concept is based on highly developed technology.
b. The EACS can be tested in place for operability and 5 efficiency.
c. The EACS performance can be predicted by verified mathematical models.
d. The EACS equipment scaleup from currently available sizes to LMFBR plant application is smal1.

5. SYSTEM CHARACTERISTICS AND FLEXIBILITY

The EACS performance shall not be critically dependent on the accident environment conditions and shall accommodate possible future design changes.
a. The EACS is effective for the entire particle size spectrum expected during the accident.
b. The system performance is not highly sensitive to the 4 atmosphere temperature, pressure and relative humidity.
c. The system energy consumption is low.
d. The system can be modified to add halogen removal com- 2 ponents, hydrogen recombiners and containment coolers.
e. The post-accident recovery is facilitated by the EACS. 1

6. FABRICATION EFFORT

The system shall be readily designed, fabricated and installed at reasonable cost and in a time frame consistent with plant construction.
a. The system cost is low. Capital cost is less than $\$ 10 \quad 5$
b. Materials and techniques used in construction are readily available and easily fabricated.
c. Components and equipment are readily available. 
TABLE B-2

CRITERIA FOR EVALUATING LMFBR EMERGENCY AIR CLEANING SYSTEMS

IN A CONTAINMENT/CONFINEMENT PLANT

Criteria Description

Weight Factor

1. SYSTEM EFFECTIVENESS

The EACS shall be effective in reducing the release of radioactive substances to the environment under DBST conditions.

a. A decontamination factor of 100 can be achieved for aerosol particles.

b. Either dry or sticky particles can be treated effectively. 7

c. System effectiveness is not degraded by the radiation 5 dose caused by the accident over the required operating period.

2. SYSTEM RELIABILITY

The EACS shall have a high degree of reliability in startup and continuance of operation during the entire accident period.

a. The EACS shall have a high probability of startup after 10 initiation of the DBST release.

b. The system does not degrade during periods of unuse. 6

c. The system shall be capable of dependable operation $\quad 10$ over the required period of time (30-d for DBST, $1-d$ for $\mathrm{Na}$ fire) under the accident conditions of temperature, pressure, humidity, and aerosol loading.

d. The system requires simple components and conservative design stresses.

3. CONTAINMENT COMPATIBILITY

The presence and operation of the EACS shall not degrade the normal effectiveness of the confinement building.

a. Inadvertent operation of the EACS shall not harm plant 4 equipment or constitute a hazard to personnel.

b. The size of the EACS shall be compatible with installation within or adjacent to the confinement building $\left(<12,000 \mathrm{ft}^{2}\right)$.

4. TECHNOLOGICAL CREDIBILITY

The effectiveness of the EACS shall be clearly demonstrable by experience, mathematical models and testing.

a. The air cleaning concept is based on highly developed technology. 
TABLE B-2 (Cont'd.)

b. The EACS can be tested in place for operability and efficiency.

c. The EACS performance can be predicted by verified mathematical models.

d. The EACS equipment scaleup from currently available sizes 3 to LMFBR plant application is sma11.

5. SYSTEM CHARACTERISTICS AND FLEXIBILITY

The EACS performance shall not be critically dependent on the accident environment conditions and sha11 accommodate possible future design changes.
a. The EACS is effective for the entire particle size spectrum expected during the accident.
b. The system performance is not highly sensitive to the atmosphere temperature, pressure and relative humidity.
c. The system energy consumption is low.
d. The system can be modified to add halogen removal com- 2 ponents and other air cleaning devices if needed.
e. The post-accident recovery is facilitated by the EACS.

6. FABRICATION EFFORT

The system shall be readily designed, fabricated and installed at reasonable cost and in a time frame consistent with plant construction.

a. The system cost is low. Capital cost is less than $\$ 10 \quad 5$ million; operating costs are low.

b. Materials and techniques used in construction are readily 1 available and easily fabricated.

c. Components and equipment are readily available. 


\section{APPENDIX C}

NUMERICAL RATINGS

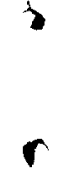

C-1 
TABLE C-1

NUMERICAL RATING OF SYSTEMS SR-1 THROUGH SR-7

\begin{tabular}{|c|c|c|c|c|c|c|c|c|c|c|c|c|c|c|c|}
\hline \multirow{2}{*}{$\frac{\text { Criterion }}{1 a^{\star}}$} & \multirow{2}{*}{$\begin{array}{l}\text { Weight } \\
\text { Factor } \\
9\end{array}$} & \multicolumn{2}{|c|}{$\begin{array}{c}\text { SR-1 } \\
\text { PF, HEPA } \\
\text { Rating Score }\end{array}$} & \multicolumn{2}{|c|}{$\begin{array}{c}\text { SR-2 } \\
\text { Graded Media } \\
\text { Rating Score }\end{array}$} & \multicolumn{2}{|c|}{$\begin{array}{c}\text { SR-3 } \\
\text { Sand Bed } \\
\text { Rating Score }\end{array}$} & \multicolumn{2}{|c|}{$\begin{array}{c}\text { SR-4 } \\
\text { Bag Fijter } \\
\text { Rating Score }\end{array}$} & \multicolumn{2}{|c|}{$\begin{array}{c}\text { SR-5 } \\
\text { Cyclone } \\
\text { Rating Score }\end{array}$} & \multicolumn{2}{|c|}{$\begin{array}{l}\text { SR-6 } \\
\text { Cyclone, HEPA } \\
\text { Rating Score }\end{array}$} & \multicolumn{2}{|c|}{$\begin{array}{c}\text { SR-7 } \\
\text { Wet Scrubber } \\
\text { Rating Score }\end{array}$} \\
\hline & & 3.5 & 31.5 & 3.3 & 29.7 & 3.5 & 31.5 & 3.5 & 31.5 & 3.3 & 29.7 & 3.5 & 31.5 & 3.3 & 29.7 \\
\hline $10^{\star}$ & 7 & 3.2 & 22.4 & 3.2 & 22.4 & 3.6 & 25.2 & 2.8 & 19.6 & 3.0 & 21.0 & 3.2 & 22.4 & 3.5 & 24.5 \\
\hline $1 c^{\star}$ & 7 & 2.0 & 14.0 & 2.8 & 19.6 & 3.0 & 21.0 & 2.0 & 14.0 & 3.5 & 24.5 & 2.5 & 17.5 & 4.0 & 28.0 \\
\hline $1 d^{*}$ & 4 & 3.7 & $\frac{14.8}{82.7}$ & 3.7 & $\frac{14.8}{86.5}$ & 4.0 & $\frac{16.0}{93.7}$ & 3.0 & $\frac{12.0}{77.1}$ & 4.0 & $\frac{16.0}{91.2}$ & 3.8 & $\frac{15.2}{86.6}$ & 3.5 & $\frac{14.0}{96.2}$ \\
\hline $2 \mathrm{a}^{\star}$ & 6 & 3.8 & 22.8 & 3.8 & 22.8 & 3.8 & 22.8 & 2.5 & 15.0 & 3.8 & 22.8 & 3.8 & 22.8 & 2.4 & 14.4 \\
\hline $2 b^{\star}$ & 5 & 3.0 & 15.0 & 3.6 & 18.0 & 3.8 & 19.0 & 3.2 & 16.0 & 3.8 & 19.0 & 3.3 & 16.5 & 3.8 & 19.0 \\
\hline $2 c^{\star}$ & 4 & 3.7 & 14.8 & 3.7 & 14.8 & 3.9 & 15.6 & 3.4 & 13.6 & 3.9 & 15.6 & 3.8 & 15.2 & 3.0 & 12.0 \\
\hline $2 \mathrm{~d}^{\star}$ & 6 & 3.3 & 19.8 & 3.5 & 21.0 & 3.6 & 21.6 & 2.9 & 17.4 & 3.5 & 21.0 & 3.3 & 19.8 & 3.0 & 18.0 \\
\hline $2 e$ & 2 & 3.6 & $\frac{7.2}{79.6}$ & 3.4 & $\frac{6.8}{83.4}$ & 3.7 & $\frac{7.4}{86.4}$ & 2.0 & $\frac{4.0}{66.0}$ & 4.0 & $\frac{8.0}{86.4}$ & 3.5 & $\frac{7.0}{81.3}$ & 3.1 & $\frac{6.2}{69.6}$ \\
\hline $3 a$ & 5 & 4.0 & 20.0 & 4.0 & 20.0 & 4.0 & 20.0 & 4.0 & 20.0 & 4.0 & 20.0 & 4.0 & 20.0 & 3.5 & 17.5 \\
\hline $3 b^{*}$ & 5 & 3.5 & 17.5 & 3.4 & 17.0 & 3.8 & 19.0 & 3.6 & 18.0 & 3.0 & 15.0 & 3.1 & 15.5 & 1.0 & 5.0 \\
\hline $3 c^{\star}$ & 4 & 2.7 & 10.8 & 2.0 & 8.0 & 0.5 & 2.0 & 2.6 & 10.4 & 2.0 & 8.0 & 2.3 & 9.2 & 2.7 & 10.8 \\
\hline $3 \mathrm{~d}^{\star}$ & 4 & 4.0 & $\frac{16.0}{64.3}$ & 4.0 & $\frac{16.0}{61.0}$ & 4.0 & $\frac{16.0}{57.0}$ & 3.5 & $\frac{14.0}{62.4}$ & 3.5 & $\frac{14.0}{57.0}$ & 3.6 & $\frac{14.4}{59.7}$ & 3.0 & $\frac{12.0}{45.3}$ \\
\hline $4 a$ & 3 & 4.0 & 12.0 & 2.5 & 7.5 & 3.0 & 9.0 & 3.8 & 11.4 & 4.0 & 12.0 & 4.0 & 12.0 & 3.5 & 10.5 \\
\hline $4 b$ & 5 & 4.0 & 20.0 & 2.5 & 12.5 & 4.0 & 20.0 & 3.3 & 16.5 & 3.0 & 15.0 & 3.0 & 15.0 & 3.3 & 16.5 \\
\hline $4 c$ & 4 & 4.0 & 16.0 & 3.5 & 14.0 & 3.8 & 15.2 & 3.8 & 15.2 & 3.0 & 12.0 & 3.0 & 12.0 & 3.0 & 12.0 \\
\hline $4 d$ & 2 & 3.8 & $\frac{7.6}{55.6}$ & 2.3 & $\frac{4.6}{38.6}$ & 3.8 & $\frac{7.6}{51.8}$ & 4.0 & $\frac{8.0}{51.1}$ & 3.5 & $\frac{7.0}{46.0}$ & 3.8 & $\frac{7.6}{46.6}$ & 4.0 & $\frac{8.0}{47.0}$ \\
\hline $5 a$ & 3 & 4.0 & 12.0 & 3.0 & 9.0 & 3.0 & 9.0 & 3.9 & 11.7 & 0.0 & 0.0 & 2.8 & 8.4 & 2.5 & 7.5 \\
\hline $5 b$ & 4 & 2.7 & 10.8 & 3.8 & 15.2 & 3.9 & 15.6 & 2.7 & 10.8 & 3.5 & 14.0 & 2.9 & 11.6 & 3.0 & 12.0 \\
\hline $5 c$ & 1 & 3.3 & 3.3 & 3.0 & 3.0 & 3.1 & 3.1 & 3.4 & 3.4 & 2.6 & 2.6 & 2.9 & 2.9 & 3.2 & 3.2 \\
\hline $5 d$ & 2 & 4.0 & 8.0 & 3.5 & 7.0 & 3.8 & 7.6 & 3.8 & 7.6 & 1.5 & 3.0 & 4.0 & 8.0 & 3.7 & 7.4 \\
\hline $5 e$ & 1 & 3.0 & $\frac{3.0}{37.1}$ & 2.9 & $\frac{2.9}{37.1}$ & 2.0 & $\frac{2.0}{37.3}$ & 2.3 & $\frac{2.3}{35.8}$ & 2.5 & $\frac{2.5}{22.7}$ & 2.5 & $\frac{2.5}{33.4}$ & 3.0 & $\frac{3.0}{33.1}$ \\
\hline $6 a$ & 5 & 2.5 & 12.5 & 2.2 & 11.0 & 1.2 & 6.0 & 2.8 & 14.0 & 2.8 & 14.0 & 2.6 & 13.0 & 2.3 & 11.5 \\
\hline $6 \mathrm{~b}$ & 1 & 4.0 & 4.0 & 3.0 & 3.0 & 3.0 & 3.0 & 3.2 & 3.2 & 4.0 & 4.0 & 4.0 & 4.0 & 4.0 & 4.0 \\
\hline $6 c$ & 1 & 3.0 & $\frac{3.0}{19.5}$ & 1.5 & $\frac{1.5}{15.5}$ & 3.2 & $\frac{3.2}{12.2}$ & 3.5 & $\frac{3.5}{20.7}$ & 3.5 & $\frac{3.5}{21.5}$ & 3.5 & $\frac{3.5}{20.5}$ & 4.0 & $\frac{4.0}{19.5}$ \\
\hline Total & $\overline{100}$ & & $\overline{338.8}$ & & $\overline{322.1}$ & & $\overline{338.4}$ & & $\overline{313.7}$ & & $\overline{324.2}$ & & $\overline{327.5}$ & & 310.7 \\
\hline
\end{tabular}

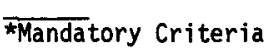


TABLE C-2

NUMERICAL RATING OF SYSTEMS SR-8 THROUGH SD-14

\begin{tabular}{|c|c|c|c|c|c|c|c|c|c|c|c|c|c|c|c|}
\hline Criterion & $\begin{array}{l}\text { Weight } \\
\text { Factor }\end{array}$ & $\begin{array}{l}S R \\
\frac{\text { Fluid. }}{\text { Rating }}\end{array}$ & $\begin{array}{l}-8 \\
\text { Bed } \\
\text { Score }\end{array}$ & $\begin{array}{r}S \\
\text { Acousti } \\
\text { Rating }\end{array}$ & $\begin{array}{l}-9 \\
+ \text { cyc. } \\
\text { Score } \\
\text { Score }\end{array}$ & $\begin{array}{l}\text { SR } \\
\text { Mech. S } \\
\text { Rating }\end{array}$ & $\begin{array}{l}10 \\
p_{\text {P. }}+\mathrm{H} \\
\text { Score }\end{array}$ & $\begin{array}{l}\text { SR } \\
\text { Sett. } \\
\text { Rating }\end{array}$ & $\begin{array}{l}11 \\
\frac{\text { ed }+H}{\text { score }}\end{array}$ & $\begin{array}{r}S F \\
\quad E S \\
\text { Rating }\end{array}$ & $\frac{12}{\text { Score }}$ & $\begin{array}{l}\text { SR } \\
\text { Steam- } \\
\text { Rating }\end{array}$ & $\begin{array}{l}13 \\
\text { Demis. } \\
\text { Score }\end{array}$ & $\begin{array}{r}\text { SD } \\
\text { Liquid } \\
\text { Rating }\end{array}$ & $\begin{array}{l}14 \\
\text { Spray } \\
\text { Score }\end{array}$ \\
\hline $1 a^{*}$ & 9 & 3.5 & 31.5 & 3.5 & 31.5 & 3.5 & 31.5 & 3.5 & 31.5 & 3.4 & 30.6 & 3.5 & 31.5 & 3.7 & 33.3 \\
\hline $1 b^{\star}$ & 7 & 3.0 & 21.0 & 2.9 & 20.3 & 2.8 & 19.6 & 3.5 & 24.5 & 3.4 & 23.8 & 3.3 & 23.1 & 3.5 & 24.5 \\
\hline $1 c^{*}$ & 7 & 2.8 & 19.6 & 3.5 & 24.5 & 1.0 & 7.0 & 2.0 & 14.0 & 3.6 & 25.2 & 4.0 & 28.0 & 4.0 & 28.0 \\
\hline $1 d^{\star}$ & 4 & 4.0 & $\frac{16.0}{88.1}$ & 4.0 & $\frac{16.0}{92.3}$ & 3.8 & $\frac{15.2}{73.3}$ & 3.8 & $\frac{15.2}{85.2}$ & 2.0 & $\frac{8.0}{87.6}$ & 3.5 & $\frac{14.0}{96.6}$ & 3.5 & $\frac{14.0}{99.8}$ \\
\hline $2 a^{\star}$ & 6 & 2.5 & 15.0 & 3.2 & 19.2 & 3.8 & 22.8 & 3.8 & 22.8 & 3.0 & 18.0 & 2.2 & 13.2 & 3.0 & 18.0 \\
\hline $2 b^{\star}$ & 5 & 3.0 & 15.0 & 3.8 & 19.0 & 3.0 & 15.0 & 3.0 & 15.0 & 3.3 & 16.5 & 3.5 & 17.5 & 4.0 & 20.0 \\
\hline $2 c^{\star}$ & 4 & 2.0 & 8.0 & 3.7 & 14.8 & 3.7 & 14.8 & 3.7 & 14.8 & 3.4 & 13.6 & 2.5 & 10.0 & 3.0 & 12.0 \\
\hline $2 \mathrm{~d}^{\star}$ & 6 & 1.0 & 6.0 & 2.9 & 17.4 & 1.5 & 9.0 & 3.3 & 19.8 & 2.9 & 17.4 & 2.0 & 12.0 & 2.5 & 15.0 \\
\hline $2 e$ & 2 & 3.0 & $\frac{6.0}{50.0}$ & 2.8 & $\frac{5.6}{76.0}$ & 3.3 & $\frac{6.6}{68.2}$ & 3.4 & $\frac{6.8}{79.2}$ & 2.0 & $\frac{4.0}{69.5}$ & 1.5 & $\frac{3.0}{55.7}$ & 3.2 & $\frac{6.4}{71.4}$ \\
\hline $3 a$ & 5 & 3.9 & 79.5 & 3.0 & 15.0 & 4.0 & 20.0 & 4.0 & 20.0 & 3.9 & 19.5 & 2.8 & 14.0 & 1.2 & 6.0 \\
\hline $3 \mathrm{~b}^{\star}$ & 5 & 3.7 & 18.5 & 3.0 & 15.0 & 3.5 & 17.5 & 3.6 & 18.0 & 3.5 & 17.5 & 1.5 & 7.5 & 0.0 & 0.0 \\
\hline $3 c^{\star}$ & 4 & 2.7 & 10.8 & 2.9 & 11.6 & 3.0 & 12.0 & 0.0 & 0.0 & 2.6 & 10.4 & 2.0 & 8.0 & 3.9 & 15.6 \\
\hline $3 \mathrm{~d}^{\star}$ & 4 & 4.0 & $\frac{16.0}{64.8}$ & 3.5 & $\frac{14.0}{55.6}$ & 3.5 & $\frac{14.0}{63.5}$ & 4.0 & $\frac{16.0}{54.0}$ & 3.8 & $\frac{15.2}{62.6}$ & 3.0 & $\frac{12.0}{41.5}$ & 3.0 . & $\frac{12.0}{33.6}$ \\
\hline $4 a$ & 3 & 1.7 & 5.1 & 1.5 & 4.5 & 3.0 & 9.0 & 2.8 & 8.4 & 3.9 & 11.7 & 1.2 & 3.6 & 3.0 & 9.0 \\
\hline $4 b$ & 5 & 3.8 & 19.0 & 2.5 & 12.5 & 3.0 & 15.0 & 4.0 & 20.0 & 3.3 & 16.5 & 2.0 & 10.0 & 1.5 & 7.5 \\
\hline $4 c$ & 4 & 2.2 & 8.8 & 2.2 & 8.8 & 2.8 & 11.2 & 3.7 & 14.8 & 3.3 & 13.2 & 3.5 & 14.0 & 2.9 & 11.6 \\
\hline $4 d$ & 2 & 1.0 & $\frac{2.0}{34.9}$ & 2.6 & $\frac{5.2}{31.0}$ & 4.0 & $\frac{8.0}{43.2}$ & 2.0 & $\frac{4.0}{47.2}$ & 4.0 & $\frac{8.0}{49.4}$ & 2.0 & $\frac{4.0}{31.6}$ & 4.0 & $\frac{8.0}{36.1}$ \\
\hline $5 a$ & 3 & 2.0 & 6.0 & 3.5 & 10.5 & 1.0 & 3.0 & 2.0 & 6.0 & 3.5 & 10.5 & 3.8 & 11.4 & 2.0 & 6.0 \\
\hline $5 b$ & 4 & 3.2 & 12.8 & 3.6 & 14.4 & 2.0 & 8.0 & 3.0 & 12.0 & 3.5 & 14.0 & 4.0 & 16.0 & 3.8 & 15.2 \\
\hline $5 c$ & 1 & 0.5 & 0.5 & 2.9 & 2.9 & 3.3 & 3.3 & 3.4 & 3.4 & 3.6 & 3.6 & 3.4 & 3.4 & 3.7 & 3.7 \\
\hline $5 d$ & 2 & 2.0 & 4.0 & 2.5 & 5.0 & 4.0 & 8.0 & 4.0 & 8.0 & 3.6 & 7.2 & 2.5 & 5.0 & 1.0 & 2.0 \\
\hline $5 e$ & 1 & 2.0 & $\frac{2.0}{25.3}$ & 2.5 & $\frac{2.5}{35.3}$ & 2.5 & $\frac{2.5}{24.8}$ & 2.0 & $\frac{2.0}{31.4}$ & 2.3 & $\frac{2.3}{37.6}$ & 3.0 & $\frac{3.0}{38.8}$ & 4.0 & $\frac{4.0}{30.9}$ \\
\hline $6 a$ & 5 & 0.7 & 3.5 & 2.3 & 111.5 & 2.7 & 13.5 & 0.2 & 1.0 & 2.4 & 12.0 & 1.5 & 7.5 & 3.4 & 17.0 \\
\hline $6 \mathrm{~b}$ & 1 & 2.8 & 2.8 & 3.5 & 3.5 & 3.5 & 3.5 & 4.0 & 4.0 & 3.5 & 3.5 & 3.0 & 3.0 & 4.0 & 4.0 \\
\hline $6 c$ & 1 & 3.2 & $\frac{3.2}{9.5}$ & 1.3 & $\frac{1.3}{16.3}$ & 3.0 & $\frac{3.0}{20.0}$ & 2.5 & $\frac{2.5}{7.5}$ & 3.5 & $\frac{3.5}{19.0}$ & 2.0 & $\frac{2.0}{12.5}$ & 4.0 & $\frac{4.0}{25.0}$ \\
\hline Total & $\overline{100}$ & & $\overline{272.6}$ & & $\overline{306.5}$ & & $\overline{293.0}$ & & $\overline{304.5}$ & & $\overline{325.7}$ & & 276.7 & & $\overline{296.8}$ \\
\hline
\end{tabular}


TABLE C-3

NUMERICAL RATING OF SYSTEMS SD-15 THROUGH SC-20

\begin{tabular}{|c|c|c|c|c|c|c|c|c|c|c|c|c|c|}
\hline \multirow[b]{2}{*}{ Criterion } & \multirow{2}{*}{$\begin{array}{l}\text { Weight } \\
\text { Factor } \\
\end{array}$} & \multicolumn{2}{|c|}{$\begin{array}{r}\text { SD-15 } \\
\text { Powder } \\
\end{array}$} & \multicolumn{2}{|c|}{$\begin{array}{l}\text { SD-16 } \\
\text { Foam }\end{array}$} & \multirow{2}{*}{\multicolumn{2}{|c|}{$\begin{array}{c}\text { SD-17 } \\
\text { Acoustic } \\
\text { Rating Score }\end{array}$}} & \multirow{2}{*}{\multicolumn{2}{|c|}{$\begin{array}{c}\text { SD-18 } \\
\text { Direct ESP } \\
\text { Rating Score }\end{array}$}} & \multirow{2}{*}{\multicolumn{2}{|c|}{$\begin{array}{c}\text { SC-19 } \\
\text { Acoustic, Cyc. } \\
\text { Rating Score }\end{array}$}} & \multirow{2}{*}{\multicolumn{2}{|c|}{$\begin{array}{c}\text { SC-20 } \\
\text { Powder, F } \\
\text { Rating Score }\end{array}$}} \\
\hline & & & Score & Rating & Score & & & & & & & & \\
\hline $1 a^{*}$ & 9 & 3.9 & 35.1 & 3.5 & 31.5 & 3.9 & 35.1 & 1.0 & 9.0 & 3.9 & 35.1 & 3.9 & $\overline{35.1}$ \\
\hline $1 b^{*}$ & 7 & 4.0 & 28.0 & 1.0 & 7.0 & 4.0 & 28.0 & 3.8 & 26.6 & 3.7 & 25.9 & 3.7 & 25.9 \\
\hline $1 c^{*}$ & 7 & 3.5 & 24.5 & 4.0 & 28.0 & 3.7 & 25.9 & 2.7 & 18.9 & 3.5 & 24.5 & 3.0 & 21.0 \\
\hline $1 \mathrm{~d}^{*}$ & 4 & 4.0 & $\frac{16.0}{103.6}$ & 3.0 & $\frac{12.0}{78.5}$ & 4.0 & $\frac{16.0}{105.0}$ & 2.0 & $\frac{8.0}{62.5}$ & 4.0 & $\frac{16.0}{101.5}$ & 3.8 & $\frac{15.2}{97.2}$ \\
\hline $2 a^{*}$ & 6 & 2.3 & 13.8 & 3.0 & 18.0 & 3.4 & 20.4 & 2.5 & 15.0 & 3.3 & 19.8 & 2.2 & 13.2 \\
\hline $2 b^{*}$ & 5 & 4.0 & 20.0 & 3.7 & 18.5 & 4.0 & 20.0 & 4.0 & 20.0 & 3.8 & 19.0 & 3.0 & 15.0 \\
\hline $2 c^{*}$ & 4 & 2.0 & 8.0 & 3.0 & 12.0 & 3.7 & 14.8 & 2.5 & 10.0 & 3.7 & 14.8 & 2.0 & 8.0 \\
\hline $2 \mathrm{~d}^{\star}$ & 6 & 2.5 & 15.0 & 1.0 & 6.0 & 2.7 & 16.2 & 2.3 & 13.8 & 3.0 & 18.0 & 2.9 & 17.4 \\
\hline $2 e$ & 2 & 3.3 & $\frac{6.6}{63.4}$ & 3.5 & $\frac{7.0}{61.5}$ & 3.0 & $\frac{6.0}{77.4}$ & 2.8 & $\frac{5.6}{64.4}$ & 2.6 & $\frac{5.2}{76.8}$ & 2.8 & $\frac{5.6}{59.2}$ \\
\hline $3 a$ & 5 & 1.0 & 5.0 & 1.0 & 5.0 & 2.2 & 11.0 & 2.5 & 12.5 & 2.2 & 11.0 & 1.0 & 5.0 \\
\hline $3 b^{*}$ & 5 & 3.9 & 19.5 & 0.0 & 0.0 & 2.0 & 10.0 & 3.5 & 17.5 & 2.0 & 10.0 & 3.6 & 18.0 \\
\hline $3 c^{*}$ & 4 & 4.0 & 16.0 & 3.9 & 15.6 & 3.9 & 15.6 & 3.6 & 14.4 & 3.2 & 12.8 & 3.6 & 14.4 \\
\hline $3 d^{\star}$ & 4 & 4.0 & $\frac{16.0}{56.5}$ & 3.0 & $\frac{12.0}{32.6}$ & 4.0 & $\frac{16.0}{52.6}$ & 3.9 & $\frac{15.6}{60.0}$ & 3.5 & $\frac{14.0}{47.8}$ & 4.0 & $\frac{16.0}{53.4}$ \\
\hline $4 a$ & 3 & 1.0 & 3.0 & 1.0 & 3.0 & 1.5 & 4.5 & 2.0 & 6.0 & 1.5 & 4.5 & 1.0 & 3.0 \\
\hline $4 \mathrm{~b}$ & 5 & 1.2 & 6.0 & 0.5 & 2.5 & 2.0 & 10.0 & 1.0 & 5.0 & 2.0 & 10.0 & 1.2 & 6.0 \\
\hline $4 c$ & 4 & 2.4 & 9.6 & 2.2 & 8.8 & 2.0 & 8.0 & 1.5 & 6.0 & 2.0 & 8.0 & 2.4 & 9.6 \\
\hline $4 d$ & 2 & 2.5 & $\frac{5.0}{23.6}$ & 3.2 & $\frac{6.4}{20.7}$ & 2.0 & $\frac{4.0}{26.5}$ & 1.0 & $\frac{2.0}{19.0}$ & 2.0 & $\frac{4.0}{26.5}$ & 2.5 & $\frac{5.0}{23.6}$ \\
\hline $5 a$ & 3 & 2.0 & 6.0 & 3.4 & 10.2 & 3.5 & 10.5 & 3.5 & 10.5 & 3.3 & 9.9 & 3.0 & 9.0 \\
\hline $5 b$ & 4 & 4.0 & 16.0 & 1.5 & 6.0 & 2.7 & 10.8 & 2.5 & 10.0 & 2.9 & 11.6 & 3.8 & 15.2 \\
\hline $5 c$ & 1 & 4.0 & 4.0 & 3.9 & 3.9 & 4.0 & 4.0 & 4.0 & 4.0 & 3.3 & 3.3 & 3.3 & 3.3 \\
\hline $5 d$ & 2 & 0.5 & 1.0 & 0.5 & 1.0 & 0.0 & 0.0 & 0.0 & 0.0 & 2.5 & 5.0 & 4.0 & 8.0 \\
\hline $5 e$ & 1 & 1.0 & $\frac{1.0}{28.0}$ & 0.0 & $\frac{0.0}{21.1}$ & 2.0 & $\frac{2.0}{25.3}$ & 0.0 & $\frac{0.0}{24.5}$ & 2.0 & $\frac{2.0}{31.8}$ & 2.0 & $\frac{2.0}{37.5}$ \\
\hline $6 a$ & 5 & 3.2 & 16.0 & 3.8 & 19.0 & 3.6 & 18.0 & 3.6 & 18.0 & 3.1 & 15.5 & 2.4 & 12.0 \\
\hline $6 \mathrm{~b}$ & 1 & 2.8 & 2.8 & 1.5 & 1.5 & 3.5 & 3.5 & 3.0 & 3.0 & 3.5 & 3.5 & 2.8 & 2.8 \\
\hline 6c & 1 & 2.5 & $\frac{2.5}{21.3}$ & 3.0 & $\frac{3.0}{23.5}$ & 1.2 & $\frac{1.2}{22.7}$ & 3.5 & $\frac{3.5}{24.5}$ & 1.2 & $\frac{1.2}{20.2}$ & 2.5 & $\frac{2.5}{17.3}$ \\
\hline Total & $\overline{100}$ & & $\overline{296.4}$ & & $\overline{237.9}$ & & $\overline{309.5}$ & & $\overline{254.9}$ & & $\overline{304.6}$ & & 288.7 \\
\hline
\end{tabular}

FManda tory Criteria 
TABLE C-4

NUMERICAL RATING OF SYSTEMS FOR USE WITH CONTAINMENT/CONFINEMENT

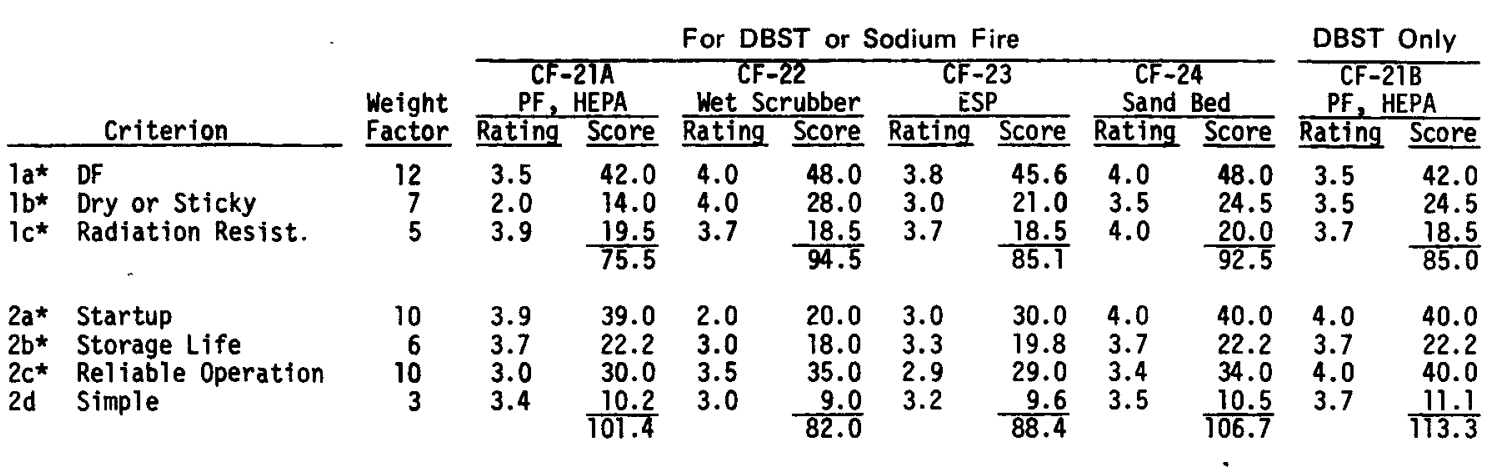

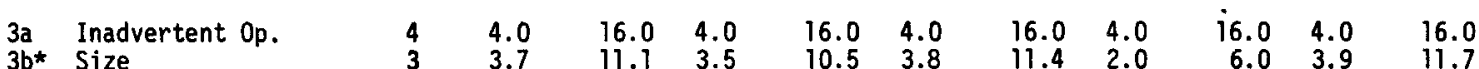

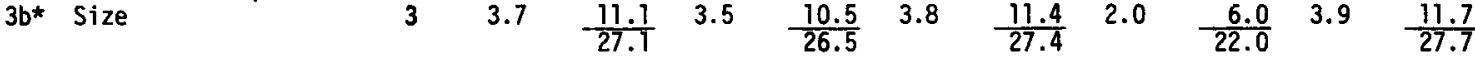

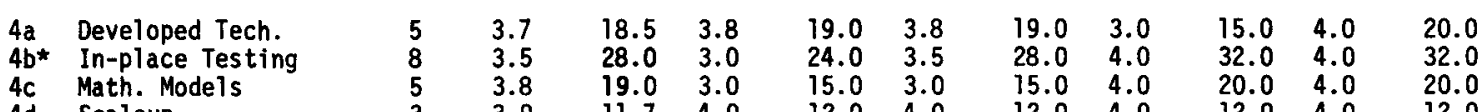

4c Math Models

4d Scaleup

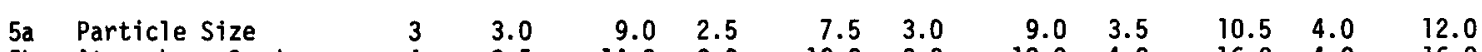

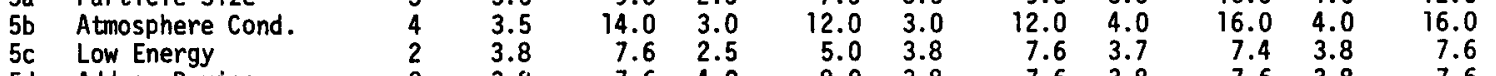

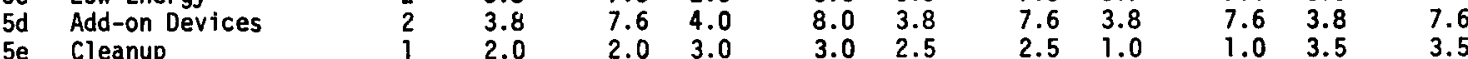

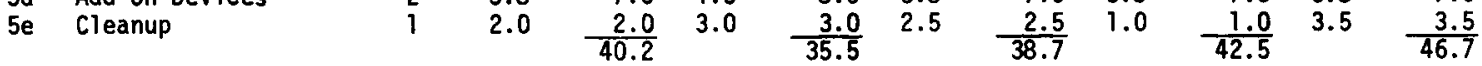

\begin{tabular}{|c|c|c|c|c|c|c|c|c|c|c|c|c|}
\hline \multirow[t]{2}{*}{$\begin{array}{l}6 \mathrm{a} \\
6 \mathrm{~b} \\
6 \mathrm{c}\end{array}$} & $\begin{array}{l}\text { Cost } \\
\text { Materials } \\
\text { Components }\end{array}$ & $\begin{array}{l}5 \\
1 \\
1\end{array}$ & $\begin{array}{l}2.8 \\
3.0 \\
3.0\end{array}$ & $\begin{array}{r}14.0 \\
3.0 \\
3.0 \\
20.0\end{array}$ & $\begin{array}{l}2.5 \\
3.5 \\
3.5\end{array}$ & $\begin{array}{r}12.5 \\
3.5 \\
3.5 \\
19.5\end{array}$ & $\begin{array}{l}3.0 \\
3.5 \\
3.5\end{array}$ & $\begin{array}{r}15.0 \\
3.5 \\
3.5 \\
22.0\end{array}$ & $\begin{array}{l}1.3 \\
3.5 \\
3.5\end{array}$ & $\begin{array}{r}6.5 \\
3.5 \\
3.5 \\
73.5\end{array}$ & $\begin{array}{l}3.5 \\
4.0 \\
4.0\end{array}$ & $\begin{array}{r}17.5 \\
4.0 \\
4.0 \\
25.5\end{array}$ \\
\hline & TOTALS & $\overline{100}$ & & $\overline{341.4}$ & & $\overline{328.0}$ & & $\overline{335.6}$ & & $\overline{356.2}$ & & $\overline{382.2}$ \\
\hline
\end{tabular}

ÆMandatory Criterion 